$E_{1}$

- Estron

$E_{2}$

$>$ Estradiol

$E_{3}$

- Estriol

\section{E 300}

- Vitamin C

\section{E 605}

> Organophosphate

EA

- Autoantikörper gegen erythrozytäre Antigene

\section{EBK}

- Eisenbindungskapazität

\section{EBM}

- Einheitlicher Bewertungsmaßstab

\section{Ebullioskopie}

> Siedepunktserhöhung

\section{EBV}

- Epstein-Barr-Viren

EC

- Kommission zur Festlegung der Nomenklatur in der Enzymologie

\section{EC 1.1.1.14}

Sorbitdehydrogenase 


\section{EC 1.1.1.37}

> Malatdehydrogenase

\section{EC 1.1.1.42}

> Isocitrat-Dehydrogenase

\section{EC 1.1.1.48}

Galaktosedehydrogenase

\section{EC 1.1.1.49}

- Glukose-6-Phosphat-Dehydrogenase

\section{EC 1.1.3.4}

> Glukoseoxidase

\section{EC 1.1.3.6}

> Cholesterinoxidase

\section{EC 1.4.1.3}

\Glutamat-Dehydrogenase

\section{EC 1.4.3.4}

\ Monoaminooxidase im Serum

\section{EC 1.14.11.2}

- Prolyl-4-Hydroxylase
EC 1.16.3.1

- Coeruloplasmin

- Ornithin-Carbamoyltransferase

\section{EC 2.3.1.43}

- Lecithin-Cholesterin-Acyltransferase

EC 2.3.2.2

$\gamma$-Glutamyltransferase

EC 2.3.2.13

- Gerinnungsfaktor XIII

\section{EC 2.5.1.18}

- Glutathion-S-Transferasen

EC 2.6.1.1

- Aspartat-Aminotransaminase

\section{EC 2.6.1.2}

- Alanin-Aminotransaminase 


\section{EC 2.7.1.1}

• Hexokinase

\section{EC 2.7.1.3}

- Fruktokinase

\section{EC 2.7.1.6}

- Galaktokinase

\section{EC 2.7.7.12}

- Galaktose-1-Phosphat-Uridyltransferase

\section{EC 3.1.1.3}

- Lipase, hepatische

- Lipase, pankreatische

\section{EC 3.1.1.4}

- Phospholipase A2

\section{EC 3.1.1.8}

> Pseudocholinesterase

\section{EC 3.1.1.47}

> Phospholipase A2, Lipoprotein-assoziierte

\section{EC 3.1.3.1}

- Phosphatase, alkalische
EC 3.1.3.5

5'-Nukleotidase

\section{EC 3.1.3.9}

- Glukose-6-Phosphatase

\section{EC 3.2.1.1}

- Amylase, pankreasspezifische

\section{EC 3.2.1.17}

- Lysozym

EC 3.2.1.22

- $\alpha$-Galaktosidase

\section{EC 3.2.1.30}

- N-Acetyl-beta-D-glukosaminidase

\section{EC 3.4.11.1}

- Leucinarylamidase(n)

\section{EC 3.4.15.1}

- Angiotensin-konvertierendes Enzym

\section{EC 3.4.21.1}

- Chymotrypsin 


\section{EC 3.4.21.4}

> Trypsin

EC 3.4.21.5

- Prothrombin

\section{EC 3.4.21.6}

> Gerinnungsfaktor X

\section{EC 3.4.21.11}

Elastase, pankreasspezifische

EC 3.4.21.21

- Gerinnungsfaktor VII

\section{EC 3.4.21.22}

> Gerinnungsfaktor IX

\section{EC 3.4.21.27}

> Gerinnungsfaktor XI

\section{EC 3.4.21.34}

> Präkallikrein

\section{EC 3.4.21.38}

$>$ Gerinnungsfaktor XII

\section{EC 3.4.21.68}

- Tissue-Plasminogenaktivator

EC 3.4.21.69

> Protein $\mathrm{C}$

\section{EC 3.4.21.73}

- Urokinase

\section{EC 3.4.23.15}

$>$ Renin

\section{EC 3.5.4.3}

> Guanase

\section{EC 4.1.1.15}

> Glutamat-Decarboxylase

\section{EC 4.1.2.13}
- Aldolase A
- Aldolase B

\section{EC4}

- European Communities Confederation of Clinical Chemistry

\section{ECA}

Ecarin-Zeit 


\section{Ecarin-Zeit}

T. Stief

Synonym(e) ECT; ECA

Englischer Begriff ecarin clotting time; ecarin chromogenic assay

Definition Ecarin ist eine Metalloproteinase ( $\triangleright$ Metalloproteinasen) aus dem Gift der Viper Echis carinatus und aktiviert - Prothrombin (Gerinnungsfaktor II [F2]) zu Meizothrombin. Meizothrombin wird durch direkte Thrombininhibitoren (Hirudin, Argatroban) gehemmt.

Physikalisch-chemisches Prinzip Ecarin spaltet humanes Prothrombin am Arg320, wodurch Meizothrombin entsteht. Autolytische Spaltung am Arg156 führt zur Abspaltung des Prothrombinfragments 1, es entsteht das Zwischenprodukt Meizothrombin-des-F1. Eine weitere autolytische Spaltung führt zu dem stabilen Produkt $\alpha$ - $>$ Thrombin. Thrombin spaltet $>$ Fibrinogen und aktiviert es zu $>$ Fibrin. Die Erfassung der Fibrinbildung kann mechanisch ( $\triangleright$ Koagulometer) oder optisch erfolgen.

Alternativ kann Thrombin auch durch seine Fähigkeit, chromogene Substrate amidolytisch zu spalten, gemessen werden. Die enzymatische Aktivität der Prothrombin-Spaltprodukte wird durch die in der Patientenprobe vorhandenen direkten Thrombininhibitoren konzentrationsabhängig gehemmt.

Einsatzgebiet Überwachung therapeutischer Antikoagulation mit direkten Thrombininhibitoren (Hirudin, Argatroban).

Untersuchungsmaterial Citratplasma, Vollblut (POCT).

Normalbereich $36 \pm 3 \mathrm{~s}$.

Instrumentierung Kann an Gerinnungsanalysegeräten oder als POCT-Methode durchgeführt werden.

Sensitivität Nachweisgrenze des chromogenen Tests: 0,032 mg Hirudin/L Plasma. Die therapeutische Hirudinkonzentration liegt allerdings oft bei nur ca. $0,01 \mathrm{mg} / \mathrm{L}$, messbar im Thrombingenerierungstest EXCA oder INCA.

Fehlermöglichkeit ECT als Gerinnungstest ist abhängig von der Prothrombin- und Fibrinogenkonzentration der Probe.

Praktikabilität - Automatisierung - Kosten Automatisierbar.
Bewertung - Methodenhierarchie (allg.) Routinemethode.

\section{Literatur}

Fenyvesi T, Harenberg J, Weiss C, Jörg I (2005) Comparison of two different ecarin clotting time methods. J Thromb Thyrombolysis 20:51-56

Lange U, Wiesenburg A, Olschewski A et al (2002) Ecarin chromogenic assay (ECA) - a new chromogenic assay useful for clinical monitoring of direct thrombin inhibitors like hirudin. Ann Haematol 81(Suppl 1):A49

Stief T (2013) A new aera in hemostasis diagnostic begins. Hemostasis Laboratory 6:135-139. https://www.novapublishers.com/catalog/ product_info.php?products_id $=48446 \&$ osCsid $=$ b17406f $46 \mathrm{~d} 25 \mathrm{c} 20$ 2a8c2998398043182. Zugegrieffen am 13.09.2017

\section{Echinococcus granulosus und Echinococcus multilocularis}

W. Stöcker

Englischer Begriff Echinococcus granulosus; Echinococcus multilocularis

Beschreibung des Erregers Familie: Taeniidae; Gattung: Echinococcus (E.); Spezies: E. granulosus, E. multilocularis, E. vogeli, E. oligarthrus u. a.

Echinococcus granulosus (Hundebandwurm) und Echinococcus multilocularis (Fuchsbandwurm) sind die bedeutendsten Vertreter der Gattung Echinococcus.

E. granulosus ist ein 3-7 mm langer Bandwurm, E. mulitlocularis ist mit 1-4 mm etwas kürzer. Sie bestehen aus einem hakenbesetzten Kopf (Skolex), einer Sprossungszone und typischerweise 3 bzw. 5 Gliedern (Proglottiden), in denen die umweltresistenten Eier heranreifen. Die Vermehrung der Echinokokken ist an einen obligaten Wirtswechsel gebunden.

Erkrankungen Die Echinokokkose ist eine durch Infektion mit Parasiten der Gattung Echinococcus hervorgerufene Infektionskrankheit. In Europa sind vor allem der Hundebandwurm (E. granulosus), Verursacher der zystischen Echinokokkose (CE), sowie der Fuchsbandwurm (E. multilocularis) als Verursacher der alveolären Echinokokkose (AE) von medizinischer Bedeutung. Die Entwicklung aller Echinokokkenarten erfordert einen obligaten Wirtswechsel: Die Endwirte sind Carnivoren, die Zwischenwirte meist Pflanzenfresser. Der Mensch stellt sowohl für den Fuchs- als auch dem Hundebandwurm einen Fehlzwischenwirt dar.

Die geschlechtsreifen Bandwürmer leben im Darm ihrer Endwirte (in Europa vor allem Hunde und Rotfüchse), die mit dem Kot die reifen Cestodeneier ausscheiden. Diese Eier sind 
gegenüber Umwelteinflüssen sehr resistent und können unter günstigen Bedingungen mehrere Monate infektiös bleiben. Mit der Nahrung werden die Eier von den Zwischenwirten (Nagetiere oder Huftiere) aufgenommen, in deren inneren Organen (vor allem Leber) sich die Larvenstadien in flüssigkeitsgefüllten Blasen (Hyatiden) entwickeln und vermehren. Die humane Infektion kann durch Schmierinfektionen, dem Umgang mit kontaminierter Erde oder der Aufnahme kontaminierter Nahrungsmittel erfolgen.

Die resultierenden Krankheitsbilder beider Echinokokkosen (CE und AE) unterscheiden sich durch das unterschiedliche Wachstumsverhalten beider Parasiten im menschlichen Körper. Das Erscheinungsbild der AE entspricht dem eines Malignoms: In der Leber entwickelt sich die Larve in Form multipler zusammenhängender Vesikel (Pseudozysten), die invasiv in das umliegende Gewebe wuchern und dieses zerstören. Der klinische Verlauf der CE ist durch das langsame Wachstum einzelner Zysten geprägt, die über die Zeit das umliegende Gewebe verdrängen. Ein Auftreten von Echinococcus-bedingten Zysten kann alle Organe betreffen. Beide Erkrankungen verlaufen beim Menschen über viele Jahre asymptomatisch, bevor sie sich nach 10-15 Jahren durch cholestatischen Ikterus, epigastrische Schmerzen, Abgeschlagenheit, Gewichtsverlust und Hepatomegalie bemerkbar machen. Unbehandelte Echinokokkosen können zum Tod des Patienten führen. Differenzialdiagnostisch sind Zysten, maligne und benigne Tumoren, Abszesse sowie die Abgrenzung zwischen $\mathrm{AE}$ und $\mathrm{CE}$ von Bedeutung.

In Mitteleuropa ist das Risiko einer Infektion gering. Gefährdet sind vor allem Menschen in Endemiegebieten, die in enger Gemeinschaft mit Hunden, Schafen, Ziegen und weiteren potenziellen Zwischenwirten leben. Wichtigste Präventionsmaßnahmen sind die Einhaltung allgemeiner Hygieneregeln und die regelmäßige Entwurmung freilaufender Hunde und Katzen. Innereien und Schlachtabfälle, insbesondere privater Herkunft, sollten nur ausreichend durchgegart verfüttert werden.

Echinokokkose-Patienten werden am effektivsten in spezialisierten Einrichtungen behandelt. Etabliert sind die chirurgische Sanierung der Infektionsherde und die Chemotherapie mit Mebendazol und Albendazol.

Analytik Direkter Antigennachweis durch Mikroskopie und - PCR (Polymerase-Kettenreaktion). Immunologische Bestimmung mit gattungs- und artspezifischen Antiseren. Standardtests zur serologischen Antikörperbestimmung sind indirekte Immunfluoreszenz ( $\triangleright$ Immunfluoreszenz, indirekte) (IIFT; Substrat: Gefrierschnitte der Echinococcus-Larven), \ Enzymelinked Immunosorbent Assay (ELISA; geeignet als Suchtest z. B. bei Verwendung hochaufgereinigter Vesikelflüssigkeit des E. multilocularis als Substrat zum Nachweis von Antikörpern gegen E. multilocularis und E. granulosus), indirekte Hämagglutination, $>$ Immunelektrophorese und $>$ Immunblot
(Kombination aus nativen und speziesspezifischen, rekombinanten Antigenen möglich). Bei positiver Serologie und Verdacht auf eine zerebrale Infektion werden die spezifischen Antikörper und die Gesamtantikörper parallel in Liquor und Serum bestimmt und der spezifische Liquor-Serum-Quotient errechnet. Ein Wert deutlich $>1$ spricht für eine intrathekale Antikörpersynthese.

\section{Untersuchungsmaterial - Probenstabilität Direktnach-} weis: aus Biopsie- und OP-Material (Hydatidenflüssigkeit).

Serologie: Serum oder Plasma für den Nachweis der Antikörper sind bei $+4{ }^{\circ} \mathrm{C}$ bis zu 2 Wochen lang beständig, bei $-20{ }^{\circ} \mathrm{C}$ über Monate und Jahre hinweg.

Diagnostische Wertigkeit Zur Diagnosestellung kommen zunächst bildgebende Verfahren wie die Sonografie, CT und MRT zum Einsatz. Die Verwendung serologischer Testsysteme zum Nachweis parasitenspezifischer Antikörper im Serum oder Plasma dienen der Bestätigung bildgebender Verfahren. Bei der Verwendung des Echinococcus-Vollantigens (aufgereinigte E.-multilocularis-Vesikelflüssigkeit oder Gefierschnitte) kann eine Echinokokkose in ELISA- und IIFT-Verfahren mit einer guten Sensitivität nachgewiesen werden. Die serologische Unterscheidung von E. granulosus und E. multilocularis ist in vielen Fällen durch die Verwendung speziesspezifischer Antigene im Linienblot ( $\triangleright$ Immunblot) möglich. Ein negatives Ergebnis der Serologie schließt eine Erkrankung nicht aus.

Differenzialdiagnose: hepatozelluläres Leberkarzinom, Lebermetastasen anderer Geschwülste; Hepatitis; Zystizerkose; Leberzirrhose; Rundherde anderer Genese in der Lunge. Die Erkrankung ist meldepflichtig nach $\S 7$ Abs. 3 Infektionsschutzgesetz.

\section{Literatur}

Centers for Disease Control and Prevention, Atlanta. 12 (2012) Parasites - Echincoccosis. https://www.cdc.gov/parasites/echinococcosis/

Institut für Hygiene und Mikrobiologie, Universität Würzburg. 28. August 2016. Konsiliarlabor für Echinokokkose. http://www.echinococcus. uniwuerzburg.de/echinococcus/. Zugegriffen am 15.02.2018

Kimmig P, Oehme R (2009) Zestodenlarven. In: Neumeister B, Geiss HK, Braun RW, Kimmig P (Hrsg) Mikrobiologische Diagnostik, 2. Aufl. Thieme, Stuttgart/New York, S 1081-1086

Robert-Koch-Institut Berlin (2005) Ratgeber InfektionskrankheitenMerkblätter für Ärzte, Echinokokkose, Nr. 45

Robert-Koch-Institut Berlin (2009) Infektionsepidemiologisches Jahrbuch für 2008:67-70

\section{Echinozyt}

- Kletten-Zellen

$\checkmark$ Stechapfelzelle 


\section{ECHO-Viren}

W. Stöcker

Englischer Begriff human Echovirus (enteric cytopathic human orphan virus)

Beschreibung des Erregers Familie: Picornaviridae; Genus: Enterovirus; Spezies: humane ECHO-Viren 1-7, 9, 11-21, 24-27, 29-33, 69, 73-78. Unbehüllte Einzelstrang-RNA-Viren mit kubischer Symmetrie, Durchmesser 24-30 nm, 4 nichtglykosylierte Viruskapsidproteine (VP1-VP4), apathogen (außer ECHO 9) für neugeborene Mäuse (Unterschied zu CoxsackieViren); weltweites Vorkommen.

Erkrankungen $90-95 \%$ der Infektionen verlaufen asymptomatisch. Im Vergleich zu Poliomyelitis-Virusinfektionen verminderter Neurotropismus (jedoch ist eine Beteiligung des ZNS wie bei Infektionen mit allen Enteroviren nicht ausgeschlossen), dafür breiteres Krankheitsspektrum: Infektionen des oberen Respirationstrakts, gastrointestinale Erkrankungen, Exantheme, Enantheme, Myoperikarditis, disseminierte Infektionen bei Neugeborenen, Meningitis, Enzephalitis. Bei immunsupprimierten Patienten chronische Meningoenzephalitis.

Übertragung: fäkal-oral, aerogen (Tröpfchen, Mund-zuMund-Kontakt, kontaminiertes Trinkwasser), nosokomial.

Inkubationszeit: im Mittel 7-14 Tage.

Therapie: symptomatisch, spezifische antivirale Medikamente sind noch nicht verfügbar.

Analytik Kultur und Direktnachweis: Die Virusvermehrung erfolgt in Monolayerzellkulturen, z. B. von MRC 5-, HeLa- oder Vero-Zellen, die Virusidentifizierung mittels Neutralisationstest unter Verwendung von Antiseren bekannter Spezifität. RT-PCR ( $\triangleright$ PCR (Polymerase-Kettenreaktion)) wird zum Nachweis viraler RNA eingesetzt, eine Typisierung ist durch anschließende Sequenzierung der kodierenden Region VP1 möglich.

Serologie: Anwendung finden indirekte Immunfluoreszenz ( $\triangleright$ Immunfluoreszenz, indirekte), $\triangleright$ Neutralisationstest und $\triangleright$ Enzyme-linked Immunosorbent Assay (ELISA). Bei Verwendung von Antigenlysaten können ELISA immunologische Kreuzreaktionen zeigen, weshalb hier die Bestimmung gruppenspezifischer Antikörper im Mittelpunkt steht. Kreuzreaktionen werden $z$. T. auch im Neutralisationstest beobachtet (Typ 1 mit 8, Typ 12 mit 29, Typ 6 mit 30). Der beste serologische Beweis einer frischen Infektion ist ein deutlicher Anstieg des IgG-Titers innerhalb 1-3 Wochen oder der Nachweis erregerspezifischer IgM-Antikörper.
Untersuchungsmaterial - Probenstabilität Direktnachweis und Kultur: Untersucht werden Rachenabstrich, Stuhl und je nach Organmanifestation Rektal- und Konjunktivalabstriche, Blut, Liquor und Bläschensekret oder Biopsien. Das Transportmedium sollte neutral sein und antibakteriell wirken. Das Material sollte bis zur Weiterverarbeitung bei +4 bis $+8{ }^{\circ} \mathrm{C}$ aufbewahrt werden. Direktnachweise sind innerhalb von 24 Stunden durchzuführen, Kulturen innerhalb von 6 Stunden anzulegen. Bei längerer Transportzeit ist das Material einzufrieren.

Serologie: Serum oder Plasma für den Nachweis der Antikörper sind bei $+4{ }^{\circ} \mathrm{C}$ bis zu 2 Wochen lang beständig, bei $-20{ }^{\circ} \mathrm{C}$ über Monate und Jahre hinweg. Zur Tiefkühlkonservierung des IgM kann man den Proben 80 \% gepuffertes Glyzerin beifügen.

Diagnostische Wertigkeit Dem Erregernachweis mittels Kultur und sich anschließender Typisierung mittels PCR kommt eine wesentliche Bedeutung zu. Der Nutzen der Serologie ist aufgrund hoher Durchseuchungsraten und massiver Kreuzreaktivitäten zwischen den verschiedenen Serotypen eingeschränkt. Hier kommt es vor allem auf die Bestimmung neutralisierender Antikörper an. Der signifikante Anstieg spezifischer Antikörpertiter innerhalb von 2 Wochen beweist eine frische Infektion.

\section{Literatur}

Pallansch M, Roo R (2007) Enteroviruses: polioviruses, coxsackieviruses, echoviruses and newer enteroviruses. In: Knipe DM et al (Hrsg) Fields virology, Bd 1, 5. Aufl. Wolters Kluwer Lippincott Williams \& Wilkins, Philadelphia, S 2839-2893

Robert-Koch-Institut Berlin (2012) Infektionen durch Enteroviren. ECHO-Virus-Infektionen. In: Kiehl W (Hrsg) Kompendium Infektiologie \& Infektionsschutz. Berlin: H. Hoffmann GmbH Verlag. https://www.rki.de/DE/Content/InfAZ/E/Enteroviren/Kompendium. html

Zeichhardt H, Grunert HP (2003) Enteroviruses: polioviruses, coxsackieviruses, echoviruses and enteroviruses. In: Cohen I, Powderly WG, Opal SM (Hrsg) Infectious diseases, Bd 213, 2. Aufl. Elsevier Health Sciences, London, S 1993-2006

\section{Echtzeit-PCR, quantitative}

- PCR, quantitative in Echtzeit

\section{ECLIA}

- Elektrochemilumineszenz-Immunoassay 


\section{ECL-Verfahren}

Elektrochemilumineszenz-Immunoassay

\section{ECMR III}

- Hyaluronan-Rezeptor

ECP

- Eosinophiles kationisches Protein

\section{Ecstasy}

T. Arndt

Definition Straßenname/Deckname für MDMA $(\triangleright$ Straßennamen von Drogen: Amphetamine).

\section{ECT}

- Ecarin-Zeit

\section{EDDP}

> Methadon

\section{EDTA}

T. Arndt

Synonym(e) Ethylendiamintetraessigsäure

Definition Sehr häufig als In-vitro-Antikoagulans eingesetzter Chelatbildner ( $\triangleright$ Chelate) mit zweiwertigen Kationen.<smiles>O=C(O)CN(CCN(CC(=O)O)CC(=O)O)CC(=O)O</smiles>

Beschreibung EDTA (Summenformel $\mathrm{C}_{10} \mathrm{H}_{16} \mathrm{~N}_{2} \mathrm{O}_{8}$, Molmasse 292,24 g) verfügt zur Komplexbildung nicht nur über die beiden freien Elektronenpaare der beiden Stickstoffatome, sondern auch über vier Carboxylgruppen. EDTA kann deshalb auch mit schwachen Komplexbildnern, wie z. B. Calcium, stabile Komplexe bilden. Diese Eigenschaft wird im medizinischen Labor genutzt, um den Gerinnungsfaktor Calcium zu binden (komplexieren) und damit die nach Blutnahme spontan einsetzende Blutgerinnung zu unterdrücken ( $\triangleright$ Antikoagulanzien in vitro). Da zahlreiche Enzyme zweiwertige Metallionen zur Ausbildung der vollen Aktivität benötigen, bewirkt EDTA häufig eine Inaktivierung dieser Enzyme (und kann damit zur Probenstabilisierung beitragen, aber auch zu einer Störung bei Enzymaktivitätsbestimmungen führen).

EDTA führt zu einer $>$ Fibrinpolymerisationsstörung und zu einer beschleunigten Inaktivierung von Gerinnungsfaktor V und VIII ( $\triangleright$ Gerinnungsfaktoren). EDTA-Plasma ist deshalb nicht für gerinnungsphysiologische Untersuchungen geeignet.

\section{Literatur}

Wisser H (1995) Präanalytik. In: Greiling H, Gressner A (Hrsg) Lehrbuch der Klinischen Chemie und Pathobiochemie, 3. Aufl. Schattauer, Stuttgart

\section{EDTA-Blut}

$>$ Antikoagulanzien in vitro

\section{EDV-Konfiguration}

$>$ Stammdaten

\section{EESI}

> Ionisationsmethoden (Massenspektrometrie) 


\section{EFCC}

European Federation of Clinical Chemistry and Laboratory Medicine

\section{Effekt der ersten Passage}

> First-Pass-Effekt

\section{Effekt, statistischer}

R.-D. Hilgers, N. Heussen und S. Stanzel

Synonym(e) Statistischer Effekt

Englischer Begriff effect

Definition Als Effekte werden die Komponenten in statistischen Modellen ( $\triangleright$ Modell, statistisches), wie etwa dem Modell der $\triangleright$ Varianzanalyse, bezeichnet.

Beschreibung Im Rahmen einer Varianzanalyse erfassen die Effekte die Hauptwirkung und $>$ Wechselwirkung von Einflussfaktoren, deren Ausprägungen in Kategorien vorliegen. So kann z. B. für den beobachteten Wert der Zielvariablen (z. B. ein Laborparameter) bei 2 Einflussfaktoren A (z. B. verschiedene Labore) und B (z. B. verschiedene Messmethoden) das folgende statistische Modell gelten:

$$
\mathrm{Y}_{\mathrm{ijk}}=\mathrm{m}+\mathrm{a}_{\mathrm{i}}+\mathrm{b}_{\mathrm{j}}+(\mathrm{ab})_{\mathrm{ij}}+\mathrm{e}_{\mathrm{ijk}}
$$

wobei $\mathrm{m}$ das Versuchsmittel und die $\mathrm{e}_{\mathrm{ijk}}$ die Fehlerkomponenten der einzelnen Beobachtungen ( $\triangleright$ Beobachtung) bezeichnen.

Von den übrigen im Modell auftretenden Größen, die Effekte genannt werden, dienen die $a_{i}$ zur Erfassung der Hauptwirkung des Faktors A, die $b_{j}$ zur Erfassung der Hauptwirkung des Faktors B und die $(\mathrm{ab})_{\mathrm{ij}}$ zur Erfassung der Wechselwirkung beider Faktoren. Dabei heißt $\mathrm{a}_{\mathrm{i}}$ der $>$ Haupteffekt der i-ten Stufe (Ausprägung) von $A, b_{j}$ der Haupteffekt der $\mathrm{j}$-ten Stufe von $\mathrm{B}$ und $(\mathrm{ab})_{\mathrm{ij}}$ der $>$ Wechselwirkungseffekt zwischen der i-ten Stufe von A und der j-ten Stufe von B. Charakteristisch an dem obigen Modellansatz ist die Annahme, dass sich die einzelnen Effekte additiv zu einem Gesamteffekt ergänzen.

Mit der Methode der Varianzanalyse können diese Effekte geschätzt ( $\triangleright$ Schätzer) und Hypothesen über interessierende Effekte getestet $(\triangleright$ Test, statistischer) werden.

\section{Literatur}

Rasch D (1988) Biometrisches Wörterbuch. Verlag Harri Deutsch, Frankfurt am Main

\section{Effizienz, diagnostische}

R.-D. Hilgers, N. Heussen und S. Stanzel

Synonym(e) Testeffizienz

Englischer Begriff test efficiency

Definition Die diagnostische Effizienz ist definiert als der Anteil der korrekten Testresultate in Relation zur Anzahl der getesteten Personen.

Beschreibung Die Testeffizienz bewertet richtig positive wie richtig negative Testergebnisse gleich. Falsch positive bzw. falsch negative Testergebnisse bleiben unberücksichtigt.

\section{Literatur}

Hilgers R-D, Bauer P, Scheiber V (2002) Einführung in die Medizinische Statistik. Springer, Berlin/Heidelberg/New York

\section{EFLM}

- European Federation of Clinical Chemistry and Laboratory Medicine

\section{EGFR}

> Human Epidermal Growth Factor Receptor

\section{B1E-Globulin}

C4-Komplement

\section{EGTA}

T. Arndt

Synonym(e) Ethylenglykoltetraessigsäure 
Englischer Begriff ethylene glycol tetraacetic acid; EGTA

Definition Chelatbildner ( $\triangleright$ Chelate) mit einer deutlich höheren Affinität zu $\triangleright$ Calcium im Vergleich zu $\triangleright$ Magnesium.<smiles>O=C(O)CN(CCOCCOCCN(CC(=O)O)CC(=O)O)CC(=O)O</smiles>

Beschreibung EGTA (Summenformel $\mathrm{C}_{14} \mathrm{H}_{24} \mathrm{~N}_{2} \mathrm{O}_{10}$; Molmasse $380,35 \mathrm{~g}$ ) wird bei komplexometrischen ( $\triangleright$ Komplexometrie) Magnesiumbestimmungen (z. B. der Umsetzung von Magnesium mit Xylidinblau zu einem purpurroten Diazoniumsalz) dem Reaktionsansatz zur Maskierung des Kalziums der Patientenprobe zugegeben. Dadurch wird die Mitreaktion von Calcium unterbunden und die Spezifität der Magnesiumbestimmung erhöht. EGTA wird u. a. auch in Kombination mit $\triangleright$ Glutathion zur Stabilisierung von Plasmaproben, z. B. zur Bestimmung von $>$ Katecholaminen, eingesetzt.

\section{Literatur}

The MERCK Index. 14th ed. MERCK Co., Inc., Whitehouse Station, New York, USA, 2006. http://www.hengler-analytik.de/media/pro ducts/Magnesium_114494-96. pdf. Zugegriffen am 24.08.2017

\section{E-Health}

> Tele-Laboratoriumsmedizin

\section{Ehrlich, Paul}

\section{A. M. Gressner und O. A. Gressner}

Lebensdaten Deutscher Mediziner, geboren am 14. März 1854 in Strehlen (Oberschlesien), gestorben am 20. August 1915 in Bad Homburg.

Verdienste Medizinstudium, im Jahr 1887 Habilitation für Innere Medizin, Mitarbeiter von Robert Koch, 1896 Direktor des Institutes für Serum-Forschung und Serum-Prüfung in Berlin, ab 1899 Direktor des Institutes für Experimentelle Therapie und ab 1906 des Georg-Speyer-Hauses in Frankfurt/Main.
1914 Ernennung zum Ordinarius an der Frankfurter Universität. Als Pathologe, Immunologe und Pharmakologe führte er u. a. zahlreiche neue Färbeverfahren (z. B. Methylen-Blaufärbung) ein und beschrieb die $>$ Diazo-Reaktion (EhrlichDiazoreagenz). Durch seine Freundschaft mit den Bakteriologen Robert Koch ( $\triangleright$ Koch, Robert) (1843-1910) und Emil von Behring ( $\triangleright$ Behring, Emil Adolf von) (1854-1917) richtete sich Ehrlichs Interesse zunehmend auf Fragen der Immunität, Infektionskrankheiten und deren antibakterieller Therapie. Er gilt als Begründer der modernen Chemotherapie (z. B. mit der Einführung von Salvarsan zur Therapie der Syphilis). Im Jahr 1908 erhielt Ehrlich den Nobelpreis für Medizin.

\section{Literatur}

Hüntelmann AC (2011) Paul Ehrlich. Leben, Forschung, Ökonomie, Netzwerke, Wallstein Verlag, ISBN:978-3- 8353-0867-1

\section{Ehrlich-Probe}

W. G. Guder und T. Arndt

\section{Englischer Begriff Ehrlich test}

Definition Eher historischer, aber mitunter immer noch angewandter qualitativer Schnelltest zur Feststellung einer vermehrten Ausscheidung von Urobilinogen oder Porphobilinogen oder Urin.

Beschreibung Testprinzip ist eine Farbreaktion mit EhrlichBauer Reagenz ( $2 \mathrm{~g} \mathrm{p}$-Dimethylaminobenzaldehyd in $100 \mathrm{~mL}$ 20 \%iger Salzsäure), wobei Porphobilinogen (20- bis 50-fach erhöht bei akuten hepatischen Porphyrien) eine Rot- und Urobilinogen eine Rotviolettfärbung geben und der Urobilinogenfarbkomplex in Chloroform extrahierbar ist. Varianten sind die Ehrlich-Probe zum Nachweis von Urobilinogen, der Watson-Schwartz-Test $(5 \mathrm{~mL}$ abgekühlter Urin plus $5-10$ Tropfen Reagenz) zum Nachweis von Porphobilinogen (rot) und Urobilinogen (fliederfarben) mit Trennung durch Chloroformextraktion und die umgekehrte Ehrlich-Probe oder Hoesch-Test ( $2 \mathrm{~mL}$ Reagenz plus 1 Tropfen Urin) zum Nachweis von Porphobilinogen über die Bildung rotvioletter Schlieren. Die Tests unterliegen Störungen durch Nahrungsbestandteile und Pharmaka und wurden deshalb weitgehend durch quantitative chromatographische Analysen abgelöst. Ehrlich-Reagenz ist die Basis des Urobilinogennachweises mit Urinteststreifen. Details zum $>$ Hoesch-Test und $>$ WatsonSchwartz-Test s. dort. 


\section{Literatur}

Hallmann L (1980) Klinische Chemie und Mikroskopie, 11. Aufl. Georg Thieme Verlag, Stuttgart

\section{EHS-Heparansulfat-Proteoglykan}

P Perlecan

El

- Massenspektrometrie

EIA

- Enzymimmunoassay

\section{Eichkurve}

Kalibrierung

\section{Eichung}

C. Vidal und W.-R. Külpmann

\section{Englischer Begriff calibration}

Definition Die Eichung besteht aus der eichtechnischen Prüfung und der Stempelung eines eichfähigen Messgeräts durch die zuständige Behörde und wird im Rahmen des Vollzugs des Eichgesetzes, der Marktüberwachung zum Verbraucherschutz und der Dienstleistungsmöglichkeiten zur Unterstützung der Wirtschaft durchgeführt.

Beschreibung Ein Messgerät ist eichfähig, wenn seine Bauart durch die Physikalisch-Technische Bundesanstalt (PTB) oder aufgrund der Art des Messgeräts allgemein zur Eichung zugelassen ist. Die Zulassung durch die PTB wird auf dem Messgerät durch ein Zulassungszeichen kenntlich gemacht.

Ein Messgerät wird nach der Prüfung als geeicht mit dem Hauptstempel gekennzeichnet, wenn es eichfähig war und bei der Prüfung den Anforderungen der Zulassung und sonstigen eichtechnischen Regeln entsprach (Beschaffenheit und Feh- lergrenzen). Einem von der zuständigen Behörde als geeicht gestempelten Messgerät steht ein Messgerät gleich, das von einem anderen Mitgliedstaat der Europäischen Gemeinschaft mit dem Zeichen für die EG-Ersteichung versehen worden ist.

Nichtselbsttätige Waagen sind gemäß Europäischer Richtlinie 2014/31/EU (bis 20.04.2016 2009/23/EG, zuvor bis 05.06.2009 90/384/EWG) vor dem erstmaligen Inverkehrbringen einer EG-Ersteichung zu unterziehen, die bei Vorliegen entsprechender Voraussetzungen auch der Hersteller durchführen kann.

Medizinische Messgeräte unterliegen den Bestimmungen der Richtlinie des Rates 93/42/EWG und dem Medizinproduktegesetz, das die Richtlinie in nationales Recht umsetzt. Danach können von den Messgeräteherstellern oder einer benannten Stelle Konformitätsbewertungsverfahren für die Messgeräte durchgeführt werden. Eine CE-Kennzeichnung bedeutet, dass ein Medizinprodukt die grundlegenden Anforderungen nach Europäischem Recht und die anerkannten Regeln der Technik erfüllt. Es besteht aus CE-Zeichen und Kennnummer der benannten Stelle, die bei der Durchführung des Konformitätsbewertungsverfahrens beteiligt ist. Beispiel: CE 0118.

Wer ein eichfähiges Messgerät anwenden will, ist dafür verantwortlich, dass das Messgerät gültig geeicht ist. Eichfähige Messgeräte können einer Ersteichung, Nacheichung oder Befundprüfung unterzogen werden. Bei der Erst- und Nacheichung wird die Einhaltung der Eichfehlergrenzen und bei der Befundprüfung die Einhaltung der Verkehrsfehlergrenzen überprüft. Die Gültigkeitsdauer der Eichung ist für die jeweiligen Messgeräte in der Mess- und Eichverordnung (MessEV) festgelegt. Gemäß § 37 (5) Mess- und Eichgesetz (MessEG) können von zugelassenen Instandsetzern instandgesetzte und entsprechend gekennzeichnete Messgeräte bei Vorliegen bestimmter Voraussetzungen bis zur nächsten Eichung weiter im eichpflichtigen Verkehr angewandt werden.

Die Eichung von Messgeräten dient seit langer Zeit dem Schutz des Verbrauchers primär überall dort, wo dieser gemessene Leistungen bezieht, seien dies nach Gewicht oder Volumen quantifizierbare Warenmengen oder messbare Energiemengen, beispielsweise im Haushaltsbereich beim Bezug von Gas, Wasser, Elektrizität oder thermischer Energie (Wärme).

Die gesetzlichen Grundlagen für das Eichwesen sind in europäischen und nationalen Gesetzen, Verordnungen und Richtlinien fixiert.

Die Eichpflicht für Messgeräte ergibt sich aus dem MessEG und der MessEV. Die MessEV regelt außerdem u. a. die

- Ausnahmen von der Eichpflicht,

- Gültigkeit der Zulassung und der Eichung,

- Verfahren der Zulassung und der Eichung,

- allgemeinen Anforderungen an Messgeräte sowie

- Bauartanforderungen und Fehlergrenzen für Messgerätearten. 
Medizinprodukte müssen für Patienten und Anwender zuverlässig einen ausreichenden Schutz bieten und die vom Hersteller angegebenen Leistungsparameter zu jedem Zeitpunkt erreichen. Die Aufrechterhaltung des in den Mitgliedstaaten der Europäischen Union erreichten Schutzniveaus ist daher ein vorrangiges Ziel der Richtlinie über Medizinprodukte und der Richtlinie über In-vitro-Diagnostika. Rechtliche Grundlage für die Behandlung von Medizinprodukten und In-vitro-Diagnostika ist in Deutschland das Medizinproduktegesetz. In ihm sind die Anforderungen an diese Messgerätegruppe im Zusammenhang mit dem Inverkehrbringen durch den Hersteller sowie die notwendigen staatlichen Überwachungsmaßnahmen geregelt. Medizinprodukte mit Messfunktion unterliegen während ihrer Verwendung einem Verschleiß und müssen daher regelmäßig messtechnisch kontrolliert werden. $\mathrm{Zu}$ diesen Medizinprodukten rechnen: Tonund Sprachaudiometer, Thermometer, Blutdruckmessgeräte, Augentonometer, Therapiedosimeter, Diagnostikdosimeter und Tretkurbelergometer. Diese Messgeräte werden nicht mehr geeicht.

\section{Literatur}

Europäische Richtlinie 2014/31/EU vom 26.02.2014 (ABl. L 96 S. 107-148), zuvor Richtlinie 90/384/EWG vom 20.06.1990 (ABl. L 189 S. 1-16), zuletzt geändert durch Richtlinie 2009/23/EG vom 23.04.2009 (AB1. L 122 S. 6)

Medizinprodukte-Betreiberverordnung vom 21.08.2002 (BGB1. I S. 3396), zuletzt geändert durch Artikel 2 der Verordnung vom 27.09.2016 (BGB1. I S. 2203)

Medizinproduktegesetz vom 07.08.2002 (BGBl. I S. 3146), zuletzt geändert am 23.12.2016 (BGB1. I S. 3191)

Mess- und Eichgesetz vom 25. Juli 2013 (BGB1. I S. 2722, 2723), zuletzt geändert durch Artikel 1 des Gesetzes vom 11. April 2016 (BGB1. I S. 718)

Mess- und Eichverordnung vom 11. Dezember 2014 (BGB1. I S. 2010, 2011), zuletzt geändert durch Artikel 16 Absatz 7 des Gesetzes vom 10. März 2017 (BGBl. I S. 420)

\section{Eicosapentaensäure}

K. J. Lackner und D. Peetz

Englischer Begriff eicosapentaenoic acid

Definition Monocarbonsäure mit 20 Kohlenstoffatomen und 5 Doppelbindungen in cis-Stellung, 20:5D5,8,11,14,17; gehört zur Familie der $\omega 3$-ungesättigten Fettsäuren.

Beschreibung Eicosapentaensäure kann entweder aus $\alpha$-Linolensäure gebildet oder mit der Nahrung aufgenommen werden. Hauptquelle sind marine Produkte. Eicosapentaensäure gilt als antiinflammatorisch, weil sie sowohl die 5-Lipoxygenase als auch die Cyclooxygenase und damit die Leukotrienund Prostaglandinsynthese hemmt. Außerdem kann sie als Substrat dieser Enzyme zu Leukotrien B5 (LTB5) oder Prostaglandin E3 umgewandelt werden. LTB5 hat nur schwache proinflammatorische Aktivität im Vergleich zu Leukotrien B4, dem Produkt der Arachidonsäure.

\section{Literatur}

Russo GL (2009) Dietary n-6 and n-3 polyunsaturated fatty acids: from biochemistry to clinical implications in cardiovascular prevention. Biochem Pharmacol 77:937-946

\section{Eigenansatz}

- Autologe Kontrolle

\section{Eigenkontrolle}

- Autologe Kontrolle

\section{Eigenunsicherheit}

C. Vidal und W.-R. Külpmann

Englischer Begriff definitional uncertainty

Definition Komponente der Messunsicherheit, die aus der endlichen Detaillierung der Definition einer Messgröße resultiert (BIPM et al. 2010). Für Beispiele und Anmerkungen s. Literatur.

\section{Literatur}

BIPM, IEC, IFCC, ILAC, ISO, IUPAC, IUPAP, OIML (2010) Internationales Wörterbuch der Metrologie (VIM) Deutsch-englische Fassung. ISO/IEC-Leitfaden 99-2007, 3. Aufl. Beuth-Verlag, Berlin

\section{Eilanalyse}

STAT 


\section{Einbau zusätzlicher Nukleotide}

$>$ Insertion

\section{Eindampfrückstand}

- Abdampfrückstand

\section{Einfache Radialimmundiffusion}

- Immundiffusion, radiale nach Mancini, Carbonara und Heremans

\section{Einfallswinkel}

$>$ Reflexion

\section{Einflüsse, biologische}

• Einflussgrößen

\section{Einflussfaktor}

> Einflussgrößen

\section{Einflussgrößen}

W. G. Guder

\section{Synonym(e) Einflussfaktor}

Englischer Begriff influence factor

Definition In vivo wirksame Größe, die nicht Messgröße ist, jedoch das Messergebnis beeinflusst.

Beschreibung Einflussgrößen verändern die Konzentration des gemessenen Analyten. Es sind nicht krankheitsbedingte Faktoren, welche die Werte der Messgröße verändern. Sie sind daher unabhängig von der angewendeten Methodik (im Gegensatz zu Störgrößen). Sie treten in vivo auf, können aber auch in vitro wirken. Sie können nach ihrem Charakter veränderlich oder unveränderlich, beeinflussbar oder unbeeinflussbar sein:

- Unveränderliche und unbeeinflussbare Einflussgrößen: Geschlecht, Rasse, genetische Varianten

- Veränderliche unbeeinflussbare Einflussgrößen: Alter, Höhe über dem Meeresspiegel, biologische Rhythmen über Jahreszeiten, Monate und Wochen, Schwangerschaft, zirkadiane Rhythmen

- Veränderliche beeinflussbare Einflussgrößen: Nahrungsund Wasseraufnahme und -entzug, Diäten, körperliche Tätigkeit, Genussgifte (Rauchen, Alkohol), Körperlage, Stauung bei der Blutgewinnung, diagnostische und therapeutische Maßnahmen

- In-vitro-Einflüsse: Veränderungen des Analyten durch Stoffwechsel und Wirkstoffeffekte während des Transports und der Lagerung von Proben, Wirkung der Zentrifugation, Kontamination mit dem Analyten.

In der präanalytischen Phase ( $\triangleright$ Präanalytische Phase) können beeinflussbare Einflussgrößen durch entsprechende Standardisierungen minimiert werden, während unbeeinflussbare Einflüsse durch Wissen Berücksichtigung bei der Interpretation des Messergebnisses finden sollten.

Zur Definition s. im Wörterbuch der Metrologie oder unter www.bimp.org (VIM 2008).

\section{Literatur}

Guder WG (1980) Einflussgrößen und Störfaktoren bei klinischchemischen Untersuchungen. Internist 21:533-542

Guder WG (2009) Die Qualität labormedizinischer Untersuchungen - Voraussetzungen in der präanalytischen und analytischen Phase. In: Guder WG, Nolte J (Hrsg) Das Laborbuch in Klinik und Praxis, 2. Aufl. Elsevier,/Urban\&Fischer, München

Guder WG, Narayanan S (2015) Biological variables influencing laboratory results. In: Guder WG, Narayanan S (Hrsg) Pre-examination procedures in laboratory diagnostics. Walter deGruyter, Berlin/Boston, S 97-132

VIM (2008) www.bimp.org. Beuth-Verlag

\section{Einfrieren der Proben}

W. G. Guder

Synonym(e) Gekühlte Lagerung; Tiefgefrorene Proben

Englischer Begriff freezing of samples

Definition Kühlung von Proben unter $0{ }^{\circ} \mathrm{C}$, sodass flüssige Proben in festen Zustand übergehen. 
Schockfrieren: Einfrieren durch flüssigen Stickstoff oder andere Kühlmittel, die ein Einfrieren innerhalb einer Sekunde ermöglichen.

Tieffrieren: Einfrieren auf Temperaturen $\leq-20{ }^{\circ} \mathrm{C}$, d. h. unter die Temperatur üblicher Gefrierfächer von Kühlschränken. Dabei werden Temperaturen von $-20,<-20$ und $-70{ }^{\circ} \mathrm{C}$ unterschieden.

Beschreibung Immer, wenn die Aufbewahrungszeit einer - Probe bis zur Analyse die Stabilität eines Analyten ( $\triangleright$ Analyt) bei Raum- oder Kühlschranktemperatur nicht sicher gewährleistet, wird Einfrieren auf mindestens $-20{ }^{\circ} \mathrm{C}$ empfohlen. Dies basiert auf der Annahme, dass metabolische Veränderungen, bakterielle Verunreinigung und Überlagerung damit verhindert werden können. Auf der anderen Seite sind durch den Einfriervorgang bedingte physikalischchemische Prozesse zu vermeiden, die eine Veränderung des Analyten in der Matrix verhindern. So werden Zellen durch Einfrieren zerstört, sollten also vorher von der analytischen Probe Serum oder Plasma abgetrennt werden. Aus Serum und/oder Urin können manche Substanzen durch Einfrieren kristallisieren oder unlösliche Komplexe bilden, sodass sie nach Wiederauftauen der Probe nicht mehr in Lösung gehen.

Aus diesen Gründen wurden für jeden Analyten getrennt Empfehlungen ausgesprochen, ab welcher Zeit und wie lange Proben einzufrieren sind. Diese Empfehlungen sind den Einsendern eines Labors zur Verfügung zu stellen, wenn instabile Analyte über längere Zeit transportiert oder aufbewahrt werden sollen.

\section{Literatur}

Guder WG, da Fonseca-Wollheim F, Heil W, Schmitt Y, Töpfer G, Wisser H, Zawta B (2012) Die Qualität diagnostischer Proben, 7. Aufl. BD, Heidelberg

\section{Eingangsgröße}

• Eingangsgröße des Modells der Messung

\section{Eingangsgröße des Modells der Messung}

C. Vidal und W.-R. Külpmann

Synonym(e) Eingangsgröße
Englischer Begriff input quantity in a measurement model, input quantity

Definition Größe, die gemessen werden muss, oder Größe, deren Wert man auf andere Weise erhalten kann, um einen Messwert einer Messgröße zu berechnen (BIPM et al. 2010). Für Anmerkungen s. Literatur.

\section{Literatur}

BIPM, IEC, IFCC, ILAC, ISO, IUPAC, IUPAP, OIML (2010) Internationales Wörterbuch der Metrologie (VIM) Deutsch-englische Fassung. ISO/IEC-Leitfaden 99:2007, 3. Aufl. Beuth-Verlag, Berlin

\section{Einheit}

Maßeinheit

\section{Einheit, kohärente abgeleitete}

- Abgeleitete Einheit, kohärente

\section{Einheit im Messwesen}

- Maßeinheit

\section{Einheiten}

W. G. Guder

Synonym(e) Messeinheiten

Englischer Begriff unit of measurement; unit

Definition Spezifisch messbare Menge, die der internationalen Konvention angemessen ist und die es erlaubt, die Mengen zu vergleichen (Dybkaer 1997).

Beschreibung In der Tradition wurden Messeinheiten für diagnostisch gemessene Substanzen (Analyte) definiert, um eine Mengenangabe und damit Vergleichbarkeit mit anderen Laboratorien, medizinischen Einrichtungen und in jüngerer Zeit Ländern und Kontinenten zu ermöglichen. Die Empfeh- 
lung der WHO basiert auf 7 Grundeinheiten und löst die im 19. Jahrhundert entstandenen Einheiten ab ( $\triangleright$ SI-Einheiten).

Dabei werden qualitative Einheiten (z. B. positiv-negativ) von gestuften Einheiten $[-,(+),+,++,+++]$ und quantitativen Einheiten unterschieden. Die Einheit wird so zum essenziellen Bestandteil der Messgröße.

\section{Literatur}

Dybkaer R (1997) Vocabulary for use in measurement procedures and description of reference materials in laboratory medicine. Eur J Clin Chem Clin Biochem 35:141-173

\section{Einheitensystem}

C. Vidal und W.-R. Külpmann

Englischer Begriff system of units

Definition Menge von Basiseinheiten und abgeleiteten Einheiten, zusammen mit ihren Vielfachen und Teilen, definiert für ein Größensystem gemäß vorgegebenen Regeln (BIPM et al. 2010). Für Anmerkungen s. Literatur.

\section{Literatur}

BIPM, IEC, IFCC, ILAC, ISO, IUPAC, IUPAP, OIML (2010) Internationales Wörterbuch der Metrologie (VIM). Deutsch-englische Fassung. ISO/IEC-Leitfaden 99:2007, 3. Aufl. Beuth-Verlag, Berlin

\section{Einheitensystem, internationales}

$>$ SI-Einheiten

\section{Einheitensystem, kohärentes}

C. Vidal und W.-R. Külpmann

Englischer Begriff coherent system of units

Definition Einheitensystem, das auf einem Größensystem basiert, in dem die Maßeinheit für jede abgeleitete Größe eine kohärente abgeleitete Einheit ist (BIPM et al. 2010). Für Anmerkungen s. Literatur.

\section{Literatur}

BIPM, IEC, IFCC, ILAC, ISO, IUPAC, IUPAP, OIM (2010) Internationales Wörterbuch der Metrologie (VIM). Deutsch-englische Fassung. ISO/IEC-Leitfaden 99:2007, 3. Aufl. Beuth-Verlag, Berlin

\section{Einheitlicher Bewertungsmaßstab}

\section{T. Arndt}

\section{$\operatorname{Synonym(e)~EBM~}$}

Definition Der Einheitliche Bewertungsmaßstab bestimmt den Inhalt der berechnungsfähigen Leistungen und ihr wertmäßiges, in Punkten ausgedrücktes Verhältnis zueinander.

Beschreibung Der EBM ist die Grundlage der Abrechnung ärztlicher Leistungen mit gesetzlichen Krankenkassen, d. h. für gesetzlich versicherte Patienten. Laboratoriumsuntersuchungen und die mit ihnen in Zusammenhang stehenden prä- und postanalytischen Aufwendungen und Leistungen werden im Abschnitt 12 (Laboratoriumsmedizinische Gebührenordnungspositionen) und im Abschnitt 32 (Laboratoriumsmedizin, Molekulargenetik und Molekularpathologie) behandelt. Gewöhnlich werden Leistungs- und Vergütungsziffern des EBM in der Labor-EDV hinterlegt (Verknüpfung der Analysenstammdaten mit der jeweiligen Gebührenziffer), um die durchgeführten Laboratoriumsuntersuchungen über EDV abrechnen zu können.

\section{Literatur}

KBV Kassenärztliche Bundesvereinigung (2015) Einheitlicher Bewertungsmaßstab (EBM) Stand 1. Quartal 2015. http://www.kbv.de/ media/sp/EBM_Gesamt_Stand_1._Quartal_2015.pdf. Zugegriffen am 28.12.2016

\section{Einkernige Granulomzelle}

- Hodgkin-Zelle

\section{Einsalzeffekt}

- Aussalzen 


\section{Einstabelektrode}

> Ionenselektive Elektrode

\section{Einstichproben-t-Test}

- Test, statistischer

\section{Einstweilig Tolerable Wöchentliche Aufnahme (PTWI-Wert)}

> PTWI-Wert

\section{Eintauchnährboden-Untersuchung}

• Urinkultur

\section{Einzelbefund}

O. Colhoun

Synonym(e) Laborbefund; Laborbericht

Englischer Begriff single report

Definition Ausgabe der Analysenergebnisse für einen Laborauftrag auf eigenem Befundblatt.

Beschreibung Der Einzelbefund zeigt alle Ergebnisse nur des aktuellen Auftrags an, Vorwerte können mit Wert und Zeitbezug zum aktuell erhobenen Ergebnis dargestellt werden.

\section{Einzelnukleotid-Polymorphismus}

- SNP

\section{Einzelrechnung}

O. Colhoun

Definition Funktion der Labor-EDV für die Erstellung einer Rechnung über erbrachte Laborleistungen für einen Patienten.
Beschreibung Ausdruck der Einzelrechnung mit Aufführung des Rechnungsempfängers, Patientennamens, Aufenthaltszeitraums, Angabe von Datum und Material der jeweiligen Aufträge, Aufführung der einzelnen Leistungsziffern nebst Beschreibung der durchgeführten Analysen. Berücksichtigung von Faktoren und vorgeschriebener Abschläge für den Rechnungsbetrag.

\section{Eisen}

D. Meißner und T. Arndt

\section{Englischer Begriff iron}

Definition Eisen (chemisches Symbol: $\mathrm{Fe}$ ) ist ein ubiquitär vorkommendes Übergangsmetall ( $\triangleright$ Übergangsmetalle) mit der Ordnungszahl 26. Es ist das vierthäufigste Element der Erdkruste und das quantitativ bedeutendste essenzielle Spurenelement ( $\triangleright$ Spurenelemente) im menschlichen Organismus.

Struktur Für den Organismus haben nur die Oxidationsstufen +2 und +3 Bedeutung, wobei die Oxidationsstufe im Verlauf der Körperpassage mehrfach wechselt. $\mathrm{Fe}^{3+}$ ist die stabile, $\mathrm{Fe}^{2+}$ die wesentlich besser lösliche Form. Bei physiologischem $\mathrm{pH}$ wird $\mathrm{Fe}^{2+}$ rasch $\mathrm{zu} \mathrm{Fe}^{3+}$ oxidiert. Eisen liegt als Funktionseisen im $>$ Hämoglobin, Myoglobin sowie in Enzymen vor. Im Plasma ist es an $\triangleright$ Transferrin gebunden. Speicherproteine sind $\triangleright$ Ferritin und $\triangleright$ Hämosiderin.

Molmasse Relative Atommasse: 55,847.

Synthese - Verteilung - Abbau - Elimination Eisen wird sowohl in ionisierter Form als auch als Hämeisen aufgenommen, benötigt werden $10-15$ mg pro Tag. Zur Resorption muss Eisen in der reduzierten Form $\left(\mathrm{Fe}^{2+}\right)$ vorliegen. Im Häm ist $\mathrm{Fe}^{2+}$ enthalten. $\mathrm{Fe}^{3+}$ wird mittels Ferrireduktasen $\mathrm{zu}$ $\mathrm{Fe}^{2+}$ reduziert, damit es mithilfe DMT1 (,divalent metal transporters") über die Mukosazellen des proximalen Duodenums aufgenommen werden kann. Das resorbierte $\mathrm{Fe}^{2+}$ wird durch Ferrioxidasen wieder $\mathrm{zu} \mathrm{Fe}^{3+}$ reoxidiert, da sowohl Transferrin und Ferritin als auch die Siderophoren nur dreiwertiges Eisen zu binden vermögen. Die Eisenhomöostase wird über die Aufnahme geregelt, die Resorptionsrate liegt zwischen $10 \%$ (normal) und $35 \%$ (bei Eisenmangel). Eisen bindet im Plasma an Transferrin und über Transferrinrezeptoren an die Zelloberfläche, von wo es über Phagosomen in die Zelle aufgenommen wird. Eisen wird, an Ferritin gebunden, in allen Zellen - mit hoher Kapazität besonders in Leber und Milz - gespeichert. Nur etwa $1 \mathrm{mg}$ Eisen wird pro Tag über Urin, Stuhl und Schweiß ausgeschieden. 
Darüberliegende Mengen werden nicht ausgeschieden, sondern in Ferritin und Hämosiderin gespeichert.

Körperbestand: 4-5 g. Bedarf: Männer 6 mg/Tag, Frauen $7 \mathrm{mg}$ /Tag, erhöhter Bedarf bei Heranwachsenden, während Menstruation, Schwangerschaft und Stillzeit. Empfohlene Zufuhr $10 \mathrm{mg} /$ Tag, bei erhöhtem Bedarf $15 \mathrm{mg} /$ Tag. Tolerierbare Aufnahme pro Tag: 0,7 mg/kg KG. Eisenreich sind Fleisch und Fleischprodukte, Gemüse, Hülsenfrüchte, Vollkorn.

Halbwertszeit Im Plasma: 3 Stunden; Ganzkörpereisen: 10 Jahre.

Funktion - Pathophysiologie Fast zwei Drittel des Gesamteisens sind im Hämoglobin enthalten. $\mathrm{Zu}$ den wichtigen Funktionen des Eisens zählen Sauerstofftransport (Hämoglobin), Elektronentransport $\left(\mathrm{Fe}^{2+} / \mathrm{Fe}^{3+}\right)$ und Oxidations-/Reduktionsreaktionen (Eisenenzyme). Pathologische Zustände und damit verbundene Störungen der physiologischen Funktionen entstehen sowohl durch Eisenmangel und Eisenüberladung als auch durch Verteilungs- und Verwertungsstörungen. Eisenmangel ist die Folge von Verlusten, gesteigertem Bedarf oder ungenügender Resorption und äußert sich in 3 Stadien:

- prälatenter Eisenmangel (Speichereisen vermindert),

- latenter Eisenmangel (Speichereisen, Transporteisen und Enzymaktivitäten vermindert) und

- manifester Eisenmangel (mikrozytäre, hypochrome Anämie).

Die erhöhte Zufuhr (Transfusionen, eisenhaltige Medikamente oder sonstige eisenhaltige Materialien) kann zu akuten und chronischen Intoxikationen führen. Die Eisenüberladung, die durch Speicherung in Hämosiderin nach erhöhter Zufuhr oder bei chronischen Erkrankungen, speziell bei Leberzirrhose, zustande kommt, wird als Hämosiderose bezeichnet. Dagegen ist die Hämochromatose eine genetisch bedingte, autosomal rezessiv vererbte und durch gesteigerte Resorption hervorgerufene Eisenspeicherkrankheit, die in unterschiedlichen Formen auftritt. Die häufigste Form beruht auf einer C282Y-Mutation des Hämochromatosegens HFE (Typ 1). Eisenverteilungsstörungen mit erhöhtem Speichersowie vermindertem Transport- und Funktionseisen treten bei malignen Tumoren oder chronischen Entzündungen auf. Eisenverwertungsstörungen, die das Bild einer Eisenmangelanämie vortäuschen, sind bei sideroachrestischer Anämie, renaler Anämie oder Erythropoetinmangel zu finden.

Untersuchungsmaterial - Entnahmebedingungen Serum, Heparin-Plasma, Urin.

Probenstabilität Blut: 2 Stunden. Serum/Plasma: $20{ }^{\circ} \mathrm{C}$ 7 Tage, $4-8{ }^{\circ} \mathrm{C} 21$ Tage, $-20{ }^{\circ} \mathrm{C}>1 \mathrm{Jahr}$. Urin: $20^{\circ} \mathrm{C} 3$ Tage, $4-8{ }^{\circ} \mathrm{C} 7$ Tage, $-20^{\circ} \mathrm{C}>1 \mathrm{Jahr}$.
Präanalytik Nur Plastikgefäße verwenden; Kontamination durch eisenhaltige Abnahmekanülen vermeiden, die ersten 1-2 mL Blut nicht für die Eisenbestimmung verwenden. Trennung Serum/Blutkuchen innerhalb 2 Stunden, Hämolyse führt zu falsch hohen Werten, EDTA-Plasma eignet sich nur für die AAS-Methode, da Interferenz mit Chelat-Chromophoren. Starke zirkadiane Schwankungen.

Analytik Flammen-AAS, Photometrie. Schritte der kolorimetrischen (photometrischen) Bestimmung sind:

- Trennung des Eisens von Transferrin durch Säuren (z. B. Salzsäure, Trichloressigsäure) oder Detergenz (z. B. Guanidiniumchlorid)

- Eiweißfällung (nicht obligat)

- Reduktion des $\mathrm{Fe}^{3+}$ - zum $\mathrm{Fe}^{2+}$-Ion durch Reduktionsmittel wie Ascorbat, Hydrochinon, Thioglykolat und Hydroxylamin

- Bildung eines gefärbten Chelatkomplexes

Bewährte Farbbildner sind Bathophenanthrolin und Ferrozin (Methode des International Committee for Standardization in Hematology, ICSH). Letzteres hat eine bessere Löslichkeit und bildet Komplexe mit einem höheren Absorptionskoeffizienten als Bathophenanthrolin.

Konventionelle Einheit $\mu \mathrm{g} / \mathrm{dL}, \mu \mathrm{g} / \mathrm{d}$.

Internationale Einheit $\mu \mathrm{mol} / \mathrm{L}, \mu \mathrm{mol} / \mathrm{d}$.

Umrechnungsfaktor zw. konv. u. int. Einheit $\mu \mathrm{mol} /$ $\mathrm{L}=0,17906 \times \mu \mathrm{g} / \mathrm{dL}, \mu \mathrm{g} / \mathrm{dL}=5,5847 \times \mu \mathrm{mol} / \mathrm{L}$. $\mu \mathrm{mol} / \mathrm{d}=0,017906 \times \mu \mathrm{g} / \mathrm{d}, \mu \mathrm{g} / \mathrm{d}=55,847 \times \mu \mathrm{mol} / \mathrm{d}$.

Referenzbereich - Frauen Aufgrund der u. g.Einflussgrößen auf die Eisenserumkonzentration schwanken die Referenzbereiche zwischen den einzelnen Studien und Quellen mehr oder weniger stark. Im konkreten Fall sollten deshalb die im Laborbefund ausgewiesenen, oft geschlechts- und altersabhängig differenzierten, Referenzbereiche beachtet werden. Die hier angegebenen Werte dienen einer ersten Orientierung. Sie repräsentieren für Plasma/Serum gerundete Mittelwerte aus den von Thomas (2005) publizierten Daten. Plasma/Serum: 6-26 $\mu \mathrm{mol} / \mathrm{L} \quad(34-145 \mu \mathrm{g} / \mathrm{dL})$. Urin: $<1,8 \mu \mathrm{mol} / \mathrm{Tag}$ $(<100 \mu \mathrm{g} / \mathrm{Tag})$ (unpublizierte Studie von Meißner).

Referenzbereich - Männer Serum/Plasma: 7-30 $\mu \mathrm{mol} / \mathrm{L}$ $(39-168 \mu \mathrm{g} / \mathrm{dL})$, s. Fauen.

Referenzbereich - Kinder Serum/Plasma: 4-28 $\mu \mathrm{mol} / \mathrm{L}$ $(22-156 \mu \mathrm{g} / \mathrm{dL})$, s. Frauen. 


\section{Indikation}

- Eisen im Serum/Plasma: Parameter zur Berechnung der - Transferrinsättigung, Verdacht auf Eisenüberladung, übermäßige Aufnahme oder Vergiftung mit Eisen.

- Eisen im Urin: Zusatzinformation bei Eisenstoffwechselstörungen, Parameter des $>$ Deferoxamin-Tests.

Interpretation Serum- oder Plasmaeisen sind zur Beurteilung des Körpereisenstatus ungeeignet. Im Serum gibt es erhebliche zirkadiane Schwankungen zwischen frühem Morgen und Mittag (Amplitude bis zu $50 \mu \mathrm{g} / \mathrm{dL}$ und mehr) sowie von Tag zu Tag. Die Eisenkonzentration wird darüber hinaus von der Nahrungsaufnahme, von akuten Entzündungen und chronischen Erkrankungen beeinflusst. Ein Eisenmangel kann dadurch maskiert werden. Eisenüberladungen werden jedoch gewöhnlich angezeigt und Serumkonzentrationen von $>54 \mu \mathrm{mol} / \mathrm{L}$ von klinischen Symptomen begleitet.

Grenzwert im Trinkwasser: 0,2 mg Fe/L (Trinkwasser-VO 2016).

Diagnostische Wertigkeit Die Eisenserumkonzentration hat lediglich für die Diagnose einer Eisenüberbeladung diagnostische Bedeutung.

Zur Diagnose eines Eisenmangels (prälatenter, latenter, manifester) sowie von verschiedenen Formen einer gestörten Eisenversorgung, - nutzung und -ausscheidung sind in erster Linie Ferritin, Transferrin und die Transferrinsättigung im Serum sowie das kleine Blutbild (Erythrozytenzahl, Erythrozytenindices, Hämoglobin) im EDTA-Blut zu bestimmen und ggf. ein Blutausstrich zu bewerten (Erythrozytenmorphologie und -färbung).

Parameter der nächsten diagnostischen Stufe können sein: der lösliche Transferrinrezeptor ( $>$ Transferrinrezeptor, löslicher), der Hämoglobingehalt des einzelnen Retikulozyten ( $\vee$ Retikulozytenhämoglobin) sowie das $>$ Zink-Protoporphyrin in Erythrozyten.

Hinweise auf eine genetisch bedingte Eisenüberbeladung (Hämochromatose) können molekularbiologisch abgeklärt und einem spezifischen Hämochromatosetyp zugeordnet werden.

\section{Literatur}

Metzgeroth G, Hastka J (2004) Diagnosic work-up of iron deficiency. J Lab Med 28:391-399

Schümann K, Weiss G (2002) Eisen. In: Biesalski HK, Köhrle J, Schümann K (Hrsg) Vitamine, Spurenelemente und Mineralstoffe. Georg Thieme Verlag, Stuttgart/New York, S 137-147

Thomas L (2005) Labor und Diagnose, 6. Aufl. TH-Books, Frankfurt am Main, S 379-411

Trinkwasser-VO (2016) Trinkwasserverordnung in der Fassung der Bekanntmachung vom 10. März 2016. https://www.gesetze-iminternet.de/bundesrecht/trinkwv_2001/gesamt.pdf. Zugegrieffen am 08.09.2017

\section{Eisenbelastungstest}

$>$ Eisenresorptionstest

\section{Eisenbindungskapazität}

D. Meißner und T. Arndt

\section{$\operatorname{Synonym(e)~EBK~}$}

Englischer Begriff iron binding capacity

Definition EBK ist ein Maß für die Menge an Eisen, die von Transferrin in einem definierten Serumvolumen gebunden werden kann.

Beschreibung Normalerweise sind die im Transferrin vorhandenen Bindungsstellen nur zu etwa einem Drittel mit Eisen beladen; die Bindungskapazität wird also nicht ausgeschöpft. Man bezeichnet die Gesamtmenge an Eisen, die das Transferrin aufzunehmen vermag, als totale Eisenbindungskapazität (TEBK) und den Anteil der Bindungsstellen, die nicht mit Eisen beladen sind, als latente (LEBK) oder freie (FEBK) Eisenbindungskapazität. Daraus ergibt sich:

TEBK - Serumeisen $=$ LEBK, $\mathrm{LEBK}+$ Serumeisen $=$ TEBK .

Bestimmung der TEBK: Dem Serum wird zur Sättigung des Transferrins ein Überschuss an $\mathrm{Fe}^{3+}$-Ionen zugesetzt, nicht gebundene Eisen werden mit basischem Magnesiumhydroxidcarbonat ausgefällt, nach Zentrifugation wird im klaren Überstand Eisen bestimmt. TEBK-Referenzwert für Erwachsene: $260-500 \mu \mathrm{g} / \mathrm{dL}(46-90 \mu \mathrm{mol} / \mathrm{L})$ (Wick et al. 1996). TEBK ist erhöht bei echtem Eisenmangel und in der Schwangerschaft und erniedrigt bei Eisenüberladung wie Hämochromatose sowie bei chronischen Entzündungen, Neoplasien, Proteinverlusten oder Störungen der Hämoglobinsynthese.

Die EBK hat heute ihre Bedeutung verloren und wird durch die Bestimmung von > Transferrinsättigung und > Ferritin ersetzt. Über die Zusammenhänge zwischen EBK und Transferrin und die gegenseitige Umrechnung $>$ Transferrin.

\section{Literatur}

Sherwood R, Pippard MJ, Peters TJ (1998) Iron homeostasis and the assessment of iron status. Ann Clin Biochem 35:693-708

Wick M, Pingerra W, Lehmann P (1996) Eisenstoffwechsel, Diagnostik und Therapie der Anämien. Springer, Berlin/Heidelberg/New York 


\section{Eisenblau}

- Berlinerblau-Reaktion

\section{Eisenfärbung}

H. Baum

Synonym(e) Berlinerblau-Färbung

Englischer Begriff iron staining

Definition Histochemischer Nachweis des dreiwertigen intrazellulären Eisens (Hämosiderin).

Beschreibung Nachweis des intrazellulär lokalisierten $\mathrm{Fe}^{3+}$ im Ausstrichpräparat, das nicht an $>$ Ferritin gebunden ist. $\mathrm{Fe}^{3+}$-Verbindungen reagieren mit Kaliumhexacyanoferrat (II) in Gegenwart von Salzsäure unter Bildung von auffällig sichtbarem Berliner Blau.

\section{Literatur}

Löffler H (1991) Zytochemische Methoden. In: Boll I, Heller S (Hrsg) Praktische Blutzelldiagnostik. Springer, Berlin/Heidelberg/New York, S 190-191

\section{Eisenmobilisationstest}

- Deferoxamin-Test

\section{Eisenresorptionstest}

W. Hubl

Synonym(e) Eisenbelastungstest

\section{Englischer Begriff iron resorption test}

Definition Der Eisenresorptionstest überprüft die Durchlässigkeit der Darmmukosa für zweiwertiges Eisen.

\section{Durchführung}

- Erste Blutentnahme am nüchternen Patienten zur SerumEisenbestimmung

- Verabreichung von $200 \mathrm{mg}$ resorbierbarem $\mathrm{Fe}^{2+}$ (z. B. 2 Kapseln Ferrosanol duodenal)

- 2 Stunden nach erster Blutentnahme erneute Blutentnahme zur Eisenbestimmung

- 4 Stunden nach erster Blutentnahme eine weitere Blutentnahme zur Eisenbestimmung

Untersuchungsmaterial - Entnahmebedingungen Serum, Hämolyse vermeiden!

Referenzbereich Anstieg des Eisens im Serum bei normalem Basiswert um 30-40 \% (9-18 $\mu \mathrm{mol} / \mathrm{L})$.

Indikation Eisenresorptionsstörung.

\section{Interpretation}

- Normaler Basiswert, Anstieg des Serumeisens um 30-40 \%: intakte intestinale Resorption

- Niedriger Basiswert mit starkem Eisenanstieg auf $>36$ $\mu \mathrm{mol} / \mathrm{L}$ : Eisenmangelanämie bei intakter intestinaler Resorption

- Niedriger Eisenausgangswert und niedriger Anstieg: Eisenresorptionsstörung, Malabsorption, Infekte

- Hoher Eisenausgangswert mit geringem Anstieg: Hämochromatose und hämolytische Anämie

Diagnostische Wertigkeit Der Eisenresorptionstest dient lediglich zur Überprüfung der Durchlässigkeit der Darmmukosa für $\mathrm{Fe}^{2+}$. Er reflektiert nicht die Aufnahme des Nahrungseisens und ist für die Ursachenabklärung des Eisenmangels nicht geeignet.

Zur Diagnostik des Eisenmangels s. \ Ferritin, \ Transferrin, \ Transferrinrezeptor, löslicher.

\section{Literatur}

Thomas L (Hrsg) (2012) Labor und Diagnose: Indikation und Bewertung von Laborbefunden für die medizinische Diagnostik, 8. Aufl. TH-Books, Frankfurt am Main

Wick M, Pinggera W, Lehmann P (2002) Eisenstoffwechsel, Anämien, Diagnostik und Therapie, 7. Aufl., Springer-Verlag, Wien, S 58

\section{Eisensåttigung, prozentuale}

Transferrinsättigung 


\section{Eisenstoffwechselplot nach Thomas}

> Thomas-Plot

\section{Eiweißhormone}

> Peptidhormone

\section{Eiweißprobe im Urin}

> Sulfosalizylsäure-Test

\section{Ejakulat}

> Seminalflüssigkeit

\section{EJ-Antikörper}

- Autoantikörper gegen Aminoacyl-t-RNS-Synthetase

\section{EKA-Wert}

T. Arndt

Synonym(e) Expositionsäquivalente für krebserzeugende Arbeitsstoffe

Definition Beziehung zwischen der Stoffkonzentration eines krebserzeugenden Arbeitsstoffs in der Arbeitsluft und der erwarteten Stoff- bzw. Metabolitkonzentration im biologischen Material exponierter Personen.

Beschreibung Die EKA-Werte werden von der in der Deutschen Forschungsgemeinschaft verankerten Senatskommission zur Prüfung gesundheitsschädlicher Arbeitsstoffe erarbeitet. Aus dem EKA-Wert kann entnommen werden, welche Belastung des Organismus bei ausschließlich inhalativer Aufnahme des krebserzeugenden Stoffs erwartet werden kann.

Arbeitsstoffe werden bezüglich ihrer krebserzeugenden Eigenschaften in 5 Kategorien unterteilt. Gekürzte Definitionen aus DFG 2017:

- Kategorie 1: Stoffe, die beim Menschen Krebs erzeugen und bei denen davon auszugehen ist, dass sie einen nennenswerten Beitrag zum Krebsrisiko leisten.
- Kategorie 2: Stoffe, die als krebserregend für den Menschen anzusehen sind.

- Kategorie 3: Stoffe, die wegen erwiesener oder möglicher krebserzeugender Wirkung Anlass zur Besorgnis geben, aber noch nicht endgültig beurteilt werden können.

- Kategorie 4: Stoffe mit krebserzeugender Wirkung, bei denen ein nicht genotoxischer Wirkmechanismus im Vordergrund steht und genotoxische Effekte bei Einhaltung des MAK- und BAT-Wertes keine oder nur eine untergeordnete Rolle spielen.

- Kategorie 5: Stoffe mit krebserzeugender und genotoxischer Wirkung, deren Wirkungsstärke jedoch so gering erachtet wird, dass unter Einhaltung des MAK- und BAT-Wertes kein nennenswerter Beitrag zum Krebsrisiko zu erwarten ist.

\section{Literatur}

DFG (2017) Ständige Senatskommission zur Prüfung gesundheitsschädlicher Arbeitsstoffe. Mitteilung 53 MAK- und BAT-Werte-Liste. Wiley-VCH, Weinheim

\section{ELA2}

> PMN-Elastase

\section{E-Labormedizin}

Tele-Laboratoriumsmedizin

\section{ELAS}

PMN-Elastase

\section{Elastase, fäkale}

- Elastase, pankreasspezifische

\section{Elastase, pankreasspezifische}

A. M. Gressner und O. A. Gressner

Synonym(e) Elastase-1; PE; Elastase, fäkale; EC 3.4.21.11 
Englischer Begriff faecal elastase 1; pancreatic elastase 1

Definition PE ist eine von den Azinuszellen des exokrinen Pankreas synthetisierte, organspezifische Endopeptidase, die als inaktive Proelastase sezerniert und intestinal durch Trypsin aktiviert wird, für die Hydrolyse des Elastins spezifisch ist und deren Ausscheidungsmenge im Stuhl als Kenngröße der exkretorischen Pankreasfunktion dient.

Molmasse $25,7 \mathrm{kDa}$.

Synthese - Verteilung - Abbau - Elimination Azinuszellen des exokrinen Pankreas synthetisieren und sezernieren Proelastase-1 und Proelastase-2, die im Intestinallumen durch - Trypsin limitiert proteolytisch aktiviert werden, um als Endoproteinase (Serinproteinase) bevorzugt am Carboxylende von Leucin, Methionin und Phenylalanin Peptide zu spalten. Es handelt sich um Glykoproteine (240 Aminosäuren, iP 4,9), die eine $52 \%$ ige Sequenzhomologie mit Trypsin und - Chymotrypsin aufweisen und im Serum mit $\alpha 1$-Proteinaseinhibitor komplexiert sind. Im Gegensatz zu anderen Endopeptidasen spaltet PE sehr effektiv $\triangleright$ Elastin. Im Intestinum bildet $\mathrm{PE}$ mit $\triangleright$ Gallensäuren und $\triangleright$ Cholesterin bzw. seinen bakteriellen Abbauprodukten Koprostanol und Koprostanon einen stabilen Protein-Sterol-Komplex. Während der Darmpassage nur geringer Abbau mit Ausscheidung von etwa $1,2 \mathrm{mg} / \mathrm{g}$ Stuhlfeuchtgewicht.

Funktion - Pathophysiologie Die PE-Normalkonzentration beträgt im Pankreassekret $0,16-0,45 \mathrm{~g} / \mathrm{L}$, eine signifikante Abnahme liegt bei exkretorischer Pankreasinsuffizienz mit konsekutiver Verminderung der fäkalen Ausscheidungsmenge vor. Bei akuter Pankreatitis kommt es zum Übertritt von Elastase-1 in das Serum und Komplexierung mit $\alpha 1$ Proteinaseinhibitor.

\section{Untersuchungsmaterial-Entnahmebedingungen Serum,} Fäzes.

Probenstabilität Bei Raumtemperatur maximal 8 \% Aktivitätsverlust pro Woche, bei $4{ }^{\circ} \mathrm{C}$ stabil über Monate. Im Stuhl stabil über 5 Tage bei Raumtemperatur.

Präanalytik Therapeutische Enzymsubstitution ist ohne Einfluss.

Analytik Für Serum und Stuhl steht ein Sandwich- $\triangleright$ Immunoassay (ELISA) unter Anwendung von 2 monoklonalen Antikörpern zur Verfügung. Nachweisgrenze $1 \mu \mathrm{g} / \mathrm{L}, \mathrm{VK}$ in der Serie 5,8\%, von Tag zu Tag $<8 \%$. Spezifität für Pankreaselastase-1 hoch.

Referenzbereich - Erwachsene Serum: $<3,5 \mu \mathrm{g} / \mathrm{L}$.
Fäzes: Erwachsene und Kinder nach dem ersten Monat: $200-400 \mu \mathrm{g} / \mathrm{g}$ Stuhl.

Mittlere bis leichte Insuffizienz: 100-200 $\mu \mathrm{g} / \mathrm{g}$ Stuhl.

Schwere Insuffizienz: $<100 \mu \mathrm{g} / \mathrm{g}$ Stuhl.

Referenzbereich - Kinder s. Erwachsene.

\section{Indikation}

- Diagnostik und Verlaufskontrolle der exkretorischen Pankreasinsuffizienz (Stuhluntersuchung)

- Diagnostik der akuten und chronisch-rezidivierenden Pankreatitis (Serum)

Interpretation Die Abnahme der fäkalen PE-Ausscheidung ist ein empfindlicherer Parameter der exkretorischen Pankreasinsuffizienz als die des Chymotrypsins. Die Ausscheidung wird nicht beeinflusst durch Darmflora oder Pankreasenzymsubstitution. Veränderungen korrelieren mit dem Ergebnis des $>$ Sekretin-Pankreozymin-Tests und sind aufgrund geringer intraindividueller Variation für die Verlaufskontrolle geeignet. Im Serum Anstieg in der Frühphase der akuten Pankreatitis, bei chronisch-rezidivierender Pankreatitis und ERCP. Im Duodenalsaft Verminderung von PE bei Pankreasinsuffizienz, z. B. chronische Pankreatitis, zystische Pankreasfibrose, Pankreastumoren.

Diagnostische Wertigkeit Bei einem Cut-off von $200 \mu \mathrm{g}$ $\mathrm{PE} / \mathrm{g}$ Stuhl beträgt die Sensitivität $63 \%$ für milde, $100 \%$ für moderate und $100 \%$ für schwere exkretorische Pankreasinsuffizienz und $93 \%$ für alle Patienten. Spezifität $93 \%$. Die Vergleichswerte für Chymotrypsin sind $64 \%$ Sensitivität und $89 \%$ Spezifität.

\section{Literatur}

Löser C, Möllgaard A, Fölsch UR (1996) Faecal elastase 1: a novel, highly sensitive, and specific tubeless pancreatic function test. Gut 39:580-586

\section{Elastase-1}

Elastase, pankreasspezifische

\section{Elastase-1 im Stuhl}

Elastase, pankreasspezifische 


\section{Elastin}

H.-D. Haubeck

\section{Englischer Begriff elastin}

Definition Elastin ist für die elastischen Eigenschaften vieler Gewebe, z. B. von Haut, Blutgefäßen und Lunge, essenziell.

Beschreibung Elastin ist der Hauptbestandteil elastischer Fasern. Tropoelastin, das lösliche Precursor-Protein des unlöslichen quervernetzten Elastins, ist ein stark hydrophobes Protein mit einer Molmasse von ca. $70 \mathrm{kDa}$, von dem im Gewebe zahlreiche Isoformen existieren. Die Tropoelastinmoleküle werden von den Fibroblasten, Myofibroblasten und glatten Muskelzellen in den extrazellulären Raum sezerniert und lagern sich in der Nähe der Plasmamembran zu elastischen Fasern zusammen. Tropoelastin enthält ähnlich wie die fibrillären Kollagene einen hohen Anteil an Prolin und Lysin, aber im Gegensatz zu den Kollagenen kaum Hydroxyprolin und kein Hydroxylysin. Die Quervernetzung der Elastinmoleküle erfolgt, ähnlich wie bei den Kollagenen, durch das Kupfer-abhängige Enzym Lysyloxidase (LOX). Hierbei wird zunächst die $\varepsilon$-Aminogruppe der Lysinseitenkette oxidativ deaminiert. Die entstehende reaktive Aldehydgruppe (Allysin) kann spontan mit einer weiteren Aldehydgruppe des gleichen Elastinmoleküls zu einem Allysinaldol und in der Folge mit weiteren reaktiven Aldehyden benachbarter Elastinmoleküle zu den Crosslinks Desmosin und Isodesmosin kondensieren. Die quervernetzten Elastinmoleküle werden dann mit Elastin-assoziierten Mikrofibrillen zu elastischen Fasern zusammengelagert. Die Mikrofibrillen bestehen hauptsächlich aus Mitgliedern der Fibrillinfamilie (Fibrillin 1 und 2) und dem kleineren Glykoprotein MAGP (,,microfibrillar associated glycoprotein“). Mutationen im Fibrillin-1Gen führen zum Marfan-Syndrom (Häufigkeit ca. 1:10.000). Entsprechend der Verteilung von Fibrillin-1 sind hierbei vor allem die elastischen Fasern im kardiovaskulären System, im Skelett und am Auge betroffen. Dadurch kommt es u. a. zur Bildung von Aortenaneurysmen, Skelettabnormitäten und zur Dislokation der Augenlinse. Mutationen der Lysyloxidase können ebenfalls die Ausbildung und Stabilität der elastischen Fasern beeinträchtigen und zu entsprechenden klinischen Symptomen führen. Dementsprechend kommt es bei der LOX-Knockout-Maus zu schweren lethalen Gefäßveränderungen. Verschiedene Mutationen und Deletionen im Elastingen können auch beim Menschen zu schweren Gefäßveränderungen, z. B. der supravalvulären Aortenstenose und dem Williams-Syndrom, führen. Darüber hinaus wird die autosomal dominant vererbte Cutis laxa durch FrameshiftMutationen im Elastingen verursacht. Elastin ist aber auch für die elastischen Eigenschaften der Lunge und insbesondere der Alveolen verantwortlich. Die Zerstörung des Elastins in den elastischen Fasern der Alveolen durch Elastasen, d. h. durch die Neutrophilenelastase, eine Serinprotease und/oder verschiedene $>$ Metalloproteinasen (MMP 2, MMP 7, MMP 9 und MMP 12 = Makrophagen-Metalloelastase), führt zur progredienten Schädigung des Lungengewebes und zum Lungenemphysem.

Die Degradation von Elastin kann über den Nachweis der Crosslinks Desmosin und Isodesmosin mit einer HPLC-MSMethode erfolgen. Allerdings zeigen die gefundenen Desmosin- und Isodesmosinkonzentrationen keine gute Korrelation mit dem klinischen Bild, z. B. mit dem Ausmaß des Lungenemphysems.

\section{Literatur}

Ma S, Lieberman S, Turino GM et al (2003) The detection and quantitation of free desmosine and isodesmosine in human urine and their peptidebound forms in sputum. Proc Natl Acad Sci 100:12.941-12.943

\section{Elastin-Autoantikörper}

- Autoantikörper gegen Elastin

\section{Elastographie, transiente}

A. M. Gressner und O. A. Gressner

Synonym(e) Gewebeelastizitätsbestimmung der Leber

Englischer Begriff transient elastography, fibroscan

Definition Zur nicht invasiven Diagnostik der Leberfibrose/zirrhose eingesetzte Technik, die die durch den im Leberparenchym erhöhten Bindegewebsanteil veränderte Ausbreitungsgeschwindigkeit ultraschallinduzierter elastischer Wellen misst.

Beschreibung Die von einer auf der Leberoberfläche handgeführten, beweglichen Sonde ausgesendeten Ultraschallwellen niedriger Frequenz (50 MHz) und Amplitude werden in das Gewebe transmittiert. Die von den Vibrationswellen induzierten elastischen Scherwellen durchsetzen das Gewebe mit einer Geschwindigkeit, die direkt mit der Lebersteifigkeit korreliert: Je steifer/härter das Gewebe, desto schneller breiten sich die Wellen aus ( $\mathrm{kPa})$. Von der Sonde wird in der Regel ein Gewebszylinder von ca. $1 \mathrm{~cm}$ Durchmesser und $5 \mathrm{~cm}$ Länge gemessen, was etwa dem 100-fachen Volumen einer perkutanen Leberbiopsie entspricht. 
Diese nicht invasive Methode erlaubt die zuverlässige und reproduzierbare Diagnose einer signifikanten Fibrose und der Zirrhose, ist schnell, unbelastend, kostensparend und erfasst einen relativ großen Anteil des Organs. Limitation sind: starke Adipositas und Aszites, akute Hepatitis.

Je nach Grenzwert $(\mathrm{kPa})$ betragen die diagnostische Sensitivitäten ( $\triangleright$ Sensitivität, diagnostische) 63-90 \%, Spezifitäten ( $\triangleright$ Spezifität, diagnostische) $82-97 \%$ und positive/negative Vorhersagewerte $(\triangleright$ Vorhersagewert, positiver; $\triangleright$ Vorhersagewert, negativer) 71-91 \% bzw. 84-95\% (॰ Fibrosekenngrößen).

\section{Literatur}

Erhard A, Lörke J, Vogt C et al (2006) Transiente Elastografie zur Diagnostik der Leberzirrhose. Dtsch Med Wochenschr 131:2765-2769

Manning DS, Afdhal NH (2008) Diagnosis and qantitation of fibrosis. Gastroenterology 134:1670-1681

\section{Electron Ionization}

- Ionisationsmethoden (Massenspektrometrie)

\section{Electrospray}

- Ionisationsmethoden (Massenspektrometrie)

\section{Electrothermal atomic absorption spectrometry (ET-AAS)}

- Atomabsorptionsspektrometrie

Elektrische Leitfähigkeit

> Leitfähigkeit des Urins

\section{Elektrochemilumineszenz- Immunoassay}
G. Töpfer

Synonym(e) ECLIA; ECL-Verfahren
Englischer Begriff electrochemiluminescence immunoassay; ECLIA

Definition ECLIA, auch als ECL-Verfahren bezeichnet, verbindet die Vorteile der Biotin-Streptavidin-Fixierung ( $\triangleright$ Biotin-Streptavidin-Technik) eines Reaktionspartners der Antigen-Antikörper-Reaktion an magnetische Mikropartikel mit einem als Elektrochemilumineszenz bezeichneten hochsensitiven Detektionsverfahren. Dabei ist an den zu bestimmenden Immunkomplex als Tracer Ruthenium-(II)-tris (bipyridyl) $^{2+}$ (Abkürzung: $[\mathrm{Ru}(\mathrm{bpy}) 3]^{2+}$ ) gekoppelt. Der Ruthenium-(II)-tris(bipyridyl)-Komplex gibt in einer Redoxreaktion an einer Anode mithilfe von sich verbrauchendem Tripropylamin (TPA) Licht der Wellenlänge $620 \mathrm{~nm} \mathrm{ab}$, wobei der Rutheniumkomplex selbst nicht verbraucht wird.

Beschreibung Bildung des Immunkomplexes:

Es handelt sich um einen Sandwich-Immunoassay (Abb. 1). Zunächst werden die biotinylierten und die Rutheniumkomplex-konjugierten Antikörper bei $37{ }^{\circ} \mathrm{C}$ mit der Probe inkubiert. Dann erfolgt die Zugabe der Streptavidinbeschichteten paramagnetischen Partikel, und die Inkubation wird fortgesetzt. Anschließend wird das Reaktionsgemisch in die Durchflussmesszelle gesaugt.

Detektion:

In der Messzelle zieht ein Magnet, der sich unterhalb der Anode befindet, die paramagnetischen Partikel mit den biotinylierten Reaktanden an:

- Partikel, die keinen Analyten gebunden haben oder

- mit gebundenem Analyten und Zweitantikörper mit konjugiertem Rutheniumkomplex.

Die Konzentration des zu messenden Analyten bestimmt den Anteil der gebundenen Rutheniumkomplexe an der Anode. Jetzt strömt Procell (eine Tripropylamin-[TPA-] haltige Pufferlösung durch die Messzelle, wodurch alle ungebundenen Partikel wie unfixierter Ruthenium-Tracer aus der Messzelle entfernt werden.

Anschließend wird die Reaktion durch Anlegen einer Spannung ausgelöst: Innerhalb von 0,4 Sekunden findet an der Anode die Aktivierung der Rutheniumkomplexe mit Hilfe von TPA statt, was sich im steigenden Aussenden von Lichtquanten der Wellenlänge $620 \mathrm{~nm}$ zeigt. Diese werden in einem Fotomultiplier in 100 Messungen registriert und zur Datenreduktion summiert.

Die Erzeugung des Lichtes an der Platinanode wird durch das Anlegen einer Spannung ausgelöst. Die Spannung führt zur Abgabe eines Elektrons eines Protons durch TPA, wodurch ein TPA-Radikal entsteht. Der Rutheniumkomplex mit dem Analyten wird ebenfalls an der Anode zum $[\mathrm{Ru}(\mathrm{bpy}) 3]^{3+}$ oxidiert. Dieser oxidierte Komplex übernimmt vom TPARadikal das freie (energiereiche) Elektron, wird dabei sowohl 


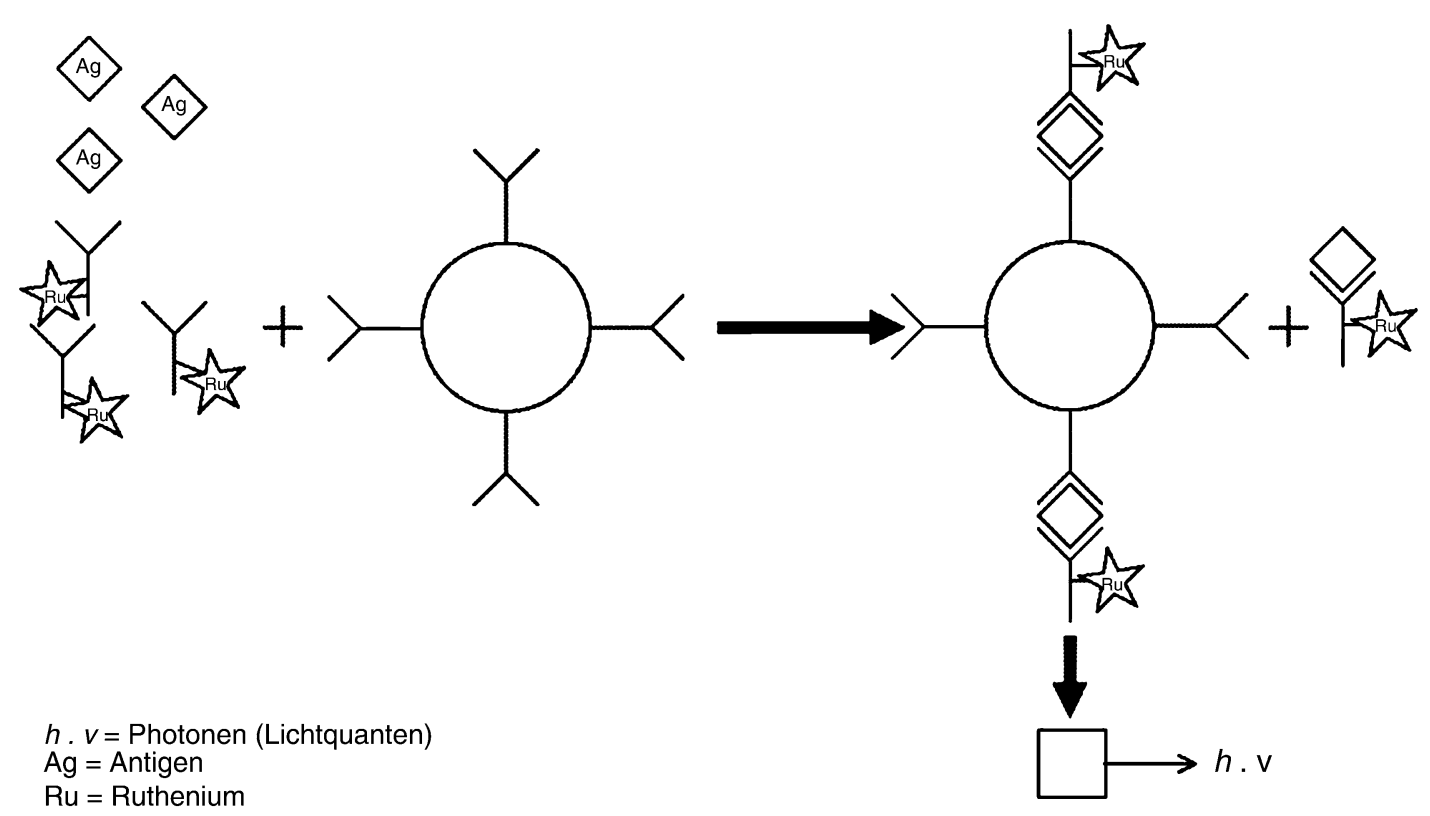

Elektrochemilumineszenz-Immunoassay, Abb. 1 Prinzip des Elektrochemilumineszenz-Immunoassays

zum $[\mathrm{Ru}(\mathrm{bpy}) 3]^{2+}$ reduziert, aber gleichzeitig durch Energietransfer in einen angeregten (energiereichen) Zustand überführt. Dieser Zustand ist labil und fällt unter Abgabe eines Photons der Wellenlänge $620 \mathrm{~nm}$ in den Grundzustand [Ru (bpy) 3$]^{2+}$ zurück. TPA wird dabei verbraucht, nicht aber der Rutheniumkomplex.

TPA wird im großen Überschuss verwendet, sodass die Lichtausbeute durch die Diffusion des TPA bestimmt wird und in der Praxis nach Durchschreiten eines Maximums $<0,4$ Sekunden nach Messbeginn langsam abnimmt. Nach der Messung wird die Messzelle mit Reinigungslösung ausgewaschen und die Elektrodenoberfläche durch mehrfache Spannungsänderung regeneriert. Analog wie Proteine lässt sich auch DNA bestimmen.

Die von der Firma IGEN (USA) entwickelte Methode wurde im Jahr 1996 nach Lizenznahme von Boehringer Mannheim, heute Roche Diagnostics, mit dem ECL-Analyzer ELECSYS auf den Markt gebracht (gegenwärtige Gerätereihe „Cobas e").

Vorteile des Verfahrens sind:

- Sehr stabiler nicht radioaktiver Marker, der an Antikörper, Antigene und DNA konjugierbar ist. Dabei lassen sich in Sandwich-Immunoassays Analyte mit hoher Molmasse (z. B. PSA) und in kompetitiven Immunoassays Analyte mit niedriger Molmasse bestimmen. Über Brückenteste lassen sich IgG- und IgM-Antikörper bestimmen. Da eine Kopplung des Rutheniumkomplexes an DNA-und RNAStränge möglich ist, können auch komplementäre DNAbzw. RNA-Stränge bestimmt werden.

- Hohe Sensitivität (attomol $=10^{-18}$ ) durch hohe Lichtausbeute.
- Kurze Inkubationszeiten (Analysenzeit 9 Minuten beispielsweise bei Troponin T).

- Großer Messbereich über 5 Zehnerpotenzen durch hohe Bindungskapazität der paramagnetischen Mikropartikel.

Der ECLIA ist heute ein im klinisch-chemischen Labor breit eingesetztes Analysenverfahren.

\section{Literatur}

Blackburn GF (1991) Electrochemiluminescence detection for development of immunoassays and DNA probe assays. Clin Chem 37:1534-1539

Forster RJ, Bertoncello P, Keyes TE (2009) Electrogenerated chemiluminescence. Annu Rev Anal Chem 2:259-285

\section{Elektrode}

T. Arndt

\section{Englischer Begriff electrode}

Definition Sammelbezeichnung für elektronenleitende Werkstoffe in einem Elektrolyten. Man unterscheidet Anoden und Kathoden.

Beschreibung Elektroden dienen der Zuführung eines elektrischen Stromes in eine Flüssigkeit, ein Gas oder einen Festkörper. Die > Anode ist der „Gegenpol“ zur > Kathode. 
In einer Elektrolytlösung wandern die Anionen (negativ geladenen Ionen) zur (positiv geladenen) Anode und die Kationen (positiv geladene Ionen) zur (negativ geladenen) Kathode. Anionen geben Elektronen an der Anode ab, während Kationen an der Kathode Elektronen aufnehmen. Der resultierende Stromfluss kann, bei bekannter Stöchiometrie, über geeignete mathematische Transformationen zum Nachweis oder zur Quantifizierung von elektrochemisch aktiven Analyten genutzt werden.

Elektroden kommen in verschiedener Form im klinischchemischen Labor zum Einsatz. Anwendungsgebiete sind z. B. die Amperometrie, \Coulometrie, Elektrophorese, $\triangleright$ Ionenselektive Elektrode, inverse Voltammetrie $(\triangleright$ Voltammetrie, zyklische und inverse), $\triangleright$ Polarographie, $\triangleright$ Potenziometrie.

\section{Literatur}

Falbe J, Regitz M (Hrsg) (1996) Römpp Chemie Lexikon, 10. Aufl. Georg Thieme Verlag, Stuttgart/New York

\section{Elektroelution}

\section{R. Westermeier}

\section{Englischer Begriff electroelution}

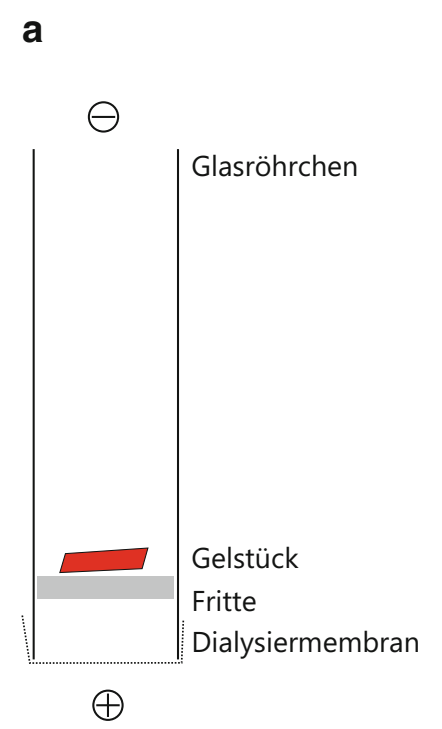

Elektroelution, Abb. 1 A Die zu eluierenden Gelstückchen werden auf Fritten in Glasröhrchen gelegt, die am unteren Ende mit einer Dialysemembran verschlossen sind. Zur Elution werden die Röhrchen in eine Vertikalelektrophoresekammer eingesetzt. B Hier werden die
Definition Rückgewinnung von Proteinfraktionen aus Polyacrylamidgelen mittels elektrischem Feld.

Physikalisch-chemisches Prinzip Um Proteinfraktionen quantitativ aus einem Polyacrylamidgel zu eluieren, benötigt man ein elektrophoretisches Verfahren. Wenn man Ammoniumkarbonat-Puffer verwendet, entweichen die Puffermoleküle später beim Lyophilisieren in die Gasphase. Es gibt mehrere unterschiedliche Konzepte:

Methode 1: Beim einfachsten Prinzip, gezeigt in Abb. 1A, wird das ausgeschnittene Gelstückchen, das die gewünschte Proteinfraktion enthält, in ein Glasröhrchen auf eine Fritte appliziert. Das Ende des Röhrchens ist mit einer Dialysiermembran verschlossen. Man setzt das Röhrchen in eine Vertikalelektrophoreseapparatur ein, die meist für mehrere parallele Elektroelutionen geeignet ist. Das Protein wandert elektrophoretisch bis zur Dialysemembran, die für die großen Moleküle unpassierbar ist. Von dort kann das reine Protein entnommen werden.

Methode 2: Wie in Abb. 1B gezeigt ist, funktioniert die zweite Methode ohne Membran. Hierbei wird ein Elutionsgefäß in ein Standardreaktionsgefäß (Typ Eppendorf-Gefäß) mit 1,5 mL Volumen eingesetzt, dessen schmale Spitze abgeschnitten ist. Das Gelstückchen wird in diese Spitze eingelegt. Das Elutionsgefäß wird mit einem porösen Polyethylenstopfen verschlossen. Nach dem Einfüllen des Puffers wird eine Elektrodenkappe aufgesetzt, die mit einer Kathode für das Elutionsgefäß und einer Anode für das Reaktionsgefäß ausgestattet ist. Mit einer speziell dafür konstruierten Elektroapparatur können mehrere Elektroelutionen parallel durchgeführt werden. Die reine Proteinfraktion wird direkt aus dem Reaktionsgefäß entnommen.

b

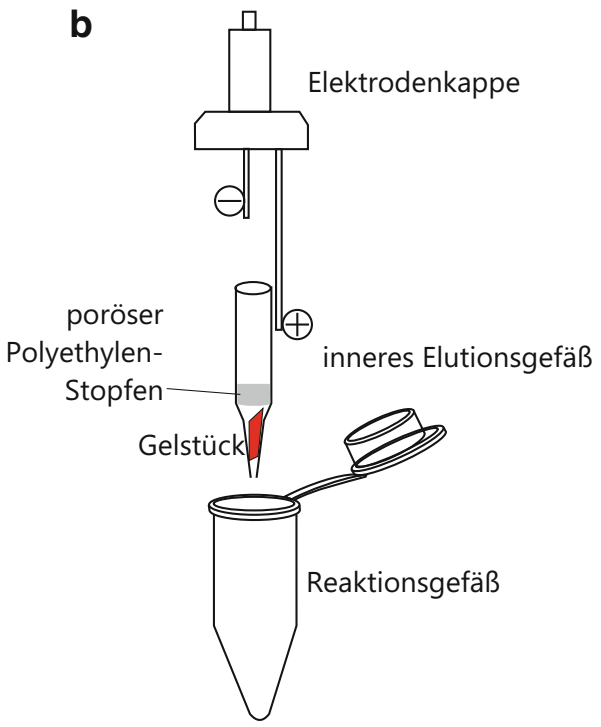

Gelstückchen in das innere Elutionsgefäß eingesetzt, das nach unten spitz zuläuft. Dieses wird in ein Reaktionsgefäß eingesetzt, das mit einer Elektrodenkappe verschlossen wird. Dieses System funktioniert ohne Dialysemembran. (Nach: Lottspeich und Engels 2012) 
Einsatzgebiet Die Methode wird bei Nukleinsäuren kaum mehr verwendet, seit man mit der Polymerasekettenreaktion (PCR) kleinste Mengen amplifizieren kann; das funktioniert auch mit entnommenen Gelstückchen und ausgekratzten Nukleinsäurebanden. Präparative Methode, wenn Proteine in Reinstform benötigt werden, z. B. für Proteinsequenzierung oder Top-Down-Massenspektrometrie.

Untersuchungsmaterial Biologische Flüssigkeiten, Gewebeextrakte, Zelllysate.

Instrumentalisierung Für beide Methoden benötigt man einen Stromversorger. Der Vorteil der ersten Methode ist die Verwendung einer Standardvertikalapparatur. Bei der zweiten Methode wird zusätzlich zur Elektrophoreseausrüstung eine weitere Apparatur benötigt.

Spezifizität Hoch, weil eine hochgereinigte Protein- oder DNA-Fraktion gewonnen wird.

Fehlermöglichkeit Bei der ersten Methode muss man eine Dialysiermembran verwenden, an die das Protein irreversibel adsorbieren kann. Leider ist es in vielen Fällen nicht möglich, alle Proteine quantitativ aus dem Gel zu eluieren.

Bewertung - Methodenhierarchie (allg.) Elektroelution ist eine Methode für klinisch-chemische und für biochemisch arbeitende Labors.

\section{Literatur}

Hunkapiller MW, Lujan E, Ostrander F, Hood LE (1983) Isolation of microgram quantities of proteins from polyacrylamide gels for amino acid sequence analysis. Methods Enzymol 91:227-236

Lottspeich F, Engels JW (2012) Bioanalytik, 3. Aufl. Springer Spektrum, Heidelberg, S 291

\section{Elektroendosmose}

R. Westermeier

\section{Englischer Begriff electroendosmosis}

Definition Phänomen bei der Elektrophorese, das durch fixierte Ladungen in der Trennmatrix oder an Glas- und Quarzoberflächen auftritt. Da fixierte Ladungen im elektrischen Feld nicht wandern können, kommt es zu einer Gegenreaktion: ein Wassertransport entgegen der elektrophoretischen Trennrichtung.
Beschreibung Elektroendosmose ist bei Celluloseacetatfolien (s. - Celluloseacetatfolien-Elektrophorese) und Agarosegelen (s. - Agarosegelelektrophorese) stärker als bei Polyacrylamidgelen. Die Qualität von Agarose wird über den Elektroendosmosewert bestimmt: je niedriger umso besser die Qualität. Bei der $>$ Elektrophorese wirkt sich die Elektroendosmose in unscharfen Trennmustern aus. Die $\triangleright$ Isoelektrische Fokussierung ist besonders anfällig gegenüber Elektroendosmose, weil sie bei sehr hohen Spannungen durchgeführt wird.

\section{Literatur}

Westermeier R (2016) Elektrophorese leicht gemacht. Wiley-VCH, Weinheim

\section{Elektrofokussierung}

- Isoelektrische Fokussierung

\section{Elektroimmundiffusion}

R. Westermeier

Synonym(e) Raketen-Elektrophorese nach Laurell; LaurellTechnik

Englischer Begriff electro immunodiffusion; electro immunoassay; rocket electrophoresis

Definition Immunpräzipitationsmethode zur quantitativen Bestimmung von Antigen in einer Probe. Hierzu lässt man geladene Proteine aus einer Probe elektrophoretisch in eine antikörperhaltige Agarosegelschicht (s. D Agarosegelelektrophorese) einwandern. Dabei entstehen an den Äquivalenzzonen (Bereich der Bildung relativ stabiler Antigen-AntikörperKomplexe) raketenförmige Präzipitatbögen, deren Peakhöhe proportional zur Antigenmenge in der Probe ist (Abb. 1).

Physikalisch-chemisches Prinzip Erst wird ein Agarosesol hergestellt, indem man $1 \mathrm{~g}$ Agarose in $100 \mathrm{~mL}$ kochendem Puffer auflöst. Dann kühlt man das Sol auf $55^{\circ} \mathrm{C}$ ab, mischt die Antikörper dazu und gießt es auf eine Glasplatte aus. Aus dem erstarrten Gel werden mit einer Stanzkanüle die Probenauftragslöcher ausgestanzt.

Die Elektroimmundiffusion beschleunigt immunologische Analysen, die ansonsten auf einfacher Diffusion beruhen. Wie in Abb. 1 gezeigt ist, entstehen raketenförmige Präzipitatbögen. 
Elektroimmundiffusion, Abb. 1 Elektroimmundiffusion, auch Raketen-Elektrophorese nach Laurell genannt. Die Probe wandert elektrophoretisch in ein antikörperhaltiges Agarosegel ein. Das Antigen bildet mit dem Antikörper einen Präzipitatbogen. Die Höhe des Bogens ist ein Maß für die Antigenkonzentration

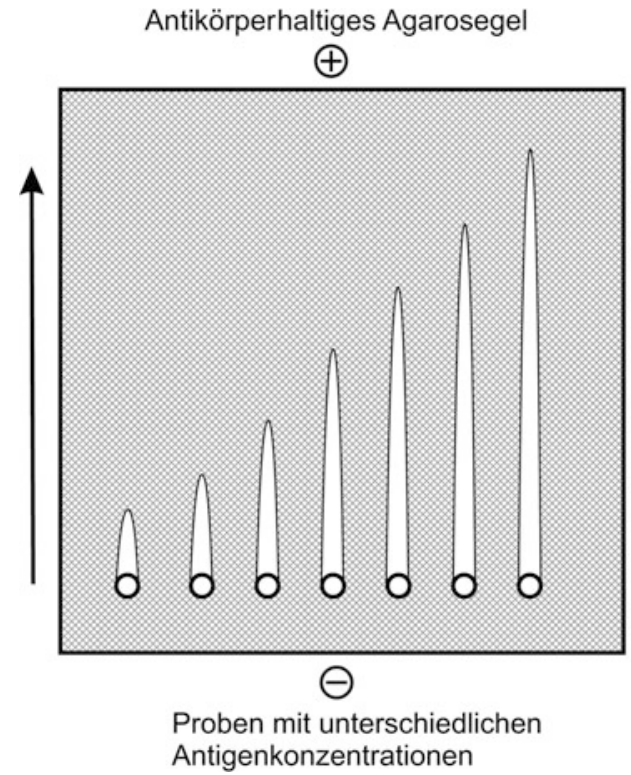

Antikörperhaltiges Agarosegel

Antigenkonzentrationen

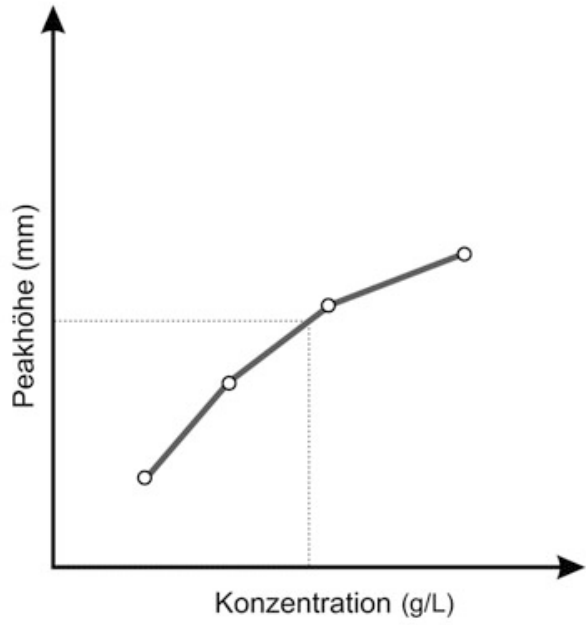

Wenn Antigene elektrophoretisch in ein antikörperhaltiges Gel einwandern sollen, müssen Antigene und Antikörper unterschiedliche isoelektrische Punkte ( Isoelektrischer Punkt) besitzen. Der Puffer wird auf denjenigen pH-Wert eingestellt, der dem isoelektrischen Punkt des verwendeten Antikörpers entspricht, damit der Antikörper nicht zu wandern beginnt. Falls Antigen und Antikörper denselben isoelektrischen Punkt haben, kann man (a) den isoelektrischen Punkt des Antigens oder (b) des Antikörpers durch Carbamylierung modifizieren. Im Fall (a) erhält man eine erhöhte Mobilität des Antigens in Richtung Anode. Im Fall (b) kann ein Puffer mit niedrigerem $\mathrm{pH}$-Wert verwendet werden, wodurch das Antigen positive Ladungen erhält.

Es ist wichtig polyklonale Antikörper zu verwenden, da monoklonale Antikörper keine dreidimensionalen Immunkomplexe bilden.

Ursprünglich wurde Tris-Barbituratpuffer $\mathrm{pH}$ 8,6 verwendet. Wegen des Betäubungsmittelgesetzes (s. - Betäubungsmittelgesetz) bekommt man nur noch sehr schwer Zugang zu Barbitursäure. Deshalb wird heutzutage meist ein Tris-TricinCalciumlactat-Puffer eingesetzt.

Die Präzipitatbögen werden nach Auswaschung der Antikörper mit physiologischer Salzlösung mit $>$ Coomassie-Färbung detektiert. Streng genommen ist das Integral der Präzipitatbogenflächen proportional zu der jeweiligen Antigenmenge. Zur Vereinfachung der Methode wird aber meist die Peakhöhe der Bögen verwendet; dies kommt dem Flächenwert sehr nahe. Zur Quantifizierung von Antigenen wird eine Verdünnungsreihe analysiert und eine Kalibrationskurve erstellt. Die Antigenkonzentration in einer Probe wird durch Interpolation bestimmt.

Die folgende Abbildung zeigt ein Beispiel für die Bestimmung von $>$ Lipoprotein(a) in Humanseren:
HYDRAGEL Lp (a)

Sebia

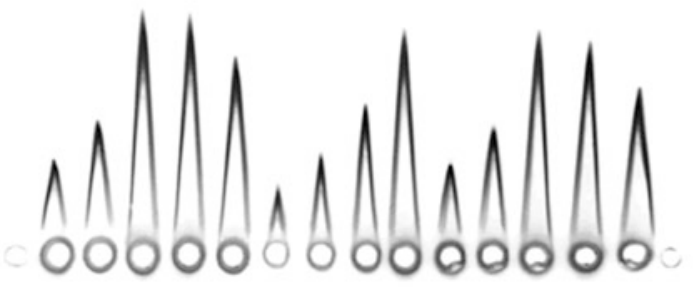

Einsatzgebiet Quantitative Bestimmung von - Apolipoprotein AI und B, Lipoprotein AI und E-Partikeln, Lipoprotein(a) u. a.

Untersuchungsmaterial In der Regel Serum.

\section{Instrumentierung}

- Elektrophoresekammer

- Stanzschablone

- Umlaufkühler

- Stromversorger

- Färbeschalen

Spezifität Hängt von der Qualität des Antikörpers ab, sonst spezifisch. 
Sensitivität $\operatorname{Im} \mu \mathrm{g}$-Bereich der Antigenkonzentrationen, für Coomassie-gefärbte Immunpräzipitate bei $18 \mathrm{ng} / \mathrm{mm}^{2}$.

\section{Fehlermöglichkeit}

- Verwendung keiner oder falscher Antikörper

- Falsches Antigen-Antikörper-Verhältnis

- Feldstärke zu hoch

- Polyvalenter Antikörper

- Bei der Quantifizierung wurde extrapoliert; korrekt ist interpolieren innerhalb der Eichkurve

Praktikabilität - Automatisierung - Kosten Die große Menge an benötigten Antikörpern macht die Methode relativ teuer.

\section{Literatur}

Lottspeich F, Engels JW (Hrsg) (2012) Bioanalytik, 3. Aufl. Spektrum Akademischer Verlag, Heidelberg

Westermeier R (2016) Elektrophorese leicht gemacht. Wiley-VCH, Weinheim

\section{Elektrolyt-balancierte Heparinlösung}

> Heparin, gepuffertes

\section{Elektrolyte}

O. Müller-Plathe

\section{Englischer Begriff electrolytes}

Definition In der Chemie versteht man unter Elektrolyten solche Substanzen, die in wässriger Lösung oder in ihren Schmelzen der elektrolytischen Dissoziation unterliegen und somit in die positiv geladenen Kationen und die negativ geladenen Anionen ( $\vee$ Nettoladung) zerfallen. Medizinischer Sprachgebrauch s. unten.

Beschreibung Es folgt eine Unterteilung in „Chemie“ und „Medizin“.

\section{Chemie}

Elektrolytische Dissoziation Starke Elektrolyte wie Salzsäure oder Schwefelsäure sind in wässriger Lösung nahezu vollständig dissoziiert. Schwache Elektrolyte wie Essigsäure, Kohlensäure und Phosphorsäure sind nur teilweise dissoziiert und folgen hierbei dem $>$ Massenwirkungsgesetz. Ihr Dissoziationsgrad bzw. ihre Stärke wird durch die $>$ Dissoziationskonstante $\mathrm{K}$ bzw. durch deren negativen dekadischen Logarithmus, den pK-Wert ausgedrückt:

$$
\mathrm{K}=\frac{c \mathrm{H}^{+} \times c \text { Base }}{c \text { Säure }} ; \mathrm{pK}=\mathrm{pH}-\lg \frac{c \text { Base }}{c \text { Säure }}
$$

Je kleiner der numerische Wert von pK, desto höher der Dissoziationsgrad des Elektrolyten und desto stärker die Säure oder die Base. Ist $\mathrm{pH}=\mathrm{pK}$, liegen Base und Säure in gleicher Konzentration vor. Ein Puffersystem (siehe auch - Säure-Basen-Stoffwechsel) hat unter diesen Umständen die größte $>$ Pufferkapazität (s. nachfolgende Tabelle).

Biologisch wichtige Dissoziationskonstanten und $\mathrm{pK}$ Werte bei $25^{\circ} \mathrm{C}$ :

\begin{tabular}{|l|l|l|}
\hline Säure & $\mathrm{K}$ & $\mathrm{pK}$ \\
\hline Ammonium & $4,39 \times 10^{-10}$ & 9,21 \\
\hline $\begin{array}{l}\text { Kohlensäure, 1. Stufe, wahre Dissoziation } \\
\text { (bezogen auf } c \mathrm{H}_{2} \mathrm{CO}_{3} \text { ) }\end{array}$ & $1,32 \times 10^{-4}$ & 3,88 \\
\hline $\begin{array}{l}\text { Kohlensäure, 1. Stufe, scheinbare } \\
\begin{array}{l}\text { Dissoziation (bezogen auf } \\
c \mathrm{CO}_{2}+c \mathrm{H}_{2} \mathrm{CO}_{3} \text { ) }\end{array}\end{array}$ & $4,45 \times 10^{-7}$ & 6,352 \\
\hline Phosphorsäure, 2. Stufe & $6,34 \times 10^{-8}$ & 7,198 \\
\hline
\end{tabular}

Ionenaktivität Nicht alle Ionen eines Elektrolyten liegen in wässriger Lösung ihrer Konzentration entsprechend frei beweglich vor. Die Hydrathülle um Anionen und Kationen, die eine hohe Abschirmung gewährleistet, hebt gegenseitige Anziehungskräfte nicht ganz vollständig auf. Der Anteil der thermodynamisch aktiven Ionen wird durch die Ionenaktivität ausgedrückt. Der Zusammenhang zwischen der molalen Konzentration an freien Ionen $\left(m_{\mathrm{M}^{+}}\right)$und der molalen Aktivität $\left(a_{\mathrm{M}^{+}}\right)$wird durch den Aktivitätskoeffizienten $\gamma$ hergestellt:

$$
a_{\mathrm{M}^{+}}=\gamma_{\mathrm{M}^{+}} \times m_{\mathrm{M}^{+}}
$$

Der Aktivitätskoeffizient wird stark beeinflusst von der Ionenstärke (I) einer Lösung. Sie ergibt sich aus den molalen Konzentrationen $\left(\mathrm{m}_{\mathrm{M}^{+}}\right)$und den Ladungszahlen $\left(\mathrm{z}_{\mathrm{M}^{+}}\right)$aller gelösten Ionen nach der Formel

$$
\mathrm{I}=\frac{1}{2} \sum\left(\mathrm{m}_{\mathrm{M}^{+}} \times \mathrm{z}_{\mathrm{M}^{+}}^{2}\right)
$$

und beträgt im Plasmawasser etwa $160 \mathrm{mmol} / \mathrm{kg}$. Mit steigender Ionenstärke nehmen die Aktivitätskoeffizienten ab. Zur Berechnung von Aktivitätskoeffizienten wird auf Lehrbücher der Physikalischen Chemie (z. B. Atkins 1987) verwiesen.

Die genannten Aktivitätskoeffizienten gelten nicht für Flüssigkeiten, deren Zusammensetzung von der des normalen Plasmas deutlich abweicht, wie z. B. Urin. 
Elektrolyte, Tab. 1 Aktivitätskoeffizienten, aktive und gesamte Molalitäten sowie molare Gesamtkonzentrationen

\begin{tabular}{|l|l|l|l|l}
\hline Elektrolyt & Aktivitätskoeffizient & $\begin{array}{l}\text { Aktive Molalität im Plasma- } \mathrm{H}_{2} \mathrm{O} \\
(\mathrm{mmol} / \mathrm{kg})\end{array}$ & $\begin{array}{l}\text { Gesamte Molalität im Plasma- } \mathrm{H}_{2} \mathrm{O} \\
(\mathrm{mmol} / \mathrm{kg})\end{array}$ & $\begin{array}{l}\text { Gesamtkonzentration im Plasma } \\
(\mathrm{mmol} / \mathrm{L})\end{array}$ \\
\hline $\mathrm{Na}^{+}$ & 0,75 & 114 & 152 & 142 \\
\hline $\mathrm{K}^{+}$ & 0,74 & 3,2 & 4,3 & 4,0 \\
\hline $\mathrm{Ca}^{2+}$ & 0,34 & 0,46 & 1,34 & 2,3 \\
\hline $\mathrm{Mg}^{2+}$ & 0,35 & 0,20 & 0,57 & 0,8 \\
$\mathrm{Cl}^{-}$ & 0,75 & 82 & 109 & 102
\end{tabular}

Medizin Hier bezeichnet man die Gesamtheit der anorganischen Ionen, die den wesentlichen Teil der osmotisch aktiven Partikel in den Körperflüssigkeiten ausmachen, als „,die Elektrolyte".

Es handelt sich dabei im engeren Sinne um

- die Kationen $\mathrm{Na}^{+}, \mathrm{K}^{+}, \mathrm{Ca}^{2+}$ und $\mathrm{Mg}^{2+}$ und

- die Anionen $\mathrm{Cl}^{-}, \mathrm{HCO}_{3}^{-}$und Phosphat $\left(\mathrm{H}_{2} \mathrm{PO}_{4}{ }^{-} /\right.$ $\mathrm{HPO}_{4}{ }^{2-}$ ).

Weitere Anionen wie Sulfat $\left(\mathrm{SO}_{4}{ }^{2-}\right)$, Laktat und negativ geladene Proteine werden nicht $\mathrm{zu}$ den „Elektrolyten“ gezählt. Es besteht eine enge Verbindung zwischen dem Stoffwechsel der Elektrolyte, besonders des Natriums, und dem Wasserhaushalt. Elektrolytzusammensetzung von Plasma, Interstitialflüssigkeit und Intrazellulärraum s. > Wasserhaushalt.

Beziehung zwischen Ionenaktivität und Gesamtkonzentration im Plasma Aus der Gesamtkonzentration eines Elektrolyten im Plasma $\left(c_{\mathrm{tM}}\right)$ erhält man die Gesamt $>$ molalität $\left(m_{\mathrm{tM}}\right)$, indem man durch die Massenkonzentration des Plasmawassers $\left(\mathrm{\rho H}_{2} \mathrm{O}\right)$, die bei normalem Protein- und Lipidgehalt $0,933 \mathrm{~kg} / \mathrm{L}$ beträgt, dividiert:

$$
m_{\mathrm{tM}}=\frac{c_{\mathrm{tM}}}{\rho \mathrm{H}_{2} \mathrm{O}}
$$

Aus der Gesamtmolalität ergibt sich der Anteil freier Ionen $\left(m_{\mathrm{M}^{+}}\right)$durch Subtraktion des proteingebundenen $\left(m_{\mathrm{Mprot}}\right)$ und des mit weiteren Anionen komplexierten Anteils $\left(\sum \mathrm{m}_{\mathrm{MX}}\right)$ :

$$
m_{\mathrm{M}^{+}}=m_{\mathrm{tM}}-\left(m_{\mathrm{Mprot}}+\sum \mathrm{m}_{\mathrm{MX}}\right)
$$

Mit den herkömmlichen Verfahren der $\gg$ Flammenemissionsspektrometrie wird die Gesamtkonzentration bestimmt $\left(c_{\mathrm{tM}}\right)$. $\mathrm{Da}$ die > Ionenselektive Elektrode (ISE) im unverdünnten Plasma die molale Aktivität $\left(a_{\mathrm{M}^{+}}\right)$misst, wird das Ergebnis unter Berücksichtigung des Aktivitätskoeffizienten sowie der Annahme eines normalen Wassergehalts und der für den jeweiligen Elektrolyten typischen protein- und komplexgebundenem Anteile an die Gesamtkonzentration angepasst, um die Ergebnisse kompatibel zu machen (,justierte Aktivität“, engl. ,adjusted activity“; Tab. 1).

Bei Plasmen mit stark abweichendem Lipid- oder Proteingehalt können dennoch Diskrepanzen auftreten, wobei das biologisch relevantere Ergebnis von der ISE stammt ( $\triangleright$ Natrium)

\section{Literatur}

Atkins PW (1987) Physikalische Chemie. VCH, Weinheim International Federation of Clinical Chemistry and Laboratory Medicine (IFCC) (2000) Use of ion-selective electrodes for blood-electrolyte analysis. Recommendations for nomenclature, definitions and conventions. Clin Chem Lab Med 38:363-370

\section{Elektrolyt-stabilisierte Heparinlösung}

$>$ Heparin, gepuffertes

\section{Elektronenmikroskop}

W. Stöcker und C. Krüger

\section{Englischer Begriff Electron microscope}

Definition Mikroskop (griech. mikros: klein; skopein: betrachten), das mithilfe im Vakuum unter Hochspannung beschleunigter Elektronen die innere Struktur oder die Oberfläche einer Probe hoch vergrößert abbildet.

Lichtmikroskope erreichen nur eine Auflösung von $300 \mathrm{~nm}$, entsprechend der Wellenlänge des sichtbaren Lichtes. Durch Verwendung von Elektronenstrahlen kann die Auflösung bis auf $0,1 \mathrm{~nm}$ verbessert werden. Damit ist es möglich, Bakterien, Viren und Zellbestandteile (z. B. Mitochondrien) direkt darzustellen.

Aufbau Das Elektronenmikroskop enthält 5 Hauptbestandteile: 
- Elektronenkanone, die einen konstanten Elektronenstrom freisetzt und beschleunigt

- Elektronenlinsen, die den Elektronenstrahl mittels magnetischer oder elektrischer Kräfte fokussieren, und Blenden, die unerwünschte Strahlung herausfiltern und dadurch den Kontrast verbessern

- Vakuumpumpen, die ein Hochvakuum für den ungehinderten Flug der Elektronen erzeugen

- Probenhalterung

- Detektorsystem, das die Elektronenstrahlung in ein sichtbares Bild umwandelt

Varianten der Elektronenmikroskope Bei den Ruhebildmikroskopen wird ein bestimmtes Probengebiet von einem feststehenden, breiten Elektronenstrahl dargestellt. Die Rasterbildmikroskope benutzen einen feinen, gebündelten Elektronenstrahl, der das Beobachtungsgebiet zeilenweise erfasst und abbildet.

Das Transmissionselektronenmikroskop sendet einen feststehenden, breiten Elektronenstrahl durch eine dünne Probe und stellt somit in der Bildebene ein Abbild der Probe her, wie im Lichtmikroskop, oder in der Beugungsebene ein Beugungsmuster zur Ermittlung der Kristallstruktur. Die Probe muss entsprechend dünn sein (max. $100 \mathrm{~nm}$ ) und erfordert eine aufwendige Präparation (Kryofixierung oder Einbettung in Kunstharz, anschließend Ultradünnschnittmikrotomie). Das Bild im Transmissionselektronenmikroskop wird durch an den Atomkernen elastisch gestreute Elektronen erzeugt.

Das Rasterelektronenmikroskop tastet mit einem sehr feinen Elektronenstrahl ein ausgewähltes Gebiet Zeile für Zeile und Punkt für Punkt ab und erzeugt damit ein plastisches, dreidimensionales Abbild der Probenoberfläche. Diese muss davor in den meisten Fällen elektrisch leitend gemacht werden, etwa durch Bedampfen mit Gold, um eine elektrostatische Aufladung zu verhindern. Das Bild wird durch Intensitätsmessung an der Probe gestreuter Sekundärelektronen oder Rückstreuelektronen erzeugt.

Geschichte Das erste Elektronenmikroskop wurde im Jahr 1931 von Ernst Ruska (geboren 25. Dezember 1906 in Heidelberg; gestorben 27. Mai 1988 in Berlin) und Max Knoll (geboren 17. Juli 1897 in Schlangenbad; gestorben 6. November 1969) gebaut. Hierfür erhielt Ruska im Jahr 1986 den Nobelpreis im Fach Physik.

\section{Literatur}

Flegler SL, Heckman JW Jr, Klomparens KL (1995) Elektronenmikroskopie: Grundlagen, Methoden, Anwendungen. Wiesbaden: Spektrum Akademischer Verlag

\section{Elektronenstoßionisation}

- Massenspektrometrie

\section{Elektronenvolt}

- Massenspektrometrie

Elektronische Auftragserfassung

$>$ Order Entry

\section{Elektronische Labordatenverarbeitung}

- Labor-EDV

\section{Elektropherogramm}

R. Westermeier

Synonym(e) Bandenmuster; Elektrophoresemuster

Englischer Begriff electropherogram

Definition Ein Elektropherogramm ist das gefärbte Elektrophoreseresultat, das ein Bandenmuster in einem Gel oder einer Celluloseacetatfolie zeigt.

Beschreibung Ein Elektropherogramm zeigt das qualitative Elektrophoreseergebnis. Zur quantitativen Auswertung benötigt man ein $>$ Densitogramm.

\section{Literatur}

Westermeier R (2016) Elektrophorese leicht gemacht. Wiley-VCH, Weinheim

\section{Elektrophorese}

R. Westermeier

Synonym(e) Zonenelektrophorese 
Englischer Begriff electrophoresis

Definition Die elektrophoretische Trennung von Probenkomponenten basiert auf ihren unterschiedlichen Wanderungsgeschwindigkeiten im elektrischen Feld in einem bestimmten Trennmedium.

Beschreibung Geladene Moleküle und Partikel in wässriger Lösung wandern im elektrischen Gleichstromfeld in die Richtung der Elektrode mit entgegengesetztem Vorzeichen. Die Wanderungsgeschwindigkeiten sind gleich für homologe Substanzen ( $\triangleright$ Substanzen, homologe), variieren jedoch für Substanzen mit unterschiedlichen Ladungen und Molekülgrößen. Es bilden sich distinkte Zonen aus (s. Abbildung).

Schematische Darstellung des Trennprinzips der Elektrophorese am Beispiel von 2 verschiedenen Proteinen:

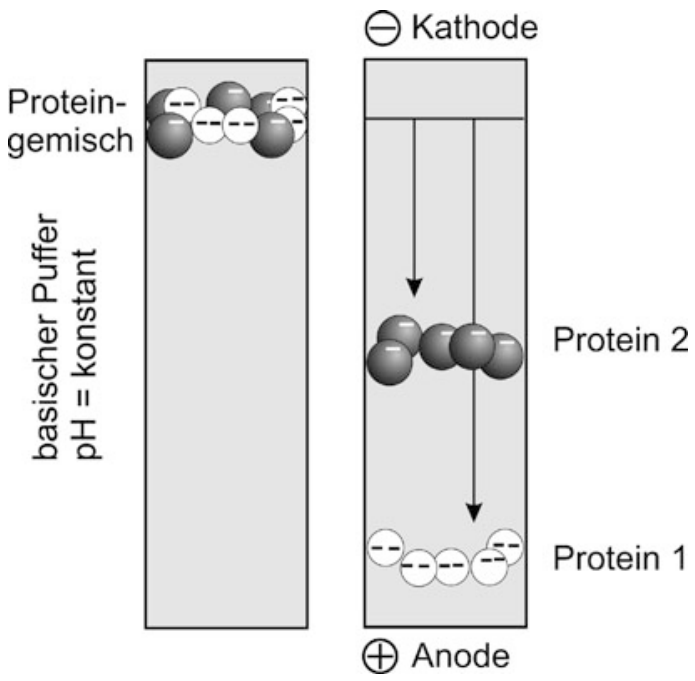

Die resultierenden Bandenmuster sind charakteristisch für bestimmte Substanzgemische. Die Intensitäten der Zonen können optisch vermessen werden, um Rückschlüsse auf die quantitative Verteilung der Einzelsubstanzen zu ermöglichen. Hauptanwendungsgebiete sind Analysen von Protein- und Nukleinsäurengemischen.

Die treibende Kraft bei der Elektrophorese ist die elektrische Feldstärke, die als V/cm gemessen wird. Die Geschwindigkeit der elektrophoretischen Wanderung eines Moleküls ist abhängig von

- seiner elektrophoretischen Mobilität (Beweglichkeit),

- der Siebwirkung oder Viskosität des Mediums,

- der Temperatur,

- der Ionenstärke des Puffers und

- der elektrischen Feldstärke.

Die elektrophoretische Mobilität wiederum ist abhängig von $>$ Nettoladung und Größe des Moleküls. Strukturprote- ine haben bei gleicher Molekularmasse eine größere Ausdehnung als globuläre Proteine ( $\triangleright$ Proteine, globuläre).

In einem nichtrestriktiven Medium, wie offenen Kapillaren, großporigen Agarosegelen und Celluloseacetatfolien, ist die Mobilität von Proteinen ausschließlich von der Nettoladung abhängig.

Das Auflösungsvermögen variiert mit dem verwendeten Trennmedium.

Abgesehen von unterschiedlichen Trennmedien gibt es zudem unterschiedliche Elektrophoresetechniken, wie z. B. saure und basische Elektrophoresen, Disk-Elektrophorese, Gradientengel-Elektrophorese, \ SDS-Elektrophorese, $>$ Isoelektrische Fokussierung und zweidimensionale Elektrophorese ( $\triangleright$ Elektrophorese, zweidimensionale).

Beim Ionentransport im elektrischen Feld entsteht Wärme, genannt Joule'sche Wärme. Zur Vermeidung von Überhitzung oder krummen Lauffronten muss entweder die elektrische Leistung limitiert oder das Medium über einen Wärmeaustauscher gekühlt werden.

Die Entstehung der Joule'schen Wärme ist auch der Hauptgrund, warum elektrophoretische Methoden beinahe ausschließlich für analytische und nicht für präparative Zwecke angewandt werden. Nur die trägerfreie Elektrophorese in einer strömenden Pufferschicht bildet hier eine Ausnahme.

Die Detektion der getrennten Fraktionen erfolgt bei der - Kapillarelektrophorese mittels UV-Detektor direkt in der Kapillare, bei allen anderen Verfahren werden Proteine oder Nukleinsäuren entweder mit fluoreszierenden Farbstoffen ( $\triangleright$ Fluorophor) markiert oder nach der Trennung im Medium angefärbt.

\section{Literatur}

Lottspeich F, Engels JW (Hrsg) (2012) Bioanalytik, 3. Aufl. Spektrum Akademischer Verlag, Heidelberg Westermeier R (2016) Elektrophorese leicht gemacht. VCH, Weinheim

\section{Elektrophorese, präparative}

R. Westermeier

Synonym(e) Präparativ-Elektrophorese

Englischer Begriff preparative electrophoresis

Definition Elektrophoretische Trennung von ladungstragenden Makromolekülen wie Proteinen, Peptiden oder Nukleinsäuren zur anschließenden Weiterverarbeitung. 
Physikalisch-chemisches Prinzip Gelelektrophorese: Die getrennten Fraktionen werden aus einer Gelschicht herausgekratzt oder herausgeschnitten. DNA-Fragmente können direkt danach mit der Polymerasekettenreaktion amplifiziert werden. Die Eluierung von intakten Proteinen aus Gelstückchen gelingt meist nur unvollständig (s. a. \ Elektroelution). In der Praxis werden die Proteine deshalb in der Gelmatrix mit Trypsin zu Peptiden verdaut, diese können heraus eluiert und mittels Massenspektrometrie weiter analysiert werden.

Elektrophorese und isoelektrische Fokussierung in wässriger Lösung: In der trägerfreien (,free flow“) Elektrophorese wird ein Proteingemisch in einem kontinuierlichen Pufferstrom in einer flachen Küvette aufgetrennt. Quer zur Fließrichtung liegt ein elektrisches Feld an, das die unterschiedlichen Probenkomponenten verschieden stark ablenkt. Die getrennten Fraktionen werden an konstanten Stellen am Ende der Küvette über ein Array von dünnen Schläuchen entnommen.

Die folgende Abbildung zeigt eine trägerfreie Elektrophorese: Die Probenkomponenten werden in einem kontinuierlich fließenden Pufferstrom durch ein elektrisches Feld unterschiedlich stark abgelenkt und treffen an konstanten Stellen am Ende der Trennküvette auf (nach: Lottspeich und Engels 2012):

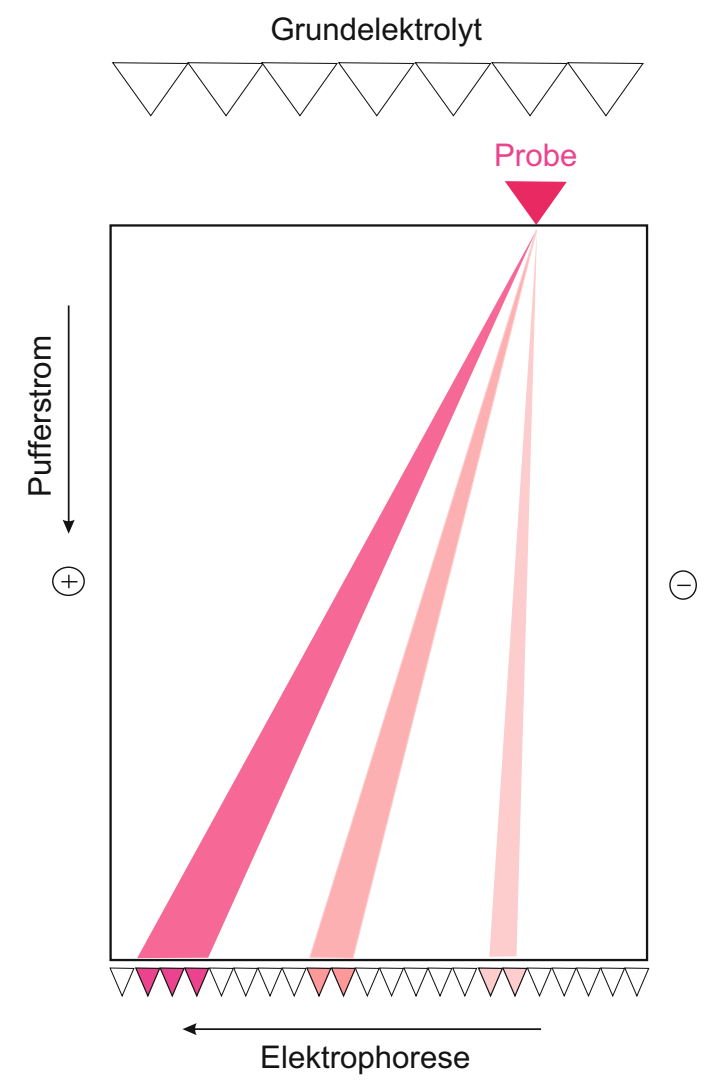

Bei der „Off-Gel“-isoelektrischen Fokussierung (Abb. 1) verwendet man schmale Polyacrylamidgel-Streifen mit immobilisierten $\mathrm{pH}$-Gradienten (IPG-Streifen), die sich in einer Horizontalkammer befinden und auf deren Oberfläche Fraktionierrahmen aufgesetzt werden. Jeweils $150 \mu \mathrm{L}$ des verdünnten Proteingemisches werden in die Kammern des Fraktionierrahmens aufgegeben. Im elektrischen Feld wandern die geladenen Proteine oder Peptide durch die Gelstreifen, bis sie den $\mathrm{pH}$-Wert erreichen, der ihrem isoelektrischen Punkt entspricht. Die Fraktionen befinden sich in wässriger Lösung und werden aus den Kammern entnommen.

Einsatzgebiet Protein- und DNA-Analytik.

Untersuchungsmaterial Biologische Flüssigkeiten, wie Plasma, Serum, Urin; Gewebeextrakte, Zelllysate.

Instrumentalisierung Für Gelelektrophoresen werden prinzipiell drei Geräte benötigt:

- einen Gleichstromversorger, bei welchem man Strom-, Spannungs-, und - am besten auch die - Leistungswerte einstellen kann.

- Eine vertikale oder horizontale Trennkammer mit zugehörigem Gelgießsystem.

- Kühl- oder Heiz-Thermostat, um reproduzierbare Ergebnisse zu erzielen.

Gegebenenfalls Freeflow Elektrophoreseapparatur oder Off-Gel Isoelektrische Fokussierung Apparatur.

Spezifizität Die Spezifität wird beeinflusst durch das Puffersystem, die Bedingungen nativ oder denaturierend, und die Porengröße der Gelmatrix.

Sensitivität Die Empfindlichkeit moderner Massenspektrometer ist so hoch, dass man kann die Proteinfraktionen aus analytischen Gelen ohne weiteres analysieren kann.

Fehlermöglichkeit Bei der Herstellung von Gelen und Puffern im Labor können sich viele Fehler ergeben durch falsches Einwiegen, Verwechslung von Puffermaterialien, Ungeschicktheiten beim Gelgießen. Die Fehlermöglichkeiten lassen sich durch die Verwendung von Fertiggelen deutlich herabsetzen. Häufig passieren die Fehler aber auch bei der Probenvorbereitung. Trägerfreie Elektrophoresen sind nicht einfach zu bedienen.

Praktikabilität - Automatisierung - Kosten Einfache Apparaturen für horizontale Agarosegele zur DNA-Trennung und vertikale Systeme zur Proteintrennung in Polyacrylamidgelen sind in der Anschaffung relativ günstig, zumal man in den meisten Fällen hierzu kein Kühlsystem und relativ einfach konstruierte Stromversorger braucht. Die Methoden der Gelelektrophorese werden durch die Verwendung von Fertiggelen und -puffern erheblich vereinfacht, dabei steigen aller- 
Elektrophorese, präparative, Abb. 1 „Off-Gel“-isoelektrische Fokussierung: Die Probenkomponenten wandern im elektrischen Feld durch einen IPG-Streifen in die jeweils nächste Kammer, bis sie den $\mathrm{pH}-$ Wert erreichen, der ihrem isoelektrischen Punkt entspricht (nach: Lottspeich und Engels 2012)
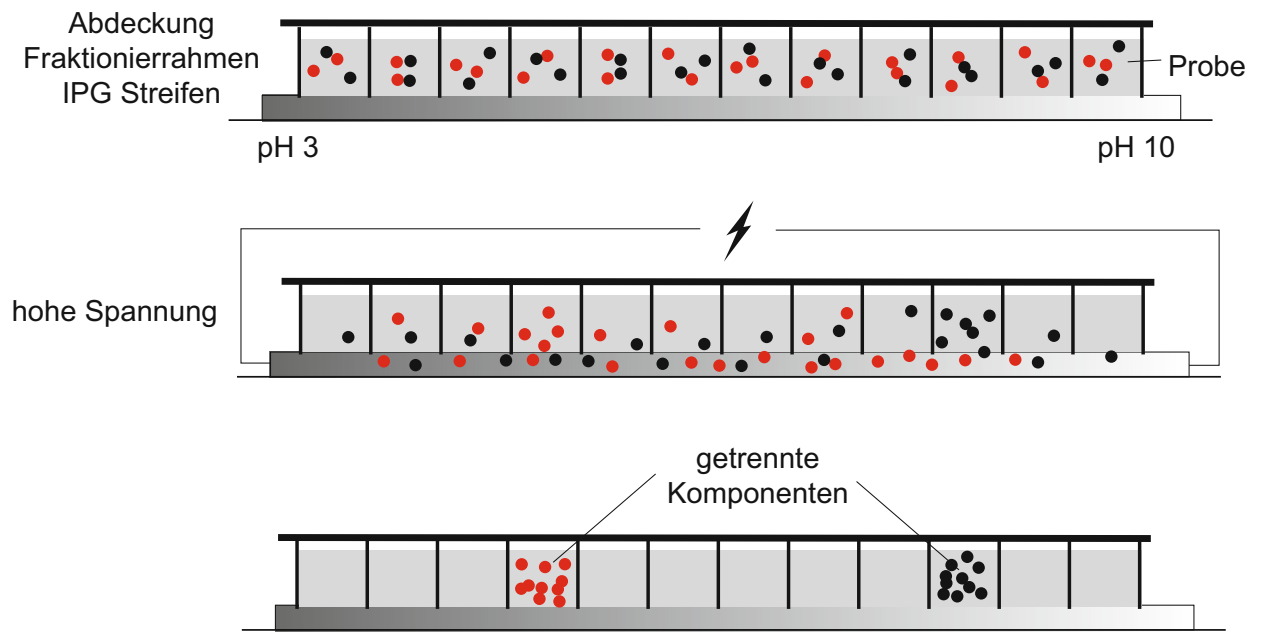

dings die Kosten für die Verbrauchsmittel. Die Apparaturen für die trägerfreie Elektrophorese und die „Off-Gel“-isoelektrische Fokussierung sind deutlich teurer in der Anschaffung und bedürfen einer sehr anspruchsvollen Expertise in ihrer Handhabung.

Bewertung - Methodenhierarchie (allg.) Verschiedene Methoden der präparativen Elektrophorese und isoelektrischen Fokussierung sind in klinisch-chemischen, biochemisch und molekularbiologisch arbeitenden Labors etabliert.

\section{Literatur}

Lottspeich F, Engels JW (2012) Bioanalytik, 3. Aufl. Springer Spektrum, Heidelberg

\section{Elektrophorese, zweidimensionale}

\section{R. Westermeier}

Synonym(e) 2-D-Elektrophorese; Zweidimensional-Elektrophorese

Englischer Begriff two-dimensional electrophoresis

Definition In der zweidimensionalen Elektrophorese werden komplexe Proteingemische nach 2 unterschiedlichen, voneinander unabhängigen physikochemischen Parametern aufgetrennt: erst nach Ladungen mit der isoelektrische Fokussierung (IEF), dann nach Molekülgrößen mit der SDS-Elektrophorese. Das Ergebnis ist ein Fleckenmuster.
Physikalisch-chemisches Prinzip Um komplexe Proteingemische mit hoher Auflösung und guter Reproduzierbarkeit auftrennen zu können, werden denaturierende Bedingungen angewandt. Das bedeutet, dass die Probe mit 8 mol/L Harnstoff, einem Reduktionsmittel, einem zwitterionischen Detergenz und einem Trägerampholytengemisch versetzt oder extrahiert wird.

Genügend hohe Auflösung für komplexe Proteingemische erhält man nur in Gelen mit großen Trenndistanzen, z. B. $20 \times 20 \mathrm{~cm}$.

Die Proteinproben werden in der ersten Dimension mit isoelektrischer Fokussierung (s. > isoelektrische Fokussierung) nach der Ladung getrennt. In der traditionellen Technik geschah dies in Trägerampholyt-pH-Gradienten in dünnen Polyacrylamidgelen in Röhrchen. In der modernen Technik verwendet man foliengestützte Polyacrylamidgelstreifen mit immobilisierten pH-Gradienten. Diese sind kommerziell erhältlich in verschiedenen Längen mit weiten $\mathrm{pH}-\mathrm{Gradienten}(\mathrm{pH} 3-11)$ und engeren $\mathrm{pH}-\mathrm{Gradienten}$ für noch höhere Auflösung.

Nach einer Äquilibrierung des Gels der ersten Dimension wird es auf ein SDS-Gel aufgelegt und mit Agarose eingebettet. Daraufhin erfolgt die Trennung in der $>$ SDS-Elektrophorese nach Molmasse. Bei der Färbung wird ein Fleckenmuster sichtbar (Abb. 1).

Die Muster werden mit geeigneten Programmen ausgewertet; visuelle Auswertung solch komplexer Ergebnisse ist praktisch unmöglich.

Zweidimensionale Differenz-Gelelektrophorese: Es ist auch möglich die Proteine verschiedener Proben mit unterschiedlichen Fluoreszenzfarbstoffen ( $\downarrow$ Fluorophor) zu markieren, welche die isoelektrischen Punkte (s. $>$ isoelektrischer Punkt) nicht modifizieren. Die Proben werden daraufhin zusammengemischt und im selben Gel aufgetrennt. Weil die Fluorophore in etwa die gleichen Molmassen haben, wandern die gleichen Proteine der verschiedenen Proben zu exakt denselben Positionen im $>$ SDS-Gel. Mithilfe eines Multifluores- 
Elektrophorese, zweidimensionale,

Abb. 1 Schematische Darstellung des Prinzips: Nach der isoelektrischen Fokussierung eines Proteingemischs in einem Polyacrylamid-Gelstreifen mit fixiertem $\mathrm{pH}-$ Gradienten werden die Proteine mit SDS-Puffer umgepuffert und in der zweiten Dimension in der SDS-

Elektrophorese nach

Molekularmassen aufgetrennt
1. Dimension:

Isoelektrische Fokussierung im IEF-Streifen

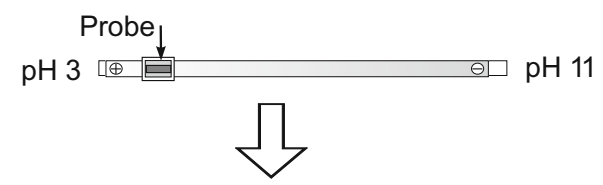

Umpuffern der 1. Dimension im SDS-Puffer

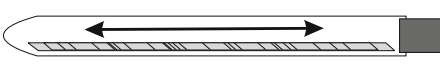

2. Dimension:

SDS-Polyacrylamidgel-Elektrophorese

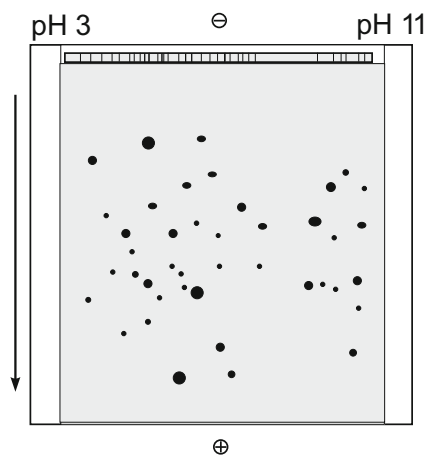

zenz-Densitometers werden die verschiedenen Fluorophoren nacheinander bei unterschiedlichen Wellenlängen angeregt und die emittierten Signale aufgezeichnet. Diese Methode ermöglicht den Vergleich von komplexen Proteingemischen unter Ausschluss von Gelvariabilitäten. Die eigentliche Stärke bei dieser Methode liegt bei der Verwendung eines inneren Standards für jedes Protein: Hierzu mischt man vor der $>$ Fluoreszenzmarkierung Aliquots von jeder Probe zu einem gepoolten Probenstandard zusammen und markiert diesen mit einem der verfügbaren Fluoreszenzmarker. Bei jeder Trennung wird dieser Standard mitgeführt. Zur Auswertung werden die Ergebnisse auf die Signale des internen Standards bezogen. Dies führt zu sehr verlässlichen quantitativen Ergebnissen mit hoher statistischer Zuverlässigkeit.

Die Identifizierung und Charakterisierung von auffälligen Proteinen erfolgt durch $>$ Massenspektrometrie.

Wegen ihres sehr hohen Auflösungsvermögens von mehreren tausend Proteinen in einem Gel ist die ZweidimensionalElektrophorese die wichtigste Trenntechnik in der Proteomik.

Die folgende Abbildung zeigt eine zweidimensionale Elektrophorese von Melanoma-Zellextrakt (Proteindetektion mit Silberfärbung):

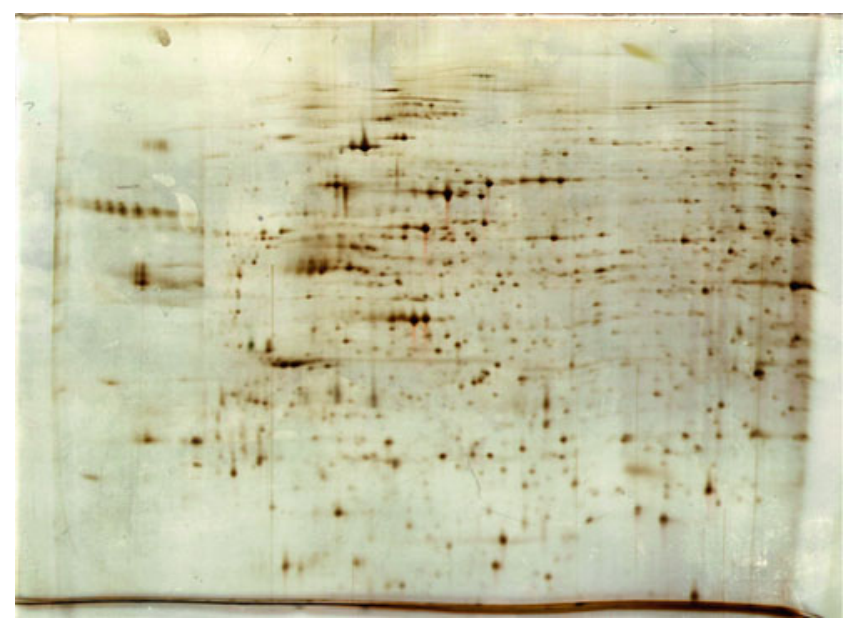

Einsatzgebiet Die Methode ist zu komplex für Routineanalysen und wird hauptsächlich in der Proteomforschung angewandt zur

- Detektion von Krankheitsmarkern,

- Aufklärung von Erkrankungsursachen,

- Auffindung von Arzneimitteltargets,

- Beobachtung von Therapien,

- Entwicklung von personenspezifischen Therapien.

\section{Untersuchungsmaterial}

- Körperflüssigkeiten: z. B. Serum, Plasma, Liquor, Urin, Semen

- Zellkulturen

- Gewebe: gesunde Zellen und Krebszellen, Gehirn, Leber, Niere, Herzmuskel

Instrumentierung Der Geräteaufwand ist relativ hoch:

- Spezialgerät für isoelektrische Fokussierung in Gelstreifen

- Vertikale SDS-Elektrophorese-Apparatur für große Gele

- Stromversorger

- Kühlthermostat

- Densitometer oder Scanner für zweidimensionale Elektrophorese

- Spezielle Auswerteprogramme und entsprechende DVMöglichkeiten

- Massenspektrometrie

Spezifität Die Spezifität der Ergebnisse wird deutlich erhöht durch zweifelsfreie Identifizierung von Proteinen mit Blotting und/oder $>$ Massenspektrometrie.

Sensitivität Man kann Proteine in pg-Mengen detektieren. 
Fehlermöglichkeit Da die Durchführung relativ komplex ist, ergeben sich viele Fehlermöglichkeiten. Durch die Anwendung der Differenz-Gelelektrophorese mit fluoreszenzmarkierten Proteinen werden die Auswirkungen von Fehlern deutlich reduziert.

Praktikabilität - Automatisierung - Kosten Die Methode ist relativ teuer. Es gibt Ansätze zur teilweisen Automatisierung des Arbeitsablaufs.

\section{Literatur}

Lottspeich F, Engels JW (Hrsg) (2012) Bioanalytik, 3. Aufl. Spektrum Akademischer Verlag, Heidelberg

Rabilloud T (Hrsg) (2000) Proteome research: two-dimensional gel electrophoresis and identification methods. Springer, Berlin/Heidelberg/New York

\section{Elektrophorese von Isoenzymen}

- Isoenzymelektrophorese

\section{Elektrophorese-Kurvendiagramm}

> Densitogramm

\section{Elektrophoresemuster}

Elektropherogramm

\section{Elektrophoretische Beweglichkeit}

> Mobilität, elektrophoretische

\section{Elektrophoretische Mobilitätsverschiebungs-Assay}

R. Westermeier

Synonym(e) Band-shift-assay; EMSA

Englischer Begriff electrophoretic mobility shift assay
Definition Methode zum Nachweis von Protein-Nukleinsäuren-Interaktionen.

Physikalisch-chemisches Prinzip Proteine werden mit einem DNA- oder RNA-Fragment bekannter Sequenz inkubiert. Bei der Elektrophorese in einem Agarose- oder Polyacrylamidgel werden die Komplexe aus Protein, DNA bzw. RNA nach ihrer Größe aufgetrennt. Dabei ergeben sich im Vergleich zum reinen Protein oder der reinen Nukleinsäure Laufweitenverschiebungen, die abhängig von der Ladung, Konformation und Größe des Protein-Liganden-Komplexes sind. Die Detektion der Nukleinsäuren erfolgt meistens über Vormarkierung der DNA- oder RNA-Moleküle mit Biotinylierung oder Fluoreszenz. Die Proteine werden meistens mit Silberfärbung visualisiert.

Einsatzgebiete Bestimmung von Protein-DNA-Interaktionen oder Protein-RNA-Interaktionen. Aufklärung der Mechanismen der Genregulation.

Untersuchungsmaterial Biologische Flüssigkeiten, Gewebeextrakte, Zelllysate.

Instrumentalisierung Ausrüstung für Agarose- oder Polyacrylamidgel-Elektrophorese bestehend aus Horizontal- oder Minivertikalkammer, Stromversorger, Umlaufthermostat.

Spezifizität Hoch bei bekannter Sequenz der Nukleinsäure.

Sensitivität Bei Silberfärbung im oberen Picogrammbereich.

Fehlermöglichkeit Bei der Herstellung von Gelen und Puffern im Labor können sich viele Fehler ergeben durch falsches Einwiegen, Verwechslung von Puffermaterialien, Ungeschicktheiten beim Gelgießen. Die Fehlermöglichkeiten lassen sich durch die Verwendung von Fertiggelen deutlich herabsetzen.

Praktikabilität - Automatisierung - Kosten Eine relativ unkomplizierte Anwendung. Die Methode wird durch die Verwendung von Fertiggelen und -puffern erheblich vereinfacht, dabei steigen allerdings die Kosten für die Verbrauchsmittel.

Bewertung - Methodenhierarchie (allg.) Elektrophoretisches Mobilitätsverschiebungs-Assay ist eine Methode für molekularbiologisch arbeitende Labors.

\section{Literatur}

Garner MM, Revzin A (1981) A gel electrophoresis method for quantifying the binding of proteins to specific DNA regions: application to components of the Escherichia coli lactose operon regulatory system. Nucleic Acids Res 9:3047-3060 


\section{Elektrovalente Bindung}

Ionenbeziehung

\section{ELF-Fibrosescore}

- Enhanced-Liver-Fibrosis-Test

\section{ELF-Test}

- Enhanced-Liver-Fibrosis-Test

\section{Eliminationshalbwertszeit}

C. Vidal und W.-R. Külpmann

Englischer Begriff elimination half-life

Definition Zeitspanne, in der die Konzentration z. B. eines Pharmakons (z. B. im Plasma) um die Hälfte abfällt.

Beschreibung Die Eliminationshalbwertszeit $\left(t_{1 / 2}\right)$ hängt $a b$ von der totalen Clearance und dem Verteilungsvolumen. Sie wird berechnet an Hand der Eliminationskonstanten $\left(\mathrm{k}_{2}\right)$ :

$\mathrm{t}_{1 / 2}=\ln 2 / \mathrm{k}_{2}(\ln 2 \sim 0,693$. $)$

\section{Literatur}

Gladtke E, von Hattingberg HM (1973) Pharmakokinetik. Springer, Berlin/Heidelberg/New York

\section{Eliminationsphase}

C. Vidal und W.-R. Külpmann

$\operatorname{Synonym}(\mathbf{e}) \quad \beta$-Phase

Definition Zeitraum nach Abschluss der Invasionsphase eines Pharmakons, in dem die Plasmakonzentration alleinig von der Eliminationsgeschwindigkeit abhängt ( $>$ Eliminationshalbwertszeit).

\section{Literatur}

Gladtke E, von Hattingberg HM (1973) Pharmakokinetik. Springer, Berlin/Heidelberg/New York

\section{Eliminationstest}

$>$ Mobilisationstest

\section{ELISA}

- Enzyme-linked Immunosorbent Assay

\section{Elliptozyt}

H. Baum

\section{Synonym(e) Ovalozyt}

Englischer Begriff elliptocyte

Definition Im Blutausstrich elliptisch geformte Erythrozyten.

Beschreibung Elliptisch bis oval geformte Erythrozyten im Ausstrichpräparat des peripheren Blutes werden als Elliptozyten bezeichnet. Unterschieden werden können dabei ,normale“ Elliptozyten von den ovalozytischen Elliptozyten und den fischmaulartigen Formen bei der südostasiatischen Ovalozytose. Meist handelt es sich bei der Elliptozytose um eine harmlose, autosomal dominant vererbte Anomalie. Auch können Elliptozyten bei einer megaloblastären oder einer Eisenmangelanämie nachgewiesen werden. Die Überlebenszeit dieser Erythrozyten kann verkürzt sein mit der Folge einer sich ausbildenden Anämie.

In der Abbildung sind Elliptozyten mit ihrer typischen ovalen Zellform zu sehen $(1000 \times$, May-Grünwald-GiemsaFärbung):

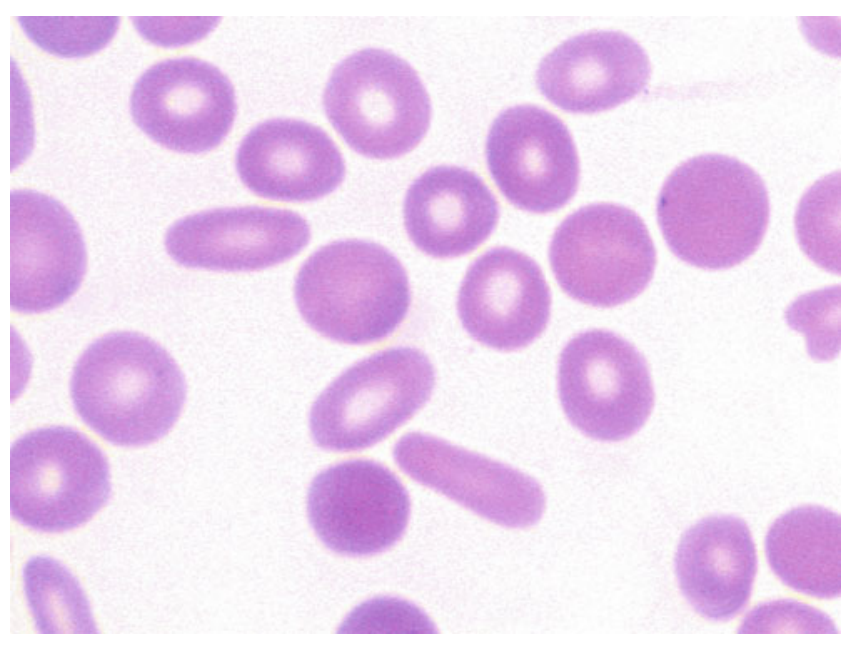




\section{Literatur}

Dietzfelbinger $H$ (1993) Hereditäre Elliptozytosen und verwandte Erkrankungen. In: Begemann H, Rastetter J (Hrsg) Klinische Hämatologie, 4. Aufl. Georg Thieme Verlag, Stuttgart, S 259-265

\section{ELM}

European Laboratory Medicine

\section{Elongation}

\section{J. Arnemann}

Synonym(e) DNA-Kettenverlängerung

Englischer Begriff elongation

Definition Elongation (deutsch: Verlängerung) ist eine Phase der $>$ PCR (Polymerase-Kettenreaktion).

Beschreibung Elongation ist diejenige Phase eines PCRZyklus, in der im Anschluss an die $>$ Annealing-Phase die DNA-Polymerase, ausgehend vom gebundenen PCR-Primer, den reziproken Strang bei $68-72{ }^{\circ} \mathrm{C}$ durch Einbau von Nukleotiden in 5'-3'-Richtung synthetisiert. Die Syntheserate variiert dabei, z. B. aufgrund des spezifischen PCR-Ansatzes oder der eingesetzten DNA-Polymerase, wird aber in der Literatur mit 1000-2500 bp/min angegeben.

\section{Literatur}

Hughes S, Moody A (Hrsg) (2007) PCR (in method express series). Scion Publishing Ltd., Bloxham

\section{Eluent}

Mobile Phase

\section{Elution}

T. Arndt

Synonym(e) Auswaschen (Chromatographie)

\section{Englischer Begriff elution}

Definition Elution (lat. eluere = auswaschen) bezeichnet in der Chromatographie die Wanderung von Probenbestandteilen in ( $>$ Dünnschichtchromatographie) oder das Herausspülen von Probenbestandteilen aus der stationären Phase ( $\triangleright$ Stationäre Phase; Säulenchromatographie).

Beschreibung In Abhängigkeit von den Wechselwirkungen der Probenbestandteile mit der stationären Phase erfolgt deren Elution zeitlich versetzt. Dies ist die Grundlage einer chromatographischen Trennung. Dabei eluieren Analyte mit starker Affinität zur stationären Phase später als jene mit keiner oder nur schwacher. In der Dünnschichtchromatographie liegen Komponenten mit schwacher Wechselwirkung mit der stationären Phase nach einer bestimmten Elutionszeit relativ weit, jene mit starker Wechselwirkung relativ nah vom Probenauftragungsort entfernt in der Dünnschichtplatte. In der Säulenchromatographie werden Komponenten mit schwacher Wechselwirkung mit der stationären Phase relativ zeitig von der Trennsäule eluiert und im Detektor detektiert, jene mit starker Wechselwirkung später.

\section{Literatur}

Falbe J, Regitz M (Hrsg) (1996) Römpp Chemie Lexikon, 10. Aufl. Georg Thieme Verlag, Stuttgart/New York

\section{Elution erythrozytärer Antikörper}

K. Kleesiek, C. Götting, J. Diekmann, J. Dreier und M. Schmidt

Synonym(e) Ätherelution; Chloroquinelution; Säureelution; Wärmeelution

Englischer Begriff elution of antibodies from sensitized red cells

Definition Die Elution erythrozytärer Antikörper ist die schonende Absprengung eines Antikörpers von seinem korrespondierenden Antigen.

Die native Anlagerung von Antikörpern an Erythrozytenantigene kann die Untersuchungsergebnisse in der immunhämatologischen Diagnostik durch eine Störung der in der Regel benutzten Agglutinations- und Präzipitationstechniken verfälschen. Insofern ist vorher eine Loslösung der interferierenden Antikörpern aus ihrer Bindung an das Antigen mit Elutionstechniken erforderlich, um analytisch richtige Ergebnisse bei der Bestimmung sowohl von Blutgruppenmerkma- 
len (Blutgruppenantigenen) als auch Blutgruppenantikörpern zu erhalten. Verschiedene Elutionsverfahren stehen für dieses Ziel zur Verfügung (Ätherelution, Wärmeelution, Säureelution, Chloroquinelution).

Zwei unterschiedlichen diagnostischen Strategien lassen sich unterscheiden:

1. Elution des Antikörpers von den Erythrozyten zum Nachweis der Spezifität des angelagerten Antikörpers ( $>$ Antikörperdifferenzierung). Diese Elutionstechnik ist so angelegt, dass der Antikörper (Autoantikörper), der von den Erythrozyten entfernt (eluiert) wird, intakt erhalten bleiben soll. Der intakte Antikörper (Autoantikörper) kann anschließend mit den weiteren Verfahren der immunhämatologischen Diagnostik (Antihumanglobulintest, $>$ Enzymtest) untersucht und spezifiziert werden.

2. Elution des Antikörpers zum Nachweis der Blutgruppenantigene der Erythrozyten. Auch bei dieser Elutionstechnik müssen die Blutgruppenmerkmale (Blutgruppenantigene) und Erythrozyten intakt bleiben, sodass die Blutgruppenantigene in der weitergehenden immunhämatologischen Diagnostik (Antihumanglobulintest) untersucht und spezifiziert werden oder auch die antikörperfreien Erythrozyten für eine Autoadsorption nicht gebundener Autoantikörper im Serum/Plasma eingesetzt werden können.

\section{Literatur}

American Association of Blood Banks, (2014) Technical manual, 18. Aufl

Salama A (2010) In: Kiefel (Hrsg) Transfusionsmedizin: Grundlagen - Therapie - Methodik, 4. Aufl. Springer, Heidelberg/Berlin/ New York, S 79-88

\section{Elution, isokratische}

$>$ Mobile Phase

\section{Elutionsmittel}

> Mobile Phase

\section{Elutionszeit}

Retentionszeit

\section{EMA}

$>$ Ethylmalonsäure

\section{E-Mailserver}

O. Colhoun

Synonym(e) Mailserver

Englischer Begriff Email server

Definition Computer mit entsprechender Software, der Versand und Empfang von E-Mails organisiert.

Beschreibung Programmserver, der E-Mails automatisch verarbeitet und in virtuelle Postfächer (Mailbox eines E-MailAccounts) verteilt. Spezielle Mailserver organisieren z. B. Mailinglisten oder automatisches Versenden von Dateien via E-Mail. Die Funktionalität eines E-Mailservers für den Versand von Befunden an bestimmte Empfänger ist Bestandteil eines modernen $>$ Labor-EDV-Systems.

\section{Emissionsspektrometrie}

Spektrometrie/Spektroskopie

\section{Emissionsspektroskopie}

- Spektrometrie/Spektroskopie

\section{EMIT}

- Enzyme-multiplied Immunoassay

\section{Empfehlungen}

$>$ Leitlinien 


\section{Empfindlichkeit eines Messsystems}

- Messempfindlichkeit

\section{Empfindlichkeit, maximale analytische und praktische analytische}

C. Vidal und W.-R. Külpmann

Englischer Begriff maximal analytical sensitivity; practical analytical sensitivity

Definition Maß für die Empfindlichkeit einer qualitativen Untersuchung.

Beschreibung Zur Bestimmung der maximalen analytischen Empfindlichkeit werden Aliquote zahlreicher Proben (z. B. 30 Urinproben von 30 verschiedenen Probanden) mit unterschiedlichen Mengen des Analyten aufgestockt.

Die Konzentration, bei der $10 \%$ der Aliquote (in diesem Beispiel: 3) einen positiven Befund ergeben, entspricht der maximalen analytischen Empfindlichkeit $\left(\mathrm{E}_{10}\right)$. Die Konzentration, bei der $90 \%$ der Aliquote (in diesem Beispiel: 27) einen positiven Befund liefern, wird als praktische analytische Empfindlichkeit bezeichnet $\left(\mathrm{E}_{90}\right)$ :

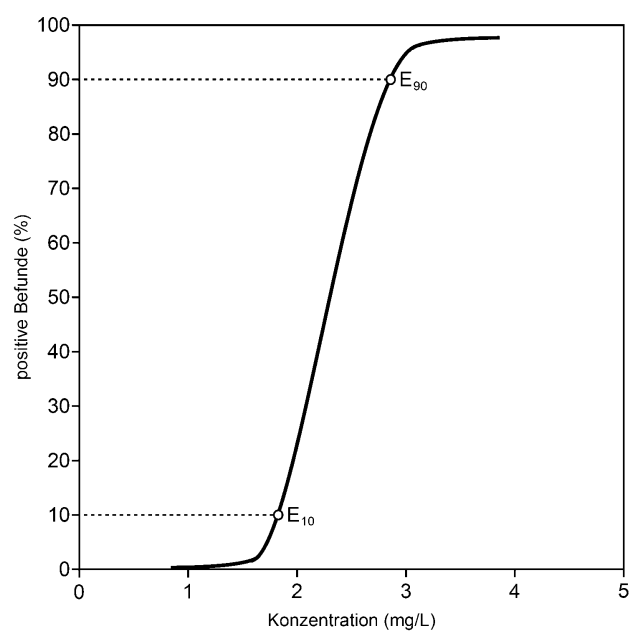

\section{Literatur}

Geldmacher-von Mallinckrodt M, Hallbach J, Külpmann WR (1995) Qualitätskontrolle qualitativer Untersuchungen. In: Gibitz HJ, Schütz H (Hrsg) Einfache toxikologische Laboratoriumsuntersuchungen bei akuten Vergiftungen. VCH-Verlag, Weinheim, S 83-99

\section{EMQN}

J. Arnemann

Synonym(e) European Molecular Genetics Quality Network

Englischer Begriff EMQN; European Molecular Genetics Quality Network

Definition EMQN (European Molecular Genetics Quality Network) ist eine nicht kommerzielle Organisation zur Förderung der Qualitätsstandards in der molekulargenetischen Diagnostik.

Beschreibung EMQN (European Molecular Genetics Quality Network), als eine nicht kommerzielle Organisation, hat es sich zum Ziel gemacht hat, die Qualitätsstandards in der genetischen Diagnostik, insbesondere in der molekulargenetischen, zu fördern und durch Best-Practice-Richtlinien zu Erkrankungen und Krankheitsbildern einheitliche Diagnosestandards zu setzen. EMQN bietet weltweit externe Qualitätskontrollen $(\mathrm{EQA}=$,external quality assessment") für Diagnostiklabore an und kollaboriert hierbei mit nationalen und internationalen Organisationen, wie z. B. auch mit dem deutschen RfB (Referenzinstitut für Bioanalytik) oder auch der Organisation CF Network. Mittels der als diagnostische Anforderungen verschickten DNA-Proben werden bei den Teilnehmern nicht nur die fachliche Methodenkompetenz und Befundvermittlung, sondern auch die korrekte medizinische Interpretation und davon abgeleitete Empfehlungen überprüft. Beurteilt werden die eingeschickten Befunde und Unterlagen von führenden Experten zu den jeweiligen Krankheitsbildern, die als Komites organisiert sind. EMQN-Zertifikate über bestandene Ringversuche werden gern als Teil eines erfolgreichen Qualtätsmanagements der Einsender gewertet. Teilnehmern, die die vorgegebenen Qualitätsziele verfehlt haben, wird vom EMQN fachlich-methodische Unterstützung und auch eine ausführliche Beratung angeboten.

EMQN entwickelte sich ab dem Jahr 1998 von einem länderübergreifenden Ringversuch zur Chorea-HuntingtonDiagnostik hin zu einer zwischenzeitlich durch die EU anschubfinanzierten europäischen Organisation, die sich seit 2002 aus den Mitgliedsbeiträgen und Einnahmen der diversen Testschemata finanziert. Neben den Angeboten zur molekularen genetischen Diagnostik werden auch Schemata für molekulare Pathologie und für ausgewählte Techniken, wie z. B. Array-CGH, Sanger-Sequenzierung oder Next-Generation-Sequencing (NGS), angeboten.

Sitz der EMQN-Organisation ist in Manchester (UK), am Department of Genetic Medicine des St. Mary's Hospital. 


\section{Literatur}

https://www.emqn.org/emqn/Home

EMSA

- Elektrophoretische Mobilitätsverschiebungs-Assay

\section{ENA}

- Autoantikörper gegen extrahierbare nukleäre Antigene

\section{Enantiomere}

C. Vidal und W.-R. Külpmann

Englischer Begriff enantiomers; enantiomorphs (chiral)

Definition Moleküle, die sich wie Bild und Spiegelbild verhalten.

Beschreibung Stereoisomere sind isomere Verbindungen, deren Atome in derselben Reihenfolge aneinander gebunden sind, die sich aber in deren räumlicher Anordnung unterscheiden (cis-trans-Isomere, Enantiomere, Diastereomere).

Chirale Moleküle verfügen nicht über eine Symmetrieebene oder ein -zentrum (im Gegensatz zu achiralen Verbindungen). Typischerweise besitzen sie (mindestens) ein asymmetrisch substituiertes C-Atom, was aber keine zwingende Voraussetzung ist. Sie zeichnen sich dadurch aus, dass sie die Ebene des linear polarisierten Lichtes drehen (optisch aktive Moleküle). Chirale Moleküle, die sich wie Bild und Spiegelbild verhalten (und nicht miteinander zur Deckung gebracht werden können wie rechte und linke Hand (griech.: cheir $=$ Hand), sind Enantiomere z. B. D-Glukose und L-Glukose. Liegen sie zu gleichen Teilen im Gemisch vor, spricht man von Razemat, das optisch inaktiv ist. Chirale Moleküle, die sich nicht wie Bild und Spiegelbild verhalten, werden als Diastereomere bezeichnet, z. B. D-Glukose und D-Galaktose oder $\alpha$-D-Glukose und $\beta$-D-Glukose. Die Notation der chiralen Moleküle der Kohlenhydrate und Aminosäuren erfolgt nach wie vor meist gemäß den Regeln der Fischerprojektion (D und L), für andere Bereiche der Chemie wird die absolute Konfiguration nach den $R$-S-Sequenzregeln von Cahn, Ingold und Prelog angegeben.

\section{Literatur}

Vollhardt KPC (1990) Organische Chemie. Weinheim, VCH

\section{Endoamylase}

- Amylase, pankreasspezifische

- fms-like tyrosine kinase 1, lösliche

- Transforming Growth Factor $\beta$

\section{Endocannabinoide}

\section{A. M. Gressner und O. A. Gressner}

Synonym(e) Cannabinoide, endogene

Englischer Begriff endocannabinoids

Definition Von der Arachidonsäure abgeleitete endogene Signalträgermoleküle, die über zwei im Zentralnervensystem und im peripheren Gewebe ubiquitär verbreitete Rezeptoren eine Vielzahl psychoaktiver und physiologischer Effekte auslösen.

Beschreibung Endogene Cannabinoide (EC) sind ubiquitäre Signalmoleküle mit Lipidstruktur, die in der Lage sind, partiell die Wirkungen des Phytocannabinoids (-)- $\Delta^{9}$ trans-Tetrahydrocannabinol $\left(\Delta^{9}\right.$-THC; verantwortlich für die psychologischen Effekte von Marihuana) zu imitieren. EC sind involviert in eine Vielzahl wichtiger zentralnervöser und peripherer physiologischer Effekte. Zu den EC gehören in erster Linie Anandamid (Arachidonylethanolamid) und 2-Arachidonylglyzerol, des Weiteren N-Arachidonyldopamin, Noladinether und Virodhamin. EC entstehen bei Bedarf durch enzymatische Abspaltung von membrangebundenen Lipidpräkursoren in einem rezeptorgesteuerten, Calcium-abhängigen Prozess in verschiedenen Zelltypen wie Neuronen, Nabelschnurendothelzellen, Neuroblastomzellen, Leukozyten, Monozyten und Makrophagen. Ihre Wirkung erfolgt über 2 Cannabinoidrezeptoren (CB1 und CB2), wobei CB1 dicht verteilt im Hirn, aber auch im peripheren Gewebe wie Gefäßendothelzellen, glatten Muskelzellen, Darm und perivaskulären Nerven lokalisiert ist. CB2 sind primär im Immunsystem, Reproduktions- und Gastrointestinaltrakt, in Lunge, Herz und Arterien lokalisiert. Ein Teil der EC-Wirkungen wird auch über Vanilloidrezeptoren vermittelt. Die CB-Rezeptoren sind gekoppelt an G-Proteine und wirken über Adenylatcyclase und Calciumkanäle. Das breite Spektrum physiologischer Wir- 
kungen erstreckt sich von psychoaktiven, analgetischen, antiemetischen Wirkungen über Stimulation des Appetits und Verbesserung der Gemütslage bis hin zu Muskelrelaxation, Immunsuppression, antiallergischen und antiinflammatorischen Effekten, Senkung des intraokularen Druckes, Bronchodilatation, neuroprotektiven und antineoplastischen Effekten. Die Breite physiologischer und psychologischer Wirkungen hat dazu geführt, pharmakologische Agonisten und Antagonisten des Endocannabinoidsystems zu entwickeln und gezielt (z. B. in der Schmerzbekämpfung) einzusetzen.

\section{Literatur}

Grotenhermen F (2005) Cannabinoids. Curr Drug Targets CNS Neurol Disord 4:507-530

Hillard CJ, Beatka M, Sarvaideo J (2016) Endocannabinoid signaling and the hypothalamic-pituitary-adrenal axis. Compr Physiol 7(1): $1-15$

\section{Endo- $\beta$-D-glukuronidase}

- Heparanase

\section{Endogene Kreatinin-Clearance}

Kreatinin-Clearance

Endogenes Pyrogen (IL-1 $\alpha$ )

$>$ Interleukin-1

\section{Endogenes \\ Thrombinbildungspotenzial}

T. Stief

\section{Synonym(e) ETP}

Englischer Begriff endogenous thrombin potential (ETP)

Definition ETP ist die Menge an Thrombin, die gebildet werden kann, nachdem die Gerinnung durch Zugabe von - Tissue Factor (TF) und Phospholipiden gestartet wird. Der Test basiert auf der Vorstellung, dass die integrierte
Gesamtmenge an Thrombin, die gebildet werden kann, letztlich die Balance zwischen den prokoagulatorischen und antikoagulatorischen Substanzen repräsentieren könnte. Eine einzige Messung der F2a-Aktivität im ansteigenden Bereich der Thrombin-Generierungs-Kinetik ( $\mathrm{t} / \mathrm{F} 2 \mathrm{a}$ Diagramm) ist jedoch in der Regel von höherer Relevanz.

Beschreibung ETP wird gegebenenfalls bestimmt, um Aussagen über einen hyper- oder hypokoagulatorischen Status der Gerinnung eines Patienten zu machen. In der jetzigen Ausführung wird die Gerinnung der Probe durch Zusatz von einem Aktivator (TF, Calcium-Ionen, Phospholipide) in Gegenwart eines fluorogenen Thrombinsubstrats (Z-Gly-Gly-Arg-AMC) gestartet. Das gewählte Thrombinsubstrat wird nur langsam umgesetzt und bindet nicht zu stark an $>$ Thrombin, dadurch wird der Gerinnungsprozess nicht beeinträchtigt und der Substratumsatz ist proportional der Konzentration des sich bildenden Thrombins. Die Verwendung eines fluorogenen statt chromogenen Substrats erlaubt die kontinuierliche Aufzeichnung des Signals, ohne dass Fibrinogen aus der Probe entfernt werden muss, weil das Fluoreszenzsignal durch die optische Trübung durch Fibrin kaum gestört wird.

Nachteile des ETP-Tests bestehen darin, dass er durch TFund Phospholipidzusatz unempfindlich ist für (patho)physiologische Aktivatoren der Thrombingenerierung und dass der Test durch Kallikrein und durch Fibrin (Antithrombin-1) empfindlich gestört wird. Alternativ kann die endogene Thrombingenerierung mittels des RECA (,recalcified coagulation acitivity assay") bestimmt werden. Im RECA wird weder TF noch Phospholipid zugesetzt, Kallikrein bzw. nicht quervernetztes Fibrin werden durch supra-1-molares Arginin inhibiert bzw. depolymerisiert und die Thrombingenerierung wird nicht in Masse (pmol), sondern Aktivität (IE) gemessen.

\section{Literatur}

Chantarangkul V, Clerich M, Bressi C et al (2003) Thrombin generation assessed as endogenous thrombin potential in patients with hyper- or hypo-coagulability. Haematologica 88:547-553

Hemker HC, Giesen PL, Ramjee M, Wagenvoord R, Beguin S (2000) The thrombogram: monitoring thrombin generation in platelet-rich plasma. Thromb Haemost 83:589-591

Stief TW (2009) Pathological thrombin generation by the synthetic inhibitor argatroban. Hemost Lab 2:83-104

\section{Endokrine Disruptoren}

W. Hubl

Synonym(e) Endokrin wirksame Substanzen; Umwelthormone; Xenohormone 
Englischer Begriff endocrine-disrupting chemicals; EDC; endocrine disruptor

Definition Endokrine Disruptoren sind endokrin wirksame Substanzen, die vorwiegend über das Abwasser in die Umwelt gelangen, infolge dessen als künstliche Hormone wirken können und Schäden für die Tierwelt und möglicherwiese auch für die Menschen verursachen können.

Beschreibung Endokrine Disruptoren beeinflussen den Hormonhaushalt, indem sie an Hormonrezeptoren andocken und dort die Wirkung von Hormonen imitieren oder den Rezeptor blockieren. Andererseits können sie Synthese, Transport oder Metabolismus von Hormonen beeinflussen.

Es sind bisher mehr als 50 endokrine Disruptoren in der Umwelt, insbesondere in Abwässern, nachgewiesen worden:

- Im Vordergrund stehen dabei zurzeit die $>$ Estrogene, die in Europa in Abwässern aus Wohngebieten (Ethinylestradiol z. B. aus Kontrazeptiva) und Industrieanlagen in erhöhten Konzentrationen nachgewiesen wurden. Besonders betroffen sind dabei im Wasser lebende Tiere, z. B. mit einer Verschlechterung der Spermienqualität von Regenbogenforellen, einem Rückgang der OstseeRobbenpopulation, einem Rückgang von Froschpopulationen. Bei Menschen wird eine Auswirkung während der Frühentwicklung (z. B. in der Gebärmutter während der Kindheit) diskutiert, während bei Erwachsenen bisher keine sichtbaren Wirkungen nachgewiesen werden konnten.

- Moschusverbindungen aus Duftstoffen können das Erbgut verändern oder Estrogene hemmen.

- Für das Insektizid DDT ist eine Beeinflussung des Progesterons beobachtet worden.

- Besondere UV-Filter in Sonnenschutzmitteln können estrogene Wirkungen zeigen.

$\mathrm{Zu}$ den natürlichen endokrinen Disruptoren gehören auch sekundäre Pflanzeninhaltsstoffe, wie die Isoflavone aus der Sojabohne oder dem Klee, die ihre Wikrung durch Bindung an Estrogenrezeptoren entfalten (Phytohormone).

Im Allgemeinen handelt es sich bei diesen endokrinen Disruptoren, von einigen verseuchten Gewässern abgesehen, um niedrige Konzentrationen. Hieraus leiten sich die wesentlichen Diskussionen ab, ob diese niedrigen Belastungen negative Auswirkungen auf den Menschen haben können. Für hohe Konzentrationen dieser endokrinen Disruptoren sind Gefährdungen der Menschen jedoch bewiesen.

Das Bundesinstitut für Risikobewertung schätzt ein, dass die derzeit vorliegenden Daten zur Exposition gegenüber einzelnen Substanzen wie Bisphenol A oder Phtalaten keine Gesundheitsgefährdung, auch nicht für Kleinkinder, ergeben.

\section{Literatur}

Bergman A, Heindel JJ, Jobling S et al (Hrsg) (2013) State of the science of endocrine disrupting chemicals 2012. An assessment of the state of the science of endocrine disruptors prepared by a group of experts for the United Nations Environment Programme (UNEP) and WHO. United Nations Environment Programme and the World Health Organization

Gore AC (2007) Endocrine-disrupting chemicals: from basic research to clinical practice. Contemporary endocrinology. Humana Press/ Springer-Verlag GmbH

Zoeller RT, Bergman A, Becher G et al (2014) A path forward in the debate over health impacts of endocrine disrupting chemicals. Environ Health 13:118, S 1-11

\section{Endokrin wirksame Substanzen}

Endokrine Disruptoren

\section{Endomysium-Antikörper}

- Autoantikörper gegen Gewebstransglutaminase

\section{Endoplasmatischer Retikulumstress}

\section{H. Fiedler}

Englischer Begriff endoplasmic reticulum stress

Definition Störungen der Homöostase bei der Faltung von Proteinen ( $\triangleright$ Proteinfaltung) und/oder die Akkumulation von falsch gefalteten Proteinen im endplasmatischen Retikulum (ER) werden als endoplasmatischer Retikulumstress (ER-Stress) zusammengefasst. Nach einer nicht bestandenen Proteinqualitätskontrolle wird zur Beseitigung der Störung eine Kaskade von Reaktionen initiiert, die als ,endoplasmic reticulum-associated protein degradation" (ERAD) und die nachfolgende ,unfolded protein response“ (UPR) eine wichtige Rolle für das Überleben und den Metabolismus der Zellen spielen.

Beschreibung Neben der Protein- und (Phospho-)Lipid-/ Steroidsynthese werden im ER der Kalziumspiegel (10.000-fach höher als im Zytosol), Transportvorgänge und der Redoxzustand auf ein hohes Niveau reguliert und Signalinformationen vermittelt.

Der ER-Stress im rauen ER wird durch viele Stimuli und Risikofaktoren ausgelöst: 
- Überschreitung der Faltungskapazität von neu synthetisierten Proteinen, besonders in Plasma-, Insel-, Panethund Leberzellen bei übermäßiger Stimulation oder Bedarf

- Unbilanzierte Synthese von Untereinheiten der Proteinkomplexe

- Expression von mutierten und/oder von zu Fehlfaltung neigenden Proteinen, wie vom CFTR-Protein bekannt

- Schädigende Faktoren, wie oxidativer Stress ( $\triangleright$ Stress, oxidativer), Lipotoxizität, Temperaturänderungen (Fieber), $\mathrm{pH}-$ Wert- und Ionenveränderungen und Kalziumerniedrigung

- Metabolische Änderungen wie Nahrungs- und ATPMangel, Adipositas mit Insulinresistenz, Lipotoxizität oder Fettleber

- Verminderung und/oder Störungen der molekularen $\checkmark$ Chaperone/Chaperonine, ER-Oxidoreduktasen und der Glykosylierungsprozesse (bei Faltung von Glykoproteinen; s. \ Glykosylierung, \ Glykoproteine)

Zur Wiederherstellung der normalen Zellfunktion und Proteinfaltung ist die Aktivierung von Signalmolekülen, Chaperonen und Transkriptionsfaktoren nach einer nicht bestandenen Qualitätskontrolle notwendig:

- Stopp der Translation des übermäßig produzierten und akkumulierenden Proteins durch Hemmung der Initiationsfaktoren (PERK und eIF2) der Transkription und Translation.

- Die Bildung oder Isomerisierung von Disulfidbindungen (oxidative Faltung) wird reguliert durch den Redoxzustand des ER, Import von Glutathion und durch Oxidoreduktasen (Foldasen): Proteindisulfidisomerase (PDI) und GRP58 (,glucose regulated protein“, $58 \mathrm{kDa}$ ) wirken zusammen mit Calreticulin/Calnexin bei der Faltung von Glykoproteinen. Nach Bildung der Disulfidbindung in den zu faltenden Proteinen wird PDI durch das membranassoziierte Protein Erolp reoxidiert, wobei auch reaktive Sauerstoffspezies (ROS) entstehen. Auch die Oxidation von - Glutathion GSH zu GSSG kann zur Reduktion und Neuordnung von inkorrekten Disulfiden in fehlgefalteten Proteinen dienen. Die benötigten Enzyme Glutaredoxin, Glutathionperoxidase und Glutathiontransferase gehören zur Thioredoxinfamilie.

- Hochregulation der Expression von Genen für benötigte Chaperone, Chaperonine, Kofaktoren und Enzyme.

- Auswärtstransport von irreversibel fehlgefalteten oder aggregierten Proteinen nach ihrer Entfaltung durch spezielle Chaperone (BiP/GRP78, HSP70, AAA+-ATP, PDI) in das Zytoplasma zu Refaltungsversuchen. Wenn die normale Faltung nicht möglich ist, werden die Proteine ubiquitiniert und zur Zerstörung durch das UbiquitinProteasom-System (UPS) freigegeben. Nach Abspaltung von $>$ Ubiquitin werden im Proteasom die fehlgefalteten oder geschädigten Proteine in Peptide von 3-5 Aminosäuren und durch Endo- und Aminopeptidasen bis zu den Aminosäuren zerlegt. Unter katabolischen Zuständen, wie Hunger, Insulinmangel oder Sepsis, wird UPS im Muskel selektiv aktiviert und liefert Aminosäuren für Glukoneogenese und Proteinneusynthese.

- Abbau von Proteinaggregaten durch Autophagie in den Lysosomen (s. unten)

Wenn das UPS überfordert ist, werden die fehlgefalteten Proteine in verschiedenen Inklusionskörpern zwischengelagert. Ubiquitinierte Proteine werden durch Chaperone in die Nähe von Zellkern und den Proteasomen gebracht (JUNQ, ,juxta nuclear quality control compartment"), wo sie nach Beseitigung der Stresssituation entweder neugefaltet oder bei erneutem Fehler im Proteasom abgebaut werden. Dagegen werden amyloidogene, nicht ubiquitinierte Proteine in der Nähe von Vakuolen gelagert (IPOD, ,insoluble protein deposit compartment"). Wenn Disaggregase-Chaperone die aggregierten Proteine nicht entfalten können, werden sie in Vakuolen (Autophagosomen) eingeschlossen und nach Verschmelzung mit Lysosomen proteolytisch abgebaut. Die Autophagie als Selbstreinigungsprozess dient dem Überleben der Zelle und gewann durch die Verleihung des Nobelpreises 2016 an Yoshinori Ohsumi allgemeine Bedeutung.

„Unfolded protein response“ ist auch an intrazellulärer Signalweiterleitung, Freisetzung von $>$ Tumornekrosefaktor- $\alpha$, Regulation des Zellzyklus, Antigenprozessierung und der Modulation von Rezeptoren und Ionenkanälen beteiligt.

ER-Stress und UPS sind an verschiedenen Krankheiten beteiligt, allerdings müssen noch viele Einzelheiten geklärt werden. Bei Umbauprozessen am Herzen nach Ischämie und Reperfusion werden ubiquitinierte aggregierte und fehlgefaltete Proteine in die Lysosomen transportiert. In Atheroseplaques wurden Marker für ER-Stress und UPS erhöht gefunden. In Immunzellen wird mit Hilfe von Interferon- $\gamma$ ein Immunproteasom gebildet, das gezielt geeignete Peptide für die Antigenprozessierung produziert. ER-Stress, UPR und oxidativer Stress sind mit Hyperglykämie, Insulinresistenz mit erhöhter (Pro-)Insulinbiosynthese und metabolischem Syndrom verknüpft. Außerdem wird das ER der $\beta$-Zellen durch das gleichzeitig synthetisierte und sezernierte $>$ Amylin (,,islet amyloid peptide“, IAPP) überlastet und dadurch der ER-Stress verstärkt.

\section{Literatur}

Eizirik DL, Cardozo AK, Cnop M (2008) The role of endoplasmic reticulum stress in diabetes mellitus. Endocr Rev 29:42-61

Fiedler H (2010) Endoplasmatischer Retikulumstress. UbiquitinProteasom- System. MTA Dialog 9:766-769

Han J, Kaufman RJ (2016) The role of ER stress in lipid metabolism and lipotoxicity. J Lipid Res 57:1329-1338 
Hebert DN, Molinari M (2007) In and out of the ER: Protein folding, quality control, degradation and related human diseases. Physiol Rev 87:1377-1408

Wang Q, Groenendyk J, Michalak M (2015) Glycoprotein quality control and ER stress. Molecules 20:13689-13704

Yalcin A, Hotamisligil GS (2013) Impact of ER protein homeostasis on metabolism. Diabetes 62:691-693

\section{Endothel-Protein-C-Rezeptor}

\section{T. Stief}

\section{Synonym(e) EPCR}

Englischer Begriff endothelial protein C receptor

Definition Der Endothel-Protein-C-Rezeptor bindet $>$ Protein $\mathrm{C}$ und aktiviertes Protein C. Durch die Bindung von Protein $\mathrm{C}$ an den membranständigen EPCR wird seine Aktivierung durch $>$ Thrombin/Thombomodulin verstärkt.

Beschreibung EPCR, bestehend aus 238 Aminosäuren mit einer Molmasse von $27 \mathrm{kDa}$, ist ein N-glykosyliertes Typ-IMembranprotein und wird vor allem auf Endothelzellen der Arterien und Venen des Herzens und der Lunge exprimiert. Das Gen, das den EPCR kodiert, liegt auf dem langen Arm des Chromosoms 20 (20q11). EPCR lokalisiert Protein C auf Endothelzellen und verstärkt die Aktivierung von Protein $\mathrm{C}$ durch Thrombin dadurch, dass er Protein C in direkten Kontakt mit dem $>$ Thrombomodulin-Thrombin-Komplex bringt.

\section{Literatur}

Kottke-Marchant K, Comp P (2002) Laboratory issues in diagnosing abnormalities of protein $\mathrm{C}$, thrombomodulin, and endothelial cell protein C receptor. Arch Pathol Lab Med 126:1337-1348

Sturn DH, Kaneider NC, Feistritzer C et al (2003) Expression and function of the endothelial protein $\mathrm{C}$ receptor in human neutrophils. Blood 102:1499-1505

\section{Endotoxin-Reaktivität}

T. Stief

Synonym(e) Lipopolysaccharid; LPS

Englischer Begriff lipopolysaccharide; LPS
Definition LPS (Fragmente der äußeren Membran gramnegativer Bakterien) oder $\beta(1 \rightarrow 3)$-D-Glukan ( $\beta$-Glukan; Fragmente der Membran von Pilzen) sind Toxine für die Monozyten des menschlichen Blutes. Pathologische Konzentrationen an freiem Endotoxin zerstören Monozyten, die Zelltrümmer (freie DNA, Phospholipide, Tissue Factor) aktivieren die Gerinnung (,first hit“). Pathologische > Thrombinaktivität in Plasma entsteht (,second hit"), die systemisch zirkulierende Mikrothrombi erzeugt, was zum Organversagen führen kann.

Untersuchungsmaterial EDTA-Plasma (gegebenenfalls Citratplasma).

Präanalytik Proben sollten frisch sein $(<2 \mathrm{~h}$ alt, gelagert bei Raumtemperatur) oder eingefroren.

Analytik Methode der Wahl ist die funktionelle Bestimmung der Endotoxin-Reaktivität mit einem chromogenen Limulus-Test. Die Limulus-Krabbe hat ein kaskadenartiges Proteinasensystem, das dem menschlichen Gerinnungssystem ähnelt. Freies LPS aktiviert Limulus-Faktor-C (FC) zu FCa. FCa aktiviert Limulus-Faktor-B zu FBa, FBa aktiviert Limulus-FA zu FAa. FAa ist vergleichbar dem menschlichen Thrombin und wandelt Limulus-Coagulogen in Cogulin um, vergleichbar der Umwandlung von Fibrinogen zu Fibrin. $\beta$-Glukan aktiviert Limulus-Faktor-G zu FGa, der (wie FBa) FAa generiert. Im chromogenen Limulus-Test wird Coagulogen durch ein niedermolekulares pNA-Substrat für FAa (z. B. Ile-Glu-Gly-Arg-pNA) ersetzt. Der Test kann als hyperboler Einstufentest oder vorzugsweise als linearer Zweistufentest durchgeführt werden. Wird der Limulus-Test in Anwesenheit von Polymixin B durchgeführt, so werden bis zu $1000 \mathrm{ng} / \mathrm{ml}$ LPS-Reaktivität inhibiert (Schwerstkranke wie z. B. Patienten mit Waterhouse-Friedrichsen-Syndrom haben bis zu ca. $100 \mathrm{ng} / \mathrm{ml}$ LPS-Reaktivität), und diese Testversion wird spezifisch für $\beta$-Glukan.

Antithrombin-3 ist ein bedeutender Störfaktor bei der Messung der Endotoxin-Limulus-Kaskade (Faktor Ca, Faktor Ba, Faktor Ga, Faktor Aa): um die Lipopolysaccharid- oder $\beta(1 \rightarrow 3)$ D-Glukan Reaktivität im EDTA-Plasma zu quantifizieren, muss AT-3 durch starke (Singlet-Oxygen-freisetzende) Oxidation mittels Chloramin zerstört werden .

Referenzbereich $0,8 \pm 0,2 \mathrm{ng} / \mathrm{ml}$ LPS-Reaktivität; $<0,1$ $\mu \mathrm{g} / \mathrm{ml} \beta$-Glukan-Reaktivität.

Reaktivität ist diejenige Aktivität von LPS oder $\beta$-Glukan, die entsteht, wenn ein LPS-/ $\beta$-Glukan-freies Plasma mit dieser Menge an reinem LPS oder $\beta$-Glukan supplementiert wurde (Additionskalibration).

\section{Indikation}

- Sepsisdiagnostik (schnell, in weniger als $1 \mathrm{~h}$ ) 
- Quantifizieren des Ausmaßes der Erregerinvasion

- Erfolgskontrolle einer antimikrobiellen Therapie

Interpretation Intensivpflichtige Patienten mit schwerer Sepsis haben meist $>5 \mathrm{ng} / \mathrm{ml}$ LPS-Reaktivität oder $>0,5$ $\mu \mathrm{g} / \mathrm{ml} \beta$-Glukan-Reaktivität; ca. ein Drittel dieser Patienten haben eine gramnegative Sepsis, ein Drittel eine Pilzsepsis und ein Drittel eine Kombination aus gramnegativer und fungaler Sepsis.

Diagnostische Wertigkeit Endotoxin-Reaktivität ist ein sehr wichtiger Parameter zur Beurteilung eines systemischen Infektes mit gramnegativen oder fungalen Erregern. Der Test kann auch mit Liquor durchgeführt werden, allerdings muss Liquor 1:10 mit Normalplasma verdünnt werden, damit die Testmatrix Plasma ist (Test ist standardisiert auf EDTAPlasma; im Limulus-Reagenz befinden sich Magnesiumionen im Überschuss, um das EDTA zu neutralisieren).

\section{Literatur}

Stief TW (2006) Thrombin generation by exposure of blood to endotoxin - a simple model to study DIC. Clin Appl Thromb Hemost $12: 137-161$

Stief TW (2008) Determination of active endotoxin in plasma. Hemost Lab 1:41-52

Stief TW, Max M (2008) Active endotoxin in sepsis. Hemost Lab $1: 53-60$

\section{Endpunkt, theoretischer}

- Äquivalenzpunkt

- Titration

\section{Engvall, Eva}

\section{A. M. Gressner und O. A. Gressner}

Lebensdaten Eva Engvall graduierte als Ph. D. 1975 an der Universität Stockholm.

Verdienste Während ihrer Ph.D.-Arbeit in der Abteilung Prof. Peter Perlmanns erarbeitete sie gemeinsam mit ihm die Methode des \ Enzyme-linked Immunosorbent Assay (ELISA), die 1971 publiziert wurde. Basierend auf dem Konzept des > Radioimmunoassays, im Jahr 1960 von Rosalyn Yalow ( $\triangleright$ Yalow, Rosalyn) und Solomon Berson beschrieben, verwendet der ELISA anstelle eines radioaktiven Reporter- labels Enzyme (vorzugsweise solche mit hohen Umsatzraten wie Meerrettich-Peroxidase, \Glukose-6-Phosphat-Dehydrogenase, \ Phosphatase, alkalische), die mit Glutaraldehyd an entsprechende Antikörper gekoppelt sind.

Zeitgleich entwickelten Bauke van Weemen und Anton Schuurs im Forschungslaboratorium von NV Organon, Oss, in den Niederlanden die als EIA bekannte Technik des - Enzymimmunoassays, die ebenfalls 1971 veröffentlicht wurde. Diese Techniken bildeten die Grundlage für weitere Varianten, die aufgrund ihrer Vielseitigkeit, ihrer im Vergleich zum Radioimmunoassay völligen Unbedenklichkeit der Anwendung, der hohen Mechanisierbarkeit und der Stabilität des Reporterlabels eine universelle Verbreitung erfahren haben.

Eva Engvall ging im Jahr 1979 an das Sanford-Burnham Medical Research Institute und war von 1994-1996 daneben Vorsitzende der Abteilung für Entwicklungsbiologie an der Universität Stockholm. Für ihre Arbeit erhielt sie zahlreiche Auszeichnungen, u. a. von der Deutschen Gesellschaft für Klinische Chemie, der US Clinical Ligand Assay Society sowie 1995 von der Ed und Mary Shea Family Foundation. Im Jahr 1994 wurde ihr die Ehrendoktorwürde der Universität Kopenhagen verliehen. Sie ist heute Professorin für Oncodevelopmental Biology am Sanford-Burnham Institute, La Jolla, CA, USA.

\section{Literatur}

Engvall E, Perlmann P (1971) Enzyme-linked immunosorbent assay (ELISA). Quantitative assay of immunoglobulin G. Immunochemistry 8:871-874

Weemen BK van, Schuurs AHWM (1971) Immunoassay using antigenenzyme conjugates. FEBS Letts 15:232-236

\section{Enhanced-Liver-Fibrosis-Test}

\section{A. M. Gressner und O. A. Gressner}

Synonym(e) ELF-Test; ELF-Fibrosescore

\section{Englischer Begriff ELF test; ELF score}

Definition Der ELF-Test ist eine multiparametrische, nicht invasive, standardisierte Kenngröße zur Diagnostik und Verlaufskontrolle der Leberfibrose.

Beschreibung Der Elf-Test ( $\triangleright$ Fibrosekenngrößen) ist ein standardisiertes Verfahren zur nicht invasiven Diagnostik der Leberfibrose, das sich der Messung von 3 Einzelparametern bedient: N-terminales Propetid des Typ III Prokollagens 
(PIIINP; Prokollagenpeptid Typ III, N-terminales); $>$ Hyaluronan (Hyaluronsäure); $>$ Tissue inhibitor of metalloproteinase-1 (TIMP-1). Die immunologisch im Serum gemessenen Konzentrationen dieser Parameter werden nach einer patentierten Formel (Algorithmus) (Siemens Healthcare) unter Berücksichtigung von Geschlecht und Alter des Patienten in einen Score umgerechnet, dessen Höhe den Schweregrad (Stadium) der Organfibrose und deren klinischen Verlauf anzeigt. Diagnostische Sensitivität $90 \%$ und Spezifität $41 \%$.

Ursachen der Leberfibrose können sein: chronische Virushepatitis B oder C (HBV, HCV), alkoholische Leberschädigung, nichtalkoholische Fettleber (Steatohepatitis, NASH), primär biliäre Zirrhose (PBC), Autoimmunhepatitis, parasitäre Infektionen (Schistosomiasis), genetische Erkrankungen wie Hämochromatose, $\alpha 1$-Antitrypsinmangel, Morbus Wilson.

\section{Literatur}

Gressner AM, Rizk M, Gao C, Gressner OA (2010) Potential novel biomarkers for monitoring the fibrogenic process in liver. Arab J Gastroenterol 10:S12-S16

Parkes J, Roderich P, Harris S et al (2010) Enhanced liver fibrosis test can predict clinical outcome in patients with chronic liver diseases. Gut 59(9):1245-1251

Rosenberg WMC, Voelker M, Thiel R et al (2004) Serum markers detect the presence of liver fibrosis: a cohort study. Gastroenterology 127:1704-1713

$\gamma$-Enolase

$>$ Neuronenspezifische Enolase im Blut

$\gamma$-Enolase Liquor

- Liquor-Neuronenspezifische Enolase (NSE)

\section{ENSEMBL}

J. Arnemann

Synonym(e) ENSEMBL-Datenbank

Definition ENSEMBL (www.ensembl.org) ist eine Website, die Informationen zu Genomen, DNA-, RNA- und Proteinse- quenzdaten liefert und auch die nötigen Software-Tools zur gezielten Bearbeitung.

Beschreibung ENSEMBL war ursprünglich nur ein bioinformatisches Forschungsprojekt zwischen dem Sanger Institut des Welcome-Trusts und dem European Bioinformatics Institut (EBI) des EMBL (European Molecular Biology Laboratory), aber ist heute eine der zentralen, frei zugänglichen Datenbanken zu Genominformationen und mittels spezifischer Tools interaktiv zu bearbeitenden Genomanalysen.

\section{Literatur}

www.ensembl.org

\section{ENSEMBL-Datenbank}

- ENSEMBL

\section{EN-Standards}

W. G. Guder

Synonym(e) Europäische Norm

Englischer Begriff European Standard (EN)

Definition Vom Europäischen Komitee für Normung (CEN), Brüssel, herausgegebene Norm (Standard).

Beschreibung Seit Gründung der Europäischen Union wurden zunächst auf fachlicher Ebene durch das European Commitee for Clinical Laboratory Standards (ECCLS), dann durch das European Committee for Standardization (CEN) Standards für technische und prozedurale Details der laboratoriumsmedizinischen Tätigkeit erarbeitet und publiziert, die teilweise parallel oder gemeinsam mit amerikanischen (CLSI) und internationalen Standards (ISO) publiziert wurden.

Sie beziehen sich auf Begriffe, Materialien und Prozeduren im Rahmen der Klinischen Chemie, Mikrobiologie und Laboratoriumsmedizin. Folgende EN-Standards wurden aus ISO ( $\triangleright$ International Organization for Standardization) und in DIN übernommen: > DIN EN ISO 15189, > DIN EN ISO 9001, > DIN EN ISO/IEC 17025; s. a. Literatur. EN-Standards haben in den Ländern der EU Gesetzescharakter. 


\section{Literatur}

EN 828 (1996) In vitro diagnostic systems. Transport packages for medical and biological specimens. Requirements, tests. European Committee for Standardization (CEN), Bruxelles

EN/DIN 14136 (2004) Verwendung externer Qualitätssicherungsprogramme bei der Bewertung der Durchführung von Untersuchungsverfahren in der In-vitro-Diagnostik. European Committee for Standardization (CEN)

EN/ISO/DIN 15189 (2012) Medical laboratories - particular requirements for quality and competence. Deutsches Institut für Normung (DIN), Berlin / International Organization for Standardization (ISO), Genf / European Committee for Standardization(EN), Brüssel

EN/ISO/DIN 6710 (2002) Single-use containers for human venous blood specimen collection. European Committee for Standardization, Brussels (CEN)

\section{Entactin}

> Nidogen (1-2)

\section{Enteiweißung}

Proteinfällung

\section{Enteramin}

$>$ Serotonin

\section{Enterogastron}

\ Gastrointestinales Peptid

\section{Enteroglukagon}

R. Tauber und F. H. Perschel

\section{Englischer Begriff Enteroglucagon}

Definition Der Begriff Enteroglukagon umfasst die 2 Glukagon-ähnlichen Peptide Glicentin und Oxyntomodulin, die die Aminosäuresequenz von \ Glukagon sowie zusätzliche Aminosäuresequenzen enthalten und die in den L-Zellen des distalen Dünndarms und der Kolonmukosa aus Proglukagon zusammen mit $\triangleright$ Glucagon-like peptide 1 (GLP-1) und GLP-2 freigesetzt werden.

Beschreibung. Das überwiegend gebildete Glicentin kann wegen der N-terminalen Sequenzverlängerung nicht an den Glukagonrezeptor binden und besitzt daher keine Glukagonähnliche Bioaktivität. Oxyntomodulin kann zwar an den Glukagonrezeptor binden, besitzt allerdings im Vergleich mit Glukagon nur 1/50 der Affinität. Außerdem findet es sich im Plasma normalerweise nur in sehr geringer Konzentration. Eine Glukagon-ähnliche Wirkung in vivo ist daher unwahrscheinlich. Gegenwärtig werden Enteroglukagone eher als Nebenprodukt bei der Bildung von GLP-1 und GLP-2 gewertet.

\section{Literatur}

Holst JJ (2000) Gut hormones as pharmaceuticals. From enteroglucagon to GLP-1 and GLP-2. Regul Pept 93:45-51

\section{Enterokinase}

$\checkmark$ Enteropeptidase

\section{Enteropeptidase}

R. Tauber und F. H. Perschel

Synonym(e) Enterokinase

\section{Englischer Begriff Enteropeptidase}

Definition Enteropeptidase (EC 3.4.21.9) ist eine Serinproteinase der intestinalen Bürstensaummembran, die Trypsinogen proteolytisch zu $>$ Trypsin aktiviert.

Beschreibung Enteropeptidase ist eine heterodimere Serinproteinase, die in den Enterozyten des Duodenums und des proximalen Jejunums exprimiert wird und in der Bürstensaummembran lokalisiert ist. Enteropeptidase aktiviert spezifisch Trypsinogen zu Trypsin durch Abspaltung eines N-terminalen Aktivierungspeptids. Durch die Aktivierung von Trypsin ist Enteropeptidase essenziell für die Aktivierung von Zymogenen (s. - Zymogene) - inaktive Vorstufen von Proteinasen, Peptidasen und Phospholipase A2 - des Pankreas. Hereditärer Mangel an Enteropeptidase führt zu schwerer Malabsorption mit Diarrhoe, Erbrechen und Wachstumsretardierung. 


\section{Literatur}

Lu D, Sadler JE (1998) Enteropeptidase. In: Barrett AJ, Rawlings ND, Woessner JFJ (Hrsg) Handbook of proteolytic enzymes. Academic, London, S 50-54

\section{Entkopplungsproteine}

H. Fiedler

Synonym(e) Thermogenin (für UCP1)

Englischer Begriff Uncoupling proteins; UCP

Definition Zur Familie der Entkopplungsproteine zählen mindestens 5 Proteine (ca. $33 \mathrm{kDa}$ ), die die oxidative Phosphorylierung entkoppeln, die unmittelbare Thermogenese ohne Muskelaktivität steigern und die ATP-Speicherung reduzieren. Allerdings ist dies nur für UCP1 im Sympathikusstimulierten braunen Fettgewebe eindeutig nachgewiesen, während UCP2/3 wahrscheinlich größere Bedeutung für die Beseitigung reaktiver Sauerstoffspezies (ROS; > Reaktive Sauerstoffspecies) haben.

Beschreibung UCP1 hat die Struktur eines Adeninnukleotid-Carriers, befindet sich in der inneren Mitochondrienmembran der braunen Fettzellen und bildet einen Protonenkanal parallel zum ATP-Synthase-Kanal. Die Entkopplung tritt ein, wenn UCP1 durch Noradrenalin und durch Lipolyse freigesetzte Fettsäuren stimuliert wird. Die Thermogenese ist bei Nagetieren und Winterschläfern ausgeprägt. UCP1 und braunes Fettgewebe wurden beim Menschen nicht nur in der Neugeborenenphase, sondern auch bei den meisten Erwachsenen durch Magnetresonanztomographie nachgewiesen und korrelieren invers mit BMI (Body-Mass-Index) und Glukosekonzentration.

Verminderung von UCP2 begünstigt die Insulinsekretion und erhöht die Resistenz gegen mikrobielle Infektionen. Ein Schutz gegen Karzinome wird diskutiert. UCP3-mRNA ist im Skelettmuskel von Diabetespatienten parallel zur Glukoseverwertung reduziert, wodurch es zur Insulinresistenz beitragen könnte. Der VV-Genotyp des Ala55Val-Polymorphismus von UCP2 ist ebenso wie der Leu229-Polymorphismus von UCP1 mit dem Risiko eines Typ-2-Diabetes assoziiert. UCP2 und UCP3 haben offenbar einen protektiven Einfluss auf den Herzstoffwechsel bei Lipotoxizität und oxidativen Stress und reduzieren die Apoptose bei Herzinsuffizienz.

\section{Literatur}

Akhmedov AT, Rybin V, Marin-Garcia J (2015) Mitochondrial oxidative metabolism and uncoupling proteins in the failing heart. Heart Fail Rev 20:227-249
Lee P, Greenfield JR, Ho KKY, Fulham MJ (2010) A critical appraisal of the prevalence and metabolic significance of brown adipose tissue in adult humans. Am J Physiol Endocrinol Metab 299:E601-E606

MacLellan JD, Gerrits MF, Gowing A et al (2005) Physiological increase in uncoupling protein 3 augment fatty acid oxidation and decrease reactive oxygen species production without uncoupling respiration in muscle cells. Diabetes 54:2343-2350

Saleh MC, Wheeler MB, Chan CB (2002) Uncoupling protein 2:evidence for its function as a metabolic regulator. Diabetologia 45:174-187

Yu X, Jacobs DR, Schreiner PJ et al (2005) The uncoupling protein 2 Ala55Val polymorphism is associated with diabetes mellitus: the CARDIA study. Clin Chem 51:1451-1456

\section{Entscheidungsgrenze}

T. Arndt

Synonym(e) Entscheidungskriterium

Englischer Begriff decision limit; cut-off

Definition Legt fest, bis zu welchem Messergebnis ein normaler oder negativer Befund und ab welchem ein abnormaler oder positiver Befund vorliegt.

Beschreibung Die Entscheidungsgrenze kann die untere oder obere Grenze des Referenz- oder Graubereichs sein und ist damit für die Entscheidung, ob eine Erkrankung vorliegt oder nicht, von Bedeutung. Der Begriff wird auch häufig im Zusammenhang mit toxikologischen Untersuchungen benutzt, bei denen anhand der Entscheidungsgrenze ( $>$ Cut-off-Wert), d. h. einer definierten Grenzkonzentration eines Analyten, über den positiven oder negativen Nachweis z. B. einer Droge entschieden wird. Um eine maximale forensische Sicherheit zu erlangen, wird die Entscheidungsgrenze gewöhnlich höher als die Nachweisgrenze des Analysenverfahrens angesetzt, d. h., trotz sicheren Nachweises von Drogenspuren (deutlich über der Nachweisgrenze) kann der Endbefund negativ (nicht nachweisbar) ausfallen, wenn die ermittelte Drogenkonzentration zwischen Nachweisgrenze und Entscheidungsgrenze (also unterhalb dieser) liegt.

\section{Literatur}

Büttner J, Stamm D (1995) Ärtzliche Verwendung von klinischchemischen Befunden. In: Greiling H, Gressner M (Hrsg) Lehrbuch der Klinischen Chemie und Pathobiochemie. Schattauer Verlag, Stuttgart/New York

Külpmann WR (Hrsg) (2002) Klinisch-toxikologische Analytik. Wiley$\mathrm{VCH}$, Weinheim 


\section{Entscheidungskriterium}

- Entscheidungsgrenze

\section{Entscheidungstafel}

C. Vidal und W.-R. Külpmann

Synonym(e) 4-Felder-Tafel (für Befundvalidierung)

\section{Englischer Begriff 4-box table}

Definition Darstellung der negativen und positiven Befunde, die für eine Messgröße bei Stichproben aus Teilgesamtheiten für Merkmalsträger bzw. Nichtmerkmalsträger gefunden wurden.

Prinzip der 4-Feldertafel:

\begin{tabular}{|l|l|l|} 
Anzahl der Personen mit & $\begin{array}{l}\text { Anzahl der } \\
\text { positiven }\end{array}$ & $\begin{array}{l}\text { Anzahl der } \\
\text { negativen }\end{array}$ \\
einem bestimmten Zustand & Befunde $\left(\mathrm{B}_{\mathrm{P}}\right)$ & Befunde $\left(\mathrm{B}_{\mathrm{N}}\right)$ \\
\hline$N_{\mathrm{V}}$ & $N_{\mathrm{RP}}$ & $N_{\mathrm{FN}}$ \\
\hline$N_{\mathrm{A}}$ & $N_{\mathrm{FP}}$ & $N_{\mathrm{RN}}$ \\
\hline
\end{tabular}

$N_{\mathrm{V}}=$ Anzahl der Personen mit diesem Zustand; $N_{\mathrm{A}}=$ Anzahl der Personen ohne diesen Zustand; $N_{\mathrm{RP}}=$ Anzahl der richtig-positiven Befunde; $N_{\mathrm{FP}}=$ Anzahl der falsch-positiven Befunde; $N_{\mathrm{FN}}=$ Anzahl der falsch-negativen Befunde; $N_{\mathrm{RN}}=$ Anzahl der richtig-negativen Befunde

Beispiel einer 4-Feldertafel:

\begin{tabular}{l|l|l|} 
& $\begin{array}{l}\text { Anzahl positiver } \\
\text { Befunde }\end{array}$ & $\begin{array}{l}\text { Anzahl negativer } \\
\text { Befunde }\end{array}$ \\
\hline $\begin{array}{l}\text { Merkmalsträger } \\
\text { (,Kranker“) }\end{array}$ & 9500 & 500 \\
$\begin{array}{l}\text { Nichtmerkmalsträger } \\
\text { (,Gesunder“) }\end{array}$ & 4500 & 85500 \\
\hline
\end{tabular}

Die 4-Feldertafel ist die Grundlage zur Berechnung von diagnostischer Spezifität ( $\triangleright$ Spezifität, diagnostische) und Sensitivität ( $\triangleright$ Sensitivität, diagnostische) (s. folgende Formeln mit Beispielrechnung):

$$
\begin{aligned}
& \text { Diagnostische Spezifitat : } \frac{85 \cdot 500}{85 \cdot 500+4500}=0,95 \\
& \text { Diagnostische Sensitivitä }: \frac{9500}{9500+500}=0,95
\end{aligned}
$$

\section{Literatur}

DIN 58985 (2003) Entscheidungsgrenzen. Beuth-Verlag, Berlin

\section{Entsorgungsbox für Nadeln und andere scharfe und infektiöse Gegenstände}

- Sicherheitsbehälter

\section{Entzündungsmarker}

- Sepsiskenngrößen

\section{Enzym}

T. Arndt

Synonym(e) Biokatalysator; Ferment

Englischer Begriff enzyme; biocatalysator

Definition Bezeichnung für eine umfangreiche Gruppe von katalytisch wirksamen Proteinen, die durch Herabsetzung der Aktivierungsenergie die Reaktionsgeschwindigkeit von chemischen Reaktionen beschleunigen und damit den Stoffumsatz erhöhen, ohne dabei selbst verbraucht zu werden.

Beschreibung Enzyme sind gewöhnlich Proteine (seltener Glykoproteine) mit einer relativen Molmasse zwischen etwa 10 und 200, aber auch bis $4000 \mathrm{kDa}$ (Multienzymkomplexe wie Pyruvatdehydrogenase), die die Hin- und Rückreaktion eines Reaktionsgleichgewichtes katalysieren. Sie enthalten ein oder mehrere sog. aktive Zentren, die für die katalytische Aktivität und Spezifität verantwortlich sind. Sog. prosthetische Grupen, z. B. Metallionen oder Vitamine, werden oft für die Ausbildung der vollen katalytischen Aktivität benötigt. Enzyme werden nach verschiedenen Charakteristika kategorisiert. Man unterscheidet z. B. nach ihrer Lokalisation zytosolische/membranständige/mitochondriale, zelluläre/extrazelluläre oder hepatische/nichthepatische Enzyme. Zu Biochemie, Nomenklatur und Klassifikation s. Lehrbücher der Biochemie.

Enzyme sind an nahezu allen Prozessen des lebenden Organismus beteiligt. Von diagnostischer Bedeutung ist ihr Erscheinen oder Verschwinden aus Körpermaterial, in dem sie unter physiologischen Bedingungen gar nicht oder nur in geringer bzw. in hoher Konzentration vorkommen. So führt die Schädigung von Hepatozyten zum Austritt von zellulären Enzymen (z. B. A Alanin-Aminotransaminase [ALT], - Aspartat-Aminotransaminase [AST]) in den Blutkreislauf und dort in Abhängigkeit vom Ausmaß der Schädigung zu 
einem messbaren Enzymaktivitätsanstieg. Andererseits führt die chronische Schädigung von Pankreaszellen zum Untergang dieser Zellen und damit zur Abnahme z. B. der Pankreas-Elastase-Konzentration ( $\triangleright$ Elastase, pankreasspezifische) im Stuhl. Enzymaktivitätsmessungen stellen einen beachtlichen Teil der im klinisch-chemischen Labor durchgeführten Analysen dar.

Die diagnostische Aussagekraft von Enzymaktivitätsmessungen kann erhöht werden durch:

- Bestimmung von $>$ Enzymaktivitäten organspezifischer Enzyme (z. B. Lipase [ $\vdash$ Lipase, pankreatische] oder Pankreasamylase [ $\triangleright$ Amylase, pankreasspezifische] für das Pankreas) oder zwar ubiquitär vorkommender, aber in bestimmten Organen in besonders hoher Aktivität vorliegender Enzyme (z. B. ALT für die Leber). Dadurch kann das von der Zellschädigung betroffene Organ oder Organsystem erkannt werden.

- Interpretation des Ausmaßes des Aktivitätsanstiegs oder -abfalls im Vergleich zum Referenzbereich Gesunder. Hierdurch kann auf das Ausmaß der Organschädigung geschlossen werden.

- Quotientenbildung von Enzymaktivitäten z. B. zytosolischer und mitochondrialer Enzyme. Sie erlaubt die Abschätzung der Schwere der Schädigung einzelner Zellen. Hohe Aktivitäten mitochondrialer Enzyme zeigen einen schweren, irreversiblen Zellschaden an.

- Gemeinsame Beurteilung der Enzymaktivitäten mehrerer Enzyme oder von Isoenzymen. Hierdurch kann z. B. die Organspezifität erhöht werden.

- Beobachtung des Verlaufs der Enzymaktivitäten unter der Therapie. Eine Normalisierung der Enzymaktivität zeigt gewöhnlich eine Ausheilung an.

\section{Literatur}

Heinrich PC, Müller M, Graeve L (Hrsg) (2014) Löffler/Petrides Biochemie und Pathobiochemie, 9. Aufl. Springer, Berlin/Heidelberg/ New York

\section{Enzymaktivität}

T. Arndt

Synonym(e) Aktivität eines Enzyms; Enzymkonzentration, katalytische

Englischer Begriff enzyme activity

Definition Die Enzymaktivität wird gewöhnlich in internationalen Einheiten (IU) angegeben. Eine IU bezeichnet dieje- nige Enzymaktivität, die den Umsatz von $1 \mu$ mol Substrat pro Minute unter Standardbedingungen ( $\mathrm{pH}$, Substratsättigung, Temperatur) katalysiert. Die Konzentrationsangabe der Enzymaktivität wird als katalytische Enzymkonzentration bezeichnet.

Beschreibung Nach IUPAC ( $\triangleright$ International Union of Pure and Applied Chemistry) ist die Enzymaktivität in (Verweis auf Katal einfügen) $>$ Katal (kat) anzugeben. Dabei entspricht der Umsatz von 1 mol Substrat/s $=1$ kat. Bis jetzt hat sich diese Definition in der (klinisch-chemischen) Praxis jedoch nicht durchgesetzt.

In biologischen Proben sind im Allgemeinen so geringe Enzymkonzentrationen vorhanden, dass sie sich der Bestimmung durch physikochemische Methoden entziehen. Die Bestimmung der katalytischen Aktivität von Enzymen ist dagegen oft ohne großen Aufwand, schnell, empfindlich und spezifisch möglich. Besitzen Substrat oder Reaktionsprodukt eine spezifische Absorptionswellenlänge, kann aus der Extinktionsänderung des Reaktionsansatzes der durch das Enzym katalysierte Umsatz an Substrat pro Zeiteinheit berechnet und der Enzymaktivität zugeordnet werden. Dieses von Otto Warburg ( $\triangleright$ Warburg, Otto Heinrich) in die biochemische Analytik eingeführte Prinzip wird insbesondere zur Aktivitätsmessung $\mathrm{NAD}^{+}$- oder $\mathrm{NADP}^{+}$-abhängiger Enzyme eingesetzt (optisch-enzymatischer Test nach Warburg, s. Lehrbücher der Biochemie). Auch die Aktivität von Enzymen, die nicht $\mathrm{NAD}^{+}$- oder $\mathrm{NADP}^{+}$-abhängig sind, kann mithilfe des optischen Tests bestimmt werden. Hierzu ist die Kopplung der eigentlichen enzymatisch katalysierten Reaktion mit einer $\mathrm{NAD}^{+}$- oder $\mathrm{NADP}^{+}$-abhängigen Indikatorreaktion erforderlich. Man spricht dann vom gekoppelten optisch-enzymatischen Test (nach Warburg).

Bei der Messung von Enzymaktivitäten ist zwischen kontinuierlichen (kinetischen), diskontinuierlichen (meist Zweipunktmethoden) und Endpunktverfahren (Endpunktmethoden) zu unterscheiden. Unter den kinetischen Verfahren spielen die o. g. optischen Tests die größte Rolle. Hier wird in einem bestimmten Zeitabschnitt die durch Bildung oder Verbrauch von NADH oder NADPH eintretende Extinktionsänderung ( $\triangleright$ Lambert-Beer-Gesetz) der Reaktionslösung kontinuierlich oder in bestimmten Zeitabständen registriert. Bei diskontinuierlichen Verfahren wird die Konzentration an Substrat oder Produkt im Testansatz oder die Extinktion der Reaktionslösung vor und nach einer definierten Inkubationszeit bestimmt. Da hier zumeist zwei Messpunkte registriert werden, spricht man auch von Zweipunktverfahren. Einige enzymatische Reaktionen (z. B. Gerinnungsreaktionen) lassen sich nur erfassen, indem man die Zeit vom Reaktionsstart bis zum vollständigen Ablauf der Reaktion, d. h. der Gleichgewichtseinstellung, misst. Als Sonderfall hierzu sei das Auftreten eines Gerinnsels in Gerinnungsuntersuchungen erwähnt. Man bezeichnet diese Verfahren als Endpunktverfahren. Enzymaktivitätsbestimmungen stel- 
len einen erheblichen Anteil der in einem klinisch-chemischen Labor durchgeführten Untersuchungen dar. Darüber hinaus werden Enzyme in vielen Analyseverfahren z. B. zur Konzentrationsbestimmung von Stoffwechselprodukten wie $>$ Cholesterin, \ Glukose, > Harnstoff etc. eingesetzt.

\section{Literatur}

Heinrich PC, Müller M, Graeve L (Hrsg) (2014) Löffler/Petrides Biochemie und Pathobiochemie, 9. Aufl. Springer, Berlin/Heidelberg/ New York

\section{Enzyme-linked Immunosorbent Assay}

\author{
G. Töpfer
}

\section{Synonym(e) ELISA}

Englischer Begriff enzyme linked immuno sorbent assay

Definition Von Engvall ( $\triangleright$ Engvall, Eva) und Perlman (Engvall und Perlman 1971) wird unter ELISA ein Sandwich-Enzymimmunoassay ( $>$ Sandwich-Assay) verstanden. In neuerer Zeit wird der kompetitive $>$ Enzymimmunoassay mit enzymmarkierten und unmarkierten Immunkomplexen an der festen Phase ebenfalls zum ELISA gezählt.

Physikalisch-chemisches Prinzip In der Erstbeschreibung von Engvall und Perlman (1971) versteht man unter dem „enzyme-linked immunosorbent assay“ heterogene Enzymimmuntests, bei denen an Festphasen immobilisierte Antigene oder Antikörper mit der Untersuchungsflüssigkeit inkubiert werden, wobei bei Anwesenheit des spezifischen Bindungspartners ein Immunkomplex gebildet wird, der nach Entfernung unspezifisch gebundener Bindungspartner (meistens durch Waschen) einen zweiten immunologischen Reaktionspartner, an den ein Enzym gebunden ist (Konjugat), bindet. Beide Reaktionsschritte können auch simultan durchgeführt werden (Einschritt-ELISA). Nach Entfernen von überschüssigem, nicht im Immunkomplex gebundenem Konjugat (Abtrennung normalerweise durch Waschen, in speziellen Fällen auch durch Absorption, Fällung, Immunpräzipitation oder Affinitätsbindung) erfolgt nach Zugabe eines Substrats die Enzym-Substrat-Reaktion, wobei die Farbentwicklung der Konzentration des Analyten direkt proportional ist.

Mit zunehmender Verbreitung der Immunoassays und Einführung zahlreicher Varianten wurde der Begriff ELISA auch auf die Gruppe der kompetitiven Enzymimmunoassays ( $\triangleright$ Immunoassay, kompetitiver) ausgedehnt. Dabei werden einfache Immunkomplexe aus an die Festphase gebundenem Antigen oder Antikörpern und um diesen Bindungspartner konkurrierende Reaktionspartner in der Untersuchungsflüssigkeit gebildet. Ein Reaktionspartner in der Untersuchungsflüssigkeit ist der zu bestimmende Analyt und der andere ein zugesetzter enzymmarkierter gleicher Reaktionspartner. Es wird umso mehr enzymmarkierter Immunkomplex gebildet, je weniger (konkurrierender) Analyt im Untersuchungsmaterial vorliegt. Die immobilisierten Immunkomplexe liegen überwiegend enzymmarkiert (bei niedriger Analytkonzentration) oder überwiegend unmarkiert (bei hoher Analytkonzentration) vor. Die Definition ELISA, die den kompetitiven Enzymimmunoassay einbezieht, wird u. a. von Davies (2005) benutzt.

Einsatzgebiet Bestimmung von Antigenen, Antikörpern und Haptenen (Antigene geringerer Molmasse).

Untersuchungsmaterial - Entnahmebedingungen Serum (Plasma), Liquor, Urin und andere Körperflüssigkeiten.

Instrumentalisierung Geräte mit hohem Automatisierungsgrad bei großen Analyseserien, manuelle Verfahren bei kleinen Analyseserien. Als feste Phase werden u. a. verwendet: Mikrotiterplatte, Röhrchen(wand), Kugel, Magnetpartikel oder Membran.

Spezifität - Fehlermöglichkeit Im Ein-Schritt-Verfahren des Sandwich-Enzymimmunoassays kann bei Antigenüberschuss das Prozonen-Phänomen ( $\triangleright$ High-Dose-Hook-Effekt) stören. Rheumafaktoren der IgM-Klasse erhöhen das Ergebnis bei der Bestimmung von spezifischen IgM, wenn die Probe gleichzeitig spezifisches IgG enthält. Sind spezifisches IgM und spezifisches IgG gleichzeitig vorhanden, so kann durch Konkurrenz der Antikörper das IgM-Ergebnis vermindert werden. Besonders in der Infektionsserologie werden Kreuzreaktionen beobachtet, die das Ergebnis einschränken können. Im Plasma als Untersuchungsmaterial kann das Fibrinogen zu Störungen der Antigen-/Antikörperbindung führen. Beim Nachweis von Autoantikörpern können falsch positive Reaktionen durch Antikörper gegen Blockierungsproteine (Rinderserumalbumin, Kasein, Gelatine u. a.) auftreten. Humane Anti-Maus-Antikörper in der Probe können in Testsystemen mit Maus-Antikörpern stören.

Sensitivität Der Sandwich-Enzymimmunoassay mit Farbdetektion zeigt eine Empfindlichkeit von $10^{-16} \mathrm{~mol} / \mathrm{L}$. Kompetitive Enzymimmunoassays stehen den Sandwich-Enzymimmunoassays nur gering nach. Die Fluoreszenzdetektion erreicht $10^{-18}$, die Chemilumineszenz $10^{-20} \mathrm{~mol} / \mathrm{L}$ (s. Tabelle im Stichwort $>$ Immunoassay).

Praktikabilität - Automatisierung - Kosten Plattenteste (Mikrotiterplatte mit der Möglichkeit zur Bearbeitung einzel- 
ner Kavitäten) für den ELISA mit Farbdetektion sind sowohl manuell als auch automatisiert bearbeitbar. Einzelteste für $>$ Chemolumineszenz-Detektion sind möglich. Labore mit höheren Probendurchsätzen verwenden Analysenautomaten für den ELISA.

Bewertung - Methodenhierarchie (allg.) Bedeutung inzwischen größer als für radioimmunologische Teste, nahezu so groß wie für klinisch chemische Teste. Die Aussage wird durch Kreuzreaktionen und andere Fehlermöglichkeiten (sog. Matrixeffekte), besonders in der Infektionsserologie, teilweise eingeschränkt.

\section{Literatur}

Davies C (2005) Principles. In: Wild D (Hrsg) The immunoassay handbook, 3. Aufl. Elsevier, Amsterdan, S 3-40

Engvall E, Perlman P (1971) Enzyme-linked immunosorbent assay (ELISA). Quantitative assay of immunglobulin G. Immunochemistry 8:871-874

Schößler W, Töpfer G, Rüger HJ (1988) Ein einfacher und schnellerEnzymimmunoassay zur quantitativen Bestimmung des C-reaktiven Proteins. J Clin Chem Clin Biochem 26:75-78

\section{Enzyme-multiplied Immunoassay}

C. Krüger und W. Stöcker

\section{Synonym(e) EMIT}

Englischer Begriff EMIT; enzyme-multiplied immunoassay technique

Definition Homogener Immunoassay zum Nachweis und zur quantitativen Bestimmung von Antigenen mit geringer Molekularmasse (Haptenen), bei dem das enzymmarkierte Reagenzantigen mit dem unmarkierten Antigen der Probe um begrenzt zur Verfügung stehende Antikörperbindungsstellen konkurriert. Dabei ist das enzymmarkierte Antigen in freier Form entweder enzymatisch aktiv und wird nach der Antikörperbindung inaktiviert oder umgekehrt. Als Messsignal dient die Änderung der enzymatischen Aktivität.

Physikalisch-chemisches Prinzip Bei der EMIT wird eine spezielle Art der Enzymmarkierung verwendet. Das Enzym, z. B. Glukose-6-Phosphat-Dehydrogenase, wird in der Nähe seines aktiven Zentrums mit einem Antigen (Hapten) gekoppelt, sodass ein gegen das Antigenmolekül gerichteter Antikörper nach seiner Bindung das katalytische Zentrum des Enzyms blockiert oder hemmt. Ein Substratumsatz ist somit nicht mehr möglich. Nach dem kompetitiven Prinzip konkurrieren das Antigen der Probe und enzymmarkiertes Antigen um eine begrenzte Anzahl Antikörper im Reaktionsansatz. Gemessen wird die im Reaktionsansatz verbleibende Enzymaktivität. Das Messsignal verhält sich direkt proportional zur Antigenkonzentration in der Probe. Bei Verwendung des Enzyms Malatdehydrogenase zur Markierung des Antigens kommt es bei Bindung eines gegen das Antigen gerichteten Antikörpers zu einer Erhöhung der Enzymaktivität, sodass sich das Messsignal hier umgekehrt proportional zur Konzentration des Antigens in der zu bestimmenden Probe verhält.

Einsatzgebiet Nachweis von Antigenen mit kleiner Molekularmasse(Haptenen), wie Medikamenten (z. B. Ciclosporin) und Drogen aus Körperflüssigkeiten (z. B. Amphetamine, Benzodiazepine, Opiate) ( $\triangleright$ Drogenscreening).

Untersuchungsmaterial Serum, Plasma, Urin.

Fehlermöglichkeit Beim Nachweis von Drogen und Medikamenten kann es zu Kreuzreaktionen mit anderen Medikamenten oder auch mit Nahrungsmitteln kommen. Daher müssen entsprechende Angaben berücksichtigt und positive Befunde i. d. R. mittels $>$ Chromatographie-Verfahren ( $\triangleright$ Massenspektrometrie) bestätigt werden.

Praktikabilität - Automatisierung - Kosten Es sind sowohl manuelle als auch automatisierte EMIT verfügbar. Der Aufbau von EMIT zur Bestimmung von Antigenen mit großer Molekularmasse ist schwierig.

Bewertung - Methodenhierarchie (allg.) Ein Vorteil der Methode ist die einfache Durchführung: „Mische und messe“ (engl.: ,mix and read“).

\section{Literatur}

Wild D (2005) The immunoassay handbook, 3. Aufl. Nature Publishing Group, New York, S 185-187

\section{Enzymhalbwertszeiten im Blutkreislauf}

A. M. Gressner und O. A. Gressner

Synonym(e) Halbwertszeiten von Enzymen

Englischer Begriff half-life time of enzymes in the circulation 
Definition - Halbwertszeit der Enzyme in der Zirkulation beschreiben die Zeitspanne, die vergeht, um 50 \% der Enzymaktivität aus der Zirkulation zu eliminieren.

Beschreibung Bei Austritt von intrazellulären Enzymen in den Extrazellulärraum kommt es zu zwei, zeitlich abgesetzten Veränderungen der Enzymaktivität:

- Soforteffekt, der in einer Verminderung oder Zunahme der Enzymaktivität aufgrund der Veränderung des Enzymmoleküls in einem fremden Milieu sowie auf eine Verteilung des Enzyms auf den gesamten Extrazellulärraum (intravasal, interstitiell, lymphatisch) zurückzuführen ist. Im Allgemeinen führt der Soforteffekt zu einem primären, schnellen Abfall der Enzymaktivität.

- Phase der Enzymelimination, die eine langsame Abnahme der Enzymaktivität im Plasma darstellt, wobei die Eliminationsgeschwindigkeit unabhängig vom absoluten Wert der Enzymaktivität ist und einer Exponentialfunktion folgt. Die Halbwertszeiten im Plasma sind spezifische Merkmale der jeweiligen Enzyme (s. Tabelle). Spezielle Eliminationsorgane gibt es nicht, jedoch haben Leber, Niere, Lungen und Gastrointestinaltrakt entscheidende Bedeutung. Hervorzuheben ist die weitgehende Konstanz der Eliminationsgeschwindigkeit auch unter pathologischen Bedingungen, was bedeutet, dass die Enzymaktivität im Blut unter Krankheitsbedingungen maßgeblich vom Einstrom und weniger von der Eliminationsrate beeinflusst wird. Dies stellt eine wesentliche Grundlage der labormedizinischen Enzymdiagnostik und klinischen Enzymologie dar.

Halbwertszeiten (Mittelwerte) von Enzymen im Blutkreislauf (Angaben entsprechen tierexperimentellen Befunden):

\begin{tabular}{|l|l|}
\hline Enzym & Halbwertszeit (h) \\
\hline Alanin-Aminotransaminase (ALT, GPT) & 47 \\
\hline Aldolase & 21 \\
\hline Alkalische Phosphatase (AP) & 144 \\
Leber-AP & 52 \\
Plazenta-AP & 168 \\
Knochen-AP & 168 \\
\hline Amylase & $3-6$ \\
\hline Aspartat-Aminotransaminase (AST, GOT) & 17 \\
Creatinkinase (CK) & 15 \\
CK-MM & 17 \\
CK-MB & 12 \\
CK-BB & 5 \\
\hline$\gamma$-Glutamyltransferase ( $\gamma$-GT) & $72-96$ \\
Glutamat-Dehydrogenase (GLDH) & 18 \\
\hline Laktat-Dehydrogenase (LDH) & 116 \\
LDH1 ( $\alpha$-HBDH) & 113 \\
LDH5 & 10 \\
\hline Leuzin-Arylamidase (LAP) & 209 \\
\hline Lipase & $3-6$ \\
& \\
\hline
\end{tabular}

\begin{tabular}{|l|l|}
\hline Enzym & Halbwertszeit (h) \\
\hline Malatdehydrogenase (MDH) & 16 \\
\hline Pseudocholinesterase (PCHE) & 240 \\
\hline Saure Phosphatase (SP) & 4
\end{tabular}

\section{Literatur}

Schmidt E, Schmidt FW (1981) Kleine Enzym-Fibel. Boehringer $\mathrm{GmbH}$, Mannheim

Wissenschaftliche Tabellen Geigy (1979), 8. Aufl. Ciba-Geigy, Basel

\section{Enzymimmunoassay}

W. Stöcker

Synonym(e) EIA; Enzymimmuntest

Englischer Begriff Enzyme immunoassay

Definition Immuntest für die quantitative Bestimmung von Antigenen oder Antikörpern, bei dem Enzyme zur Markierung immunologischer Reaktionspartner eingesetzt werden. Die Enzyme katalysieren eine von der Konzentration des Messparameters der Probe abhängige Reaktion, die visuell erfasst oder durch Fotometrie, Fluorometrie, Luminometrie oder andere Detektionsmethoden quantifiziert wird. Zur Markierung bevorzugte Enzyme sind Meerrettichperoxidase, alkalische Phosphatase und Glukose-6-Phosphat-Dehydrogenase.

Physikalisch-chemisches Prinzip Enzymimmunoassays teilen sich in 2 große Kategorien auf: die heterogenen Assays, bei denen eine physikalische Phasentrennung obligat ist und der gebundene oder ungebundene markierte Reaktionspartner gemessen wird, sowie die homogenen Assays, bei denen keine Phasentrennung erforderlich ist und der freie Anteil des markierten Reaktionspartners in Gegenwart des gebundenen Reaktionspartners gemessen wird oder umgekehrt.

Eine andere Klassifizierung unterscheidet kompetitive Assays ( $\triangleright$ Immunoassay, kompetitiver), bei denen 2 Reaktionspartner (einer von ihnen die zu bestimmende Substanz) simultan oder nacheinander um einen dritten konkurrieren, und nicht kompetitive Assays ( $\triangleright$ Sandwich-Assay), bei denen die zu bestimmende Substanz von 2 Reaktionspartnern umfangen wird. Die Bindung an beide Reaktionspartner kann simultan (Einschrittassay) oder in 2 Schritten erfolgen.

Ferner werden Assays zum Antigen- von Assays zum Antikörpernachweis unterschieden. 
Heterogene Enzymimmunoassays sind meistens als Festphasentests aufgebaut. Eine Komponente der Immunreaktion, Antigen oder Antikörper, ist an einen Träger fixiert: Röhrchenwand, Kugel, Magnetpartikel, Mikrotiterplatte oder Membran. Der heterogene EIA beinhaltet mindestens 2 Arbeitsschritte: Der Antigen-Antikörper-Reaktion folgt die Enzym-Substrat-Reaktion. Klassische Form des Festphasentests ist der Enzyme-linked Immunosorbent Assay (ELISA). Darüber hinaus kommen Chemilumineszenz-Immunoassays (CLIA) zum Einsatz, die u. a. auf magnetischen Beads als Festphase basieren. Die unmittelbare Nähe zwischen den mit Antigen beschichteten Beads und den Antikörper in der Lösung führt zu schnelleren Bindungsreaktionen und damit zu verkürzten Inkubationszeiten; weitere Vorteile sind eine hohe Sensitivität und ein erweiterter Messbereich im Vergleich zum ELISA. Bei heterogenen Flüssigphasenassays werden gebildete Immunkomplexe von den ungebundenen Komponenten durch Adsorption, Fällung, Immunpräzipitation oder Affinitätsbindung abgetrennt. Heterogene Enzymimmuntests eignen sich zur Bestimmung von Substanzen mit sowohl niedriger (Haptene) als auch höherer Molekularmasse (Antigene, Antikörper). Das Messsignal ist bei diesen Assays direkt proportional zur Konzentration des zu bestimmenden Antigens oder Antikörpers.

Bei den heterogenen, kompetitiven Enzymimmunoassays konkurriert das Antigen der Probe mit einer definierten Menge markierten Antigens um die Bindungsstellen eines im Unterschuss vorliegenden spezifischen Antikörpers, der an eine feste Phase gekoppelt ist. Während der Inkubation stellt sich ein Gleichgewicht zwischen markiertem und nicht markiertem Antigen ein. Je mehr natürliches Antigen die Probe aufweist, umso weniger markiertes Antigen wird gebunden. Bei einer weiteren kompetitiven Methode konkurrieren Festphase-gebundenes Antigen und Antigen der Probe um einen markierten Antikörper. Je weniger Antigen die zu untersuchende Probe enthält, umso mehr markierte Antikörper binden sich an das Festphase-fixierte Antigen (immunenzymometrischer Test). Auch in diesem Fall ist das Messsignal umgekehrt proportional zur Antigenkonzentration in der Probe.

Heterogene, nicht kompetitive Enzymimmunoassays werden auch als Sandwich-Enzymimmunoassays bezeichnet. Die wichtigste Form ist der ELISA, eine Sonderform der Capture-Assays: Hier wird das zu messende Antigen ( $\triangleright$ Antigen Capture Assay) oder der zu bestimmende Antikörper ( $\triangleright$ Antibody Capture Assay) der Probe zwischen 2 Antikörpern bzw. 2 Antigenen gebunden. Zur Antigenbestimmung wird das Antigen der Probe in einem ersten Inkubationsschritt mit einem an der festen Phase fixierten (Capture-)Antikörper zur Reaktion gebracht. Anschließend werden die ungebundenen Anteile der Probe mit einem Waschschritt entfernt. Je höher die Antigenkonzentration der Probe ist, umso mehr Antigen kann gebunden werden.
Im nächsten Schritt reagieren die enzymmarkierten Antikörper mit den Immunkomplexen an der festen Phase, und nach Beendigung der Reaktionszeit wird überschüssiger Marker mit einem Waschschritt entfernt.

Beim Einschrittassay werden die maßgeblichen Reaktanden simultan inkubiert - entweder die Antigenprobe zusammen mit den enzymmarkierten Antikörpern und den Festphase-fixierten Antikörpern oder der zu bestimmende Antikörper mit den markierten Antikörpern und dem an die feste Phase fixierten Antigen. Anschließend werden ungebundene Anteile der Probe weggewaschen, und man lässt die Enzymkatalysierte Farbreaktion ablaufen.

Es existiert eine Vielfalt von Varianten nicht kompetitiver Enzymimmunoassays: Beim $\mu$-Capture-Assay wird speziesspezifisches IgG, das gegen den Fc-Teil des IgM gerichtet ist, an die feste Phase gekoppelt. Hier verankert sich das IgM der Probe. Davon binden die Antigen-spezifischen IgM-Moleküle zugesetztes korrespondierendes Antigen. Zur Messung der gebundenen Antigenmenge wird ein gegen das Antigen gerichteter, enzymmarkierter IgG-Antikörper hinzugegeben, danach wird gewaschen, und man lässt die Farbreaktion ablaufen (das Antigen kann auch direkt markiert werden, ein Inkubationsschritt wird gespart). Vorteile des $\mu$-CaptureAssay: geringere Antigenabschwächung im Vergleich zur direkten Antigen-Bindung an die Festphase, keine Störung durch Rheumafaktoren. Nachteil: Für jeden Parameter ist ein spezielles Markierungsreagenz erforderlich, man kann nicht mehrere Analyte im selben Tropfen untersuchen.

Homogene Enzymimmunoassays erfordern keine Phasentrennung, alle Komponenten der Immun- und Substratreaktion sind in Lösung. Bei EMIT ( $\triangleright$ Enzyme-multiplied Immunoassay) konkurriert das enzymmarkierte Reagenzantigen mit dem unmarkierten Antigen der Probe um begrenzt zur Verfügung stehende Antikörperbindungsstellen. Dabei ist das enzymmarkierte Antigen in freier Form entweder enzymatisch aktiv und wird nach Antikörperbindung inaktiviert oder umgekehrt. Als Messsignal dient die Änderung der enzymatischen Aktivität. Das Messsignal verhält sich hier proportional oder umgekehrt proportional zur Konzentration des Antigens in der Probe. Beim Inhibitor-labelled EIA ist das Antigen an den Inhibitor eines Enzyms gekoppelt. Antikörper gegen das Antigen blockieren den Inhibitor, sodass dieser den Substratumsatz des Enzyms nicht hemmen kann. Zugabe des Antigens (Probe) entfernt den korrespondierenden Antikörper vom Inhibitor, der nun den Substratumsatz des Enzyms hemmt. Das Messsignal verhält sich hier umgekehrt proportional zur Konzentration des Antigens in der Probe. Bestimmt werden können mit diesen EIA-Techniken vorwiegend Antigene mit niedriger Molekularmasse (Haptene). Bei den immunchromatographischen EIA ist der spezifische Antikörper für das zu bestimmende Antigen an eine feste Phase, z. B. Celluloseacetatfolie, gebunden. Werden die antigenhaltige Probe und das enzymmarkierte Antigen auf die Folie getropft, konkurrieren beide um die begrenzte Anzahl 
immobilisierter Antikörper und binden sich an diese. Der ungebundene Anteil enzymmarkierten Antigens wandert aus der Reaktionszone, und seine katalytische Aktivität wird durch Substratzugabe bestimmt. Sie ist direkt proportional zur Antigenkonzentration der Probe. Diese Technik gestattet vor allem die Bestimmung von Antigenen mit großem Molekulargewicht.

Einsatzgebiet Antigen- und Antikörperbestimmung.

Instrumentierung Aufgrund der Vielfalt der Enzymimmunoassay-Systeme existieren die unterschiedlichsten Geräte zur manuellen und automatisierten Durchführung.

Sensitivität Die analytische Sensitivität von Enzymimmunoassays mit Farbdetektion liegt bei $10^{-16} \mathrm{~mol} / \mathrm{L}$, mit $>$ Fluoreszenz-Detektion bei $10^{-18} \mathrm{~mol} / \mathrm{L}$ und mit $\triangleright$ Chemolumineszenz bei $10^{-20} \mathrm{~mol} / \mathrm{L}$.

Fehlermöglichkeit Ein Störfaktor, der zu einer starken Verfälschung der Messwerte führen kann, ist bei SandwichEnzymimmunoassays, die nach dem immunometrischen Prinzip der Einschrittinkubation funktionieren, der $>$ HighDose-Hook-Effekt (Prozonen-Phänomen). Falsch positive Resultate werden darüber hinaus durch $\triangleright$ Rheumafaktoren der Klasse IgM in Sandwich-Enzymimmunoassays zum Nachweis spezifischer IgM-Antikörper verursacht, wenn die zu untersuchende Probe auch spezifische IgG-Antikörper enthält; falsch zu niedrige IgM-Werte können durch konkurrierendes spezifisches $\mathrm{IgG}$ entstehen.

Praktikabilität - Automatisierung-Kosten Enzymimmunoassays können manuell und automatisiert durchgeführt werden.

\section{Literatur}

Deshpande SS (1996) Enzyme immunoassays: from concept to product development. Chapman \& Hall, New York, S 231-273

Wild D (2005) The immunoassay handbook, 3. Aufl. Nature Publishing Group, New York, S 3-39

\section{Enzymimmuntest}

$>$ Enzymimmunoassay

\section{Enzyminduktion}

C. Vidal und W.-R. Külpmann

Englischer Begriff enzyme induction
Definition Prozess, der zu einer Zunahme von Enzymen (-aktivitäten) führt.

Beschreibung Enzyminduktion (EI) wird häufig im Laufe der Dauermedikation von bestimmten Pharmaka, z. B. Phenobarbital, Phenytoin, Rifampicin, beobachtet. Die EI bewirkt in der Regel einen beschleunigten Abbau des auslösenden Pharmakons, aber auch häufig anderer Pharmaka oder auch körpereigener Substanzen. Sie ist wesentlich an der Entwicklung der Toleranz beteiligt.

\section{Enzymkonzentration, katalytische}

- Enzymaktivität

\section{Enzymmarker der Cholestase}

$>$ Cholestase-anzeigende Enzyme

\section{Enzymtest}

K. Kleesiek, C. Götting, J. Diekmann, J. Dreier und M. Schmidt

Synonym(e) Bromelintest; Ficintest; Papaintest; Proteolytischer Enzymtest

Englischer Begriff proteolytic enzyme test

Definition Der Enzymtest ist eine Technik, die in der immunhämatologischen Diagnostik eingesetzt wird, um Antigen-Antikörper-Reaktionen auf Erythrozyten zu verstärken.

Beschreibung Der Enzymtest ist in seltenen Fällen die einzige Technik, mit der Antigen-Antikörper-Reaktionen erfolgreich nachweisbar sind (z. B. bei einigen Autoantikörpern). In anderen Fällen können durch proteolytische Vorbehandlung der Erythrozyten bestimmte Antigene ganz oder teilweise zerstört werden, sodass die Reaktionen mit spezifischen Antikörpern deutlich abgeschwächt sind oder negativ ausfallen (z. B. > Duffy-(FY-)Blutgruppensystem, > MNS-Blutgruppensystem).

Das Prinzip des Enzymtests liegt in dem proteolytischen Abbau von (Strukturen von) Proteinen bzw. Glykoproteinen von der erythrozytären Membran. Viele dieser Glykoproteine enthalten Zuckerketten mit endständig negativ geladenen Neuraminsäuregruppen, die für die negative Ladung der Ery- 
throzytenoberfläche verantwortlich sind. Die Enzymbehandlung reduziert die negativen Ladungsträger und verkürzt die Distanz zwischen den einzelnen Erythrozyten. Antikörper der Immunglobulinklasse IgG können die Distanz nach Enzymbehandlung zwischen den Erythrozyten überbrücken. Die für den Enzymtest eingesetzten Enzyme (Papain, Bromelin, Ficin) gehören zur Familie der Cystein-Endopeptidasen (Cystein-Proteinase). Der Enzymtest kann insbesondere sehr erfolgreich eingesetzt werden, um Rhesus- ( $\triangleright$ RhesusBlutgruppensystem), Kidd- ( $>$ Kidd-Blutgruppensystem) und Lewis-Antikörper ( $\triangleright$ Lewis-(Le-)Blutgruppensystem) nachzuweisen. Insgesamt stellt der Enzymtest eine sinnvolle Ergänzungstechnik im Rahmen eines Antikörpersuchtests oder einer Antikörperdifferenzierung dar.

Die Testdurchführung kann mit den in der immunhämatologischen Diagnostik üblichen Testsystemen wie

- $>$ Säulenagglutinations-Test,

- $>$ Röhrchentest und

- Mikrotiterplattentest (s. > Mikrotiterplatte) erfolgen.

\section{Literatur}

Engelfried CP, Meulenbroek AJ (Hrsg) (2003) Immunohaematology. Sanquin Blood Supply Foundation, Amsterdam

Klein HG, Anstee DJ (2005) Mollison's blood transfusion in clinical medicine, 11. Aufl. A revision of the 10th ed. written by Mollison PL, Engelfriet CP, Contreras M. Blackwell Publishing, Oxford

Mueller-Eckhardt C, Kiefel V (Hrsg) (2004) Transfusionsmedizin: Grundlagen - Therapie - Methodik, 3. Aufl. Springer, Berlin/Heidelberg/New York

\section{Eosin-Methylenblau-Lösung nach May-} Grünwald

> May-Grünwald-Lösung

\section{Eosinophile}

- Granulozyten, eosinophile

\section{Eosinophiles kationisches Protein}

H. Renz und B. Gierten

Synonym(e) ECP; RNase 3

Englischer Begriff eosinophil cationic protein
Definition RNase, die aus den Granula aktivierter eosinophiler Granulozyten ausgeschüttet wird.

Struktur Einkettiges, stark negativ geladenes Protein, nachweisbar in drei unterschiedlich stark glykosylierten Formen.

Molmasse Isoformen: 18,5 kDa, $20 \mathrm{kDa}, 22 \mathrm{kDa}$.

Untersuchungsmaterial - Entnahmebedingungen Serum, andere Körperflüssigkeiten, bronchoalveoläre Lavage.

Präanalytik Verwendung von Plasma und hämolytischen Proben nicht möglich.

Da die Konzentration an freigesetztem ECP vom Material des Blutentnahmesystems, Gerinnungszeit und Temperatur abhängig ist, sind folgende Bedingungen einzuhalten:

- Entnahme in Kunststoffröhrchen,

- nach Entnahme das Röhrchen 5-mal schwenken und 60-120 min bei Zimmertemperatur gerinnen lassen,

- Zentrifugation bei 1000-1300 g für $10 \mathrm{~min}$,

- Serum zur Lagerung in Sekundärröhrchen dekantieren.

Analytik Enzymimmunoassay.

Konventionelle Einheit $\mu \mathrm{g} / \mathrm{L}$.

Internationale Einheit $\mu \mathrm{g} / \mathrm{L}$.

Referenzbereich - Erwachsene $<11,3 \mu \mathrm{g} / \mathrm{L}$.

Referenzbereich - Kinder $<11,3 \mu \mathrm{g} / \mathrm{L}$.

Indikation Aktivierung eosinophiler Granulozyten im Rahmen von

- allergischen Reaktionen (bes. Asthma bronchiale, NSAIDinduziertes Asthma),

- atopischen Erkrankungen,

- inflammatorischen Prozessen nach Ozonexposition und

- Frühdiagnostik von Vaskulitiden der kleinen Gefäße (bes. Churg-Strauss-Syndrom).

Interpretation ECP wird durch Aktivierung eosinophiler Granulozyten ( $\triangleright$ Granulozyten, eosinophile) freigesetzt und ist somit ein Parameter zur Darstellung dieses Vorgangs. Aussagen über den Zustand des Erfolgsorgans (Lunge, Haut u. a.) sind nur begrenzt möglich, da die zelluläre Aktivierung diesem vorausgehen oder hinterherhinken kann.

Die Konzentration des ECP korreliert nicht mit der Anzahl der eosinophilen Granulozyten im peripheren Blut. 
Diagnostische Wertigkeit ECP-Konzentrationen sind starken interindividuellen Schwankungen unterworfen und dadurch als Einzelwert kaum zu interpretieren. Intraindividuell schwankt der Wert jedoch gering, sodass er sich gut zur Verlaufsbeobachtung bekannter Erkrankungen eignet. Ermöglicht wird dadurch ein Aktivitäts- und Therapiemonitoring an selektionierten Patienten.

ECP stellt einen Aktivierungsmarker für eosinophile Granulozyten dar, er korreliert nicht natürlicherweise mit der Anzahl der Zellen.

\section{Literatur}

Friedman RB, Young DS (1997) Effects of disease in clinical laboratory tests, 2. Aufl. AACC Press, Washington DC

Venge $P$ et al (1993) Serum measurements of eosinophil cationic protein (ECP) in bronchial asthma. Clin Exp Allergy 23(Suppl):3-7

\section{EPCR}

Endothel-Protein-C-Rezeptor

\section{Ephedrin}

Alkaloide

\section{Epibolin}

$\checkmark$ Vitronectin

\section{Epidermale Basalmembran-Antikörper}

- Autoantikörper gegen epidermale Basalmembran

\section{Epigenetik}

J. Arnemann

Synonym(e) Erbliche Genmodifikationen

Englischer Begriff epigenetic

Definition Mit Epigenetik bezeichnet man vererbbare genetische Veränderungen, die nicht durch Änderungen in der Nukleotidabfolge verursacht werden, sondern beispielsweise durch Modifikationen der Nukleotide, der Histone oder der Chromosomen aufgrund externer Faktoren.

Beschreibung Das wissenschaftliche Interesse am Gebiet der Epigenetik hat in den vergangenen Jahren stark zugenommen. Im Vordergrund steht die Frage, welche Faktoren, die nicht eine Änderung der Nukleotidsequenz betreffen, die Aktivität und Expression eines Gens so verändern, dass es einem scheinbar erblichen Mechanismus folgt. Häufig genannte Beispiele sind z. B. die zelluläre Differenzierung von totipotenten Stammzellen über pluripotente Zelllinien hin zu ausdifferenzierten, organspezifischen Zellen. Die Modulation der Genaktivität, sowohl Inaktivierung als auch Aktivierung, wird erreicht durch eine Modifikation der Mikrostruktur der Gene oder der Chromatinproteine, wie z. B. DNAMethylierung oder Histonmodifikation. Diese Prozesse können durch äußere Einflüsse wie Nahrung, Lifestyle oder Umwelt in einem gewissen Grad beeinflusst werden und führen zu einem individuenspezifischen Muster, das an die Nachkommen über die sog. epigenetische Transgenerationenvererbung weitergegeben werden kann.

Durch diese Mechanismen können auch Prozesse wie X-Inaktivierung oder veränderte Expressionsmuster als sog. Positionseffekte bei chromosomalen Translokalisationen erklärt werden.

Ein anderes Beispiel ist der genomische Imprint, bei dem Gene bereits in der elterlichen Keimbahn eine Modifikation, sog. Imprint, erhalten und gemäß der parentalen Herkunft ab dem Zygotenstadium entweder exprimiert oder inhibiert werden. Mutationen dieses Imprintmusters können beim Menschen zu genetischen Syndromen, wie z. B. Prader-Willi- oder Angelman-Syndrom führen.

Die wichtigsten epigenetischen Mechanismen sind somit die in Wechselwirkung stehenden Prozesse DNA-Methylierung, vor allem Cytosin zu Methylcytosin, und Histonmodifikation, die eine kompakte oder offene Chromatinkonstellation bedingen und u. U. zu einer veränderten Nukleosompositionierung mit daraus folgender veränderter Genexpression führen.

\section{Literatur}

Alberts et al (2015) Molecular biology of the cell, 6. Aufl. Garland Science, New York

\section{Epimere}

T. Arndt

Synonym(e) Epimerisierung

Englischer Begriff epimer 
Definition Begriff aus der Stereochemie, der auf Verbindungen (Diastereomere) angewandt wird, die sich in der Konfiguration von lediglich einem (von oft mehreren) asymmetrischen C-Atom(en) unterscheiden.

Beschreibung Zunächst wurde der Begriff zur Bezeichnung epimerer Zuckerverbindungen angewandt, heute allgemeiner auch auf andere Verbindungen, die o. g. Definition entsprechen. Unter Epimerisierung versteht man die spontane oder katalysierte Konformationsänderung an einem asymmetrischen C-Atom.

In der Klinischen Chemie erlangten Epimere jüngst erhöhte Aufmerksamkeit durch den Nachweis epimerer 25-Hydroxy-Vitamin-D3-Verbindungen (25-Hydroxy-Vitamin D3 und 3-epi-25-Hydroxy-Vitamin D3). Diese verfügen über jeweils 5 asymmetrische Zentren, unterscheiden sich aber nur in der sterischen Stellung der am C-Atom 3 gebundenen Hydroxylgruppe (in die Ebene hineingehend = 25-HydroxyVitamin D3, aus der Ebene herausragend = 3-epi-25-HydroxyVitamin D3). Siehe auch $\triangleright$ Vitamin D.

\section{Literatur}

Cashman KD et al (2014) The 3 epimer of 25-hydroxycholecalciferol is present in the circulation of the majority of adults in a nationally representative sample and has endogenous origins. J Nutr 144:1050-1057

Falb J, Regitz M (Hrsg) (1990) Römpp Chemie Lexikon Band 2 (Cm-G), 9. Aufl. Thieme, Stuttgart/New York

\section{Epimerisierung}

$>$ Epimere

\section{Epinephrin}

- Katecholamine

\section{Epi proLung BL reflex assay}

- SHOX2-Test

\section{Epitop}

H. Renz und B. Gierten

\section{Englischer Begriff epitop}

Definition Oberflächenanteile eines Antigens, die eine spezifische Immunantwort auslösen.

Beschreibung Als Epitope bezeichnet man antigene Determinanten in einem Molekül. Sie interagieren mit den variablen Regionen (Paratope) der Mitglieder aus der Immunglobulinsuperfamilie, wie Immunglobulinen und T-Zell-Rezeptoren. Bindungen zwischen Epitop und Paratop bestehen aus $>$ Vander-Waals-Kräften, $>$ Wasserstoffbrückenbindungen und/oder Ionenbindungen. Ein einziges Antigen kann viele Epitope enthalten, die wiederum jedes einzeln die Bildung von Immunglobulinen anregen können.

Ein einzelnes Epitop besteht gewöhnlich aus 6 Aminosäuren oder Monosacchariden. Die Anordnung der Moleküle kann linear, also der Proteinprimärstruktur entsprechend sein (lineares Epitop) oder erst durch Faltung der Molekülkette, etwa im Sinne von Sekundär-, Tertiär- oder Quartärstruktur, entstehen (Konformationsepitop). Konformationsepitope sind meist nur auf nativen Proteinen erhalten, da hier die Faltungen der Molekülketten unverändert sind.

B-Zell-Epitope, also solche Epitope, die von Immunglobulinen erkannt werden, sind in der Regel Konformationsepitope. T-Zell-Epitope dagegen sind lineare Peptide, die in der Bindungsgrube des $>$ Major Histocompatibility ComplexMoleküls gehalten werden und dem T-Zell-Rezeptor präsentiert werden.

Epitope, die besonders starke Immunantworten auslösen, werden als immundominante Epitope bezeichnet.

\section{Literatur}

Cruise JM, Lewis RE (1999) Atlas of immunology. Springer, Berlin/ Heidelberg/New York

\section{EPO}

- Erythropoetin

\section{Eponyme in Klinischer Chemie und Laboratoriumsmedizin}

A. M. Gressner und O. A. Gressner

Synonym(e) Personen- oder ortsnamenbezogene Begriffe

Englischer Begriff eponyms 
Definition Mit Personennamen oder (seltener) mit Ortsnamen belegte Begriffe, hier beschränkt auf die im Gebiet von Klinischer Chemie und Laboratoriumsmedizin gebräuchlichen namensgebenden Sachbegriffe. Aktuell sind über 10.000 medizinische Eponyme bekannt und im Internet verfügbar (http://www.whonamedit.com).

Beschreibung Eponyme in Laboratoriumsmedizin und Klinischer Chemie sind die von Personennamen oder gelegentlich Ortsnamen sich herleitenden Bezeichnungen, die überwiegend auf Erstbeschreiber, Entdecker, Entwickler oder Erfinder labordiagnostisch relevanter Verfahren und Beobachtungen im weiteren Sinne beruhen. Die so definierten Eponyme lassen sich in folgende, nicht streng getrennte Kategorien unterteilen:

- Analytische Methoden und Reaktionen, Phänomene, naturwissenschaftliche Gesetzmäßigkeiten/Regeln/Prinzipien $(\triangleright$ Addis-Count, $\triangleright$ Amadori-Reaktion, $\triangleright$ BatemanFunktion, \& Berlinerblau-Reaktion, $>$ Berthelot-Reaktion, - Bratton-Marshall-Reaktion, Clarke und Freeman $>$ Immunelektrophorese, zweidimensionale nach Clarke und Freeman, Coombs-Test, \C Coulometrie, \ Donath-Landsteiner-Test, > Dost-Prinzip, Ehrlich-Reaktion s. \ DiazoReaktion, Erlenmeyer-Kolben s. > Messvorrichtungen, volumetrische, Faraday-Tyndall-Effekt s. \ Tyndall-Phänomen, $>$ Fenton-Reaktion, Fibrinogenbestimmung nach Claus s. $>$ Fibrinogen, Fibrinogenbestimmung nach Ratnoff-Menzie s. > Fibrinogen, $>$ Folin-Ciocalteu-Methode, > Forrest-Reaktion, > Fujiwara-Reaktion, Giemsa-Bandenfärbung, Grabar und Williams s. \ Immunelektrophorese, eindimensionale nach Grabar und Williams, HardyWeinberg-Gleichgewicht, $>$ Heidelberger-Kurve, HemkerThrombinbildungspotenzial s. - Endogenes Thrombinbildungspotenzial, Hitzefibrinogenbestimmung nach Schulz s. > Fibrinogen, \ Jaffe-Reaktion, JendrassikGrof-Methode s. > Bilirubin, Kageyama-Reaktion s. > Harnsäure, > Kjeldahl-Methode, Koller-Häkchen-Methode s. > Koagulometer, Laurell-Technik, > LambertBeer-Gesetz, \ Landsteiner Regel, Mancini-Heremans s. - Immundiffusion, radiale nach Mancini, Carbonara und Heremans, > Mie-Streuung, > Nylander-Test, OuchterlonyImmunodiffusion s. > Immundiffusion, doppelte radiale, Oudin s. \ Immundiffusion, lineare nach Oudin, Pasteurisieren, $>$ Peltier-Effekt, Ratnoff-Menzie-Methode s. \ Fibrinogen, > Rayleigh-Debye-Streuung, > Rayleigh-Streuung, - Sandell-Kolthoff-Reaktion, > Sanger-Sequenzierung, Sayk-Sedimentationskammer für Liquorzellen s. > LiquorSedimentierkammer-Verfahren, Snellius-Brechungsgesetz s. $\checkmark$ Refraktion, Southern-Blot-Analyse, > StansfeldWebb-Methode, \ Thrombozytenzählung nach Fonio, Trinder-Reaktion s. > Harnsäure, Turnbullsblau s. > Berlinerblau-Reaktion, \ Tyndall-Phänomen, Van-de-Kamer-
Methode s. > Stuhlfett, > Van-der-Waals-Kräfte, > Widmark-Verfahren der Alkoholbestimmung, \ Zeeman-Effekt, - Zeeman-Kompensation, > Ziehl-Neelsen-Färbung)

- Instrumentelle Entwicklungen (Clark-Elektrode s. > Sauerstoffpartialdruck, \Coulter-Prinzip der Zellzählung, Eppendorf-Pipette s. > Messvorrichtungen, volumetrische, > Liquor-Fuchs-Rosenthal-Zählkammer, > Nernst-Stift, Nissl- Röhrchen s. > Fibrinogen, \ Quincke-Schliff, Schilling-Zählkammer s. D Erythrozytenzählung und > Leukozytenzählung, Schnitger-Gross-Methode s. > Koagulometer, \ Sprotte-Nadel, Thoma-Zählkammer s. \ Erythrozytenzählung und > Thrombozytenzählung, UlbrichtKugel s. > Reflexionsspektrometrie)

- Definierte Reagenzlösungen $(\triangleright$ Drabkin-Lösung, $\triangleright$ Fullererde, \ Giemsa-Lösung, \ Gomori-Färbung, \ Hayem-Lösung, Lloyd's Reagenz s. \ Fullererde, \ May-GrünwaldLösung, > Pappenheim-Färbung, > Ponceaurot-Färbung, > Sudan-Schwarz, > Türk-Lösung)

- Abgeleitete Algorithmen, Formeln, Indices, Isoenzyme, Scores und Quotienten ( $\triangleright$ Child-Turcotte-Pugh-Score, $\checkmark$ Cockroft-Gault-Formel, Colombi-Index, DelpechLichtblau-Index s. > IgM-Index, $>$ IgG-Index, $>$ IgAIndex, > De-Ritis-Quotient, > Donnan-Gleichgewicht, > Fischer-Quotient, $>$ Forns-Index, > Fredrickson-Klassifikation, Friedewald-Formel, Gerlach-Quotient s. > Laktatdehydrogenase/Aspartataminotransaminase-Quotient, Huber-Herklotz-Formel, \Kasahara-Isoenzym, - Mentzer-Index, Michaelis-Menten-Konstante, NagaoIsoenzym s. > Phosphatase, alkalische, > NernstGleichung, > Price-Jones-Kurve, Regan-Isoenzym s. - Phosphatase, alkalische, Reiber-Diagramm, ReiberFelgenhauer-Formeln, Reiber-Schema s. > Immunglobulinbestimmung, intrathekal empirisch, Rosner-Index s. - Kaolin Clotting Time, Schmidt-Quotient s. > Transaminasen-GLDH-Quotient, Schuller-Sagar-IgG-Formel, - Schwartz-Formel, > Shine- und Lal-Index, SiggardAndersen-Nomogramm, \ Szasz-Quotient, > Szent-Györgyi-Quotient, > Watson-Formel, > Widmark-Formel)

- Dimensionen/Einheiten ( $\vee$ Becquerel, Henri, $\triangleright$ BethesdaEinheiten, Curie, Marie, Dalton, Morgan-Einheit, - Svedberg-Einheit)

- Krankheitserreger (Bakterien, Viren, Parasiten, Strahlungen) ( $\vee$ Bartonella, $\triangleright$ Bordetella pertussis und parapertussis, > Borrelia burgdorferi, > Brucella sp., > Dane-Partikel, > Döderlein'sche Stäbchen, \ Epstein-Barr-Viren, \ Klebsiella pneumoniae, $\triangleright$ Listeria monocytogenes, $>$ RiftValley-Fieber-Viren, > Toxoplasma gondii, > Yersinia enterocolitica u. a.)

- Diagnostische morphologische, quantitative und qualitative Kenngrößen ( $\vee$ Alder-Granulationsanomalie, \ Apt-Test, - Auer-Stäbchen, > Australia-Antigen, Barr-Körperchen, - Bence-Jones-Protein, > Bennett-Goodspeed-Antigen, Beutler-Test s. \ Galaktose-1-Phosphat-Uridyltransferase, 
$>$ Bial-Probe, $>$ Bombay-Phänotyp, $>$ Cabot-Ringe, $>$ Charcot-Leyden-Kristalle, $>$ Chido/Rodgers-Blutgruppensystem, Christmas-Faktor s. Gerinnungsfaktor IX, - Colton-Blutgruppensystem, Cromer-Blutgruppensystem, Curschmann-Spiralen, Diego-(DI-)Blutgruppensystem, $>$ Dittrich-Pfröpfe, $>$ Dombrock-(DO-) Blutgruppensystem, Donath-Landsteiner-Antikörper, > Döhle-Körperchen, > Duffy-(FY-)Blutgruppensystem, $>$ Ehrlich-Probe, $>$ Esbach-Probe, $>$ Fehling-Probe, Fitzgerald-Faktor s. > High-Molecular-Weight Kininogen, Fletcher-Faktor s. \ Präkallikrein, \ Fouchet-Test, > Gaucher-Zelle, > Gerbich-(GE-)Blutgruppensystem, > GmelinProbe, Gram-Färbung, \Griess-Test, > GumprechtKernschatten, Guthrie-Test s. > Phenylbrenztraubensäure im Urin, Hagemann Faktor s. Gerinnungsfaktor XII, $>$ Heinz-Innenkörper, > Heitzmann-Hämatoblasten, > Heller-Ringprobe, Heremanns-Schmid-Glykoprotein s. $>\alpha_{2}$-HS-Glykoprotein, $>$ Hodgkin-Zelle, $>$ Hoesch-Test, > Howell-Jolly-Körper, Kasahara-Isoenzym, > KellBlutgruppensystem, Kendall's compound F s. D Kortisol, - Kidd-Blutgruppensystem, Kleihauer-Betke-Test, > Knops-Blutgruppensystem, > Landsteiner-Wiener-(LW-) Blutgruppensystem, $>$ Lange-Test, $>$ Legal-Test, $>$ Lewis(Le-)Blutgruppensystem, > Lutheran-(LU-)Blutgruppensystem, Mac-Lagan-Test s. > Thymol-Trübungstest, > MayHegglin-Anomalie, Meixner-Test s. - Zeitungspapier-Test, - Millon-Test, - Nessler-Reaktion, Nylander-Test, $>$ Obermayer-Test, $>$ Paigen-Test, Pandy-Reaktion s. - Liquor-Pandy-Reaktion, > Pelger-Formation (PelgerHuet), Pfeiffer-Zellen, P Philadelphia-Chromosom, - Reed-Sternberg-Zelle, Reichsteins Substanz M s. > Kortisol, Rosenthal-Faktor s. Gerinnungsfaktor XI, $>$ Rivalta-Test, $>$ Rosin-Jodprobe, $>$ Russell-Körperchen, Sandkühler-Ringprobe, Sapporo-Kriterien, > Schlesinger-Probe, > Schmidt-Probe, SchüffnerTüpfelung, Schwangerschaftstest nach Aschheim und Zondek, Schwangerschaftstest nach Glaser und Hempel s. Bitterlingstest zum Nachweis einer Schwangerschaft, - Schwartz-Watson-Test, Scienna-Blutgruppensystem, > Seliwanoff-Test, Stuart-Prower-Faktor s. > Gerinnungsfaktor X, > Sulkowitch-Test, > Takata-Reaktion, > TammHorsfall-Protein, $>$ Tennessee-Antigen, > Tolidin-Test, > Tollens-Test, > Thormählen-Test, > Trommer-Test, > Von-Willebrand-Faktor, > Wai-Index, > WeltmannKoagulationsband, Westergren-Methode s. > Blutkörperchensenkungsgeschwindigkeit nach Westergren, WielandZeitungstest s. Zeitungspapier-Test, Williams-Faktor s. > High-Molecular-Weight Kininogen, > Wöhlk-Probe)

- Funktions- und Belastungsteste ( $>$ Bengalrosa-Test, CarterRobbins-Test s. > Kochsalz-Belastungstest, > Gordon-Test, Hickey-Hare-Test s. \ Kochsalz-Belastungstest, > Hollander-Test, $>$ Koller-Test, $>$ Lundh-Test, Quick-Test s. > Thromboplastinzeit, Schilling-Test s. $>$ Vitamin-B12-
Resorptionstest, $>$ Thorn-Test, V Volhard-Konzentrationsversuch)

- Statistische Methoden und Verfahren ( $>$ Bayesian prediction method, Pearsonscher Korrelationskoeffizient s. > Korrelationskoeffizient nach Pearson, Shewhart-Kontrollkarte, - Korrelationskoeffizient nach Spearman, WilcoxonRangsummentest s. > Test, statistischer, > YoudenDiagramm)

Dem Querschnittscharakter des Fachgebiets entsprechend stammen die „Eponymen-Geber“ (Erstbeschreiber) vorwiegend aus dem breiten Umfeld der klinischen und theoretischen Medizin sowie den Naturwissenschaften. Eponyme in der Laboratoriumsmedizin haben historischen Charakter und bezeichnen häufig „Teste“, Reaktionen oder Entwicklungen, die in der Vergangenheit zum Einsatz kamen.

\section{Literatur}

Fiedler H (2015) Eponyme in der Medizin-Geschichte und Gegenwart. MTA Dialog 16(1):24-28

Whitworth JA, Firkin BG (2002) Dictionary of medical eponymes, 2. Aufl. Parthenon, Camforth, Lancs

Witworth JA (2007) Should eponyms be abandoned? NO. Br Med J 335:425

Woywodt A, Matteson E (2007) should eponyms be abandoned? YES. Br Med J 335:424

$(3 \alpha, 5 \beta, 11 \beta)-11,18-E p o x y-3,18,21-$ trihydroxypregnan-20-one

- Tetrahydro-Aldosteron

$11 \beta, 18-E p o x y-3 \alpha, 18,21-T r i h y d r o x y-$ $5 \beta$-pregnan-20-one

> Tetrahydro-Aldosteron

\section{Eppendorf-Pipette}

- Messvorrichtungen, volumetrische

\section{Epstein-Barr-Viren}

W. Stöcker

Synonym(e) Humanes Herpes-Virus 4; HHV-4 


\section{Englischer Begriff Epstein-Barr virus}

Beschreibung des Erregers Familie: Herpesviridae; Unterfamilie: Gammaherpesvirinae; Gattung: Lymphocryptovirus.

Das Epstein-Barr-Virus gehört den humanen Herpes-Viren an. Es hat eine Größe von 150-180 nm und besitzt ein lineares dsDNA-Genom (ca. $172 \mathrm{~kb}$ ). Die DNA ist um eine CoreStruktur gewunden und von einem Kapsid aus einer Proteinmatrix umhüllt. Dieses ist wiederum von einer Lipidhülle mit Glykoproteinen umschlossen.

Erkrankungen Epstein-Barr-Virus (EBV) ist der Erreger der infektiösen Mononukleose. Die Infektion verläuft im Kindesalter häufig inapparent, bei Erstinfektion junger Erwachsener kommt es in 30-60\% der Fälle nach einer Inkubationszeit von 30-50 Tagen zur infektiösen Mononukleose („Kusskrankheit““, Pfeiffer-Drüsenfieber), die in der Regel mit einer Pharyngitis und einer Lymphadenopathie beginnt, dazu kann sich ein Exanthem und häufig auch eine Hepatosplenomegalie entwickeln. Charakteristisch ist ein verändertes Blutbild (mononukleäre $\triangleright$ Pfeiffer-Zellen). Selten persistieren die Symptome über längere Zeit (chronische Form). EBV kann verschiedene Tumorerkrankungen hervorrufen: endemisches Burkitt-Lymphom in Afrika, ein Teil der Morbus-Hodgkin-Erkrankungen und das Nasopharynxkarzinom. Bei angeborenen oder erworbenen Immundefekten kann eine EBV-Infektion zu schweren Komplikationen führen, wie dem X-gekoppelten lymphoproliferativen Syndrom oder der Posttransplantations-Lymphoproliferation, beide mit hohen Mortalitätsraten.

Das Virus befällt ausschließlich den Menschen. Es wird vorwiegend durch Speichel übertragen und infiziert zunächst B-Lymphozyten (s. > B-Lymphozyt), die sich zu Lymphoblasten differenzieren. Alternative Übertragungswege sind Bluttransfusion und Transplantation. EBV persistiert lebenslang (Latenz in sog. „Memory-Lymphozyten“). Bei immunkompetenten Personen kommt es immer wieder zu klinisch kaum wahrgenommenen Reaktivierungen mit Ausscheidung des Virus. Die Prävalenz von EBV in Deutschland steigt von 40 \% bei 2-jährigen Kindern auf nahezu 100 \% im Erwachsenenalter.

Analytik Direktnachweis: Nachweis von EBV-DNA mittels $>$ PCR (Polymerase-Kettenreaktion).

Serologie: Goldstandard zum Nachweis von Antikörpern der Klassen IgA, IgG und IgM gegen die verschiedenen EBVAntigene Viruskapsidantigen (VCA), Early-Antigen (EA) und Epstein-Barr-Nuclear-Antigen (EBNA) ist der indirekte Immunfluoreszenztest ( $\triangleright$ Immunfluoreszenz, indirekte). Daneben kommen vielfach auch $>$ Enzymimmunoassay ( $\triangleright$ Enzyme-linked Immunosorbent Assay, Chemilumineszenz Immunoassays) und $\triangleright$ Immunblot mit nativen als auch rekombinanten Antigenen zum Einsatz. Mehrdeutige Anti- körperkonstellationen lassen sich durch die Untersuchung der $\triangleright$ Avidität des IgG gegen VCA differenzieren (niedrige Avidität: frische Infektion). Bemerkung: Der Nachweis heterophiler Antikörper (Paul-Bunnel-Reaktion) findet kaum noch Anwendung.

Untersuchungsmaterial - Probenstabilität Direktnachweis: Mittels PCR. Untersucht wird EDTA-Blut. Das Material sollte bis zur Weiterverarbeitung bei +4 bis $+8{ }^{\circ} \mathrm{C}$ aufbewahrt werden. Direktnachweise sind innerhalb von 24 Stunden durchzuführen.

Serologie: Serum, Plasma oder Liquor für den Nachweis der Antikörper sind bei $+4{ }^{\circ} \mathrm{C}$ bis zu 2 Wochen lang beständig, bei $-20{ }^{\circ} \mathrm{C}$ über Monate und Jahre hinweg. Zur Tiefkühlkonservierung des IgM kann man den Proben $80 \%$ gepuffertes Glyzerin beifügen.

Diagnostische Wertigkeit Direktnachweis: Die quantitative Bestimmung von EBV-DNA mittels PCR ist die Methode der Wahl, um die Reaktivierung einer EBV-Infektion bzw. eine unkontrollierte Virusreplikation mit Gefahr eines EBVassoziierten Lymphoproliferationsprozesses bei immunsupprimierten Patienten festzustellen. Die Serologie ist hier ungeeignet, da die Antikörpertiter keine Korrelation zur Viruslast aufweisen.

Serologie: Nachweis von Antikörpern der Klassen IgA, IgG und IgM gegen VCA, EA und EBNA zur Differenzierung akuter und abgelaufener EBV-Infektionen. Charakteristisch für eine akute Primärinfektion sind Antikörper der Klasse IgM und IgG gegen VCA und EA. Im Infektionsverlauf treten zunächst VCA-IgM auf, gefolgt von VCA-IgG und dann EA-IgG. Während VCA-IgM und EA-IgG in der Regel nach einigen Monaten wieder verschwinden, persistieren VCA-IgG lebenslang. Etwa 6-8 Wochen nach einer Infektion kommt es zur Ausbildung von EBNA-1-IgG, sie kennzeichnen eine abgelaufene Infektion. Die EBNA-Antigene 1-6 werden im Laufe der Infektion früher als EA und VCA synthetisiert. Sie werden dem Immunsystem aber erst nach der Zerstörung der B-Zellen präsentiert, weshalb im zeitlichen Verlauf Antikörper gegen VCA und EA vor den Antikörpern gegen EBNA erscheinen. Die für eine EBV-Infektion typischen heterophilen Antikörper ( $\triangleright$ Antikörper, heterophile) treten ebenfalls vor den Antikörpern gegen EBNA auf.

Die Unterscheidung frischer von länger bestehenden Infektionen gehört zu den größten Herausforderungen der Serologie. Störfaktoren sind beispielsweise eine Persistenz der IgM-Antwort, zu schwache oder verzögerte IgM-Bildung sowie unspezifische IgM-Reaktionen durch polyklonale BZell-Stimulation bei akuten Infektionen oder fehlendes EBNA-1-IgG bei abgelaufenen Infektionen. Bei bis zu $20 \%$ aller akuten EBV-Infektionen können keine Antikörper der Klasse IgM gegen VCA nachgewiesen werden, bei $15 \%$ wird das IgM verzögert gebildet, andererseits persistiert es bei $4 \%$. 
Bei etwa $5 \%$ infizierter Patienten werden keine EBNA-1-IgG gebildet. Antikörper gegen EA werden sowohl in Patienten mit frischen als auch mit überstandenen EBV-Infektionen gefunden. Für die sichere Identifizierung von Primärinfektionen hat sich in den letzten Jahren die Untersuchung der Avidität der gebildeten IgG-Antikörper etabliert: Das Immunsystem reagiert auf eine Infektion zunächst mit der Bildung niedrig avider Antikörper. Mit fortschreitender Krankheitsdauer wird den Antigenen immer genauer angepasstes IgG sezerniert - die Avidität nimmt zu. Solange im Serum noch kein hoch avides IgG nachweisbar ist, kann man davon ausgehen, dass sich die Infektion in einem frühen Stadium befindet.

Differenzialdiagnostisch sind Infektionskrankheiten abzugrenzen, die ähnliche klinische Bilder hervorrufen, wie HIV, CMV, Röteln, Ringelröteln, HCV, Streptokokken-Infektion, Toxoplasmose und Malaria.

\section{Literatur}

Andersson A, Vetter V, Kreutzer L, Bauer G (1994) Avidities of IgG directed against viral capsid antigen or early antigen: useful markers for significant Epstein-Barr-Virus serology. J Med Virol 43:112-115

Huzly D, Hess RD (2007) Möglichkeiten und Grenzen der serologischen Epstein-Barr-Virus-Diagnostik. Dtsch Med Wochenschr 132:151-154

Paschale M de, Clerici P (2012) Serological diagnosis of Epstein-Barr virus infection: problems and solutions. World J Virol 1(1):31.43

\section{ERAD (endoplasmic reticulum} associated protein degradation)

- Endoplasmatischer Retikulumstress

\section{ErbB}

- Human Epidermal Growth Factor Receptor

\section{Erbliche Genmodifikationen}

$>$ Epigenetik

\section{Ergebnisbestätigung}

O. Colhoun
Definition Ausdrückliche Bestätigung extremer und/oder unplausibler Werte bei der Erfassung von Analysenergebnissen durch den Benutzer des $>$ Labor-EDV-Systems.

Beschreibung Ergebnisse, die aufgrund der in den Stammdaten definierten Prüfkriterien unplausibel erscheinen oder extrem weit außerhalb der Referenzbereiche (s. $>$ Referenzbereich, biologischer, $>$ Referenzbereich, dosisbezogener) liegen, müssen ausdrücklich bestätigt werden. Hierzu erfolgt eine Aufforderung an den Benutzer am Bildschirm, den Wert z. B. nochmals einzugeben oder die Eingabe mit seiner Benutzerkennung zu bestätigen.

\section{Ergebnisdatenänderungen}

> Datenänderungen

\section{Ergebniserfassung}

O. Colhoun

Synonym(e) Messwerterfassung

Englischer Begriff result input

Definition Eingabe des Ergebnisses einer Messung in die Labor-EDV.

Beschreibung Die Erfassung geschieht offline, also händisch in einer entsprechenden Ergebniserfassungsmaske des Labor-EDV-Clients (s. > Client) am Bildschirm, > online durch Datenübertragung vom Analysengerät an die LaborEDV oder durch Generierung von Ergebnissen aus $>$ Berechnungen. Für die Offline-Erfassung stehen verschiedene Optionen der Eingabe zur Verfügung; Ergebniserfassung durch

- Auftragsnummer,

- Labornummer,

- Arbeitsplatzliste,

- Parameternamen oder direkt in

- $>$ Resteliste.

\section{Ergebniskommentierung}

O. Colhoun

Synonym(e) Medizinische Validation

Englischer Begriff result confirmation
Englischer Begriff result comment 
Definition Ausgabe eines kommentierenden Hinweises im Laborbefund, der für die Ergebnisbewertung durch den Kliniker relevant ist.

Beschreibung Befundkommentare enthalten z. B. Hinweise auf medizinische Unplausibilitäten, > Störgrößen von Präanalytik oder $\triangleright$ Matrix sowie Empfehlung der Wiederholung einer Untersuchung oder Empfehlung zur sinnvollen Ergänzung eines Befundes.

\section{Ergebnisstatus}

O. Colhoun

\section{Englischer Begriff result status}

Definition Kennzeichnung des Bearbeitungsstatus eines Messwerts in der Labor-EDV.

Beschreibung Mögliche Werte sind „angefordert“, „eingangsbestätigt“, „gemessen - in Validation“, „technisch validiert - Freigabe als Notfallwert“, „Wiederholung der Messung angefordert“, „medizinisch validiert“, „freigegeben".

\section{Ergebnistexte}

$\checkmark$ Texte

\section{Ergebnistypen}

\section{O. Colhoun}

\section{Englischer Begriff result types}

Definition Verschiedene Typen von Messergebnissen, die Analysen in der Labor-EDV innehaben können.

Beschreibung Die Stammdaten legen fest, welche bestimmten Eingaben im Ergebnisfeld zulässig sind. Diese Festlegung gilt für die Offline-Messwerterfassung, \ OnlineErgebnisübernahme und Ergebnisgenerierung aus Berechnungen und steuert die Darstellung auf dem Befund und die Plausibilitätsprüfungsregeln (s. > Plausibilität) bei der Messwerterfassung.
Quantitative Ergebnisse sind Zahlenwerte, ggf. mit einer festgelegten Zahl von Nachkommastellen.

Qualitative Ergebnisse (Text oder semiquantitativ): Es können beliebige Zeichen eingegeben werden. Durch Eingabe festgelegter Textkürzel wird die Generierung eines bestimmten Textes in diesem Ergebnisfeld bewirkt. Um welchen Typ es sich handelt, ergibt sich einerseits aus dem erfassten Datenstring (z. B. ,neg“, , , $<12$ ") und andererseits aus der Größe des Ergebnisses (z. B. „38“" kann als semiquantitativ „, $<50$ “ gelten).

Titerergebnisse: Eingabe des Titerstufenwerts, auf dem Befund wird daraus die Titerangabe generiert (aus „100“ wird im Befund beispielsweise „1:100“).

\section{Literatur}

Porth AJ, Weiß R, Mansfeld E et al (2000) Pflichtenheft Labordatenverarbeitung. GMDS Arbeitsgruppe Labordatenverarbeitung: http://www.labor.uni-muenster.de/gmds/pflichtenheft. Zugegriffen am 11.11.2012 https://medizin-informatik.org/download/ scripte/lis.pdf. Zugegriffen am 12.04.2018

\section{Ergebnisübermittlung}

O. Colhoun

\section{Synonym(e) Reportierung}

Englischer Begriff result transmission

Definition Art der Datenübergabe vom Analysegerät an das > Labor-EDV-System.

Beschreibung Das jeweilige gerätespezifische Treiberprogramm der Labor-EDV bringt die vom Analysegerät gelieferten Messwerte in eine einheitliche Form und legt sie im Zwischenspeicher ab. Ein Programm zur Messwertzuordnung übernimmt deren Zuordnung zu den jeweiligen Aufträgen. Die Übermittlung der Messwerte kann vom Gerät probenspezifisch (Beispiel: Eilanforderung, die am Gerät vorrangig bearbeitet wurde) oder blockweise (vorgegebenes Zeitintervall zur Übermittlung aller seit der letzten Datensendung gemessenen Werte) erfolgen.

\section{Ergocalciferol (Vitamin $\mathrm{D}_{2}$ )}

Vitamin D 


\section{Ergosterin}

$>$ Vitamin D

\section{Ergosterol}

Vitamin D

\section{Erkrankungsanfälligkeit}

Prädisposition, genetische

\section{Erlenmeyer, Emil}

T. Arndt

Lebensdaten Deutscher Chemiker, geb. am 28. Juni 1825 in Taunusstein, gest. am 22. Januar 1909 in Aschaffenburg.

Verdienste Professor der Chemie in Heidelberg und München. Klärte die Strukturen von Naphthalin, Azo-, Hydrazound Azoxykörpern auf. Herausgeber von „Liebigs Annalen“. Erfinder des Erlenmeyer-Kolbens.

\section{Erreger-Direktnachweis}

W. Stöcker

Englischer Begriff direct detection of pathogens

Beschreibung In der Laboratoriumsdiagnostik der Infektionskrankheiten werden 2 Prinzipien angewendet:

1. Direkter Nachweis des Erregers, von Bestandteilen des Erregers oder seiner Produkte

2. Erfassung spezifischer Immunreaktionen gegen den Erreger (indirekter Nachweis)

Mittels verschiedener mikroskopischer Methoden und Färbeverfahren sind Aussagen über die charakteristischen Eigenschaften des Erregers in einer Untersuchungsprobe möglich. Zusätzlich werden heute molekularbiologische Techniken wie Genamplifikation ( $>$ PCR (Polymerase-Kettenreaktion)), DNA-Sequenzierung und -Hybridisierung zur Identifizierung der Mikroorganismen eingesetzt. Darüber hinaus können Bakterien und Pilze auf geeignet festen und flüssigen Nährmedien herangezüchtet und anschließend anhand erregerspezifischer morphologischer, physiologischer, metabolischer, chemischer oder genetischer Merkmale bestimmt werden. Hierfür sind sowohl klassische Verfahren wie Mikroskopie, biochemische und serologische Identifizierung von großer Bedeutung als auch moderne molekularbiologische Verfahren und Massenspektrometrie (MALDI-TOF). Erregerspezifische Antigene können durch polyklonale oder monoklonale Antikörper nachgewiesen werden.

\section{Literatur}

Kayser FH, Böttger EC (2005) Allgemeine Aspekte der medizinischen Mikrobiologie. Labordiagnostik von Infektionen. In: Kayser FH, Böttger EC, Zinkernagel RM, Haller O, Eckert J, Deplazes P (Hrsg) Medizinische Mikrobiologie, 11. Aufl. Thieme Verlag, Stuttgart, S 12-32

\section{Erregerspezifische Antikörper (ASI) im Liquor cerebrospinalis (CSF)}

Liquor-Antikörper, spezifischer Index

\section{Erstmilch}

Kolostrum

\section{Erwartungswert von Messwerten}

\section{G. Schumann}

\section{Englischer Begriff expectation}

Definition Das mittlere Ermittlungsergebnis, das aus der unablässig wiederholten Anwendung des unter vorgegebenen Bedingungen angewendeten Ermittlungsverfahrens gewonnen werden könnte (DIN 55350:1987).

Beschreibung Mittelwert derjenigen Wahrscheinlichkeitsverteilung der Messwerte, die zu einer bestimmten Realisierung eines Analyse-/Messverfahrens gehört. Bei Vorliegen mehrerer Messergebnisse kann er durch deren arithmetisches Mittel geschätzt werden, und zwar umso besser, je größer ihre 


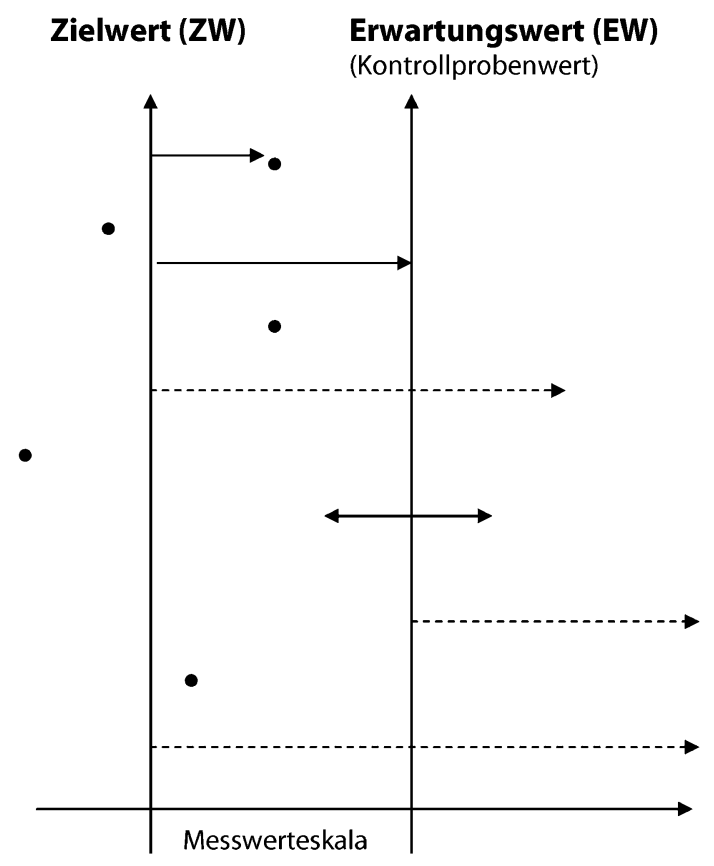

Erwartungswert von Messwerten, Abb. 1 Graphische Darstellung verschiedener Fehlerarten bei laboratoriumsmedizinischen Untersuchungen am Beispiel Erwartungswert $>$ Zielwert. $E W$, Erwartungswert; $M W$, Messwert (Punkte); $s$, Standardabweichung; $V K$, Variationskoeffi-

Anzahl ist. Die Differenz zwischen dem Erwartungswert und dem Zielwert wird als systematische Messabweichung (vom Zielwert) bezeichnet (Abb. 1).

\section{Literatur}

Begriffe der Qualitätssicherung und Statistik (1987) DIN 55350 Teil 13, 1.5. Beuth-Verlag, Berlin

\section{Erworbenes B-Antigen}

$>$ Acquired-B-Antigen

\section{Erythema infectiosum}

> Parvo-Viren

\section{Erythroblasten}

H. Baum

Englischer Begriff erythroblast
Fehlerart Kenngröße

Messabweichung (des Einzelwertes) $\quad$ MW - ZW

systematische Messab- ZW - EW

weichung (Unrichtigkeit,

(bias, Maß für die Richtigkeit)

maximal zulässige Unrichtigkeit

$\left(\right.$ bias $\left._{\max }\right)$

zufällige Messabweichung,

Unpräzision (Maß für die Präzision)

maximal zulässige Unpräzision

$\left(\mathrm{VK}_{\max }\right)$

maximal zulässige Abweichung

des Einzelwertes ${ }^{2)}$

s oder VK

$2 \times \mathrm{VK}_{\max }+$ bias $_{\max }{ }^{11}$

zient (relative Standardabweichung); $Z W$, Zielwert. ${ }^{1)}$ in Prozent des Zielwerts; ${ }^{2)}$ auch als ,total error“ bezeichnet: bias $_{\max }+1,96 \times \mathrm{VK}$ $(1,96=$ zentrales $95 \%$-Intervall der Messwerteverteilung)

Definition Kernhaltige Vorstufen der Erythropoese.

Beschreibung Erythroblasten sind kernhaltige Vorstufen der Erythropoese und sind beim Gesunden lediglich im Knochenmark (Pfeile) nachweisbar (s. Abbildung):

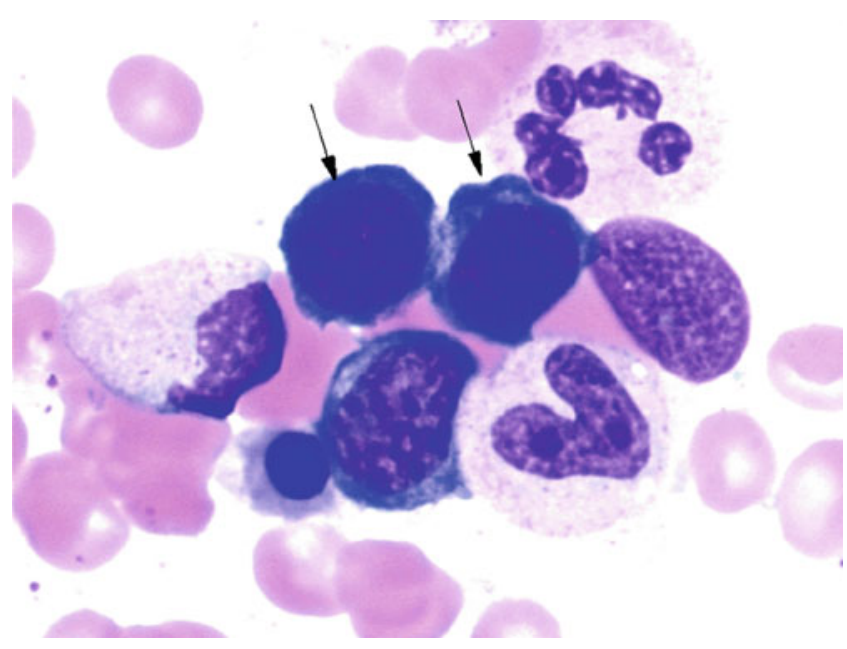

Die Ausreifung erfolgt ausgehend vom $>$ Proerythroblasten als unreifster Form über den basophilen Erythroblasten, polychromatischen Erythroblasten und orthochromatischen (oxyphilen) Erythroblasten zum reifen Erythroblasten.

In der folgenden Abbildung sind ein polychromatischer Erythroblast (1) und zwei orthochromatische Erythroblasten 
(2) zu sehen (Knochenmark, 1000×, May-GrünwaldGiemsa-Färbung):

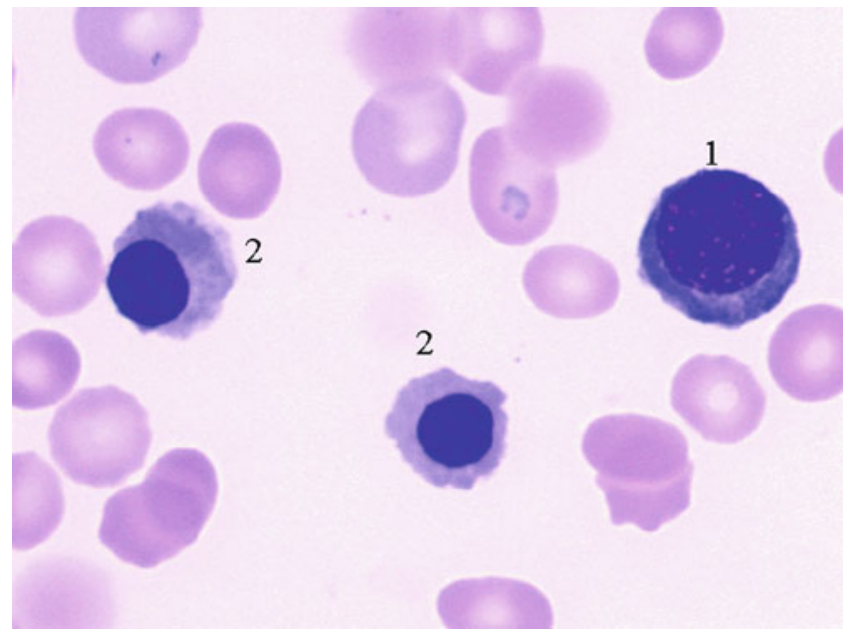

Dabei behalten die Erythroblasten die Fähigkeit zur Teilung. Während dieser Entwicklung ändert sich die Färbung des Zytoplasmas von dunkelbasophil zur rötlichen Färbung der reifen Erythrozyten. Der Kern verändert sich von einem großen runden Kern (Durchmesser 10-17 $\mu \mathrm{m}$ ) mit dichter netzartiger $>$ Chromatin-Struktur zu einem kleinen sehr dichten, pyknotischen Kern (Durchmesser $6 \mu \mathrm{m}$ ). Im peripheren Blut wurden die Erythroblasten früher als - Normoblast bezeichnet. Der Anteil der Erythroblasten an den kernhaltigen Zellen des Knochenmarks beträgt etwa $19 \%$ an der Gesamtzellzahl und $95 \%$ innerhalb der erythrozytären Zellreihe.

\section{Literatur}

Boll I (1991) Knochenmark-Zytologie. In: Boll I, Heller S (Hrsg) Praktische Blutzelldiagnostik. Springer, Berlin/Heidelberg/New York, S 288-292

\section{Erythrocuprein}

$\checkmark$ Cerebrocuprein

\section{Erythroleukämoide Reaktion}

H. Baum

Englischer Begriff erythroleukemoid reaction
Definition Auftreten kernhaltiger Vorstufen der Erythrozyten sowie unreifer Formen der Granulozytopoese im peripheren Blut im Verlauf von nicht hämatologischen Erkrankungen.

Beschreibung Die erythroleukämoide Reaktion beschreibt das Auftreten von kernhaltigen Vorstufen der Erythropoese, aber auch Vorläuferzellen der Granulopoese im peripheren Blut. Es handelt sich dabei nicht um eine hämatologische Systemerkrankung, sondern das Auftreten erythrozytärer Vorstufen ist sekundärer Natur. Sie ist im Regelfalle ein Ausdruck einer extramedullären Blutbildung. Dabei kommen ursächlich in erster Linie Knochenmetastasen solider Tumoren infrage, die dann sekundär zu einer extramedullären Blutbildung führen.

\section{Literatur}

Begemann H, Begemann M (1997) Praktische Hämatologie, 10., unveränderte Aufl. Georg Thieme Verlag, Stuttgart, S 141

\section{Erythron}

A. M. Gressner und O. A. Gressner

Synonym(e) Erythrozytenorgan

Englischer Begriff erythron

Definition Gesamtmasse der Erythrozyten im Körper.

Beschreibung In der Hämatologie relativ selten gebrauchter Begriff für die Gesamtmasse der Erythrozyten und deren Kern-Zellreifungsklassen (Vorläuferzellen) unabhängig von deren intra- oder extravasaler Lokalisation, z. B. im Knochenmark.

\section{Erythropoese, ineffektive}

H. Baum

Englischer Begriff ineffective eythropoiesis

Definition Verminderung der effektiv produzierten Erythrozyten bei ausreichender Anzahl erythrozytärer Vorstufen im Knochenmark. 
Beschreibung Die ineffektive Erythropoese beschreibt Zustände, bei denen die Zellreifung im Proliferations- und Reifungskompartiment der Erythropoese gestört ist. Während der Proliferations- und Reifungsphase geht ein Großteil der - Erythroblasten wieder zugrunde mit dem Ergebnis einer ungenügenden Anzahl an reifen Erythrozyten. Bei intaktem Regulationskompartiment kommt es intramedullär zu einer regulativen Erhöhung der Anzahl unreifer Erythroblasten mit erhöhter Markzelldichte.

\section{Literatur}

Heimpel H, Prümmer O (1998) Bedeutung und Effizienz der Blutzelldiagnostik. In: Boll I, Heller S (Hrsg) Praktische Blutzelldiagnostik. Springer, Berlin/Heidelberg/New York, S 6-35

\section{Erythropoese-Leukozytopoese- Verhältnis}

H. Baum

Synonym(e) Granulozytopoese/Erythropoese-Index; G/EIndex

Beschreibung Das Erythropoese-Leukozytopoese-Verhältnis beschreibt als Verhältniszahl den Anteil an Zellen der Granulozytopoese zu den kernhaltigen Zellen der Erythropoese im Knochenmark. Das Verhältnis liegt beim Gesunden bei einem G/E-Index von ca. 3,0. Änderungen des G/E-Index können durch Vermehrung oder Verminderung einer der beiden Zelllinien bedingt sein.

\section{Literatur}

Boll I (1998) Knochenmark-Zytologie. In: Boll I, Heller S (Hrsg) Praktische Blutzelldiagnostik. Springer, Berlin/Heidelberg/New York, S 287

\section{Erythropoetin}

H. Baum

Synonym(e) Erythropoietin; EPO

Englischer Begriff erythropoietin; EPO
Definition Glykoprotein, das die erythrozytäre Vorläuferzellen zur Ausdifferenzierung stimuliert.

Struktur Glykoprotein mit 4 antiparallelen $\alpha$-Helix-Strukturen.

Molmasse Ca. $30 \mathrm{kDa}$, wobei der Peptidanteil 18,4 kDa beträgt.

Halbwertszeit Stunden.

Funktion - Pathophysiologie Erythropoetin wird überwiegend $(>90 \%)$ von den Fibroblasten der peritubulären Kapillaren in der Niere gebildet und steht im Mittelpunkt der Regulation der Erythropoese. Ein kleinerer Teil wird in der Leber und in Makrophagen synthetisiert. Die Regulation der Erythropoetinsynthese erfolgt auf Transkriptionsebene durch den Transkriptionsfaktor Hypoxie-induzierbarer Faktor (HIF-1). Dieser konstant synthetisierte Faktor besteht aus den beiden Untereinheiten $\alpha$ und $\beta$. Bei hohem $\mathrm{O}_{2}$-Druck erfolgt eine Hydroxylierung der $\alpha$-Untereinheit, was zu einem verstärkten Abbau des HIF-1 und somit zu einer Repression der Erythropoetintranskription führt. Das Erythropoetin bindet an spezifische Rezeptoren der erythrozytären Progenitorzellen ( $\triangleright$ BFU-E, CFU-E). Dies führt zu einer Zellteilung und -reifung mit Erhöhung der Erythrozytenmasse und über den Anstieg des $\mathrm{O}_{2}$-Drucks zu einer negativen Rückkopplung auf die Erythropoetintranskription und -sekretion.

Untersuchungsmaterial - Entnahmebedingungen Serum, Heparinplasma. Keine besonderen Abnahmebedingungen.

Probenstabilität Bei Raumtemperatur bis zu 2 Wochen, bei $-20{ }^{\circ} \mathrm{C}>2$ Monate.

Präanalytik Andere Materialien als Serum oder Heparinplasma führen zu einer niedrigeren Wiederfindung.

Analytik

- RIA

- ELISA

Konventionelle Einheit $\mathrm{mIU} / \mathrm{mL}$.

Internationale Einheit IU/L.

Umrechnungsfaktor zw. konv. u. int. Einheit 1.

Referenzbereich - Erwachsene 6-25 IU/L, jedoch stark abhängig vom eingesetzten Assay.

Referenzbereich - Kinder S. Erwachsene. 


\section{Indikation}

- Verdacht auf renale Anämie

- Unklare normozytäre Anämie

- Vor einer Therapie mit Erythropoetin als Ausgangswert

Interpretation Bei einer erhöht gemessenen EPO-Konzentration sind differenzialdiagnostisch in Erwägung zu ziehen:

- Eisenmangelanämie

- Hämolytische Anämien

- Zustand nach einem akuten Blutverlust

- Sekundäre Polyglobulien

- Paraneoplastisch bei einigen Tumoren

- Im zweiten und letzten Drittel der Schwangerschaft

Bei einer verminderten EPO-Konzentration kommen differenzialdiagnostisch in Betracht:

- Renale Anämie (Ausmaß hängt vom funktionsfähigen Rest des Nierenparenchyms ab)

- Polycythämia vera

Diagnostische Wertigkeit Die Bestimmung des Erythropoetins ist primär zur Differenzialdiagnostik einer normochromen, normozytären hyporegenerativen Anämie indiziert. Ein Mangel an EPO ist dabei am häufigsten durch eine chronische Niereninsuffizienz verursacht. Eine erhöhte Konzentration ist bei absoluten oder relativen Anämien mit einer verminderten Sauerstoffsättigung des Gewebes nachweisbar.

\section{Literatur}

Kurtz A (2007) Funktion der Niere und Regulation des Wasser- und Elektrolythaushaltes - Erythropoietin. In: Löffler G, Petrides PE (Hrsg) Biochemie und Pathobiochemie, 8. Aufl. Springer, Berlin/ Heidelberg/New York, S 911-913

Tabbara IA (1993) Erythropoietin, Biology and Clinical Application. Arch Intern Med 153:298-304

\section{Erythropoietin}

- Erythropoetin

\section{Erythrosiderophage}

$\checkmark$ Siderophagen

\section{D-Erythro-6-Trihydropropyl-Pterin}

- Neopterin

\section{Erythroxylon coca}

Kokastrauch

\section{Erythroxylum coca}

- Kokastrauch

\section{Erythrozytäre Blutgruppenmerkmale}

> Blutgruppenantigene, erythrozytäre

\section{Erythrozyten}

H. Baum

Synonym(e) Normozyten

Englischer Begriff erythrocytes

Definition Kernlose hämoglobinhaltige Zellen des Blutes, die dem Sauerstofftransport dienen.

Beschreibung Erythrozyten sind die Effektorzellen der Erythropoese. Sie sind kernlose bikonkave Scheiben mit einem mittleren Durchmesser von 7,5 $\mu \mathrm{m}$ bei einer mittleren Dicke von 1,5 $\mu \mathrm{m}$. Hauptinhaltsstoff der Erythrozyten ist das $>$ Hämoglobin, das reversibel Sauerstoff binden kann, gleichzeitig auch dem $\mathrm{CO}_{2}$-Transport und als Puffer dient. Das Zytoskelett der Erythrozyten besteht überwiegend aus Spektrinmolekülen. Diese verleihen dem Erythrozyten eine sehr hohe Verformbarkeit. Durch die flache diskoide Form haben die Erythrozyten eine sehr große Oberfläche sowie kurze Diffusionsstrecken, was den Gasaustausch erleichtert. Durch ihre hohe Verformbarkeit können Erythrozyten auch kleinste Kapillaren mit Durchmessern von $5 \mu \mathrm{m}$ durchströmen; s. a. > Blutbild, kleines, - Erythrozytenzählung. 


\section{Literatur}

Bauer C, Walzog B (2005) Blut: Ein flüssiges Organ. In: Klinke R, Pape H-C, Silbernagl S (Hrsg) Physiologie, 5., kompl. überarb. Aufl. Georg Thieme Verlag, Stuttgart/New York, S 223-254

\section{Erythrozyten, polychromatische}

H. Baum

\section{Synonym(e) Polychromasie}

Englischer Begriff polychromatic erythrocyte

Definition In der panoptischen Färbung nach Pappenheim ( $\triangleright$ Pappenheim-Färbung) bläulich (basophil) gefärbte Erythrozyten.

Beschreibung Im Ausstrichpräparat sind Erythrozyten nachweisbar, bei denen die Kern- und Zytoplasmareifung nicht parallel abgelaufen sind. Obwohl der Kern bereits ausgestoßen ist, enthält das Zytoplasma noch RNA, die sich mit basischen Farbstoffen bläulich anfärbt. Der Nachweis polychromatischer Erythrozyten (s. Abbildung) ist ein Zeichen einer erhöhten Regenerationsaktivität des Knochenmarks und kann häufig bei Anämien beobachtet werden. Sie entsprechen somit den Retikulozyten.

Neben oxyphilen Erythrozyten sind in der Abbildung bläulich gefärbte (polychromatische) Erythrozyten nachweisbar $(1000 \times$, May-Grünwald-Giemsa-Färbung):

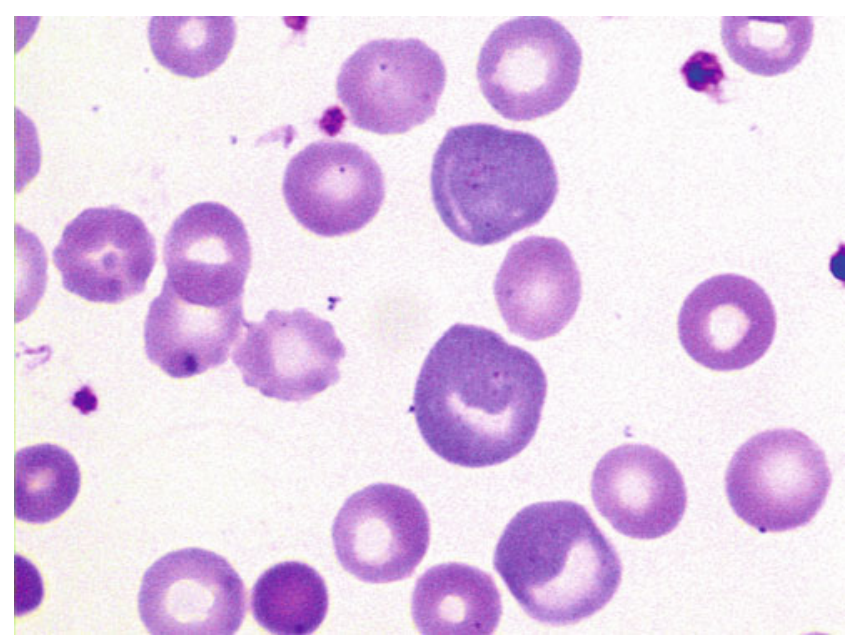

\section{Literatur}

Bain BJ (2001) Blood cell morphology in health and disease. In: Lewis SM, Bain BJ, Bates I (Hrsg) Practical haematology, 9. Aufl. Churchill Livingstone, London, S 86

\section{Erythrozytenantikörper}

- Autoantikörper gegen erythrozytäre Antigene

\section{Erythrozytendysmorphie}

Dysmorphe Erythrozyten im Urin

\section{Erythrozyteneinschlüsse}

\section{H. Baum}

Englischer Begriff erythrocyte inclusions

Definition In der panoptischen Färbung nach Pappenheim ( $\triangleright$ Pappenheim-Färbung) nachweisbare intraerythrozytäre Einschlusskörper.

Beschreibung Erythrozyteneinschlüsse sind im Ausstrichpräparat nachweisbare intraerythrozytäre Strukturen unterschiedlichster Ätiologie. Unterschieden werden $>$ Howell-Jolly-Körper, > Basophile Tüpfelung, > Pappenheim-Körper, > HeinzInnenkörper, $\triangleright$ Cabot-Ringe, Kerne ( $\triangleright$ Erythroblasten) oder Parasiten.

\section{Literatur}

Bartel R, Thomas L (2005) Differenzialblutbild. In: Thomas L (Hrsg) Labor und Diagnose, 6. Aufl. TH-Books Verlagsgesellschaft, Frankfurt, S 527

\section{Erythrozytenenzyme}

H. Baum

\section{Englischer Begriff erythrocyte enzymes}

Definition Intraerythrozytäre Enzyme des anaeroben Glukosestoffwechsels.

Beschreibung An der Energiebereitstellung des Erythrozyten sind verschiedene Enzyme beteiligt. Ein Mangelzustand bzw. eine veränderte funktionelle Enzymaktivität kann die 
Energiebereitstellung des Erythrozyten beeinträchtigen. Dies führt zu einer verkürzten Erythrozytenüberlebenszeit sowie zu hämolytischen Anämien. Grundsätzlich eingeteilt werden die Enzymdefekte in solche des Pentose-Phosphat-Shunts und der Glykolyse. Die klinisch bedeutendsten Enzymopathien sind dabei der $>$ Glukose-6-Phosphat-DehydrogenaseMangel und der $>$ Pyruvatkinase-Mangel. Dabei ist die klinische Ausprägung des Enzymmangels sehr unterschiedlich. In Abhängigkeit des zugrunde liegenden Gendefektes reicht die Symptomatik von inapparenten Verläufen über hämolytische Krisen bei oxidativem Stress bis hin zu schwersten permanenten hämolytischen Krisen.

Zum Nachweis einer verminderten intraerythrozytären Enzymaktivität wird die Messung der Enzymaktivität im Hämolysat durchgeführt. Bei einigen Enzymopathien müssen jedoch zusätzliche Parameter wie z. B. die Enzymkinetik, pH-Optimum, Thermostabilität oder eine Elektrophorese als zusätzliches Kriterium herangezogen werden. In der folgenden Tabelle sind die Referenzbereiche der einzelnen Enzyme aufgelistet (Kohne 2005):

\begin{tabular}{|c|c|c|}
\hline Enzym & $\begin{array}{l}\mu \mathrm{mol} \\
\text { Substratumsatz/ } \\
\mathrm{g} \mathrm{Hb} / \mathrm{min}\end{array}$ & $\begin{array}{l}\mu \mathrm{mol} \\
\text { Substratumsatz/ } \\
10^{11} \text { Ery } / \mathrm{min}\end{array}$ \\
\hline \multicolumn{3}{|l|}{ Glykolyse } \\
\hline Pyruvatkinase & $20,2 \pm 2,2$ & $41 \pm 10$ \\
\hline Hexokinase & $1,0 \pm 0,1$ & $2,3 \pm 0,5$ \\
\hline Glukosephosphatisomerase & $44,7 \pm 4,8$ & $124 \pm 13$ \\
\hline Triosephosphatisomerase & $2180 \pm 254$ & $6055 \pm 705$ \\
\hline \multicolumn{3}{|c|}{ Pentosephosphatzyklus und Glutathionstoffwechsel } \\
\hline $\begin{array}{l}\text { Glukose-6-Phosphat- } \\
\text { Dehydrogenase }\end{array}$ & $11,0 \pm 1,6$ & $30,6 \pm 4,5$ \\
\hline $\begin{array}{l}\text { 6-Phosphogluconat- } \\
\text { Dehydrogenase }\end{array}$ & $9,5 \pm 1,5$ & $26,2 \pm 4,1$ \\
\hline Glutathionreduktase & $4,6 \pm 0,8$ & $25,7 \pm 3,0$ \\
\hline
\end{tabular}

\section{Literatur}

Kohne E (2005) Erythrozyten-Enzyme. In: Thomas L (Hrsg) Labor und diagnose, 6. Aufl. TH-Books Verlagsgesellschaft, Frankfurt, S 506-509

\section{Erythrozyten-Indices}

H. Baum

Englischer Begriff red blood cell indices

Definition Rechnerisch ermittelte Kenngrößen zur Charakterisierung der Erythrozyten und Klassifizierung von Anämien.
Untersuchungsmaterial EDTA-Blut.

Präanalytik Abgeleitete Kenngrößen der Erythrozyten.

\section{Referenzbereich $\mathrm{MCH} 28-33$ pg; MCV 80-96 fL; MCHC} 330-360 g/L.

Bewertung Die Erythrozytenindices können aus den Kenngrößen Erythrozytenzahl, Hämatokrit und Hämoglobinkonzentration ermittelt werden. Unterschieden werden das mittlere Erythrozytenvolumen (MCV: mean corpuscular volume), der mittlere Hämoglobingehalt des Einzelerythrozyten (MCH: mean corpuscular hemoglobin) und die mittlere korpuskuläre Hämoglobinkonzentration (MCHC: mean corpuscular hemoglobin concentration). Mit ihrer Hilfe können die verschiedenen Anämieformen eingeteilt und klassifiziert werden:

\begin{tabular}{|c|c|c|}
\hline Messgröße & Anämieform & Erkrankung/Zustände \\
\hline $\begin{array}{l}\mathrm{MCH}, \mathrm{MCV} \text { und } \\
\mathrm{MCHC} \text { normal }\end{array}$ & $\begin{array}{l}\text { Normochrome } \\
\text { normozytäre } \\
\text { Anämie }\end{array}$ & $\begin{array}{l}\text { Nicht regenerative Anämien, } \\
\text { akuter Blutverlust, chronisch } \\
\text { entzündliche Erkrankungen, } \\
\text { Maldigestion, Malabsorption, } \\
\text { endokrine Störungen }\end{array}$ \\
\hline $\begin{array}{l}\text { MCV normal, } \\
\text { MCH und MCHC } \\
\text { erhöht }\end{array}$ & $\begin{array}{l}\text { Hyperchrome } \\
\text { normozytäre } \\
\text { Anämie }\end{array}$ & $\begin{array}{l}\text { Intravaskuläre Hämolyse, } \\
\text { Störungen der } \\
\text { Hämoglobinmessung durch } \\
\text { Hyperlipidämie }\end{array}$ \\
\hline $\begin{array}{l}\text { MCV und } \mathrm{MCH} \\
\text { erniedrigt, } \\
\text { MCHC normal }\end{array}$ & $\begin{array}{l}\text { Hypochrome } \\
\text { mikrozytäre } \\
\text { Anämie }\end{array}$ & $\begin{array}{l}\text { Eisenmangelanämie, } \\
\text { Hämoglobinopathien }\end{array}$ \\
\hline $\begin{array}{l}\text { MCV und MCH } \\
\text { erhöht, MCHC } \\
\text { normal }\end{array}$ & $\begin{array}{l}\text { Hyperchrome } \\
\text { makrozytäre } \\
\text { Anämie }\end{array}$ & $\begin{array}{l}\text { Vitamin-B12- und/oder } \\
\text { Folsäuremangel }\end{array}$ \\
\hline $\begin{array}{l}\text { MCV erniedrigt, } \\
\text { MCH und MCHC } \\
\text { erhöht }\end{array}$ & & $\begin{array}{l}\text { Schwere hereditäre } \\
\text { Sphärozytose } \\
\text { (Kugelzellanämie) }\end{array}$ \\
\hline $\begin{array}{l}\mathrm{MCV}, \mathrm{MCH} \text { und } \\
\mathrm{MCHC} \text { erhöht }\end{array}$ & & $\begin{array}{l}\text { Störung der Messung durch } \\
\text { Kälteagglutinine. Es werden } \\
\text { die Erythrozyten zu niedrig } \\
\text { und das MCV zu hoch } \\
\text { bestimmt. Dadurch wird der } \\
\text { Hämatokrit zu niedrig und in } \\
\text { der Folge das MCH und } \\
\text { MCHC zu hoch gemessen }\end{array}$ \\
\hline
\end{tabular}

\section{Literatur}

Stobbe H (1998) Erythrozytenindizes. In: Boll I, Heller S (Hrsg) Praktische Blutzelldiagnostik. Springer, Berlin/Heidelberg/New York, S $73-78$

\section{Erythrozyten-Makrophagen im Liquor cerebrospinalis (CSF)}

- Liquor-Erythrophagen 


\section{Erythrozytenorgan}

- Erythron

\section{Erythrozytensedimentationsrate}

> Blutkörperchensenkungsgeschwindigkeit nach Westergren

\section{Erythrozytensenkungsgeschwindig-} keit nach Wintrobe

- Wintrobe-Methode der Blutkörperchensenkungsgeschwindigkeit

\section{Erythrozytensenkungsreaktion (ESR)}

- Blutkörperchensenkungsgeschwindigkeit nach Westergren

\section{Erythrozytenverteilungsbreite}

H. Baum

\section{$\operatorname{Synonym(e)~RDW~}$}

Englischer Begriff red cell distribution width

Definition Mittlere Abweichung des mittleren Erythrozytenvolumens in automatischen Zählgeräten.

Beschreibung Der RDW ist ein Maß für die Variation des mittleren korpuskulären Volumens (MCV) der Erythrozyten. Mathematisch ist es der Variationskoeffizient des MCV nach der Formel

$\mathrm{RDW}=($ Standardabweichung des MCV/MCV $) \times 100$

Bei Erwachsenen ist ein RDW von $<14 \%$ als normal anzusehen, Neugeborene haben einen höheren RDW. Werte darüber bedeuten das Vorhandensein von ungleich großen Erythrozyten. In der morphologischen Differenzierung entspricht dies der $\triangleright$ Anisozytose.

\section{Literatur}

Bessman JD (1986) Automated blood counts and differentials. A practical guide. Johns Hopkins University Press, Baltimore, S 5-56

\section{Erythrozytenverteilungskurve nach}

Price-Jones

- Price-Jones-Kurve

\section{Erythrozytenvolumen}

H. Baum

Synonym(e) MCV

Englischer Begriff mean red cell (corpuscular) volume

Definition Volumen des Einzelerythrozyten.

Untersuchungsmaterial-Entnahmebedingungen EDTABlut.

Probenstabilität Bei Raumtemperatur mindestens 24 Stunden lagerfähig.

Analytik Rechnerisch aus den Kenngrößen $>$ Hämatokrit und $>$ Erythrozyten-Zahl:

$\mathrm{MCV}(\mathrm{fL})=$ Hämatokrit $(\mathrm{L} / \mathrm{L}) /$ Erythrozytenzahl $\left(\times 10^{12} /\right.$

L) $\times 10^{3}$

oder direkt als Messgröße in Blutzellzählgeräten.

\section{Konventionelle Einheit fL.}

Internationale Einheit fL.

Referenzbereich - Erwachsene $80-96 \mathrm{fL}$.

Referenzbereich - Kinder Altersabhängig, wobei Säuglinge und Kleinkinder deutlich höhere MCV-Werte haben.

Indikation Differenzialdiagnostik und Klassifikation der Anämien.

Interpretation Anämien können anhand des $\mathrm{MCV}$ eingeteilt werden. Dabei sollte jedoch das MCV immer im Zusammenhang mit dem $\mathrm{MCH}$ und $\mathrm{MCHC}$ interpretiert werden:

- Mikrozytär (MCV erniedrigt); vor allem bei Eisenmangelanämien, Thalassämien

- Normozytär (MCV normal); vor allem bei chronischer Blutungsanämie, akutem Blutverlust, aplastische Knochenmarksyndrome

- Makrozytär (MCV erhöht); vor allem bei Vitamin $\mathrm{B}_{12^{-}}$ oder Folsäuremangel 
Ein erhöhtes MCV kann auch präanalytische Ursachen haben; so schwellen die Erythrozyten im Blutröhrchen (z. B. während des Probentransports in ein externes Labor) gewöhnlich an, was zu Fehlinterpretationen bzgl. einer makrozytären Anämie führen kann.

Diagnostische Wertigkeit Das MCV ist eine Screeningmethode in der Anämiediagnostik. Werte unterhalb oder oberhalb der Referenzbereichsgrenze müssen in der Zusammenschau mit den anderen Parametern des kleinen Blutbildes $(\triangleright$ Blutbild, kleines) gewertet werden.

\section{Literatur}

Stobbe H (1998) Erythrozytenindices. In: Boll I, Heller S (Hrsg) Praktische Blutzelldiagnostik. Springer, Berlin/Heidelberg/New York, S $73-78$

\section{Erythrozytenzählung}

H. Baum

Englischer Begriff red blood cell count

Definition Bestimmung der Erythrozytenzahl in einem definierten Volumen.

\section{Physikalisch-chemisches Prinzip}

- Manuelle Kammerzählung, z. B. in einer Neubauer- oder Thoma-Zählkammer einer mit Hayem-Lösung verdünnten Blutprobe.

- Mechanisierte Zählung

- Impedanzmessung: Messung der Widerstandsänderung zwischen 2 Elektroden bei Durchtritt der Erythrozyten durch eine Kapillare im elektrischen Feld. Die in einer isotonen Salzlösung suspendierten Erythrozyten führen beim Durchtritt durch die Kapillare zu einer Änderung des Widerstandes, da ihre elektrische Leitfähigkeit im Vergleich zur Salzlösung geringer ist. Die Höhe der Widerstandänderung ist dabei proportional der Größe.

- Streulichtmessung im kontinuierlichen Durchfluss (optisches Dunkelfeldprinzip): Die Erythrozyten passieren einzeln eine Kapillare. Ein durch diese Kapillare geleiteter monochromatischer Lichtstrahl wird an den Erythrozyten gestreut. Das auf einer Fotozelle auftreffende Streulicht ist dabei proportional zur Zellgröße, die Anzahl der Impulse proportional zur Zellzahl.

Einsatzgebiet Kleines Blutbild, Differenzialdiagnostik der Anämien.
Untersuchungsmaterial EDTA-Blut.

\section{Fehlermöglichkeit}

- Manuelle Methode: EDTA-Blut nicht genügend gemischt, falsche Verdünnung. Insgesamt ist die manuelle Zählung mit einer großen Unpräzision behaftet (VK $>10 \%$ der Doppelbestimmung).

- Bei der automatisierten Bestimmung führen Erythrozytenaggregate zu einem falsch niedrigen Ergebnis, während eine ausgeprägte Leukozytose $>100 \mathrm{G} / \mathrm{L}$ zu falsch hohen Ergebnissen führt, da die Leukozyten miterfasst werden. Auch Riesenthrombozyten werden mitgemessen, dies führt zu einer fälschlich niedrigen Thrombozytenzahl.

Praktikabilität - Automatisierung - Kosten Die Handmethode ist mit großem Zählfehler behaftet, weshalb diese Methode nicht mehr empfohlen werden kann. Die automatisierte Messung gilt als Standardmethode. Die Kosten der Untersuchung sind gering.

Bewertung - Methodenhierarchie (allg.) Die Erythrozytenzählung sollte nur noch mit automatisierten Zählsystemen erfolgen, da die manuelle Zählung mit einem zu hohen VK behaftet ist. Bei der automatisierten Zählung werden jedoch keine Erythrozyten, sondern nur Ereignisse innerhalb eines vorher definierten Größenbereichs gezählt. Da bei der Erythrozytenzählung auch die Leukozyten mitgezählt werden, was aufgrund der geringen Leukozytenzahl im Vergleich zur Erythrozytenzahl normalerweise unproblematisch ist, kommt es bei Leukozytenzahlen $>100 \mathrm{G} / \mathrm{L}$ zu einer signifikant erhöht gemessenen Erythrozytenzahl. Auch Riesenthrombozyten werden bei den automatisierten Systemen als Erythrozyten mitgemessen, was zu falsch niedrigen Thrombozytenwerten führt. Dies hat dann direkte Auswirkungen auf die - Erythrozyten-Indices MCH, MCV und kann zu Falschinterpretationen in der Anämiediagnostik führen.

\section{Literatur}

Thomas L (2012) Erythrozyten. In: Thomas L (Hrsg) Labor und diagnose, 8. Aufl. TH-Books Verlagsgesellschaft, Frankfurt, S 818-826

\section{Erythrozytenzylinder}

- Zylinder im Urin

\section{Erythrozytose}

$\checkmark$ Polyglobulie 


\section{Esbach-Hayward-Albuminometer}

- Esbach-Probe

\section{Esbach-Probe}

W. G. Guder

Synonym(e) Albuminometer nach Esbach; Esbach-Hayward-Albuminometer

Englischer Begriff Esbach's albuminometer test

Definition Historische Methode zur quantitativen Erfassung von Protein im Urin mithilfe von Pikrinsäure.

Beschreibung Das von Georg Hubert Esbach (1843-1890) entwickelte Albuminometer beruht auf der Beobachtung, dass Urinalbumin (Protein) ausfällt, wenn dem Urin Pikrinsäure zugesetzt wird. Das Reagenz bestand aus $10 \mathrm{~g}$ Pikrinsäure, 20 g Citronensäure ad 1 L destilliertes Wasser. Ein bis zur Marke mit Urin gefülltes Esbach-Röhrchen wurde mit einigen Milliliter Reagenz bis zur Marke $\mathrm{R}$ versetzt und das Röhrchen nach Umschwenken für 24 Stunden unter Lichtabschluss stehen gelassen. Die niedergeschlagene Proteinmenge konnte am Röhrchen in Promill (g/L) abgelesen werden.

Dieser unspezifische und zeitaufwendige Test wurde von Aufrecht modifiziert, indem nach Zusatz der Pikrinsäure das Röhrchen gemischt und 2-3 Minuten zentrifugiert wurde, sodass die Ablesung nach wenigen Minuten möglich war.

Das Verfahren hat sich bis in die 1950er-Jahre gehalten, ist jedoch heute vollständig von quantitativen Methoden zur Proteinbestimmung im Urin abgelöst ( $\triangleright$ Protein, gesamt im Urin).

\section{Literatur}

Hallmann L (1980) Klinische Chemie und Mikroskopie, 11. Aufl. Georg Thieme Verlag, Stuttgart

\section{ESI}

- Ionisationsmethoden (Massenspektrometrie)

- Massenspektrometrie

\section{ESR}

Blutkörperchensenkungsgeschwindigkeit nach Westergren

\section{Essenzielle Fettsäuren}

- Vitaminoide

\section{Essigsäurealdehyd}

- Acetaldehyd

\section{Essigsäuresalz}

$>$ Acetat

\section{Esterasenachweis mit $\alpha$ -} Naphthylacetat

- $\alpha$-Naphthylacetat-Esterase-Reaktion

\section{Estradiol}

M. Bidlingmaier

Synonym(e) Östradiol; 17 $\beta$-Estradiol; 1,3,5(10)-Estratrien3,17ß-diol; $\mathrm{E}_{2}$

Englischer Begriff oestradiol; 17 $\beta$-estradiol; estra -1,3,5(10)triene-3,17 $\beta$-diol; E2

Definition C18-Steroid, außerhalb der Schwangerschaft bedeutsamstes der natürlichen $>$ Estrogene bei der Frau im reproduktionsfähigen Alter.

Struktur $\mathrm{C}_{18} \mathrm{H}_{24} \mathrm{O}_{2}$. Die Bezeichnung $\mathrm{E}_{2}$ bezieht sich auf die 2 im Estradiolmolekül vorhandenen Hydroxygruppen.

Molmasse 272,38 Da. 
Synthese - Verteilung - Abbau - Elimination Estradiol entsteht im Rahmen der Steroidbiosynthese aus $>$ Androstendion, wobei abhängig von Lebensalter und Gewebe 2 Stoffwechselwege bedeutsam sind: Einerseits wird $>$ Androstendion $\mathrm{zu}$ - Estron aromatisiert, das dann durch eine17 $\beta$-HydroxysteroidDehydrogenase in Estradiol umgewandelt wird. Dieser hauptsächlich in den Granulosazellen der Ovarien unter FSH-Einfluss ablaufende Syntheseweg spielt bei der Frau im reproduktionsfähigen Alter die größte Rolle. Daneben kann > Androstendion auch in $>$ Testosteron überführt werden, aus dem dann durch Aromatisierung Estradiol entsteht. Geringere Mengen Estradiol werden auch in anderen Organen wie Nebenniere, Fettgewebe und Gehirn sowie beim Mann in den Hoden gebildet. Estradiol zirkuliert zu einem großen Teil (98 \%) gebunden an Albumin und $\triangleright$ Sexualhormon-bindendes Globulin, lediglich $2 \%$ sind frei und können somit den intrazellulären Rezeptor erreichen. Estradiol unterliegt verschiedenen Abbauwegen. Unter anderem erfolgt eine Metabolisierung hin zu den weniger aktiven $>$ Estrogene $>$ Estron und $>$ Estriol sowie eine unspezifische Hydroxylierung durch verschiedene Cytochrome P450 (CYP) Enzyme in der Leber. Dort wird Estradiol zudem unterschiedlich konjugiert (Sulfatierung, Glukuronidierung) und hauptsächlich renal, in geringem Umfang auch über die Gallenwege in den Darm eliminiert.

Halbwertszeit Ca. 15 Stunden.

Pathophysiologie Estradiol ist das potenteste $>$ Estrogene. Bei der Frau erfolgt ab der Menarche eine an den Menstruationszyklus gekoppelte, mehrphasige Sekretion. Auf niedrige Estradiolkonzentrationen in der frühen Follikelphase folgt ein deutlicher Anstieg gegen die Zyklusmitte mit Sekretionsmaximum kurz vor der Ovulation. Danach sinken die Konzentrationen, zeigen über die Lutealphase aber ein Plateau auf mittlerem Niveau und erreichen erst gegen Zyklusende wieder die niedrigen Konzentrationen der frühen Follikelphase. Beim Mann und bei postmenopausalen Frauen liegen die Estradiolkonzentrationen dagegen stabil auf einem noch niedrigeren Niveau. Stark erhöhte Estradiolwerte finden sich in der Schwangerschaft.

Charakteristische Funktionen des Estradiols bei der geschlechtsreifen, prämenopausalen Frau sind die Induktion von Wachstum des Uterus und des Endometriums mit zunehmender Vaskularisierung sowie die Veränderung der Zusammensetzung des Zervixschleims. Außerdem stimuliert Estradiol die Ausbildung sekundärer weiblicher Geschlechtsmerkmale. Neben reproduktiven Geweben beeinflusst Estradiol auch das Zentralnervensystem, die Knochen sowie die Synthese vieler Proteine in der Leber. Letzteres erklärt auch die Effekte auf das Gerinnungssystem.

Störungen der komplexen Regulation der Ovarialfunktion auf unterschiedlichsten Ebenen führen zu Veränderungen der Estradiolsekretion und - aufgrund der zentralen Bedeutung des Estradiols für viele reproduktive Prozesse - nachfolgend Störungen der Fertilität.

Untersuchungsmaterial Serum, Plasma.

Probenstabilität Bis 24 Stunden bei Raumtemperatur, eingefroren $\left(-20^{\circ} \mathrm{C}\right)$ mehrere Jahre.

Präanalytik Die Erfassung des Zykluszeitpunkts zum Zeitpunkt der Blutentnahme ist für eine sinnvolle Interpretation der Messergebnisse unerlässlich.

Analytik Immunoassay. Gaschromatographie-Massenspektrometrie, zunehmend Flüssigkeitschromatographie-Massenspektrometrie.

Estradiolassays müssen einen breiten linearen Messbereich aufweisen, um die physiologischerweise vorkommenden sehr unterschiedlichen Konzentrationsbereiche abdecken zu können.

\section{Konventionelle Einheit $\mathrm{pg} / \mathrm{mL}$}

Internationale Einheit $\mathrm{pmol} / \mathrm{L}$.

Umrechnungsfaktor zw. konv. u. int. Einheit $1 \mathrm{pg} / \mathrm{mL}=$ $3,671 \mathrm{pmol} / \mathrm{L}$.

Referenzbereich - Erwachsene Die Messergebnisse sind stark von der verwendeten Assaymethodik abhängig. Daher müssen Referenzbereiche methodenspezifisch validiert sein.

Frauen:

- Follikelphase $12-170 \mathrm{pg} / \mathrm{mL}$

- Ovulationsphase $85-500 \mathrm{pg} / \mathrm{mL}$

- Lutealphase 40-200 pg/mL

- Schwangerschaft $200->4000 \mathrm{pg} / \mathrm{mL}$

- Postmenopause $<50 \mathrm{pg} / \mathrm{mL}$

Männer: $<50 \mathrm{pg} / \mathrm{mL}$

Referenzbereich - Kinder Die Messergebnisse sind stark von der verwendeten Assaymethodik abhängig. Daher müssen Referenzbereiche methodenspezifisch validiert sein. $\mathrm{Au}-$ Berdem sind Referenzbereiche bei Kindern und Adoleszenten stark abhängig vom genauen Alter sowie der Pubertätsentwicklung. Laboratorien müssen entsprechend detaillierte, validierte Referenzbereiche vorhalten.

Bei Kindern unter 10 Jahren liegen die gemessenen Konzentrationen typischerweise $<30 \mathrm{pg} / \mathrm{mL}$.

\section{Indikation}

- Beurteilung der Ovarialfunktion 
- Abklärung von Störungen der gonadotropen Achse bei der Frau

- Verlaufskontrolle hormoneller Sterilitätstherapie

- Abklärung Gynäkomastie beim Mann

- Estradiolproduzierende Tumoren sind selten (z. B. Granulosazelltumoren)

Interpretation Reduzierte Werte finden sich bei Ovarialinsuffizienz (oft $<10 \mathrm{pg} / \mathrm{mL}$ ), anovulatorischen Zyklen sowie bei Corpus-luteum-Insuffizienz. Die engmaschige Bestimmung des Estradiol wird in der hormonellen Sterilitätstherapie zusammen mit dem Ultraschallbefund zur Bestimmung des optimalen Zeitpunkts der hormonellen Auslösung der Ovulation verwendet.

Diagnostische Wertigkeit S. Pathophysiologie, Referenzbereich und Interpretation.

\section{Literatur}

Ketha H, Girtman A, Singh RJ (2015) Estradiol assays - the path ahead. Steroids 99(Pt A):39-44

Miller WL, Auchus RJ (2011) The molecular biology, biochemistry, and physiology of human steroidogenesis and its disorders. Endocr Rev 32(1):81-151

Tavita N, Greaves RF (2017) Systematic review of serum steroid reference intervals developed using mass spectrometry. Clin Biochem 50(18):1260-1274

\section{$17 \beta$-Estradiol}

$\checkmark$ Estradiol

1,3,5(10)-Estratrien-3,17 $\beta$-diol

$\checkmark$ Estradiol

Estra-1,3,5(10)-trien-3,16 $\alpha, 17 \beta$-triol

- Estriol

\section{Estriol}

M. Bidlingmaier

$\operatorname{Synonym(e)~} 16 \alpha$-Hydroxy-17 $\beta$-estradiol; $E_{3}$; Estra-1,3,5(10)trien-3,16 $\alpha, 17 \beta$-triol; Östriol
Englischer Begriff oestriol; 16 $\alpha$-hydroxyestradiol; estra1,3,5(10)-triene-3,16 $\alpha, 17 \beta$-triol; $\mathrm{E}_{3}$

Definition C18-Steroid, eines der natürlichen $>$ Estrogene. Schwächer estrogenartig wirksam als $>$ Estradiol. In der Schwangerschaft aufgrund der plazentaren Metabolisierung fetaler Vorstufen quantitativ bedeutsamstes Estrogen.

Struktur $\mathrm{C}_{18} \mathrm{H}_{24} \mathrm{O}_{3}$. Die Bezeichnung $\mathrm{E}_{3}$ bezieht sich auf die 3 im Estriolmolekül vorhandenen Hydroxygruppen.

Molmasse 288,39 Da.

Synthese - Verteilung - Abbau - Elimination Anders als - Estradiol und $>$ Estron wird Estriol nicht in den Ovarien synthetisiert, sondern entsteht bei der nicht schwangeren Frau fast ausschließlich durch die vor allem von hepatischen Cytochrom-P450-Enzymen katalysierte Hydroxylierung von - Estradiol und $>$ Estron. In der Postmenopause entstammt ein nennenswerter Anteil des Estriols auch der Aromatisierung von Androstendion im Fettgewebe. Insgesamt sind bei der nicht schwangeren Frau die zirkulierenden Konzentrationen von Estriol sehr gering. Anders ist die Situation in der Schwangerschaft. Hier wird plazentar gebildetes Pregnenolon von der fetalen Nebennierenrinde und Leber metabolisiert. Aus den hierbei entstehenden Vorstufen entstehen dann über wiederum plazentar lokalisierte Enzyme große Mengen Estriol, die im Wesentlichen in die maternale Zirkulation abgegeben werden. Die Estriolproduktion in der Schwangerschaft ist quantitativ bedeutsamer als die von Estradiol und Estron, die Konzentrationen steigen bis zum dritten Trimester um den Faktor 1000 an. Estriol unterliegt wie die anderen $>$ Estrogene einer hepatischen Konjugation (Sulfatierung, Glukuronidierung). Die Ausscheidung erfolgt hauptsächlich renal.

Halbwertszeit Unkonjugiertes Estriol $<20$ Minuten.

Pathophysiologie Estriol ist ein relativ schwaches $>$ Estrogene und wird - anders als $>$ Estron - nicht zu $>$ Estradiol konvertiert. Damit ist die Estrogenaktivität des Estriols sehr gering. Störungen der fetalen Produktion von Estriol mit erniedrigten Konzentrationen wurden bei chromosomalen Aberationen (Trisomie 21) gehäuft beobachtet, was den Einsatz im Rahmen des Triple-Tests ( $\triangleright$ Triple-Test) begründete.

Untersuchungsmaterial Serum, Plasma.

Probenstabilität Bis 24 Stunden bei Raumtemperatur, eingefroren $\left(-20^{\circ} \mathrm{C}\right)$ mehrere Jahre.

Analytik Immunoassay.

Konventionelle Einheit $\mathrm{ng} / \mathrm{mL}$. 


\section{Internationale Einheit $\mathrm{nmol} / \mathrm{L}$.}

Umrechnungsfaktor zw. konv. u. int. Einheit $1 \mathrm{pg} / \mathrm{mL}=$ $3,47 \mathrm{pmol} / \mathrm{L}$.

Referenzbereich - Erwachsene Frauen (nicht schwanger): $<2 \mathrm{ng} / \mathrm{mL}$.

Während der Schwangerschaft deutlicher Anstieg der Konzentrationen bis über $30 \mathrm{ng} / \mathrm{mL}$ im 3. Trimester, methodenspezifische Referenzbereiche nach Schwangerschaftswoche erforderlich.

Indikation Einsatz im Rahmen vom $>$ Triple-Test, zur Indikation s. dort.

Interpretation Die Interpretation erfolgt im Rahmen der Auswertung des Triple-Tests ( $>$ Triple-Test).

Diagnostische Wertigkeit $>$ Triple-Test.

\section{Literatur}

Albrecht ED, Pepe GJ (1990) Placental steroid hormone biosynthesis in primate pregnancy. Endocr Rev 11(1):124-125

Yao Y, Liao Y, Han M, Li SL, Luo J, Zhang B (2016) Two kinds of common prenatal screening tests for Down's syndrome: a systematic review and meta-analysis. Sci Rep 6:18866. https://doi.org/10.1038/ srep 18866

\section{Estrogene}

M. Bidlingmaier

Synonym(e) Follikelhormone; Östrogene; Weibliche Sexualhormone

\section{Englischer Begriff estrogens}

Definition Oberbegriff für die weiblichen Sexualhormone. Chemisch sind damit die natürlichen oder synthetischen C19-Steroide gemeint, deren Struktur sich vom Estran (auch: 13ß-Methyl-gonan) ableitet. Die wichtigsten Estrogene beim Menschen sind Estradiol, Estron und Estriol.

Beschreibung. Estrogene entstehen durch Aromatisierung von $>$ Testosteron. Dieser über das Enzym $>$ Aromatase vermittelte Schritt erfolgt bei der Frau hauptsächlich in den Granulosazellen der präovulatorischen Graaf-Follikel sowie später im Corpus luteum, zudem während der Schwangerschaft in der Plazenta. Beim Mann findet sich eine altersab- hängig in unterschiedlichen Zelltypen lokalisierte Expression der Aromatase im Hoden. Präpubertär zeigt sie sich vor allem in den Sertoli-Zellen, postpubertär in Leydig-Zellen, ferner in Keimzellen und Spermien. Zudem findet sich die Aromatase bei beiden Geschlechtern in der Nebennierenrinde und im Fettgewebe. Wie die Androgene zirkulieren die Estrogene zum größten Teil gebunden an Proteine. Neben der relativ schwachen Bindung an Albumin und kortisolbindendes Globulin (CBG) erfolgt eine spezifische Bindung an - Sexualhormon-bindendes Globulin (SHBG). Diese hat allerdings eine geringere Affinität als die von $>$ Dihydrotestosteron und $>$ Testosteron. Die Ausscheidung der Estrogene erfolgt nach Glucuronidierung renal.

Die Wirkung der Estrogene wird über nukleäre Estrogenrezeptoren vermittelt. Während des weiblichen Zyklus sind die Estrogene wesentlich an der Regulation der Follikereifung, der hypophysären Sekretion von luteinisierendem Hormon (LH, s. > Luteinisierendes Hormon) und follikelstimulierendem Hormon (FSH; s. > Follikelstimulierendes Hormon), dem Aufbau der Gebärmutterschleimhaut sowie der Konsistenz des Zervixschleims beteiligt. Neuere Untersuchungen belegen auch eine Wirkung in der Regulation der männlichen Fertilität. Darüber sind Estrogeneffekte auf nahezu alle Gewebe beschrieben. So regulieren sie den Knochenstoffwechsel, die renale Natriumund Wasserretention, die Basaltemperatur, aber auch zentralnervöse Vorgänge und das Immunsystem.

Therapeutisch ist die Gabe von Estrogenen zentrales Wirkprinzip der meisten Kontrazeptiva. Reine oder partielle Estrogen-Rezeptorantagonisten oder auch Inhibitoren der Aromatase werden therapeutisch beim hormonsensitiven Mammakarzinom eingesetzt.

\section{Literatur}

Cooke PS, Nanjappa MK, Ko C, Prins GS, Hess RA (2017) Estrogens in male physiology. Physiol Rev 97(3):995-1043

Miller WL, Auchus RJ (2011) The molecular biology, biochemistry, and physiology of human steroidogenesis and its disorders. Endocr Rev 32(1):81-151. https://doi.org/10.1210/er.2010-0013

Simpson ER, Misso M, Hewitt KN, Hill RA, Boon WC, Jones ME, Kovacic A, Zhou J, Clyne CD (2005) Estrogen - the good, the bad, and the unexpected. Endocr Rev 26(3):322-330

\section{Estron}

M. Bidlingmaier

Synonym(e) 3-Hydroxyestra-1,3,5(10)-trien-17-on; E E $_{1}$ Östron

Englischer Begriff estrone; oestrone; estra-1,3,5(10)-triene3-ol-17-one; $\mathrm{E}_{1}$ 
Definition C18-Steroid, eines der natürlichen $>$ Estrogene. Schwächer estrogenartig wirksam als $>$ Estradiol, quantitativ bedeutsamstes Estrogen in der Postmenopause und beim Mann.

Struktur $\mathrm{C}_{18} \mathrm{H}_{22} \mathrm{O}_{2}$. Die Bezeichnung $\mathrm{E}_{1}$ bezieht sich auf die eine im Estronmolekül vorhandene Hydroxygruppe.

Molmasse 270,36 Da.

Synthese - Verteilung - Abbau - Elimination Estron entsteht einerseits durch die Aromatisierung von $>$ Androstendion. Im Gegensatz zum Estradiol ist dieser Stoffwechselweg beim Estron nur zu ca. $50 \%$ in den Gonaden lokalisiert, der übrige Teil des vom Androstendion stammenden Estrons entsteht durch periphere Aromatisierung, vornehmlich im Fettgewebe. Andererseits kann Estron auch aus $>$ Estradiol entstehen, da die $17 \beta$-Hydroxysteroid-Dehydrogenase permanent beide Estrogene reversibel ineinander umwandelt. In Zirkulation ist Estron wie > Estradiol zu einem großen Teil (98 \%) proteingebunden. Estron hat jedoch eine niedrigere Affinität zum $\triangleright$ Sexualhormon-bindendes Globulin als Estradiol, der größte Teil des Estrons ist an Albumin gebunden. Neben der Konversion in Estradiol unterliegt Estron einer hepatischen Konjugation insbesondere zu Estronsulfat und Estronglukuronid. Das in hohen Konzentrationen zirkulierende Estronsulfat kann über die Steroidsulfatase hydrolisiert und so wieder in Estron umgewandelt werden, aus dem über die $17 \beta$-Hydroxysteroid-Dehydrogenase das Estradiol entsteht. Somit kann das Estronsulfat auch als eine Art Estrogenspeicher betrachtet werden. Die Ausscheidung des Estrons erfolgt hauptsächlich renal, in geringem Umfang auch über die Gallenwege.

\section{Halbwertszeit 20-30 Minuten.}

Pathophysiologie Estron ist ein relativ schwaches $\triangleright$ Estrogene, es hat eine deutlich geringere Affinität zum Estrogenrezeptor als Estradiol und verfügt nur über ca. $4 \%$ von dessen Estrogenaktivität. In vivo ist ein Großteil der Estrogenaktivität des Estrons auf die Konversion in Estradiol zurückzuführen. Nachdem es zu einem bedeutenden Teil extragonadalen Ursprunges ist, spielt das Estron als Estrogenquelle einerseits beim Mann und bei der postmenopausalen Frau, andererseits aufgrund der starken Aromataseaktivität des Fettgewebes bei der Adipositas eine Rolle. Die geringere Abhängigkeit von der ovariellen Synthese erklärt, warum der Estronabfall in der Menopause nicht so stark ausgeprägt ist wie der Estradiolabfall. Höhere Estronkonzentrationen in der Postmenopause sind einerseits mit einem geringeren Risiko für osteoporotische Frakturen, andererseits mit einem höheren Risiko für Endometriumatypien assoziiert.
Untersuchungsmaterial Serum, Plasma.

Probenstabilität Bis 24 Stunden bei Raumtemperatur, eingefroren $\left(-20^{\circ} \mathrm{C}\right)$ mehrere Jahre.

Präanalytik Trotz der verglichen mit Estradiol geringeren Zyklusabhängigkeit ist die Erfassung des Zykluszeitpunkts zum Zeitpunkt der Blutentnahme für die Interpretation der Messergebnisse sinnvoll.

Analytik Immunoassay. Gaschromatographie-Massenspektrometrie, zunehmend Flüssigkeitschromatographie-Massenspektrometrie.

\section{Konventionelle Einheit $\mathrm{pg} / \mathrm{mL}$.}

Internationale Einheit $\mathrm{pmol} / \mathrm{L}$.

Umrechnungsfaktor zw. konv. u. int. Einheit $1 \mathrm{pg} / \mathrm{mL}=$ $3,699 \mathrm{pmol} / \mathrm{L}$.

Referenzbereich - Erwachsene Die Messergebnisse sind stark von der verwendeten Assaymethodik abhängig. Daher müssen Referenzbereiche methodenspezifisch validiert sein.

Frauen:

- Follikelphase: $50-100 \mathrm{pg} / \mathrm{mL}$

- Lutealphase: $100-300 \mathrm{pg} / \mathrm{mL}$

- Postmenopause: $10-60 \mathrm{pg} / \mathrm{mL}$

Männer: $10-60 \mathrm{pg} / \mathrm{mL}$

\section{Indikation}

- Beurteilung der Ovarialfunktion

- Abklärung von Störungen der gonadotropen Achse bei der Frau

- Verlaufskontrolle hormoneller Sterilitätstherapie

- Abklärung Gynäkomastie beim Mann

- Estradiolproduzierende Tumoren

Interpretation Reduzierte Werte finden sich bei Ovarialinsuffizienz (oft $<10 \mathrm{pg} / \mathrm{mL}$ ), anovulatorischen Zyklen sowie bei Corpus-luteum-Insuffizienz.

Die engmaschige Bestimmung des Estradiols wird in der hormonellen Sterilitätstherapie zusammen mit dem Ultraschallbefund zur Bestimmung des optimalen Zeitpunkts der hormonellen Auslösung der Ovulation verwendet.

Im Unterschied zur transdermalen oder parenteralen Applikation von Estrogenen kommt es bei der oralen Estrogenzufuhr (orale Kontrazeption) zu einer starken Umwandlung von Estradiol in Estron in der Leber. Abhängig von Ausmaß und Richtung der reversiblen Konversion in Estra- 
diol können so teilweise hohe Estronkonzentrationen im Blut gefunden werden.

Zum Teil drastisch erhöhte Werte finden sich auch bei den sehr seltenen estradiolproduzierenden Tumoren (z. B. Granulosazelltumoren).

Diagnostische Wertigkeit S. Pathophysiologie, Referenzbereich und Interpretation. Insgesamt ist Estron ein guter Parameter zur Beurteilung des Estrogenstatus in der Periund Postmenopause.

\section{Literatur}

Cooke PS, Nanjappa MK, Ko C, Prins GS, Hess RA (2017) Estrogens in male physiology. Physiol Rev 97(3):995-1043

Reed MJ, Purohit A, Woo LW, Newman SP, Potter BV (2005) Steroid sulfatase: molecular biology, regulation, and inhibition. Endocr Rev 26(2):171-202. Epub 23 Nov 2004

Wang Q, Bottalico L, Mesaros C, Blair IA (2015) Analysis of estrogens and androgens in postmenopausal serum and plasma by liquid chromatography-mass spectrometry. Steroids 99(Pt A):76-83

\section{Etalon}

$\triangleright$ Normal

EtG

- Ethylglukuronid

\section{Ethanal}

Acetaldehyd

\section{Ethandiolsäure}

> Oxalsäure

\section{Ethanol}

A. M. Gressner und O. A. Gressner

Synonym(e) Alkohol; Äthanol; Blutalkohol; Ethylalkohol; $\mathrm{EtOH}$
Englischer Begriff ethanol; ethyl alcohol; grain alcohol; alcohol

Definition Ethanol (Summenformel: $\mathrm{C}_{2} \mathrm{H}_{6} \mathrm{O}$ ) ist eine klare, farblose, in Wasser unbeschränkt lösliche Flüssigkeit mit toxischer Wirkung, die nach oraler Aufnahme intestinal resorbiert wird, sich in Körpergeweben proportional zu deren Wassergehalt verteilt und vorwiegend in der Leber schnell oxidativ metabolisiert wird.

Molmasse $46,07 \mathrm{~g}$.

Synthese - Verteilung - Abbau - Elimination Ethanol $\left(\mathrm{CH}_{3} \mathrm{CH}_{2} \mathrm{OH}\right)$ wird nach oraler Aufnahme zu ca. $25 \%$ bereits im Magen und zu $75 \%$ im Duodenum und Jejunum aufgrund seiner geringen Molmasse (46,07 g), seiner guten Wasserlöslichkeit und geringen Löslichkeit in Lipiden durch einfache Diffusion resorbiert. Die Resorptionsrate ist verzögert bei gefülltem Intestinum. Die Gewebeverteilung ist direkt proportional zu ihrem Wassergehalt. Da Alkohol nur gering gradig fettlöslich ist, nehmen die Gewebelipide nur etwa $4 \%$ des Ethanols auf. Deshalb ist die Blutalkoholkonzentration bei adipösen Patienten, die dieselbe Menge wie normgewichtige Probanden aufnehmen, deutlich höher.

Das intestinal resorbierte Ethanol wird über die Pfortader der Leber zugeführt, die an der Ethanolelimination mit 90-95\% beteiligt ist (die > Alkoholdehydrogenasen der Magenmukosa metabolisieren ca. $5 \%$, über die Lunge werden etwa $5 \%$ und über die Niere etwa $1 \%$ des resorbierten Ethanols ausgeschieden). Ein normgewichtiger Mann eliminiert ca. $100 \mathrm{mg}$ Ethanol $/ \mathrm{kg} \mathrm{KG} /$ Stunde entsprechend $7 \mathrm{~g}$ Ethanol/Stunde bei einer $70 \mathrm{~kg}$ schweren Person. Auf Serum (Blut) bezogen beträgt die mittlere Abbaurate/Stunde 0,18 g/ L Serum $(0,15 \mathrm{~g} / \mathrm{kg}$ Vollblut).

Der Metabolismus erfolgt nahezu ausschließlich oxidativ (90-95\%) zu $\triangleright$ Acetaldehyd, $\triangleright$ Acetat und letztlich $\mathrm{CO}_{2}$ und Wasser, nur eine kleine Fraktion wird nichtoxidativ durch Veresterung von Ethanol mit langkettigen > Fettsäuren (Fettsäureethylesterbildung) in Pankreas und Leber metabolisiert oder zu > Ethylglukuronid, > Ethylsulfat und Ethylphosphat konjugiert. Der oxidative Abbau in den Hepatozyten kann grundsätzlich über 3 Abbauwege erfolgen (Abb. 1):

- Der Hauptabbauweg (ca. 75-80 \% des hepatischen Ethanolabbaus) erfolgt unter physiologischen Bedingungen durch die Alkoholdehydrogenase (ADH), die in Anwesenheit von $\mathrm{NAD}^{+}$als Coenzym die Oxidation zum Acetaldehyd katalysiert. Das Reaktionsprodukt Acetaldehyd wird nach Aufnahme in die Mitochondrien durch die dort lokalisierte Acetaldehyddehydrogenase $(\mathrm{Km}$-Wert ca. $1 \mu \mathrm{mol} / \mathrm{L})$ in Anwesenheit von $\mathrm{NAD}^{+}$zu Acetat abgebaut, um schließlich in Acetylcoenzym A umgewandelt und in den Intermediärstoffwechsel der Leber eingeschleust zu werden. Eine grö- 


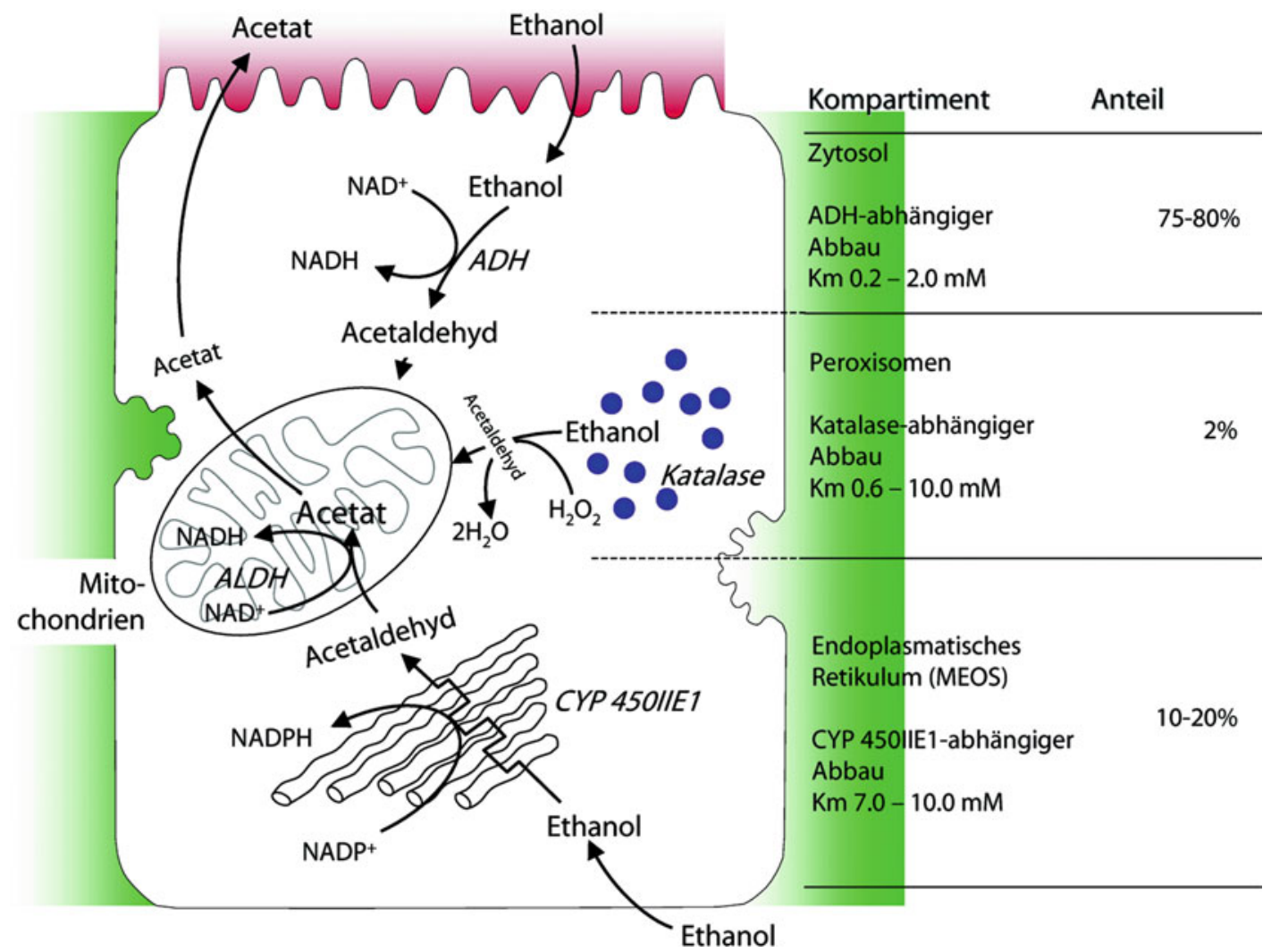

Ethanol, Abb. 1 Oxidative Metabolisierung des Ethanols

ßere Fraktion gelangt über die systemische Zirkulation zum oxidativen Endabbau in periphere Gewebe.

- Das mikrosomale Ethanol oxidierende System (MEOS) ist im endoplasmatischen Retikulum (Mikrosomenfraktionen) der Hepatozyten gelegen und mit etwa 10-20\% am oxidativen Ethanolabbau beteiligt. Die Cytochrom P450 II E1 (CYP II E1) ist aufgrund ihres höheren $\mathrm{Km}$-Werts von 7-10 $\mathrm{mmol} / \mathrm{L}$ erst bei höherem Substratangebot (Blutalkohol $>1,2 \mathrm{~g} / \mathrm{L}$ Serum bzw. 1,0 g/kg Vollblut) am Ethanolabbau beteiligt. Im Gegensatz zum ADH-Abbauweg ist das MEOS-Enzymsystem durch chronischen Alkoholkonsum und einige im Biotransformationssystem metabolisierte Medikamente (Xenobiotika) stark induzierbar. Damit ergeben sich klinisch wichtige Interferenzen von Alkohol- und Xenobiotikastoffwechsel, die zur Beschleunigung (durch Induktion) oder Hemmung (durch Kompetition) führen können.

- Katalaseabbauweg in den Peroxisomen. Weniger bedeutsam ist der von Katalase katalysierte Oxidationsweg von Ethanol durch Wasserstoffperoxid $\left(\mathrm{H}_{2} \mathrm{O}_{2}\right)$ zum Acetaldehyd, der aufgrund seines hohen $\mathrm{Km}$-Werts von $0,6-10$ $\mathrm{mmol} / \mathrm{L}$ konzentrationsabhängig nur mit etwa $2 \%$ am Ethanolabbau beteiligt ist. Geschwindigkeitsbestimmend ist die physiologische Rate der $\mathrm{H}_{2} \mathrm{O}_{2}$-Produktion, die unter Normalbedingungen gering ist.
Funktion - Pathophysiologie Metabolische Konsequenzen des Ethanolstoffwechsels. Sie bewegen sich auf drei Ebenen:

Direkte Wirkungen des Ethanols (Abb. 2)

Neben physikalischen Veränderungen der Plasmamembranen (Fluidität), der mikrosomalen Enzyminduktion und der Aktivierung von Kupffer-Zellen zur Sekretion wichtiger Zytokine kommt es zur Beeinträchtigung der rezeptorvermittelten Endozytose von zirkulierenden Plasmaproteinen.

\section{Ethanolinduzierte Änderung des Redoxstatus (Abb. 3)}

Beim oxidativen Ethanolabbau kommt es zu einem Anstieg des hepatischen NADH/NAD ${ }^{+}$-Verhältnisses, als deren Folge neben verminderter Fettsäureoxidation und Erhöhung der Triglyzeridsynthese, Hyperlaktatämie, Hemmung der Glukoneogenese und andere Veränderungen bedeutsam sind. Die Reoxidationsrate von NAD(P)H ist nicht nur für den oxidativen Ethanolabbau, sondern auch für die Redoxstatusabhängigen metabolischen Effekte des Alkohols entscheidend.

Toxische Wirkungen von Acetaldehyd und Lipidperoxidation (Abb. 4)

Der hochreaktive Acetaldehyd trägt zur Fibrogenese chronischer alkoholischer Lebererkrankungen, zur Bildung von 


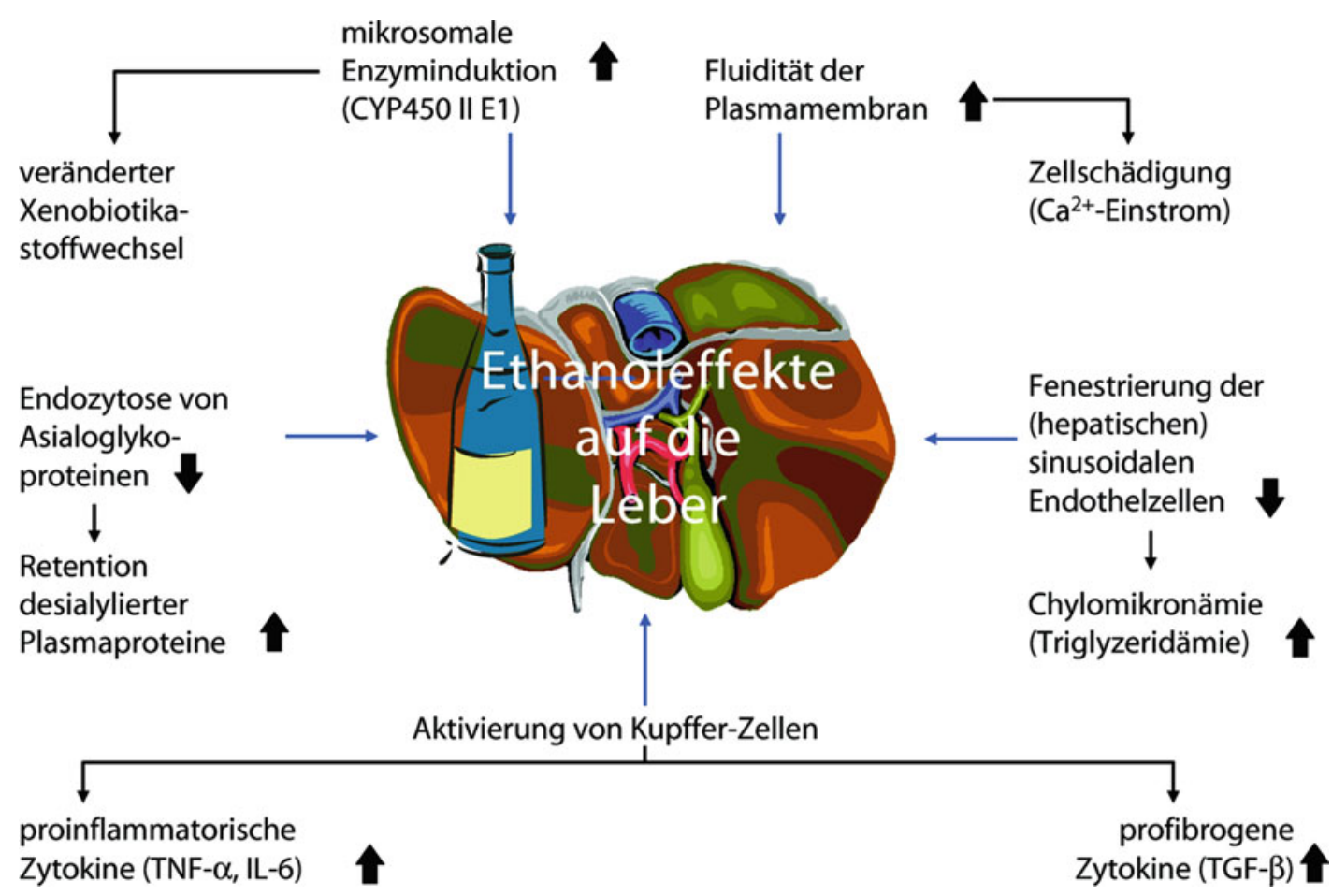

Ethanol, Abb. 2 Ethanoleffekte auf die Leber. $\uparrow=$ erhöht; $\downarrow=$ vermindert

Ethanol, Abb. 3 Ethanoleffekte auf den NADH-NAD-Quotienten. $\uparrow=$ erhöht; $\downarrow=$ vermindert

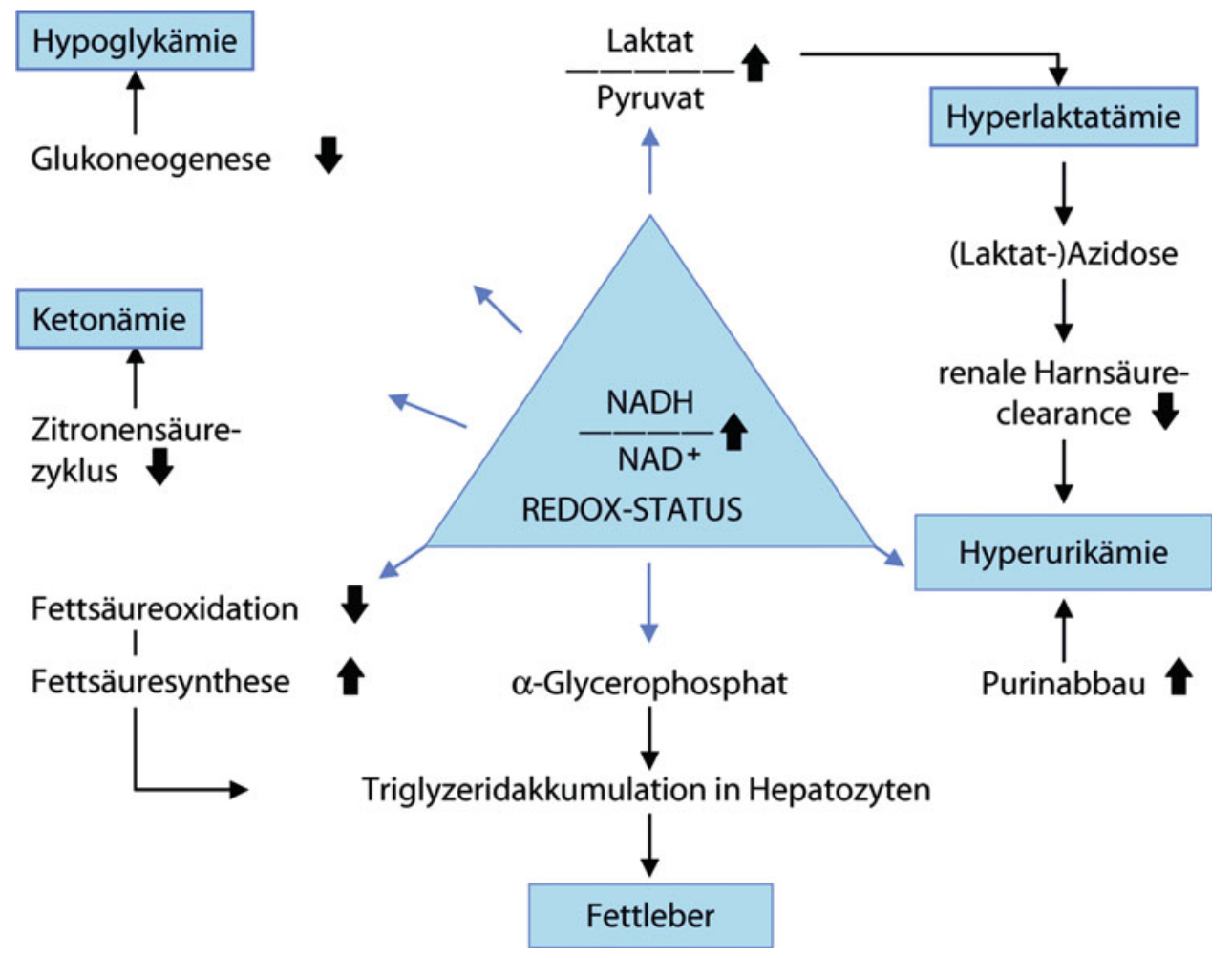

Proteinaddukten und zur Lipidperoxidation von Zellmembranen bei. Durch Bildung kovalenter Verbindungen zwischen Acetaldehyd und Hämoglobin, Kollagen, Phospholipiden,
Cytochrom P450 II E1 und Plasmaproteinen können Neoantigene entstehen, die zur Autoantikörperbildung führen und für die Pathogenese alkoholischer Organschäden bedeutsam sind. 
Ethanol, Abb. 4 Effekte von Azetaldehyd. EZM, extrazelluläre Matrix; $\uparrow=$ erhöht;

$\downarrow=$ vermindert

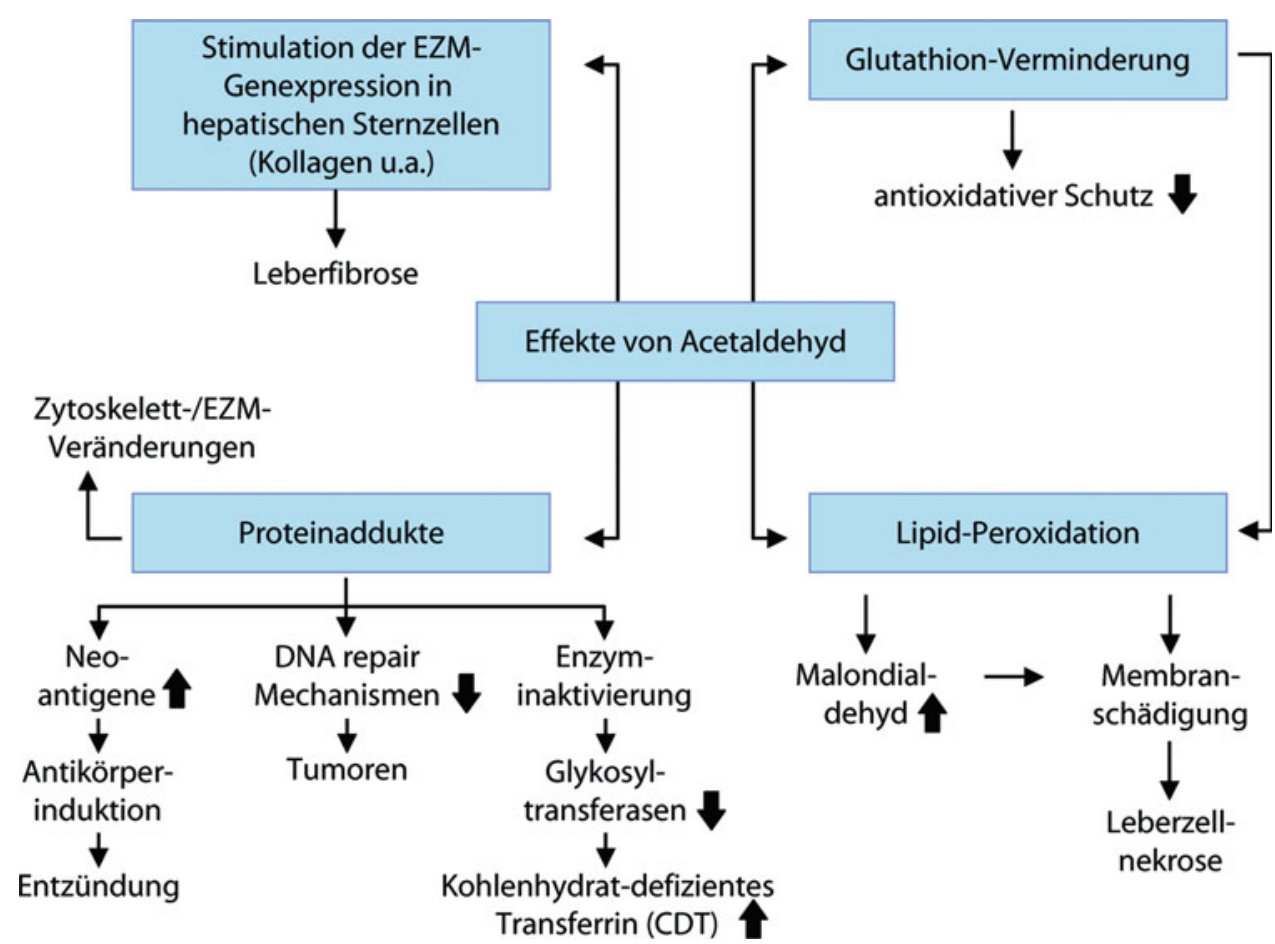

Untersuchungsmaterial - Entnahmebedingungen Serum, Plasma (Heparin-, EDTA-, Fluorid- oder Oxalat-Plasma), Vollblut (nach Enteiweißung mit Trichloressigsäure), Spontanurin.

Präanalytik Die Probenentnahme muss Kontaminationen vermeiden (keine Desinfektion mit Alkohol!). Wegen Verdunstung von Alkohol muss das Probengefäß möglichst vollständig gefüllt und fest verschlossen sein und darf nicht länger als 5 Minuten offen stehen. Für forensische Zwecke werden Kunststoffvenülen in verschiedener Ausführung, z. B. Vacutainer, oder andere Varianten als Entnahmegefäße gefordert.

Analytik Es stehen heute grundsätzlich zwei Methoden zur Verfügung:

Enzymatische Methode Ethanol und $\mathrm{NAD}^{+}$werden unter Mitwirkung von Alkoholdehydrogenase (ADH) zu Acetaldehyd und $\mathrm{NADH}+\mathrm{H}^{+}$gemäß folgender Reaktion umgesetzt:

$$
\text { Ethanol }+\mathrm{NAD}^{+} \stackrel{\mathrm{ADH}}{\rightleftarrows} \text { Acetaldehyd }+\mathrm{NADH}+\mathrm{H}^{+}
$$

Die Menge des gebildeten $\mathrm{NADH}+\mathrm{H}^{+}$, photometrisch durch Absorptionszunahme bei 334 oder 366 nm gemessen, ist der Ethanolmenge direkt proportional.

Die enzymatische Methode ist spezifisch für Alkohole, weist einen intraseriellen VK von 1,2\% und eine Nachweisgrenze von $0,1 \mathrm{~g} / \mathrm{L}$ auf. Stärkere Hämolyse (Hämoglobin) führt zu signifikanter negativer Beeinflussung der Messreak- tion. Die Methode ist für klinisch-toxikologische Untersuchungen gut geeignet.

Head-Space-> Gaschromatographie Sie stellt ein spezifisches Verfahren zur quantitativen Ethanolbestimmung in Blut- und Urinproben dar, die aufgrund folgender Kriterien für forensisch-toxikologische Untersuchungen geeignet ist: gute Differenzierbarkeit von Ethanol und anderen flüchtigen Substanzen, gute Reproduzierbarkeit, weitgehende Automatisierung, kurze Analysendauer. Die Dampfraumanalyse (Head-Space-Analyse) gilt heute als anerkanntes Verfahren. Das Probengefäß wird auf eine eingestellte Temperatur thermostatisiert, sodass sich ein dynamisches Gleichgewicht zwischen der flüssigen Phase und der Gasphase einstellt. Analysiert wird nur die Dampfphase, was eine Bestimmung flüchtiger Substanzen unabhängig von der Probenmatrix ermöglicht. Bei der Ethanolbestimmung erfolgt die Quantifizierung über den internen Standard tert-Butanol.

$\mathrm{Zu}$ den aktuellen Anforderungen für forensische Blut- oder Serumethanolanalysen (Blutalkoholanalysen) siehe die in der Literatur genannten Richtlinie in ihrer jeweils aktuellen Version unter www.gtfch.org. Ethanolanalysen unter klinischchemischen Bedingungen, $d$. h. ohne oder nur mit teilweiser Beachtung der in dieser Richtlinie gelisteten präanalytischen, analytischen und postanalytischen Anforderungen, sind für forensische Zwecke prinzipiell nicht verwertbar.

Referenzbereich - Erwachsene Physiologische Ethanolkonzentrationen (,endogener Alkohol“) im Blut von Alkoholabstinenten betragen bis $\mathrm{zu} 0,75 \mathrm{mg} / \mathrm{L}$ entsprechend 
$0,00075 \%$. Sie sind mit den üblichen enzymatischen und auch gaschromatographischen Methoden mit Nachweisgrenzen von ca. $0,1 \%$ nicht zu erfassen. Hierzu wären sensitivere Applikationen wie die Begleitstoffanalyse mit GC-MS erforderlich (Gilg 2012).

Die Umrechnung der Serumkonzentration $(\mathrm{g} / \mathrm{L})$ in die Vollblutkonzentration $(\mathrm{g} / \mathrm{kg}=$ Promille) erfolgt durch Teilung mit 1,236, was dem Verhältnis der Wassergehalte von Serum (91 \%) zu Vollblut (76 \%) entspricht:

$$
\begin{aligned}
C_{B} & =C_{S} \times M_{r} \times D_{S}^{-1} \times W^{-1} \\
& =C_{S} \times 37,36 \times 10^{-3}
\end{aligned}
$$

$\mathrm{C}_{\mathrm{B}}$ : Ethanolkonzentration im Blut $(\mathrm{g} / \mathrm{kg})[\%$ ]

$\mathrm{C}_{\mathrm{S}}$ : Ethanolkonzentration im Serum $(\mathrm{mmol} / \mathrm{L})$

$\mathrm{M}_{\mathrm{r}}$ : relative Molmasse von Ethanol $(=46)$

$\mathrm{D}_{\mathrm{S}}$ : Dichte des Serums $(=1,026 \mathrm{~kg} / \mathrm{L}$; festgelegt $)$

W: Wasserverteilungskoeffizient zwischen Serum und Blut $(1,2 ;$ festgelegt $)$

Indikation Verdacht auf akuten oder chronischen Ethanolmissbrauch (Alkoholmissbrauch).

Interpretation Absorption, Verteilung und Abbauraten unterliegen einer Reihe von externen, individuellen und genetischen Faktoren (s. a. > Widmark-Formel und $>$ WatsonFormel).

Langzeitiger, ausgeprägter Alkoholkonsum führt durch Enzyminduktion des MEOS zu einer deutlichen Zunahme der Ethanoleliminationsrate. Durch Inhalation können maximale Ethanolkonzentrationen von $0,24 \mathrm{~g} / \mathrm{L}(0,2 \mathrm{~g} / \mathrm{kg}$ Vollblut $)$ erreicht werden. In Abhängigkeit von der Dosis wirkt Ethanol zunächst stimulierend, in höherer Dosierung hemmend oder sogar lähmend auf das ZNS. Bei akuter Intoxikation kommt es zunächst zur Erregung des Atemzentrums, Erhöhung von Pulsfrequenz, Blutdruck und Herzminutenvolumen und zur Erweiterung der Hautgefäße. Im weiteren Verlauf nimmt das Reaktionsvermögen, das Seh- und Hörvermögen ab. Ethanolkonzentrationen von $4,2-4,8 \mathrm{~g} / \mathrm{L}$ Serum $(3,5-4,0 \mathrm{~g} / \mathrm{kg}$ Vollblut $)$ gelten bei Erwachsenen als potenziell letal. Metabolische Azidose, osmotische Lücke ( $\triangleright$ Osmolalität), signifikante Hypoglykämie und Acetonurie ohne Glukosurie stellen klinisch-chemische Befunde der schweren Ethanolintoxikation dar. Das Risiko der Entwicklung einer alkoholischen Leberzirrhose steigt ab einem Schwellenwert von $20 \mathrm{~g}$ Ethanol/Tag bei Frauen und $40 \mathrm{~g}$ Ethanol/Tag bei Männern dosisabhängig an: 80-160 g Ethanol/Tag hat ein 5-fach erhöhtes, $160 \mathrm{~g}$ Ethanol/Tag ein 25-fach erhöhtes Risiko. Neben Alkoholzirrhose stellen alkoholische Fettleber und Alkoholhepatitis bekannte Manifestationen alkoholischer Lebererkrankungen dar. Als spezifische Kenngröße des chronischen Alkoholabusus gilt die Bestimmung des > Carbohydrate-deficient Transferrins (s. hierzu auch $>$ Alkoholmissbrauchskenngrößen).
Diagnostische Wertigkeit Die spezifische Ethanolbestimmung in Körperflüssigkeiten hat für klinische, toxikologische und forensische Zwecke eine herausragende Bedeutung.

\section{Literatur}

Batra A, Müller CA, Mann K et al (2016) Abhängigkeit und schädlicher Gebrauch von Alkohol. Dtsch Ärzteblatt 113(17):301-310

Deutsche Gesellschaft für Rechtsmedizin, Gesellschaft für Toxikologische und Forensische Chemie und Deutsche Gesellschaft für Verkehrsmedizin (2011) Richtlinien zur Bestimmung der Blutalkoholkonzentration (BAK) für forensische Zwecke - BAK-Richtlinien. Blutalkohol 48:137-143. www.gtfch.org. Zugegriffen am 20.06.2017

Gilg T (2012) Alkohol. In: Madea B, Mußhoff F, Berghaus G (Hrsg) Verkehrsmedizin - Fahreignung, Fahrsicherheit, Unfallrekonstruktion, 2. Aufl. Deutsche Ärzte-Verlag, Köln, S 453-485

\section{Ethanol als Einflussgröße}

- Alkohol als Einflussgröße

\section{Ethanolamin}

\section{A. C. Sewell}

Englischer Begriff ethanolamine

Definition Eine organische Verbindung, die einerseits ein primäres Amin (Aminogruppe) und andererseits ein primärer Alkohol (Hydroxylgruppe) ist.

Beschreibung Ethanolamin wird routinemäßig im Rahmen der $>$ Aminosäurenanalytik nachgewiesen. Bei Kindern ist die Urinausscheidung höher als bei Erwachsenen. Erhöhte Werte im Urin werden bei Patienten mit unspezifischen Lebererkrankungen gesehen, können aber auch durch bakterielle Kontamination aus $>$ Phosphoethanolamin entstehen.

\section{Literatur}

Bremer HJ, Duran M, Kamerling JP et al (1981) Disturbances of aminoacid metabolism: clinical chemistry and diagnosis. Urban \& Schwarzenberg, München/Baltimore

\section{Ethansäuresalz}

- Acetat 


\section{Etherelution}

- Elution erythrozytärer Antikörper

\section{Ethosuximid}

C. Vidal und W.-R. Külpmann

Englischer Begriff ethosuximide

Definition Antiepileptikum.

Strukturformel:<smiles>CCC1(C)CC(=O)NC1=O</smiles>

Molmasse $141,17 \mathrm{~g}$.

Halbwertszeit 33-55 Stunden.

Funktion - Pathophysiologie Behandlungen von generalisierten Absencen. Als Nebenwirkungen wurden Übelkeit und Erbrechen sowie Lethargie und Ataxie beobachtet.

Untersuchungsmaterial-Entnahmebedingungen Plasma (P), Serum (S).

Analytik Immunoassay, HPLC, GC, GC-MS, LC-MS/MS.

Indikation Therapeutisches Drug Monitoring, Verdacht auf Intoxikation.

Interpretation Therapeutischer Bereich (S, P): $40-100 \mathrm{mg} / \mathrm{L}$; toxisch ab $120 \mathrm{mg} / \mathrm{L}$ (Hiemke et al. 2012), komatös-letal ab $250 \mathrm{mg} / \mathrm{L}$ (Hannak et al. 2009).

\section{Literatur}

Hannak D, Külpmann WR, Hallbach J (2009) Anticonvulsants. In: Külpmann WR (Hrsg) Clinical toxicological analysis. Wiley-VCH, Weinheim, S 287-300

Hiemke C et al (2012) AGNP-Konsensus-Leitlinien für therapeutisches Drug-Monitoring in der Psychiatrie: Update 2011. Psychopharmakotherapie 19:91-122

\section{Ethylaldehyd}

- Acetaldehyd

\section{Ethylalkohol}

$>$ Ethanol

\section{Ethylendiamintetraessigsäure}

$>$ EDTA

\section{Ethylenglykol}

C. Vidal und W.-R. Külpmann

Englischer Begriff ethylene glycol

Definition $\mathrm{HO}-\mathrm{CH}_{2}-\mathrm{CH}_{2}-\mathrm{OH}$. Lösungsmittel, Frostschutzmittel.

Molmasse $62,07 \mathrm{~g}$.

Synthese - Verteilung - Abbau - Elimination Nach oraler Zufuhr wird Ethylenglykol rasch resorbiert und schnell im Organismus verteilt. Es wird hepatisch metabolisiert zu Glykolaldehyd, Glykolsäure, Glyoxylsäure und Oxalsäure. 20 \% des inkorporierten Ethylenglykol werden unverändert renal eliminiert.

Halbwertszeit 3-5 Stunden (Plasma).

Funktion - Pathophysiologie Bei Vergiftung mit Ethylenglykol (enthalten in Kfz-Frostschutzmitteln sowie als Lösungsmittel in Haushaltsprodukten) treten Symptome wie bei $>$ Ethanol-Intoxikation auf, später Krämpfe, Somnolenz, Koma. Die Ethylenglykol-Metabolite führen zu einer schweren metabolischen Azidose ( $\triangleright$ Anionenlücke im Plasma, osmotische Lücke [ $\triangleright$ Osmolalität]), wobei $\triangleright$ Oxalsäure nur eine geringe Rolle spielt ( $2 \%$ Ethylenglykol werden zu Oxalsäure oxidiert). Im zweiten Stadium entwickeln sich kardiorespiratorische Komplikationen, im dritten Nierenschmerzen und Nierenversagen. 
Untersuchungsmaterial - Entnahmebedingungen Plasma, Serum.

\section{Analytik GC.}

Indikation Verdacht auf Vergiftung.

Interpretation Komatös-letale Konzentration: 300-4300 $\mathrm{mg} / \mathrm{L}$.

\section{Literatur}

Degel F, Desel H (2009) Solvents and inhalants: Glycols. In: Külpmann WR (Hrsg) Clinical toxicological analysis. Wiley-VCH, Weinheim, S 531-539

\section{Ethylenglykol-bis-( $\beta$ - aminoethylether)- $\mathbf{N}, \mathbf{N}, \mathbf{N}^{\prime}, \mathbf{N}^{\prime}-$ tetraessigsäure}

$>$ EGTA

\section{Ethylenglykoltetraessigsäure}

$>$ EGTA

\section{Ethylglukuronid}

T. Arndt

Synonym(e) EtG; Ethyl- $\beta$-Glucopyranosiduronsäure

Englischer Begriff ethyl glucuronide; EtG

Definition Stoffwechselprodukt von Ethanol, das durch Konjugation von Ethanol und Glukuronsäure entsteht. Strukturformel:

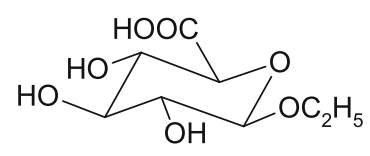

Molmasse $222 \mathrm{~g}$.

Synthese - Verteilung - Abbau - Elimination Im menschlichen Organismus werden ca. 0,5\% (bis 1,6\%) der aufgenom- menen Ethanolmenge durch Konjugation mit Glukuronsäure in Ethylglukuronid umgewandelt und nach glomerulärer Filtration mit dem Urin ausgeschieden. EtG-Spitzenkonzentrationen im Blut werden 2-3,5 Stunden nach Alkoholaufnahme gefunden. Eine Korrelation zwischen der EtG-Konzentration in Urin und Blut wurde nicht gefunden. Stattdessen existieren offenbar erhebliche interindividuelle Unterschiede im EthanoldosisEthylglukuronidbildungs-Verhältnis. Die Nachweisbarkeitsdauer in Serum oder Urin ist stark dosisabhängig und individuell verschieden. Dabei ist die Serumkonzentration (wenige $\mathrm{mg} / \mathrm{L}$ ) deutlich geringer als jene von Urin (bis mehrere Hundert $\mathrm{mg} / \mathrm{L}$ ). EtG wird über die Haarwurzel in das Haar eingelagert und wächst mit diesem aus der Kopfhaut heraus.

\section{Halbwertszeit 2-3 Stunden.}

Untersuchungsmaterial - Entnahmebedingungen Serum, Urin, Haare, Gewebs- und Leichengewebsproben.

Probenstabilität EtG ist im Urin mindestens 140 Stunden stabil.

Präanalytik Eine Kontamination der Probenentnahmebestecke und Probengefäße mit Ethanol ist zu vermeiden.

Analytik Gaschromatographie-Massenspektrometrie ( $\triangleright$ GC-MS), Flüssigkeitschromatographie-Tandem-Massenspektrometrie (LC-MS/MS), • Immunoassay.

Konventionelle Einheit $\mathrm{mg} / \mathrm{L}, \mathrm{mg} / \mathrm{g}$.

Referenzbereich - Erwachsene und Kinder Klassische Referenzbereiche wurden bisher nicht ermittelt. Stattdessen kommen Entscheidungsgrenzen (Cut-offs) zum Einsatz: EtG im Urin: $0,1 \mathrm{mg} / \mathrm{L}$ als Abstinenzbeleg (Schubert et al. 2013) oder $0,5 \mathrm{mg} / \mathrm{L}$ (klinisch-chemisch); EtG in Haaren: ab 5-7 pg/mg Alkoholkonsum, ab 25-30 pg/mg erhöhter Alkoholkonsum (Schubert et al. 2013).

Indikation Nachweis einer zurückliegenden Ethanolaufnahme für verkehrs- oder berufsmedizinische Fragestellungen, insbesondere jedoch zur Rückfalldiagnostik im Rahmen der Alkoholentzugsbehandlung.

Interpretation $\mathrm{EtG}$ im Urin

- Die immer wieder berichteten 3-4 Tage Nachweisbarkeitsdauer von $\mathrm{EtG}$ im Urin sind bei moderatem Alkoholkonsum unrealistisch. Da Ethanoldosis, interindividuelle Differenzen im Ethanolmetabolismus und die Nachweisgrenze des Analysenverfahrens über die Nachweisbarkeitsdauer entscheiden, 
sind stattdessen allgemeine Aussagen nicht möglich. Geringe Ethanolmengen, entsprechend z. B. 1-2 Glas Wein oder 1 Flasche Bier (typische Rückfallsituation unter Ethanolentzugstherapie), sind gewöhnlich nur ca. 12-24 Stunden über EtG im Urin nachweisbar.

- Bereits $1 \mathrm{~g}$ Ethanol kann $\mathrm{zu}$ einem positiven EtGNachweis im Urin führen. Deshalb sind unter Abstinenzauflage alle offenen und verdeckten exogenen Ethanolquellen konsequent zu meiden.

- EtG kann im bakteriell besiedelten Urin durch die Wirkung bakterieller Glukuronidasen abgebaut werden, wodurch falsch negative Befunde bzgl. Ethanolaufnahme resultieren können.

- EtG kann bei Anwesenheit von Glukose (Diabetiker) und Hefe im Urin in vitro gebildet werden (Vergärung der Glukose durch Hefe zu Ethanol und anschließend Konjugation mit Glukuronsäure zu EtG), was zu falsch positiven Befunden führen kann.

- EtG wird auch nach inhalativer Exposition gegenüber ethanolhaltiger Umgebungsluft, z. B. bei Händedesinfektion, gebildet und dosisabhängig in $z$. T. deutlich über den aktuellen Cut-offs liegenden Konzentrationen im Urin ausgeschieden.

- Falsch positive immunologische EtG-Befunde können auftreten durch Kreuzreaktion des EtG-Antikörpers mit Trichlorethylglukuronid (Chloralhydratmedikation), mit Hexafluoroisopropyl-Glukuronid (Abbauprodukt des Inhalationsanästhetikums Sevofluran), mit n- und iso-Pentylglukuronid (Inhalation $\mathrm{n}$ - und/oder iso-Propanol-haltiger Desinfektionsmitteldämpfe oder Lösungsmittelabusus) sowie mit Glukuroniden von Methanol, Butanolen und Pentanolen (Begleitstoffe von Alkoholika oder Lösungsmittelabusus).

- Zur zusätzlichen Erhöhung der diagnostischen Spezifität wird der parallele Nachweis von $>$ Ethylsulfat im Urin empfohlen.

\section{EtG in den Haaren}

- Die hydrophilen Eigenschaften von EtG führen mit den üblichen Haarpflegemaßnahmen und der Alterung des Haares zu Ausspülung und Abbau von EtG. Trotz ggf. gleichbleibenden Ethanolkonsums werden dadurch mit zunehmender Entfernung des untersuchten Haarsegmentes von der Kopfhaut abnehmende EtG-Konzentrationen und ggf. falsch negative Befunde bzgl. Ethanolaufnahme erhalten.

- Haaranalysen auf EtG sollten sich deshalb auf das 0-3-cmSegment beschränken. Dieses ermöglicht eine diagnostische Rückschau auf ca. 3,5 Monate (0,5 Monate Wachstum in der Kopfhaut + ca. $1 \mathrm{~cm} /$ Monat für Kopfhaar). Bei der Untersuchung alternativer Haarproben (z. B. von Achseln,
Bart, Brust, Scham) sind die z. T. deutlich abweichend durchschnittlichen Wuchsgeschwindigkeiten zu beachten.

- Ethanolhaltige Haarkosmetika sind ohne Einfluss auf die EtG-Konzentration im Haar, aber EtG-haltige Haarkosmetika können, auch nach sorgfältiger Dekontamination im Rahmen der Probenvorbereitung, zu analytisch richtig positiven, aber bzgl. Ethanolaufnahme falsch positiven EtG-Befunden führen (was als Hinweis auf eine Einlagerung von exogenem EtG in die Haarstruktur gewertet wird).

- Ob eine chronisch inhalative Exposition gegenüber ethanolischen Dämpfen zur Einlagerung von EtG in das Haar führt, ist derzeit noch nicht untersucht.

Diagnostische Wertigkeit EtG im Urin: Der massenspektrometrisch erhobene EtG-Befund im Urin ist ein spezifischer Kurzzeitmarker einer Ethanolaufnahme oder Ethanolexposition. EtG im Urin kann die diagnostische Lücke zwischen den Kenngrößen einer unmittelbaren Ethanolintoxikation ( $\triangleright$ Ethanol), einer ca. 1 Tag zurückliegenden Alkoholaufnahme (Ethanol im Urin) und den Kenngrößen eines chronischen Alkoholmissbrauchs ( $\triangleright$ Carbohydrate-deficient transferrin und $\triangleright \gamma$-Glutamyltransferase) verkürzen, wenn jegliche Quellen einer unbeabsichtigten oralen (z. B. Nahrungskonservierungsmittel, Kochen mit Wein etc.) oder inhalativen (z. B. Desinfektions-, Reinigungs- und Hygieneartikel) Ethanolaufnahme zuverlässig ausgeschlossen werden.

EtG in Haaren: Der massenspektrometrische Nachweis von EtG in den Haaren ist bei Ausschluss exogener EtGQuellen ein Langzeitmarker für eine Ethanolaufnahme.

\section{Literatur}

Arndt T, Buschmann HC, Schulz K, Stemmerich K (2017) Lessons learned from a case of tert-butyl glucuronide excretion in urine „New" Psychoactive Alcohols knocking on the back door? Forensic Sci Int 281:9-12.

Arndt T, Grüner J, Schröfel S, Stemmerich K (2012) False-positive ethyl glucuronide immunoassay screening caused by a propyl alcoholbased hand sanitizer. Forensic Sci Int 223:359-363

Arndt T, Schroefel S, Guessregen B, Stemmerich K (2014) Inhalation but not transdermal resorption of hand sanitizer ethanol causes positive ethyl glucuronide findings in urine. Forensic Sci Int 237:126-130

Schubert W, Dittmann V, Brenner-Hartmann J (Hrsg) (2013) Beurteilungskriterien - Urteilsbildung in der Fahreignungsbegutachtung, 3. Aufl. Kirschbaum, Bonn

Sporkert F, Kharbouche H, Augsburger MP, Klemm C, Baumgarten MR (2012) Positive EtG findings in hair as a result of a cosmetic treatment. Forensic Sci Int 218:97-100

\section{Ethylmalonat}

- Ethylmalonsäure 


\section{Ethylmalonsäure}

\section{G. F. Hoffmann, C.-D. Langhans und A. Schulze}

Synonym(e) Ethylmalonat; EMA

Englischer Begriff ethylmalonic acid

Definition Die verzweigtkettige Dicarbonsäure entsteht als pathologischer Metabolit bei Störungen der Fettsäureoxidation sowie bei Störungen im Elektronentransfer.

Struktur $\mathrm{C}_{5} \mathrm{H}_{8} \mathrm{O}_{4}$; Strukturformel:<smiles>CCC(C(=O)O)C(=O)O</smiles>

Molmasse $132,11 \mathrm{~g}$.

Synthese - Verteilung - Abbau - Elimination Ethylmalonsäure ist das Carboxylierungsprodukt von Butyryl-CoA (C4-CoA), das im mitochondrialen $\beta$-Oxidationszyklus der Fettsäuren durch die katalytische Wirkung längenspezifischer, FAD-abhängiger Dehydrogenasen (VLCAD, MCAD, SCAD) und eines $\mathrm{NAD}^{+}$-abhängigen trifunktionellen Enzymkomplex mit Dehydrogenase-, Hydratase- und Thiolase-Aktivität gebildet wird.

Bei einem Defekt der mitochondrialen kurzkettigen AcylCoA-Dehydrogenase (SCAD) erfolgt die weitere Verstoffwechselung des C4-CoA durch die Propionyl-CoACarboxylase bevorzugt zu Ethylmalonsäure.

Die Ethylmalonsäure verteilt sich in allen Körperflüssigkeiten. Sie wird effizient renal ausgeschieden.

Funktion - Pathophysiologie Die Ethylmalonsäure wird im Nebenschluss der Fettsäureoxidation gebildet und hat keine bekannte physiologische Bedeutung.

Untersuchungsmaterial - Entnahmebedingungen Urin, in Ausnahmefällen Liquor oder Plasma.

\section{Präanalytik.}

- Durch > Flüssig-Flüssig-Extraktion im sauren Medium mittels Ethylacetat oder Diethylether

- Mittels Gaschromatographie-Massenspektrometrie (> GCMS) als Di-Trimethylsilylester

Retentionsindex RI: 1287

$\mathrm{M}+(\mathrm{m} / \mathrm{z}): 276$
Quant Ion (m/z): 217

Conf. Ion (m/z): 261

Internationale Einheit $\mathrm{mmol} / \mathrm{mol}$ Kreatinin (Urin). $\mu \mathrm{mol} / \mathrm{L}$ (Plasma, Liquor).

Referenzbereich - Kinder Normalbereich - Urin (altersabhängig):

- 0-4 Monate: 0-15 mmol/mol Kreatinin

- Bis 2 Jahre: 0-15 mmol/mol Kreatinin

- Bis 10 Jahre: 0-9 mmol $/ \mathrm{mol} \mathrm{Kreatinin}$

- >10 Jahre: 2-10 mmol/mol Kreatinin

Pathologischer Bereich:

- SCAD: 180-1150 mmol/mol Kreatinin

- EMA-Enzephalopathie: $34-880 \mathrm{mmol} / \mathrm{mol}$ Kreatinin

- GA Typ II: 180-1150 mmol/mol Kreatinin

Indikation Unerklärte Ketoazidose, vor allem im Säuglingsund Kleinkindesalter, Hypoglykämie, Petechien, chronische Diarrhoen und/oder psychomotorische Entwicklungsstörung.

Interpretation Eine erhöhte Urinausscheidung von Ethylmalonsäure wird bei einem SCAD-Mangel beobachtet.

Allerdings sind auch Ethylmalonazidurien bekannt, die mit einer normalen SCAD-Aktivität einhergehen wie im Fall der EMA-Enzephalopathie.

Erhöhte EMA-Werte werden auch beim multiplen AcylCoA-Dehydrogenase-Mangel (Glutarazidurie Typ II) und einigen Atmungskettendefekten beobachtet.

Letztlich muss die korrekte Diagnose auf der Messung der SCAD-Aktivität in Fibroblasten basieren. Die EMA-Enzephalopathie lässt sich durch Mutationsnachweise im ETHE1-Gen bestätigen.

Diagnostische Wertigkeit Erhöhte Konzentrationen der Ethylmalonsäure sind als pathologisch zu werten und Ausdruck einer spezifischen Störung der Fettsäureoxidation oder allgemeiner des Energiestoffwechsels.

\section{Literatur}

Blau N, Duran M, Gibson KM, Dionisi-Vici C (Hrsg) (2014) Physician's guide to the diagnosis, treatment, and follow-up of inherited metabolic diseases. Springer, Berlin/Heidelberg

\section{Ethylphosphat}

Ethylsulfat 


\section{Ethylsulfat}

T. Arndt

$\operatorname{Synonym(e)~EtS~}$

Englischer Begriff ethyl sulfate; EtS

Definition Stoffwechselprodukt von Ethanol, das durch Konjugation von Ethanol und Sulfat entsteht. Strukturformel:<smiles>CCOS(=O)(=O)O</smiles>

Beschreibung EtS wird wie $\triangleright$ Ethylglukuronid $(\mathrm{EtG})$ nach Aufnahme von $>$ Ethanol (Alkohol) gebildet, glomerulär filtriert und mit dem Urin ausgeschieden. Die Konzentrationen von EtS und EtG im Urin zeigen einen ähnlichen zeitlichen Verlauf mit einem nach ca. 2-4 Stunden auftretenden Maximum.

Die Analyse erfolgt gewöhnlich parallel mit EtG über GC-MS oder LC-MS/MS. Immunoassays für EtS sind nicht verfügbar. Einheitliche Entscheidungsgrenzen wurden nicht definiert. Der Nachweis orientiert sich deshalb zumeist an der Detektions- oder Berichtsgrenze des Labors (zwischen 0,01-0,1 mg/L).

EtS wird im Unterschied zu EtG im Urin kaum oder nicht durch Bakterien abgebaut. Die Präsenz von EtS bei fehlendem EtG kann deshalb auf einen bakteriellen EtG-Abbau hinweisen (Bestätigung durch z. B. Teststreifen auf Bakterien).

$\mathrm{Ob}$ die inhalative Aufnahme von ethanolhaltigen Dämpfen, z. B. während Händedesinfektion wie für $>$ Ethylglukuronid zu falsch positiven EtS-Befunden bzgl. Ethanolaufnahme führen kann, ist ebenso unerforscht wie eine mögliche Aufnahme von exogenem EtS z. B. aus Desinfektionsmitteln (z. B. Mecetroniumetilsulfat in Sterillium Classic Pure) oder (Haushalts-)Chemikalien. Ethylsulfat ist eine vielfältig eingesetzte Industriechemikalie.

\section{Literatur}

Arndt T (Hrsg) (2011) Proceedings of the XVII. GTFCh-Symposium: New drugs of abuse - from structural characterization to toxicology. Toxichem Krimtech 35:165-446

Helander A, Beck O (2004) Mass spectrometric identification of ethyl sulfate as an ethanol metabolite in humans. Clin Chem 50:936-937

\section{Ethyl- $\beta$-Glucopyranosiduronsäure}

- Ethylglukuronid

\section{Etiketten}

O. Colhoun

\section{Englischer Begriff labels}

Definition Bedruckbarer, barcodierter Identifikationsaufkleber zur Kennzeichnung von Probenröhrchen und Patientendokumenten.

Beschreibung Bei Druck durch das Labor-EDV-System können entweder speziell formatierte Papierbögen (z. B. DIN-A4-Etikettenbögen im Laserdrucker) oder Etiketten von der Rolle in speziellen Etikettendruckern generiert werden. Es werden Etiketten z. B. für die Identifikation von Einsendern, Patienten, Laborspezimen und Qualitätskontrollmaterialien gedruckt. Dazu ist eine systematische eindeutige Nummerierung z. B. der Einsender in den Stammdaten vorzunehmen, die auf den Etiketten als Barcode verschlüsselt und um den Einsender-Klarnamen ergänzt ausgegeben wird. Ein einfaches Etikettenkopierprogramm unterstützt den Druck von Sekundäretiketten für die Probenverteilung im Labor durch Einscannen des Primärröhrchens für den Druck. Beim Druck von Primärprobenetiketten auf Station durch die Labor-EDV aufgrund der $\triangleright$ Online-Auftragsanforderung des Einsenders sollen neben der barcodierten Probenidentifikationsnummer auch der Name und evtl. das Geburtsdatum des Patienten in Klarschrift sowie Hinweise auf das zu benutzende Probenröhrchen und Besonderheiten der Präanalytik aufgrund der speziellen Anforderung (z. B. ,,5 mL SerumRöhrchen, blaue Kappe, sofort gekühlt ins Labor bringen“) ausgedruckt werden.

\section{EtOH}

$\checkmark$ Ethanol

\section{ETP}

- Endogenes Thrombinbildungspotenzial 


\section{EtS}

$\checkmark$ Ethylsulfat

\section{Euglobulin-Lysezeit}

\section{A. M. Gressner und O. A. Gressner}

\section{Synonym(e) Fibrin-Lysezeit}

Englischer Begriff euglobulin (clot) lysis time; ECLT

Definition Zeitaufwendiger, nur grob informativer Test zur Bestimmung der fibrinolytischen Aktivität des Plasmas durch Messung der Zeit, in der sich die durch Ansäuern ausgefällte, durch Thrombin zur Gerinnung gebrachte Euglobulinfraktion des zu untersuchenden Plasmas wieder auflöst.

Beschreibung Zur Bestimmung der fibrinolytischen Aktivität selten eingesetzter, da zeitaufwendiger und nur grob orientierender Test. Innerhalb von 30 Minuten nach Gewinnung des Citratplasmas erfolgt durch leichtes Ansäuern mit verdünnter Essigsäure bei $\mathrm{pH} 5,2$ und $2-4{ }^{\circ} \mathrm{C}$ eine Präzipitation von F Fibrinogen, > Plasminogen und Plasminogenaktivatoren (t-PA). Nach Abzentrifugation dieses als Euglobulinfraktion bezeichneten Präzipitates erfolgt dessen Auflösung in Puffer und durch Zugabe von frischem - Thrombin die Induktion des Gerinnungsvorganges bei $37^{\circ} \mathrm{C}$ im Wasserbad. Es wird im Zeitintervall von zunächst 15 Minuten, dann 30-60 Minuten die Zeit gemessen, die vom Gerinnungseintritt bis zur Auflösung des Gerinnsels vergeht. Der Referenzbereich beträgt 4-6 Stunden. Eine Verkürzung unter 2 Stunden weist auf Hyperfibrinolyse, z. B. bei disseminierter intravaskulärer Koagulation oder Streptokinasetherapie hin. Der Test erlaubt nur eine orientierende Aussage, da neben dem primär relevanten $>$ Tissue-Plasminogenaktivator (t-PA) auch dessen Inhibitoren, die Fibrinogenkonzentration und auch freies Plasmin das Ergebnis beeinflussen.

\section{Literatur}

Bartels M, von Depka M (2003) Das Gerinnungskompendium. Georg Thieme Verlag, Stuttgart

Nordby E, Amesen H, Andersen P, Godal HC (1980) The euglobulinclot lysis time, a rapid and sensitive method for the assay of fibrinolytic activity after venous stasis. Scand J Hematol 25(5):407-411

\section{Euglobulin-Test}

- Sia-Waldenström-Test

\section{Euglykämische Insulin-Clamp}

K. J. Lackner und D. Peetz

Englischer Begriff euglycemic clamp; hyperinsulinemic euglycemic clamp

Definition Funktionstest zur Bestimmung der Insulinansprechbarkeit; gilt als Referenzverfahren für diese Fragestellung.

Durchführung Bei diesem Funktionstest wird Insulin in einer konstanten Rate (ca. 50-60 $\mathrm{mU} \times \mathrm{m}^{-2} \times \mathrm{min}^{-1}$ je nach Protokoll) infundiert. Dadurch wird die hepatische Glukoseproduktion weitestgehend unterdrückt. Die Glukosekonzentration im Blut wird durch eine entsprechende, bedarfsadaptierte Infusion auf dem Ausgangsniveau so konstant wie möglich gehalten. Die Infusionsrate wird kurzfristig (ca. alle $5 \mathrm{~min}$ ) anhand der Glukosekonzentration im Blut angepasst. Der Glukosebedarf unter diesen Bedingungen ist ein Maß für die Insulinansprechbarkeit. Der Test ist aufwendig, bedarf einiger Erfahrung und ist deshalb für die Routinediagnostik nur bedingt geeignet. Deshalb wird er meist nur zur Validierung anderer Verfahren (z. B. \ Glukosetoleranztest, intravenös) eingesetzt.

\section{Literatur}

DeFronzo R, Tobin J, Andres R (1979) Glucose clamp technique: a method for quantifying insulin secretion and resistance. Am J Pyhsiol 237:214-233

\section{Eumelanin}

Melanin

\section{E und e-Antigen}

- Rhesus-Blutgruppensystem

\section{Eur Clin Chem}

- European Specialist in Clinical Chemistry and Laboratory Medicine 


\section{Europäische Norm}

- EN-Standards

\section{European Communities Confederation of Clinical Chemistry}

\section{H. Baum}

\section{Synonym(e) EC4}

Beschreibung Die EC4 wurde von den nationalen Fachgesellschaften der Mitgliedsstaaten der Europäischen Union gegründet. Ein Hauptziel ist, die Fort- und Weiterbildung für alle im Fach Klinische Chemie und Laboratoriumsmedizin tätigen akademischen Professionals europaweit vergleichbar zu gestalten und ein europäisches Register aufzubauen. Zusätzlich strebt EC4 eine gegenseitige Anerkennung der Weiterbildung innerhalb der Europäischen Union an. Diese Aufgabe nimmt dabei die „Registration Commission“ (EC4-RC) wahr. Nach der Verschmelzung von EC4 mit der $₹$ Forum of the European Societies of Clinical Chemistry and Laboratory Medicine zur $>$ European Federation of Clinical Chemistry and Laboratory Medicine blieb die EC4-RC als selbständige Organisation bestehen.

\section{Literatur}

www.ec-4.org

\section{European Confederation of Laboratory Medicine (ECLM)}

- European Laboratory Medicine

\section{European Federation of Clinical Chemistry and Laboratory Medicine}

H. Baum

Synonym(e) EFLM
Beschreibung Die EFCC ist die europäische Unterorganisation der $>$ International Federation of Clinical Chemistry and Laboratory Medicine und ging im Jahr 2007 aus der Verschmelzung des $\triangleright$ Forum of the European Societies of Clinical Chemistry and Laboratory Medicine und $>$ European Communities Confederation of Clinical Chemistry hervor. Die Hauptaktivitäten der EFLM umfassen die Aus- und Weiterbildung im Fach Klinische Chemie und Laboratoriumsmedizin, Forschung, Weiterentwicklung des Berufsfelds, Qualitätssicherung und Akkreditierung von Laboren, Organisation von Kongressen und Veröffentlichungen.

\section{Literatur}

www.eflm.eu

\section{European Laboratory Medicine}

\section{G. Schumann}

Synonym(e) ELM; European Confederation of Laboratory Medicine (ECLM)

Englischer Begriff European Laboratory Medicine; ELM

Definition Plattform Europäischer Gesellschaften aller Disziplinen der Laboratoriumsdiagnostik zur Koordinierung gemeinsamer Interessen.

Beschreibung Im Jahr 1993 wurde die European Confederation of Laboratory Medicine (ECLM) unter der Schirmherrschaft der Weltgesundheitsorganisation (WHO) in Kopenhagen gegründet. 2002 wurden die Statuten und der Name in European Laboratory Medicine (ELM) geändert. Europa wird im geographischen Sinne gemäß der WHO-Definition verstanden. Laboratoriumsmedizin umfasst die Wissenschaft und die Anwendung verschiedener Disziplinen auf dem Gebiet der Laboratoriumsmedizin, die mono- oder multidisziplinär organisiert sein können, beispielsweise Klinische Chemie, Klinische Mikrobiologie (Bakteriologie, Virologie, Parasitologie, Mykologie). Klinische Immunologie, Klinische Hämatologie, Immunhämatologie und Immungenetik. Die ELM war ein Pendant zur nationalen Arbeitsgemeinschaft Medizinische Laboratoriumsdiagnostik (AML). Die Geschäftsstelle war wechselweise an die Adresse des jeweiligen Schriftführers gebunden. Aktivitäten von ECLM bzw. ELM sind seit Jahren nicht mehr zu verzeichnen. Ein Internetauftritt war in 2016/2017 nicht auffindbar. 


\section{European Molecular Genetics Quality Network \\ $\checkmark$ EMQN}

\section{European Specialist in Clinical Chemistry and Laboratory Medicine}

H. Baum

Synonym(e) Eur Clin Chem

Beschreibung Die Anerkennung als „European Specialist in Clinical Chemistry and Laboratory Medicine" wird durch die Registrierungskommission der $>$ European Communities Confederation of Clinical Chemistry (EC4-RC) vergeben. Dabei wird von EC4-RC überprüft, ob die Weiterbildungsinhalte im jeweiligen Mitgliedsstaat den von der Registrierungskommission erarbeiteten Mindeststandards entspricht. Die Inhalte sind in einem Syllabus zusammengefasst, wobei auch die speziellen Bedingungen der einzelnen Mitgliedsstaaten berücksichtigt werden. Voraussetzung für die Anerkennung ist die Registrierung im jeweiligen Mitgliedsstaat. Für Deutschland ist dies die Registrierung als „Klinische Chemikerin/Klinischer Chemiker" bei der $>$ Deutsche Gesellschaft für Klinische Chemie und Laboratoriumsmedizin e.V. (DGKL).

\section{Literatur}

www.eflm.eu

\section{Evakuierte Röhrchen}

\Vakuumröhrchen

\section{Everolimus}

H.-D. Haubeck

\section{Englischer Begriff everolimus}

Definition Everolimus ist das 40-O-(2-Hydroxyethyl)-Derivat von $>$ Sirolimus (Molmasse 958,224 g/mol).
Beschreibung Der Wirkungsmechanismus und die Nebenwirkungen von Everolimus entsprechen denen des $\triangleright$ Sirolimus. Im Gegensatz zu Sirolimus (Halbwertszeit ca. 60 Stunden) besitzt Everolimus eine deutliche kürzere Halbwertszeit (ca. 17 Stunden). Auch Everolimus zeigt größere intra- und interindividuelle Schwankungen in der Pharmakokinetik. Die Everolimusbestimmung erfolgt in EDTA-Blut mit $>$ Immunoassay oder $>$ LC-MS. Der vorläufige therapeutische Bereich wird mit 3-8 $\mu \mathrm{g} / \mathrm{L}$ angegeben. Der therapeutische Bereich ist wie bei allen Immunsuppressiva abhängig vom Transplantationstyp und dem klinischen Zustand des Patienten und des Transplantats.

\section{Literatur}

Armstrong VW, Streit F (2003) Drug monitoring of sirolimus and everolimus. J Lab Med 27:222-227

\section{Evidenzbasierte Laboratoriumsmedizin}

A. M. Gressner und O. A. Gressner

Synonym(e) Beweis-basierte Labormedizin

Englischer Begriff evidence-based laboratory medicine

Definition Wissenschaftlich begründete Vorgehensweise in der $\triangleright$ Laboratoriumsmedizin.

Beschreibung Zweckentsprechende und gewissenhafte Anwendung der besten und beweisbaren Erkenntnisse aus Erfahrung und Forschung zur Erstellung von symptom- und krankheitsbezogenen Laborbefunden für den individuellen Patienten. Zielsetzung ist die Bereitstellung der zurzeit bestmöglichen und Kosten-Nutzen-effektivsten Diagnostik für den Patienten.

\section{Literatur}

Price CP, Christenson RH (2003) Evidence-based laboratory medicine: from principles to outcomes. AACC Press, Washington DC

\section{Evidenzbasierte Medizin}
A. M Gressner und O. A Gressner

Englischer Begriff evidence-based medicine 
Definition Wissenschaftlich begründete Vorgehensweise in der Medizin.

Beschreibung Zweckentsprechende und gewissenhafte Anwendung der besten und beweisbaren Erkenntnisse aus klinischer Erfahrung und Forschung für Entscheidungsfindungen in der Patientenbehandlung. Zielsetzung ist die Bereitstellung der zurzeit bestmöglichen und Kosten-Nutzeneffektivsten Behandlung für den Patienten. Der Verbreitung, Weiterentwicklung und Anwendung der evidenzbasierten Medizin widmet sich das Deutsche Netzwerk Evidenzbasierter Medizin e.V., Kuno-Fischer-Str. 8, D-14057 Berlin, Tel. 030 30833660, E-Mail: kontakt@ebm-netzwerk.de.

\section{Literatur}

Sackett DL, Rosenberg WMC, Gray JAM et al (1996) Evidence-based medicine: what it is and what it isn't. Br Med J 312:71-72

\section{Exercise-Test}

W. Hubl

Synonym(e) HGH-Stimulationstest; STH-Stimulationstest; Wachstumshormon-Belastungstest; Wachstumshormon-Stimulationstest

\section{Englischer Begriff exercise test}

Definition Durch körperliche Belastung kommt es physiologischerweise zur Ausschüttung des Wachstumshormons ( $\triangleright$ Wachstumshormon). Bei hypophysären Wachstumshormondefekten bleibt dieser Anstieg aus.

\section{Durchführung}

- Erste Blutentnahme nach 30 Minuten körperlicher Ruhe zur Wachstumshormonbestimmung

- 15 Minuten körperliche Belastung (Ergometer, Treppensteigen)

- 20 Minuten Ruhepause

- Zweite Blutentnahme zur Wachstumshormonbestimmung

Untersuchungsmaterial - Entnahmebedingungen Serum.

Referenzbereich Anstieg des Wachstumshormons auf über $7 \mu \mathrm{g} / \mathrm{L}$.

Indikation Minderwuchs, Zwergwuchs, Verdacht auf Wachstumshormonmangel, Wachstumsretardierung in der Pädiatrie.
Kontraindikation(en) Einschränkungen der körperlichen, besonders der kardiopulmonalen Belastbarkeit.

Interpretation Das Ausbleiben eines Anstieges der Wachstumshormonkonzentration kann auf einen absoluten Wachstumshormonmangel hinweisen.

Diagnostische Wertigkeit Diagnostische Sensitivität: 90 \%; diagnostische Spezifität: $11 \%$.

Angesichts der geringen diagnostischen Relevanz ist ein Hypophysen-Stimulationstest mit Releasinghormonen ( $\triangleright$ Wachstumshormon-Stimulationstest (GHRH- und/oder Arginin-induziert)) dem Exercise-Test vorzuziehen.

\section{Literatur}

Donaubauer J, Kratzsch J, Fritzsch C, Stach B, Kiess W, Keller E (2001) The treadmill exhausting test is not suitable for screening of growth hormone deficiency! Horm Res 55:137-140

Schäffler A (Hrsg) (2015) Funktionsdiagnostik in Endokrinologie, Diabetologie und Stoffwechsel. Indikation, Testvorbereitung und -durchführung, Interpretation. Springer, Berlin/Heidelberg

\section{Exokriner Pankreasfunktionstest nach Lundh}

> Lundh-Test

\section{Exom-Komplettanalyse}

Exom-Sequenzierung

\section{Exom-Sequenzierung}

J. Arnemann

\section{Synonym(e) Exom-Komplettanalyse}

\section{Englischer Begriff exome sequencing}

Definition Exom-Sequenzierung ist eine Form des NextGeneration-Sequencings (NGS), bei der zeitgleich und parallel sämtliche Exome der bekannten humanen Gene sequenziert werden, deshalb auch als Whole-Exome-Sequencing (WES) bezeichnet. 
Beschreibung Ungefähr $2 \%$ des menschlichen Genoms sind proteinkodierende DNA-Sequenzen, die gleichzeitig über $85 \%$ der bekannten genetischen Erkrankungen kodieren. Die Sequenzierung dieser Bereiche mittels $>$ Next-Generation-Sequencing (NGS) wird auch als Whole-Exome-Sequencing (WES) definiert und ist vom Kosten-Nutzen-Vergleich in der Routineanwendung wesentlich kostengünstiger als Whole-GenomeSequencing (WGS). Weiterhin umfasst die Zahl der Reads für WES nur 4-5 Gb gegenüber $90 \mathrm{~Gb}$ für WGS, was die Menge zu analysierender Daten erheblich reduziert und damit auch die Analysezeit. Gleichzeitig ist im Vergleich bei WES die Coverage und damit auch die Sensitivität höher.

Als Anwendungsbereich stehen die Mutationssuche bei genetischen Erkrankungen sowie die Mutationssuche bei Tumorerkrankungen oder -studien im Vordergrund.

Zur praktischen Vorgehensweise wird die genomische DNA zunächst enzymatisch oder mittels Ultraschall fragmentiert, um anschließend mittels einer ausgewählten, sog. TargetEnrichment Methode, wie z. B. PCR oder Hybrid-Capture, die Exom-Bereiche selektiv anzureichern, die dann mittels der entsprechenden NGS-Technologie sequenziert werden. Eine Sequenzauswertung erfolgt dann mittels einer BioinformatikPipeline.

\section{Literatur}

Yang Y et al (2013) Clinical whole-exome sequencing for the diagnosis of mendelian disorders. N Engl J Med 369:1502-1511

\section{Exon}

J. Arnemann

\section{Englischer Begriff exon}

Definition Ein Exon ist derjenige Abschnitt eines Gens, der nach der Transkription der genomischen DNA in prä-mRNA durch den Vorgang des Spleißens in eine analoge mRNA (messenger RNA) umgebaut und anschließend der eigentlichen Translation zugeführt wird. Exone können sowohl kodierende als auch regulatorische Funktionen haben.

Beschreibung Im Gegensatz zu Prokaryoten zeigen die Gene der Eukaryoten eine Unterteilung in kodierende (Exon) und in nicht kodierende Abschnitte (Intron). Beginnend mit dem Transkriptionsstartpunkt werden die eukaryotischen Gene auf genomischer DNA-Ebene komplett in eine prä-messenger RNA (prä-mRNA) umgeschrieben. Durch den
Prozess des Spleißens werden anschließend die nicht kodierenden Abschnitte (Introns), herausgeschnitten und eine mature mRNA aus den Exonabschnitten zusammengefügt.

An der Übergangsstelle von Exon zu Intron bzw. Intron zu Exon finden sich spezifische Spleißsignale, die vom Spliceosom, dem eigentlichen Spleißkomplex erkannt werden und das Herausschneiden der Intronabschnitte und Zusammenfügen der kodierenden Exonabschnitte zur reifen mRNA katalysieren.

\section{Literatur}

Strachan T, Read AP (2005) Molekulare Humangenetik. Elsevier $\mathrm{GmbH}$, München

\section{Exon-Skipping}

J. Arnemann

\section{Synonym(e) Exon-Verlust}

\section{Englischer Begriff exon skipping}

Definition Unter Exon-Skipping versteht man das Überspringen (,skipping“) eines Exons während des Spleißprozesses aufgrund fehlerhafter Spleißsignale, meist sog. Spleißmutationen.

Beschreibung Bei der Transkription eines Gens wird die komplette genomische DNA-Sequenz vom Transkriptionsstart aus in eine prä-mRNA transkribiert, die sowohl intronische als funktionelle, exonische Abschnitte enthält. Durch den Prozess des Spleißens werden die intronischen Abschnitte herausgeschnitten und die exonischen miteinander verknüpft. Zur Erkennung des Übergangs von Intron zu Exon sind in der prä-mRNA spezifische Signale vorhanden, wie Spleißakzeptor- und Spleißdonorsignale, die für die Ausbildung von Spliceosomen wichtig sind. Die Spliceosomen stellen die Maschinerie zum Ausschneiden der Intronsequenzen und Zusammenknüpfen der Exon-Abschnitte zur „reifen“ messenger RNA (mRNA). Sie bestehen aus 6 SNRNPs (,small nuclear ribonucleoproteins") SNRPN U1 bis SNRPN U6. Initial bindet SNRPN U1 an die 5'-Spleißstelle im Intron und katalysiert unter Mithilfe weiterer Proteinfaktoren die Anlagerung der weiteren SNRPNs und die Ausbildung eines aktiven Spliceosoms, das an der $3^{\prime}$-Spleißstelle des Introns bindet, den Intronabschnitt entfernt und gleichzeitig die Exonabschnitte miteinander verknüpft. 
Sind die Spleißsignale durch eine Sequenzvariation verändert, so erfolgt oftmals keine korrekte oder nur sporadische Ausbildung eines Spliceosoms, was nur wenige korrekt gespleißte und translatierte Moleküle bedingt. Im Falle einer fehlerhaften Spleißsequenz erfolgt die Bindung des Spliceosoms an der Spleißsequenz des nachfolgenden Exons bzw. Introns, und das im aktiven Spliceosom erfasste fehlerhafte Exon wird herausgespleißt und nicht in die mRNA eingebaut. Bei der Translation dieser verkürzten mRNA fehlen im Protein die Aminosäuren des herausgeschnittenen Exons. Das Protein ist in trunkierter Form nur eingeschränkt funktionsfähig.

\section{Literatur}

Strachan T, Read AP (2005) Molekulare Humangenetik. Elsevier $\mathrm{GmbH}$, München

\section{Exonuklease-Aktivität}

\section{J. Arnemann}

\section{Englischer Begriff exonuclease}

Definition Exonukleasen zeichnen sich durch die Fähigkeit aus, in $3^{\prime}-5^{\prime}$ - als auch $5^{\prime}-3^{\prime}$-Orientierung bei DNA und RNA Nukleinsäuremonomere abzuspalten.

Beschreibung Eine $3^{\prime}-5^{\prime}$-Exonuklease-Aktivität findet sich bei verschiedenen Polymerasen, die über eine ProofreadingAktivität die Fähigkeit zur Korrektur verfügen. Diese Polymerasen sind in der Lage, den Einbau eines falschen Nukleotids zu erkennen und mittels der $3^{\prime}-5^{\prime}$-Exonuklease aus dem bereits synthetisierten DNA-Strang zu entfernen und durch ein passendes Nukleotid zu ersetzen.

Die bei Escherichia coli vorkommende DNA-PolymeraseI, besitzt eine $5^{\prime}-3^{\prime}$-Exonuklease-Aktivität, die zur Reparatur von Einzelstrangbrüchen die DNA in $5^{\prime}-3^{\prime}$-Richtung abbaut, während die Polymerase-Aktivität den fehlenden DNAAbschnitt neu synthetisiert. Diese Eigenschaft wird im Labor genutzt, DNA-Sonden mittels Nicktranslation mit modifizierten oder markierten Nukleotiden zu versehen.

\section{Literatur}

Khare V, Eckert KA (2002) The proofreading $3^{\prime}->5^{\prime}$ exonuclease activity of DNA polymerases: a kinetic barrier to translesion DNA synthesis. Mutat Res 510:45-54

Shevelev IV, Hübscher U (2002) The $3^{\prime}-5^{\prime}$ exonucleases. Nat Rev Mol Cell Biol 3:364-376

\section{Exon-Verlust}

- Exon-Skipping

\section{Expertensystem}

O. Colhoun

Synonym(e) Wissensbasiertes Befundungssystem

Englischer Begriff expert system

Definition Computerprogramm, das die Expertise eines Spezialisten in einem umschriebenen Bereich, z. B. der Labordiagnostik, abbildet und anderen Nutzern verfügbar macht.

Beschreibung Hierzu dient die sog. Wissensbasis, also eine Datenbank oder ein Regelwerk in Form von Wenn-DannAussagen. Das Kernstück eines medizinischen Expertensystems, das besser als „Wissensbasiertes Befundungssystem“ bezeichnet wird, ist ein Inferenzmaschine genanntes Modul, das anhand der in der Wissensdatenbank/Regellogik abgelegten Implikationen Schlüsse aus den vom Nutzer dargebotenen Fakten zieht. Die Programmierung von Expertensystemen geschieht z. B. in Lisp, Prolog oder heutzutage Java. Das erste Expertensystem überhaupt war im Jahr 1965 das System Dendral zur Identifizierung von organischen Substanzen in massenspektrometrischen Datengrammen; aus den 1970er-Jahren stammen das medizinische System Mycin zur Diagnose von Blutinfektionen und dessen Nachfolger NeoMycin.

Die Hauptschwierigkeiten bestehen darin, das oft prozedural, unbewusst oder in Form von assoziativen Gedächtnisinhalten im Gehirn gespeicherte Expertenwissen in eine formalisierte Sprache umzusetzen und das einmal formalisierte Wissen zu pflegen, also zu aktualisieren, ergänzen und verbessern.

Die Interpretation geeigneter Parameterkonstellationen ist eine wichtige medizinische Aufgabe der Labormedizin und sollte generell unabhängig vom Einsatz wissensbasierter Befundungssysteme erfolgen, wenn die geeignete Methodik verfügbar und die entsprechenden labormedizinischen Kenntnisse vorhanden sind. D. h., das Labor muss auch ohne den Einsatz des Expertensystems in der Lage sein, die Konstellationen medizinisch zu bewerten und einen Befund zu erstellen; das System unterstützt und verbessert die Routine durch Beschleunigung der Abläufe und deren Standardisierung.

Die Unterstützung der medizinischen Befundung durch wissensbasierte Befundungssysteme ist unter Beachtung einiger Voraussetzungen medizinisch sinnvoll; dazu zählt etwa 
die Integration eines Befundungssystems in den medizinischen Datenfluss (Labor-EDV) und die Möglichkeit des Zugriffs (Anpassung, Veränderung, Pflege) auf das formulierte Wissen.

Der größte Teil medizinischer Informationen (z. B. anamnestische Details, Tastinformationen, visuelle Informationen, zunächst unwichtig erscheinende Beobachtungen) können dem System meist erst gar nicht bekannt gemacht werden. Ergänzt sei in diesem Zusammenhang auch, dass sogar die Abschlussdiagnose des klinischen Spezialisten in einem relativ hoch erscheinenden Prozentsatz trotz klinischer Verfügbarkeit einer Fülle von unterschiedlichsten Informationen falsch sein kann. Deshalb sollten bei der labormedizinischen Befundinterpretation (mit dem geringeren Umfang zusätzlich zur Verfügung stehender Informationen) nie Diagnosen suggeriert werden, auch diagnostische Hinweise müssen immer zurückhaltend formuliert sein.

\section{Literatur}

Brockhaus Computer und Informationstechnologie (2003) Bibliographisches Institut \& F.A. Brockhaus, Mannheim/Leipzig

Trendelenburg C, Pohl B (1990) Medizinische Diagnostik mit Expertensystemen. Eine Einführung mit Disketten für die Expertensystemschale, 3. Aufl. Georg Thieme Verlag, Stuttgart/New York

Trendelenburg C, Colhoun O, Wormek A (1998) Knowledge-based test result interpretation in laboratory medicine. Clin Chim Acta 278:229-242

\section{Expositionsäquivalente für krebserzeugende Arbeitsstoffe}

$\rightarrow$ EKA-Wert

\section{Exsudat}

\section{A. M. Gressner und O. A. Gressner}

\section{Englischer Begriff exudate}

Definition Extravasales Auftreten eines relativ proteinreichen und zellhaltigen Filtrates des Bluts in präformierten Körperhöhlen überwiegend auf der Basis eines entzündlichen Prozesses.

Beschreibung Lokale entzündliche Prozesse führen zu einer Erhöhung der Permeabilität des kapillären Blutstromgebiets mit Austritt einer im Vergleich zum $>$ Transsudat relativ proteinreichen (Gesamtprotein über $30 \mathrm{~g} / \mathrm{L}$ ), zellreichen (neutrophile Granulozyten, Lymphozyten), serösen, seltener blutigen Flüssigkeit in präformierte Körperhöhlen (z. B. Perikard-, Pleuraerguss, Aszites). Je nach Art und Zahl der Blutzellen unterscheidet man

- seröses,

- serös-eitriges,

- eitriges und

- hämorrhagisches Exsudat.

Die Aktivität der $>$ Laktatdehydrogenase (LDH) liegt $>200$ U/L (im Gegensatz zum Transsudat). Mikrobiologische Untersuchungen (Ausstrich, Kultur, Serologie etc.) sind wegen der infektiösen Ätiologie des Exsudates in der Regel angezeigt. Da ein Exsudat auch im Rahmen maligner Tumoren auftreten kann, ist eine Bestimmung von $>$ Tumormarkern und Tumorzellen ( $\triangleright$ Tumorzellen, zirkulierende) in diesen Fällen diagnostisch wegweisend. Da es fließende Übergänge zwischen Exsudat und Transsudat geben kann, ist eine Unterscheidung beider Körperflüssigkeiten nur noch von eingeschränkter diagnostischer Bedeutung.

\section{Extensible Markup Language}

$\triangleright \mathrm{XML}$

\section{Extensive-Metabolizer}

- Dextromethorphan-Test

\section{Externe Qualitätssicherung}

Q Qualitätssicherung, externe

\section{Extinktion}

> Lambert-Beer-Gesetz

\section{Extinktionskoeffizient}

- Lambert-Beer-Gesetz 


\section{Extraanalytische Qualität}

- Qualität, extraanalytische

\section{Extractive Electrospray Ionization}

- Ionisationsmethoden (Massenspektrometrie)

\section{Extraktion}

T. Arndt

Englischer Begriff extraction

Definition Extraktion (lat. extrahere $=$ herausziehen) bezeichnet ein Trennverfahren zum Herauslösen von Bestandteilen eines Substanzgemisches mithilfe eines geeigneten Extraktionsmittels (Lösungsmittel), wobei zwischen extrahierter Substanz und Lösungsmittel keine chemische Reaktion stattfindet.

Beschreibung Man unterscheidet Flüssig-Flüssig-Extraktionen, z. B. die Extraktion eines lipophilen Bestandteils einer flüssigen Probe wie Serum in ein organisches Lösungsmittel, und Flüssig-Fest-Extraktionen, z. B. die Extraktion von Analyten einer flüssigen Probe an ein festes Extraktionsmittel, z. B. einen Ionenaustauscher. Allerdings spricht man hierbei gewöhnlich von einer Adsorption des Analyten an der festen Phase ( $\triangleright$ Mikrosäulen).

Extraktionsschritte sind häufig Bestandteil der Probenaufbereitung im Labor der Speziellen Klinischen Chemie oder der Toxikologie. Sie werden hier zur Herauslösung der Analyte aus der komplexen Probenmatrix (Blut, Haare, Mageninhalt, Stuhl, Urin) und gleichzeitig oft zur Analytanreicherung (Konzentrationserhöhung) eingesetzt. Eine vollständige, zumindest jedoch reproduzierbare und möglichst spezifische Extraktion ist oft die Voraussetzung für eine valide Analytik. Bei unvollständiger Extraktion treten Analytverluste auf, die durch Zugabe eines internen Standards (IS; $\gg$ Standard, interner) und Betrachtung von Analytsignal/IS-Signal-Quotienten kompensiert werden können.

\section{Literatur}

Falbe J, Regitz M (Hrsg) (1996) Römpp Chemie Lexikon, 10. Aufl. Georg Thieme Verlag, Stuttgart/New York

\section{Extrasäulenvolumen}

- Totvolumen

\section{Extravasale Körperflüssigkeiten}

> Körperflüssigkeiten, extravasale

\section{Extravasate}

- Körperflüssigkeiten, extravasale

\section{Extrazellulärer Raum}

- Wasserhaushalt

\section{Extrinsic Faktor}

- Vitamin $\mathrm{B}_{12}$

\section{Exzellenzmodelle}

\section{U. Zimmermann und A. Steinhorst}

Englischer Begriff excellence models

Beschreibung Die Ansätze für Qualitätsmanagementsysteme nach den ISO-Normen (ISO 9001, ISO 17025, ISO 15189) und der Exzellenzmodelle für Organisationen beruhen auf gemeinsamen Prinzipien. Beide Ansätze

- ermöglichen es einer Organisation, ihre Stärken und Schwächen zu erkennen,

- enthalten die Beurteilungsmöglichkeiten anhand allgemeiner Modelle,

- stellen eine Grundlage für ständige Verbesserung bereit und

- enthalten Möglichkeiten zur externen Anerkennung.

Der Unterschied zwischen den Ansätzen für Qualitätsmanagementsysteme der ISO-Normen und den Exzellenzmodel- 
len liegt in ihrem Anwendungsbereich. Die ISO-Normen stellen Anforderungen an Qualitätsmanagementsysteme und Anleitungen zur Leistungsverbesserung bereit. Durch das Beurteilen von Qualitätsmanagementsystemen wird die Erfüllung dieser Anforderungen ermittelt. Die Exzellenzmodelle enthalten Kriterien, die eine vergleichende Beurteilung der Leistung von Organisationen ermöglichen. Diese sind auf alle Tätigkeiten und alle interessierten Parteien einer Organisation anwendbar. Bewertungskriterien in Exzellenzmodellen bieten einer Organisation eine Grundlage, ihre Leistung mit denen anderer Organisationen zu vergleichen.

Ein Beispiel eines Exzellenzmodells ist das Modell von EFQM.

\section{Literatur}

DIN EN ISO 9000:2015 „Qualitätsmanagementsysteme - Grundlagen und Begriffe"

\section{Exzisionsreparatur}

J. Arnemann

Synonym(e) Reparatur durch Ausschneiden der DNA

Englischer Begriff base excision repair (BER)

Definition Unter Exzisionsreparatur versteht man einen DNA-Reparaturmechanismus, der kleinere Läsionen von wenigen Basen repariert, indem diese ausgeschnitten und durch die korrekten Basen ersetzt werden.

Beschreibung Der Exzisionsreparatur- oder „,base excicsion repair (BER)-"Mechanismus dient im Wesentlichen der
Reparatur der relativ häufigen fehlerhaften oder Zerfallprodukte der DNA, die durch Reaktionen mit endogenen Substanzen, insbesondere reaktive Sauerstoffradikale (ROS), verursacht werden. Beispiele hierfür sind $u$. a. der Ersatz von Uracil oder der Austausch von 3-Methyladenin oder 8-Oxo-G, die durch Deaminierung, Alkylierung oder Oxidation entstanden sind.

Der Exzisionsmechanismus (BER) zeigt eine gewisse Variabilität hinsichtlich der Substanzen, folgt jedoch im Prinzip den folgenden 5 Schritten:

1. Erkennung einer fehlerhaften oder geschädigten Base durch einen UVrA/B-Komplex, wobei ein UVrA-Dimer mit einem UVrB-Dimer bindet und sich um die geschädigte Base legt.

2. Öffnen der Wasserstoffbrückenbindungen unter ATPVerbrauch und Ersatz der UVrA-Dimer durch ein UVrCMolekül.

3. Ausschneiden der defekten Base durch den als Endonuklease wirkenden UVrB/C-Komplex. Dabei wird eine Phosphodiesterverbindung 4 Nukleotide downstream der eigentlichen DNA-Schädigung und 8 Nukleotide upstream gespalten, insgesamt ein Fragment von 12 Nukleotiden.

4. Ausschneiden des Fragmentes und Auflösung der Basenpaarung durch DNA-Helicase II und unter Verlust von UVrC. UVrB bleibt, um ein Reannealing mit dem ausgeschnittenen DNA-Fragment zu verhindern.

5. Auffüllen der Lücke mittels dNTPs und DNA-Polymerase I unter Verdrängung von UVrB. Knüpfung der letzten Phosphodiesterverbindung durch DNA-Ligase.

\section{Literatur}

Kim YJ, Wilson DM (2012) Overview of Base Excision Repair Biochemistry. Curr Mol Pharmacol 5:3-13 